\title{
III. »DEUTSCHLANDS ZWEIFELN IST MIR NÄHER ALS FRANKREICHS HEUTIGE GEWISSHEITEN«: ALS KULTURELLER MITTLER IN BERLIN (1926-1930)
}

\section{Viénot und das Deutsch-Französische Studienkomitee}

\subsection{Die Gründung des Studienkomitees}

\section{Émile Mayrischs Ideen einer europäischen Verständigung}

In seinem Germania-Artikel vom August 1925 stellte Pierre Viénot ein Programm vor, das seiner Meinung nach geeignet war, zur Lösung des deutschfranzösischen Konflikts beizutragen. In seinen Augen konnte dazu nur ein beiderseitiger, deutscher wie französischer Versuch angetan sein. Darüber hinaus stellte sich die deutsch-französische Annäherung für den jungen Publizisten als eine nationale Aufgabe dar, die über einzelne Parteiinteressen hinweg verfolgt werden müsse. Als Fazit dieser Überlegungen entwarf Viénot ein Aktionsprogramm, in dem sich die späteren Strukturen des Deutsch-Französischen Studienkomitees bereits erkennen lassen. Er forderte die "Gründung eines in Frankreich wie in Deutschland tätigen Organismus durch private deutsch-französische Initiative: Dieser Organismus müßte sowohl deutsches wie auch französisches Personal zur Verfügung haben, das irgendwie die geistige, sentimentale und sittliche Sprache beider Nationen zu sprechen weiß«. ${ }^{1}$ Vorrangige Aufgabe dieser Organisation sollte es in Viénots Augen sein, "zunächst eine Massenbewegung zugunsten des Prinzips der Annăherung beider Länder [zu] erzeugen ${ }^{2}{ }^{2}$ Um dieses Ziel zu erreichen, sollten über die Presse exakte Auskünfte über beide Länder und deren Mentalitäten verbreitet, über die Mitglieder Einfluß auf die jeweiligen herrschenden Klassen im Sinne der Verständigungsbestrebungen genommen und die Kontakte von Persönlichkeiten beider Länder vervielfacht werden. Es war vorgesehen, der Organisation ein »Komitee von Protektoren « vorzustellen, dessen Mitglieder moralisches Gewicht und materielle Macht vereinten. Die Zielsetzung Viénots ging also ganz in Richtung einer Überwindung psychologischer Barrieren auf dem Weg zur Verständigung. Dabei sollte der Pressepolitik und der zwischenstaatlichen Kontaktpflege das Hauptaugenmerk gelten. Um eine deutsch-französische Verständigung über den Weg der beiderseitigen Befriedigung partikularer Interessen etwa der Wirtschaft ging es Viénot in seiner Konzeption nicht. Das Projekt fand ein po-

Pierre VIÉNOT, Das wahre deutsch-französische Problem.

Ibid. 
sitives Echo vor allem in der konservativen Presse Frankreichs ${ }^{3}$. Der Weg vom Stadium des intellektuellen Gedankenspiels hin zur Verwirklichung des Projekts konnte jedoch nur mit Unterstützung jener Kreise zurückgelegt werden, die Viénot als Patronagekomitee eingeplant hatte. Entscheidend wurde hier die Person Émile Mayrischs, der eben jene Autorität und Macht besaß, ein derartiges Konzept in die Tat umzusetzen, und gleichzeitig als Luxemburger von beiden Seiten als neutrale Persönlichkeit akzeptiert wurde.

Von der Auflösung der deutsch-luxemburgischen Zollunion 1919 infolge des Versailler Vertrages stark betroffen, orientierte sich Mayrisch nach Kriegsende zunächst nach Frankreich, wo er eine Verbindung mit der lothringischen Schneider-Creusot-Gruppe einging. Nach Abschluß der von ihm geförderten belgisch-luxemburgischen Wirtschaftsunion im Juli 1921 expandierte er nach Belgien. Mayrisch, der auch im Aufsichtsrat des Kölner Kabelwerkes Felten \& Guilleaume saß und an anderen rheinischen Unternehmen beteiligt war, hatte ein vitales Interesse an einer deutsch-französischen Wirtschaftsverständigung. Sein Versuch, französische und deutsche Stahlproduzenten an einen Tisch zu bringen, scheiterte jedoch ${ }^{4}$. Mayrisch hielt als Gegner der französischen Ruhrbesetzung auch während dieser Zeit die Kontakte mit Industriellen beider Länder aufrecht. Dennoch setzte er gegen Ende 1923 anscheinend kurzzeitig seine Hoffnungen auf die Schaffung einer Rheinischen Republik mit wirtschaftlicher Westanbindung ${ }^{5}$. Bereits seit 1922 ließ er seine wirtschaftspolitischen Bemühungen in der von ihm aufgekauften Luxemburger Zeitung durch Jacques Rivières Artikel propagandistisch flankieren. Während Rivière für eine europäische Einigung auf dem Weg wirtschaftlicher Annährung warb, führte Mayrisch die Verhandlungen, die im Juni 1925 in das Luxemburger Abkommen mündeten, das eine Zusammenarbeit der deutschen, französischen, luxemburgischen und saarländischen Stahlindustrie vorsah ${ }^{6}$. Seit Januar 1926 vermittelte Mayrisch zwischen Humbert de Wendel und Théodore Laurent vom französischen Interessenverband der Stahlproduzenten, dem Comité des Forges, auf der einen und Fritz Thyssen und Ernst Poensgen von der Deutschen Rohstahlgemeinschaft ${ }^{7}$ auf der anderen Seite. Diese privaten Absprachen um Pro-

3 Vgl. Viénot an Lyautey, 10.8.1925: 475 AP 311. Die linke Presse, so Viénot, ignoriere seinen Artikel: "lls craignent de perdre leur faux monopole de l'idée de paix. C'est révélateur!«

4 Vgl. MULLER, Émile Mayrisch und westdeutsche Industrielle, S. 549.

5 Vgl. BARIÉTY, Les relations franco-allemandes, S. 228 und 242.

6 Vgl. DERS., Sidérurgie, littérature, politique et journalisme: une famille luxembourgeoise, les Mayrisch, entre l'Allemagne et la France après la première guerre mondiale, in: Bulletin de la Société d'Histoire moderne 10 (1969) S. 7-10, hier S. 9; DERS., Le rôle; DERS., Industriels allemands et industriels français à l'époque de la République de Weimar, in: La Revue d'Allemagne 6 (1974) Nr. 2, S. 1-16; DERS, Das Zustandekommen, S. 565.

7 Diese war in November 1924 v.a. auf Initiative von Fritz Thyssen als nationales Eisenkartell gegründet worden. Es diente einerseits dazu, den Stahl- und Eisenmarkt innerhalb Deutschlands zu sanieren, auf der anderen Seite sollte bei Wirtschaftsverhandlungen mit 
duktions- und Absatzquoten in der von der Stagnation des Welthandels, der innereuropäischen Absatzkrise und Überproduktion betroffenen Stahlindustrie führte zur Gründung der Internationalen Rohstahlgemeinschaft am 30. September $1926^{8}$, deren Präsident Émile Mayrisch wurde. Vor allem unter kontinentaleuropäischen Stahlproduzenten galt die internationale Kartellierung als angemessene Antwort auf die veränderten Bedingungen der Branche ${ }^{9}$. Das Abkommen, das von Vertretern der Stahlindustrie Deutschlands, Frankreichs, Luxemburgs und Belgiens unterzeichnet wurde, sollte eine Anpassung der Erzeugung an die Nachfrage erreichen und dadurch zu höheren Preisen führen ${ }^{10}$. Dieses Ziel wurde letztlich nicht erreicht, dennoch haftet »der IRG und ihrer Gründung [...] ein Mythos an. Dies rührt vor allem daher, daß es hier nationalistisch eingestellten, miteinander verfeindeten Produzenten [...] gelungen war, auf dem Wege der Verhandlungen ihre Differenzen beizulegen und zu einer , Verständigung` zu gelangen«." Der große Erfolg Mayrischs bestand vor allem darin, einen deutsch-französischen Ausgleich erreicht und gleichzeitig der luxemburgischen Industrie einen bedeutenden Platz auf den internationalen Märkten gesichert zu haben ${ }^{12}$.

Frankreich eine geschlossene deutsche Front der Stahlindustriellen stehen. Vgl. DERS., Le rôle, S. 129f.; DERS., Das Zustandekommen, S. 562f.

8 Vgl. zur IRG DERS., Das Zustandekommen, S. 567f.; Ulrich NOCKEN, Das Internationale Stahlkartell und die deutsch-französischen Beziehungen 1924-1932, in: Gustav SCHMIDT (Hg.), Konstellationen intemationaler Politik 1924-1932. Politische und wirtschaftliche Faktoren in den Beziehungen zwischen Westeuropa und den Vereinigten Staaten, Bochum 1983, S. 165-202; DERS., International Cartels and Foreign Policy: The Formation of the International Steel Cartel 1924-1926, in: Clemens A. WURM (Hg.), Internationale Kartelle und Außenpolitik. Beiträge zur Zwischenkriegszeit, Stuttgart 1989 (Veröffentlichungen des Instituts für Europäische Geschichte Mainz: Beiheft, 23), S. 33-82; Karl Heinrich POHL, Weimars Wirtschaft und die Außenpolitik der Republik 1924-1926. Vom DawesPlan zum Internationalen Eisenpakt, Düsseldorf 1979, S. 233f.; John GILLINGHAM, Coal, steel, and the rebirth of Europe, 1945-1955. The Germans and French from Ruhr conflict to economic community, Cambridge 1991, S. 21-28.

9 Derlei Bestrebungen hatten bereits bald nach dem Ersten Weltkrieg eingesetzt, fuihrten jedoch erst ab 1924 mit dem politischen Tauwetter zu Ergebnissen. Vgl. allg. Clemens A. WURM, Politik und Wirtschaft in den internationalen Beziehungen. Internationale Kartelle, Außenpolitik und weltwirtschaftliche Beziehungen 1919-1939, in: DERS, Internationale Kartelle und Außenpolitik, S. 1-31.

${ }^{10}$ In dem Abkommen wurde die Gesamterzeugungsmenge an Rohstahl festgelegt. Dabei entfielen folgende Quoten auf die einzelnen Länder: Deutschland 40,45\%, Frankreich $31,89 \%$, Belgien 12,57\%, Luxemburg 8,55\%, Saargebiet 6,54 \%. Vg1. z.B. DERS., Industrielle Interessenpolitik und Staat. Internationale Kartelle in der britischen Außen- und Wirtschaftspolitik während der Zwischenkriegszeit, Berlin, New York 1988 (Veröffentlichungen der Historischen Kommission zu Berlin, 71), S. 40f.

11 Ibid. S. 42. Jacques Bariéty weist jedoch darauf hin, daß das Zustandekommen der IRG nicht eine Ursache, sondern eine Folge der Normalisierung der deutsch-französischen Beziehungen darstellte. Vgl. BARlÉtY, Das Zustandekommen, S. 561.

12 Vgl. DERS., Sidérurgie, S. 9. 
Das Deutsch-Französische Studienkomitee wurde zeitgleich mit der Internationalen Rohstahlgemeinschaft verhandelt, was zu der Interpretation führte, ersteres habe Mayrisch als Instrument „vorwiegend der rohstoffmäßigen Absicherung seines Konzerns zwischen den Wirtschaftsblöcken Deutschland und Frankreich/Belgien ${ }^{13}$ gedient oder sei gar waus der wirtschaftspolitischen Sicht sozusagen ein >Abfallprodukt « $^{14}$ gewesen. Diese Beurteilungen werden jedoch Mayrischs eigentlichen Absichten nicht gerecht. Mayrisch selbst teilte die von vielen vertretene Annahme, eine wirtschaftliche Verständigung führe zu einer europäischen Befriedung, nicht, sondern ging vielmehr über diese zum Beispiel von Jacques Rivière vertretene These hinaus. Der Direktor der ARBED-Werke, der in großen, weltwirtschaftlichen Zusammenhängen dachte, legte seine Auffassungen zu Wirtschaftspolitik und Friedenssicherung selbst publizistisch dar. 1926 nahm er Stellung zu der auf deutscher wie französischer Seite populären Idee einer europäischen Zollunion ${ }^{15}$. Der Industrielle glaubte nicht an eine pazifizierende Wirkung der Zollunion, da diese den Interessen Großbritanniens als Kolonialmacht sowie Rußlands und der USA zuwiderlief. Nicht die Zollunion führte seiner Meinung nach zum Frieden, sondern nur ein europäischer Friede konnte eine Zollunion erst ermöglichen ${ }^{16}$.

Das Ziel einer Zollunion konnte für Mayrisch erst in mehreren Generationen erreicht werden. In der Zwischenzeit müßten Versuche mit begrenzter Reichweite unternommen werden, die relativ rasch zu Erfolgen führten. Diese Funktion kam seiner Meinung nach den privaten wirtschaftlichen Absprachen zu, die von vorneherein zeitlich limitiert waren. Um einen friedlichen Ausgleich zu fördern, sollten sie allerdings, so Mayrisch, eine prononciert soziale Komponente enthalten. Nur wenn es gelänge, auch die industriellen und agrarischen Massen von der Notwendigkeit einer Verständigung zu überzeugen, könnten ökonomische Bestrebungen überhaupt einen Sinn haben. Wenn aus einem puren Waffenstillstand ein echter Friede werden solle, dann müsse die internationale Verständigung den Arbeitern höhere Löhne und einen besseren Lebensstandard gewährleisten:

13 Bernd MARTnN, Friedens-Planungen der multinationalen Großindustrie, in: Geschichte und Gesellschaft 2 (1976) S. 66-88, hier S. 68.

14 MÜLLER, Émile Mayrisch und westdeutsche Industrielle, S. 552.

15 Obwohl sich Mayrischs Ausführungen hier konkret auf die Zollunion beziehen, können sie doch als allgemeingültig für seine Ansichten zu Wirtschaftspolitik und Friedenssicherung angesehen werden. Vgl. zur Idee der Zollunion FrOMMELT, Paneuropa, S. 23-27 und S. 41-45; Peter KRUGER, Die Ansätze zu einer europäischen Wirtschaftsgemeinschaft in Deutschland nach dem Ersten Weltkrieg, in: Helmut BERDING (Hg.), Wirtschaftliche und politische Integration in Europa im 19. und 20. Jahrhundert, Göttingen 1984 (Geschichte und Gesellschaft: Sonderheft, 10), S. 149-168.

$16 \mathrm{Vgl}$. Émile MAYRISCH, Une opinion luxembourgeoise sur un projet d'union douanière européenne, in: L'Europe nouvelle, 24.4.1926, S. 555-556, hier S. 556. 
[...] die Vorteile der Verständigung dürfen nicht einseitig dem Produzenten zugute kommen, und der Zweck der Verständigung darf nicht allein Erzielung höheren Gewinns, sondern muß in gleichem, wenn nicht erhöhtem Maße, die Verbilligung der Erzeugung sein, das bedeutet Rationalisierung bis zum Äußersten, und diese wiederum bedingt weitgehende Konzentration, zuerst auf nationalem Boden, dann auf internationalem Boden ${ }^{17}$.

Mayrisch, der in seinem Konzern selbst eine aktive Sozialpolitik betrieb, griff hier Gedanken auf, die zumindest in Deutschland Mitte der zwanziger Jahre sowohl bei Unternehmern als auch bei den Gewerkschaften sehr populär waren. Durch Rationalisierung der Betriebe sollte deren Produktivität und Wettbewerbsfähigkeit erhöht werden. Hofften die Unternehmer in erster Linie auf eine Steigerung ihrer Rendite, so zielten die Gewerkschaften auf eine Senkung der Arbeitszeit, auf Lohnerhöhung und eine Erleichterung der Arbeitsbedingungen $a b^{18}$. Die mögliche Folge einer Freisetzung von Arbeitskräften durch Konzentration und Rationalisierung wurde von Mayrisch nicht thematisiert. In seinem Kalkül stellte die Optimierung der Produktionsbedingungen ein wichtiges Mittel zur Verbesserung der Lebensbedingungen der Arbeiter dar, um, langfristig gesehen, deren positive Haltung zu internationalen Verständigungsabsichten zu fördern. Das internationale Kapital sollte gemäß Mayrisch dazu dienen, die jeweiligen Interessen auszubalancieren. Dafür sei jedoch »ein gegenseitiges und allgemeines Vertrauen [...], ein Vertrauen nicht allein zwischen den direkt Beteiligten, sondern auch ein allgemeines Vertrauen in die zukünftige Befriedung der Völker und den regelmäßigen normalen Wirtschaftsverkehr « ${ }^{19}$ vonnöten. Privatwirtschaftliche Abkommen könnten dieses Vertrauen zwar stärken und so zu einem Beitrag zur Friedenssicherung werden, aber gleichzeitig müsse als Grundlage derartiger Verhandlungen ein gewisses Maß an Vertrauen bereits existieren.

Mayrisch ging also von einem engen Wechselverhältnis zwischen wirtschaftlicher und politisch-psychologischer Annäherung aus. Die beiden Konzepte erforderten und ergänzten sich dabei gegenseitig. Okonomische Absprachen waren die auf die Gegenwart bezogenen Komponenten der Friedenssicherung, vertrauensbildende Maßnahmen, die sich im Bewußtsein der Völker niederschlagen sollten, die langfristige Perspektive. Mayrisch war sich bewußt, daß er mit dieser Konzeption ein selbst für die Locarno-Ära ehrgeiziges Ziel for-

17 DERS., Das System der internationalen Wirtschaftsverständigung, in: Europdische Revue 3,2 (1927/28) S. 856-862, hier S. 861. Der Artikel erschien auf französisch unter dem Titel: Les ententes économiques internationales et la paix, in: L'Europe nouvelle, 24.12.1927, S. 1702-1705. Er findet sich auch abgedruckt in: CRE, Émile Mayrisch, S. 47-54.

18 Vgl. Heinrich August WDKLER, Der Schein der Normalität. Arbeiter und Arbeiterbewegung in der Weimarer Republik 1924 bis 1930, Berlin, Bonn 1985 (Geschichte der Arbeiter und der Arbeiterbewegung in Deutschland seit dem Ende des 18. Jahrhunderts, 10), S. 467.

19 Émile MAYRISCH, Das System der internationalen Wirtschaftsverständigung, in: Europdische Revue 3,2 (1927/28) S. 856-862, hier S. 861. 
mulierte, »das vielleicht heute chimärisch erscheint, in der Folge aber ein Element der Befriedung werden kann ${ }^{20}{ }^{20}$

In diesem Sinne war Mayrisch tatsächlich ein Eurovisionär, der über die wirtschaftlichen Interessen seines Konzerns hinaus in längerfristigen historischen Prozessen dachte. Die zeitgleiche Planung von Internationaler Rohstahlgemeinschaft und Deutsch-Französischem Studienkomitee trug dieser Doppelstrategie Rechnung. Während das Wirtschaftsabkommen eine Ad-Hoc-Maßnahme zur Absicherung der europäischen Stahlkonzerne und zur Schaffung eines Wirtschaftsfriedens darstellte, war das Studienkomitee als Instrument konzipiert, eine langfristige Änderung der Mentalitäten und Einstellungen zu erwirken. Nur in einem friedlichen Europa konnte ein Unternehmen wie die ARBED seine multinationalen Interessen verwirklichen ${ }^{21}$.

\section{Von der Planung zur Realisierung}

Zu dem Zeitpunkt, als Viénot in näheren Kontakt mit den Mayrischs trat, waren in deren Umfeld bereits Überlegungen in Gange, auf welche Art und Weise ein funktionierendes deutsch-französisches Netzwerk im Sinne der Verständigung errichtet werden könnte. Mit dem Tod Jacques Rivières am 14. Februar 1925 wurde Viénot als dessen Nachfolger bei der Luxemburger Zeitung endgültig in diese Planungen miteinbezogen. Es ist anzunehmen, daß Viénot die einmalige Chance erkannte, die eine Zusammenarbeit mit Mayrisch für seine Pläne bedeuten würde. Wladimir d'Ormesson erinnerte sich später daran, daß ihm Viénot Ende 1924 von seinem Vorhaben, eine Organisation zur bilateralen Annäherung zu gründen, erzählt habe. Er sei von seinem Deutschlandaufenthalt zurückgekehrt »frappé - et angoissé - par l'Himalaya d'incompréhension qui séparait l'opinion française et l'opinion allemande ${ }^{22}$ Offensichtlich versuchte Viénot, über Aline Mayrisch seine Ideen bei ihrem Mann zu lancieren, was zunächst nur langsam voranging: "L'affaire Viénot n'a pas encore beaucoup avancé«, schrieb Aline Mayrisch im Oktober 1924 an Ernst Robert Curtius, denn Mayrisch sei "strop occupé ces temps-ci et a eu quelques ennuis de santé«. ${ }^{23}$ Im Januar 1925 kam es dann zu einem Treffen mit Mayrisch in Colpach. Diesem folgten Gespräche der beiden in Berlin und Paris mit eventuellen Interessenten der Gründung einer deutsch-französischen Organisation ${ }^{24}$. Dabei war der Kreis um Lyautey, namentlich die Viénot-Freunde Wladimir d'Ormesson und Félix de Vogüé, von Anfang an in diese Planungen einbezo-

20 Ibid. S. 862.

${ }^{21}$ Vgl. hierzu BocK, Émile Mayrisch und die Anfänge, S. 576.

22 Wladimir d'ORMESSON, Une tentative de rapprochement, S. 20.

23 A. Mayrisch an Curtius, 19.10.1924: ULB Bonn, NL Curtius, Korrespondenz Aline Mayrisch.

$24 \mathrm{Vgl}$. Viénot an Lyautey, 8.1.1925: AN, $475 \mathrm{AP} 311$. 
gen $^{25}$. Viénots Absichten nahmen jedoch erst in der zweiten Jahreshälfte konkretere Formen an. In der Zwischenzeit hatte er das Ziel einer diplomatischen Laufbahn verworfen und einige öffentlich beachtete Artikel publiziert. Im Juli 1925 vertraute er Lyautey an, er werde bald in Luxemburg wichtige Gespräche führen, »d'où peut sortir un organisme privé d'informations et d'études francoallemandes, dont notre ambassade à Berlin souhaite très vivement la fondation et qu'il m'appartiendrait d'organiser «. ${ }^{26}$ Nach seiner Rückkehr aus Luxemburg präzisierte er das Vorhaben: Es handle sich bei den in Frage kommenden Teilnehmern um einige der wichtigsten Persönlichkeiten in Frankreich und Deutschland, die eher nach rechts orientiert seien. Er selbst werde die Organisation in Berlin leiten ${ }^{27}$. Die Grundstrukturen des künftigen Komitees hatten demnach bereits durch die zahlreichen Gespräche mit Mayrisch Gestalt angenommen, und Viénot ließ sich gegenüber Lyautey zu der Äußerung hinreißen: »[...] j'ai maintenant déterminé $\mathrm{M}$. Mayrisch [...] à prendre la chose en mains et à servir d'intermédiaire neutre pour les pourparlers. ${ }^{28}$ Der Eindruck, den er hier erweckt, er selbst sei alleiniger Initiator des Komitees und Mayrisch in seinem Auftrag tätig, ging an der Wirklichkeit vorbei. Die Aufgabenverteilung sah vielmehr so aus, daß Mayrisch der Auftraggeber der künftigen Organisation war, während Viénot als "cheville ouvrière ${ }^{29}$ die inhaltliche und organisatorische Ausgestaltung übernahm ${ }^{30}$. Daß Mayrisch und Viénot in der Gründungsphase des Komitees und auch später anscheinend sehr gut miteinander harmonierten, war von vorneherein nicht unbedingt abzusehen gewesen, zu ungleich waren die beiden Persönlichkeiten. Mayrisch stand bereits im sechsten Lebensjahrzehnt, war in den höchsten Kreisen in Wirtschaft und Politik allseits bekannt und geachtet und verfügte über Geld, Macht und Einfluß. Viénot hingegen war ein junger unbekannter Mann, der sich gerade anschickte, erste Kontakte mit Intellektuellen und Politikern zu knüpfen und sich einen Namen als Deutschlandkenner zu machen. Er stammte aus guter, wenngleich nicht prominenter $\mathrm{Fa}$ milie und hatte eine durchaus gediegene, aber keineswegs brillante Hochschulausbildung, etwa an einer Grande École, absolviert. Angesichts dieser Ausgangslage war die Protektion durch Lyautey entscheidend, die Viénot Eingang finden ließ in elitäre Intellektuellenzirkel und dadurch den Kontakt zu einer Familie

D'Ormesson berichtet, die ersten vorbereitenden Treffen für das Projekt hätten in der Pariser Wohnung Lyauteys stattgefunden. Vgl. d'Ormesson, Pierre Viénot, S. 87: NL d'Ormesson II.

${ }^{27} \mathrm{Vgl}$. ders. an dens., 10.8.1925: AN, 475 AP 311.

28 Ibid.

29 Fernand L'HUILLIER, Allemands et Français au temps de Locarno: Accords, dialogues et malentendus (1924-1929). Un aperçu, in: La Revue d'Allemagne 4 (1972) S. 558-568, hier S. 564.

${ }^{30}$ Mit dem Bild von Bauherr und Architekten bezeichnet Hans Manfred Bock sehr treffend die Aufgabenverteilung. Vgl. BocK, Émile Mayrisch und die Anfänge, S. 561. 
wie den Mayrischs ermöglichte. Viénot stand mit nichts als seinem Ehrgeiz und seinen Ideen vor Mayrisch, und es stellt sich die Frage, warum der erfahrene Industriekapitän ausgerechnet den jungen Viénot in seine Pläne miteinbezog.

Die Zusammenarbeit zwischen Mayrisch und Viénot hatte sich sukzessive entwickelt und erreichte 1925/26 mit der Gründung des Deutsch-Französischen Studienkomitees ihren Höhepunkt. Seit Viénot 1923 Aline Mayrisch in Pontigny kennengelernt hatte, hegte diese offenbar eine besondere Sympathie für den stilbewußten Viénot, dem sie Charakterstärke und ein »cœur tendre ${ }^{31}$ zusprach. Es ist anzunehmen, daß sie sich ihrem Mann gegenüber für Viénot verwendete. Die Mayrisch-Tochter Andrée war ebenfalls freundschaftlich mit Viénot verbunden. Zum Zeitpunkt der Vorbereitungsphase für die Komiteegründung war er für die Mayrischs bereits ein Freund des Hauses geworden. Zudem waren Viénots deutschlandpolitische Ansichten von Beginn an bei den Mayrischs auf fruchtbaren Boden gefallen. Viénot besaß eine eigenständige Konzeption im Hinblick auf die Zukunft der deutsch-französischen Beziehungen und den unbedingten Willen, diese in Form einer Organisation zu verwirklichen. Mit ihren verschiedenen Qualitäten ergänzten sich Mayrisch und Viénot bei der Organisation des Studienkomitees, und diese Tatsache wurde von Mayrisch sicherlich auch erkannt.

Zur Ausarbeitung des von Mayrisch in Auftrag gegebenen detaillierten Projektentwurfs zog sich Viénot zu seinem Freund Jean Schlumberger zurück, und bei einem Zwischenstop auf Schloß d'Ormesson präsentierte er es dem Hausherrn und Félix de Vogüé, bevor er seine Arbeit im September in Colpach ablieferte. Als künftige Komiteemitglieder hatte Viénot Jean Schlumberger und den Präsidenten des französischen Kohlensyndikats, Henri de Peyerimhoff, im Auge. Sein Freund d'Ormesson schlug den katholischen Schriftsteller Paul Claudel und den Physiker Maurice de Broglie vor ${ }^{32}$. Viénot zeigte sich sehr zufrieden mit seinem Projekt, das er selbstbewußt für die beste Arbeit seines Lebens hielt: »Il est bien, très bien même, je crois, clair et convainquant [sic] et d'un ton d'objectivité si prudente qu'il doit pouvoir trouver prise très loin à droite. ${ }^{33}$

31 Aline Mayrisch an Curtius, 5.5.1925: ULB Bonn, NL Curtius, Korrespondenz Aline Mayrisch. Viénot seinerseits betonte gegenüber Aline Mayrisch »mon amitié [...] et ma totale confiance«. Viénot an Schlumberger, o.D. [Feb. 1926]: BLJD, Fonds Schlumberger, Ms 18320.

${ }^{32}$ Laut Tagebuch von d'Ormesson hatte Viénot ihm am 15. September das Projekt vorgestellt. Vgl, hierzu die unveröffentlichte Arbeit von Diane de VoGỨ, Wladimir d'Ormesson et le rapprochement franco-allemand 1925-1933, Maîtrise d'Histoire, Université de Paris IV-Sorbonne, 1988-1989, S. 18. Die Autorin hatte als Urenkelin von Wladimir d'Ormesson Zugang zum Familienarchiv. Eine ausführliche biographische Untersuchung über das publizistische und politische Wirken d'Omessons stellt noch immer ein Desiderat der Forschung dar. Zu d'Ormesson siehe auch DIES., Wladimir d'Ormesson 1888-1973, DEA d'Histoire, Université Paris IV-Sorbonne, 1995-1996.

33 Viénot an de Cénival, 18.9.1925: NL Viénot. 
In seinen »Vorschlägen zur Errichtung eines deutsch-französischen Informierungsausschusses ${ }^{34}{ }^{34}$ legte Viénot in seiner einführenden Analyse zum Wesen des deutsch-französischen Gegensatzes jene Thesen dar, die er schon seit Beginn der zwanziger Jahre verfocht. Er führte aus, es handle sich um einen srein psychologischen Konflikt der Feindschaft aus Voreingenommenheit und der Geistesverfassung " ${ }^{35}$, hervorgerufen durch die subjektive Art der gegenseitigen Berichterstattung. Die Verpflichtung auf das gemeinsame demokratische Prinzip oder eine wirtschaftliche Annäherung allein könnten nicht automatisch eine politische Entspannung nach sich ziehen. Da es im nationalen Interesse beider Länder liege, die Spannungen zu beenden, schlug Viénot vor, san das Nationalgefühl zu appellieren«, und sah "gerade in diesem Wagemut eine Gewähr des Erfolges«. ${ }^{36}$ Im Gegensatz zu den Unternehmungen mit europäischem Charakter, deren Erfolglosigkeit Viénot auf das wenig ausgeprägte internationale Bewußtsein zurückführte, könnte seine geplante Organisation sofort Wirkung zeigen, da sie sich auf bereits vorhandene Gefühle stütze, 》und zwar die stärksten, die zurzeit in den Völkern Europas lebendig sind«. ${ }^{37}$ Augenscheinlich war Viénot in besonderem Maße daran gelegen, politisch eher konservativ und national eingestellte Kreise für sein Projekt zu gewinnen. Es war deshalb frei von jeglichen internationalistischen Bezügen, sondern versuchte die Verständigung als nationale Aufgabe darzustellen ${ }^{38}$. Für Viénot, der zu diesem Zeitpunkt seine politische Heimat noch suchte ${ }^{39}$, stellte dieses Bestreben kein Bekenntnis zur politischen Rechten dar. Eine Verständigung auf nationaler Grundlage spiegelte jedoch jene Konzepte wider, die er im Umkreis von Ernst Robert Curtius und André Gide angetroffen hatte und die seinen eigenen Überzeugungen entsprachen. Zudem gehörte es zu seiner Intention, mit seinem Programm gerade jene Kreise anzusprechen, die der deutsch-französischen Annäherung traditionell eher ablehnend gegenüberstanden. Somit sollten erstmals auch dezidiert nationalkonservative Kreise in die Verständigungsbemühungen aktiv mit einbezogen werden. Mit dieser Herangehensweise konnte sich Viénot innerhalb des Feldes der Verständigungsbestrebungen außerdem in einer Nische positionieren, in der die Linke, die sich klassischerweise um internationale Zusammenarbeit bemühte, nicht dominierte.

${ }^{34}$ Ders., Vorschläge zur Errichtung eines deutsch-französischen Informierungsausschusses, Luxemburg o.J. [1925]: PAAA, Botschaft Paris, DFS, Bd. 1. Die französische Version erschien unter dem Titel: Projet de fondation d'un comité franco-allemand d'information, Luxembourg o.J. [1925]: NL d'Ormesson I, CFA, Fondation 1925, Notes de base.

35 Ders., Vorschläge zur Errichtung eines deutsch-französischen Informierungsausschusses, Luxemburg o.J. [1925]: PAAA, Botschaft Paris, DFS, Bd. 1, S. 4. Ibid. S. 7.

37 Ibid

38 So betonte Viénot besonders, „daß sich heute eine nationale Einstellung sehr wohl verträgt mit dem Studium der politischen, wirtschaftlichen, psychologischen und sozialen Tatsachen, aus denen sich das Verhalten des Nachbarn erklärt«. Ibid. S. 11.

39 Vgl. dazu ausführlich Kap. IV. 
Die öffentliche Meinung und vor allem die Presse spielte in den Augen Viénots eine zentrale Rolle bei der Beilegung des deutsch-französischen Konflikts, da sie aufgrund verzerrter Darstellungen für die Entstehung des Antagonismus die Verantwortung trug. Ziel war demnach eine "Gesundung der Informierung ${ }^{40}$ hin zu einer objektiven Berichterstattung, an deren Möglichkeit Viénot, in dieser Hinsicht zweifellos sehr idealistisch, fest glaubte. In der Praxis bedeutete dies die Formation eines »deutsch-französischen Informierungsausschusses«, dem je drei Deutsche und Franzosen angehören sollten sowie eine aufgrund ihrer Staatsangehörigkeit neutrale Person. Darüber hinaus sollte je ein weiteres deutsches und französisches Mitglied dazukommen, die zwei geplante "Informierungsinstitute in Paris und Berlin leiten sollten ${ }^{41}$. Threr Tätigkeit widmete Viénot besonders viel Aufmerksamkeit in seinem Exposé. Die Direktoren sollten alle Zeitungen auf falsche oder tendenziöse Nachrichten über das Gastland durchlesen und diese richtigstellen, und zwar durch erklärende Briefe an die jeweilige Zeitungsredaktion. Viénot war zutiefst davon überzeugt, daß ein Großteil der falschen Nachrichten aus Unkenntnis über den tatsächlichen Sachverhalt veröffentlicht wurde, und er glaubte an die Wirksamkeit seiner Maßnahmen. Angesichts des Arbeitsaufwands, als Einzelperson alle tendenziösen oder falschen Nachrichten auswerten und berichtigen zu wollen, sowie der doch zumindest fraglichen Erfolgschancen dieser Maßnahme, erscheint Viénots Idee als sehr optimistisch, wenn nicht gar illusorisch. Den Direktoren kam weiterhin die Aufgabe zu, eine umfangreiche Dokumentation über das Gastland anzulegen und diese den Auslandskorrespondenten zur Verfügung zu stellen. Aufgrund ihrer eigenen Kenntnisse über die kulturellen Gegebenheiten und Unterschiede beider Länder sollten sie zu gesuchten Ansprechpartnern für Journalisten, die eigene Botschaft und politisch einflußreiche Kreise werden. Auch für die Kontaktanbahnung zwischen Deutschen und Franzosen waren sie verantwortlich. Vor allem die Begegnung der Jugend sollte von den Direktoren vermittelt werden. Den Institutsdirektoren kam demnach eine zentrale Rolle innerhalb der Organisation zu. Ihre Aufgabe war die eines kulturellen Mittlers, der mit der Mentalität des Gastlandes vertraut sein mußte, um in seinem eigenen Land auf Fehleinschätzungen hinweisen zu können. Tiefere Kenntnisse über das andere Land, Verständnis für die jeweiligen Eigenheiten und nicht zuletzt kommunikative Fähigkeiten stellten unabdingbare Voraussetzungen für die Ausübung dieser Tätigkeit dar. Zweifellos schrieb sich Viénot diese Rolle in seinem Programm selbst auf den Leib. Die Finanzierung des Unternehmens sollte von beiden Seiten zu gleichen Teilen übernommen werden und zwar für drei Jahre im voraus, so daß der Bestand der Einrichtungen für eine bestimmte Zeit gesichert war.

40 Pierre Viénot, Vorschläge zur Errichtung eines deutsch-französischen Informierungsausschusses, Luxemburg o.J. [1925]: PAAA, Botschaft Paris, DFS, Bd. 1, S. 8.

4i Ibid. S. 12. 
Nachdem Mayrisch Viénots Entwurf zugestimmt hatte ${ }^{42}$, begannen beide mit der Umsetzung des Projekts. Während Mayrisch, der seit seiner Studienzeit in Aachen Kontakte nach Deutschland hatte, mit Unterstützung des Krupp-Aufsichtsratsmitglieds Bruhn in Deutschland tätig wurde, war Viénot an der Mitgliederrekrutierung in Frankreich beteiligt. Dabei wurden beide von der politischen Entspannung begünstigt, die sich zeitgleich zu den Gründungsvorbereitungen vollzog und schließlich im Oktober 1925 zum Abschluß der LocarnoVerträge führte. Viénot war jedoch davon überzeugt, daß die Abkommen von Locarno Makulatur bleiben würden, wenn die künftigen deutsch-französischen Beziehungen nicht auf echte Kenntnis des Gegenübers gründeten ${ }^{43}$. Das Studienkomitee sollte dazu beitragen, diese Sicherheitslücke zu schließen, indem es in Deutschland und Frankreich an einer Verbesserung und Versachlichung der Berichterstattung über das Nachbarland mitarbeitete.

Von Anfang an wurde von Mayrisch auf französischer Seite Jacques Seydoux, der einflußreiche politische Direktor im Quai d'Orsay, in die Planungen einbe$z^{z o g e n}{ }^{44}$. Seydoux nutzte seine vielfältigen Kontakte zu Kreisen der französischen Industrie und Banken und spielte eine aktive Rolle bei der Mitgliederrekrutierung ${ }^{45}$. Offensichtlich sah er im Studienkomitee die Möglichkeit, seine Vorstellungen einer wirtschaftlichen Verständigung zwischen Frankreich und Deutschland zu verwirklichen ${ }^{46}$. Hinter dem Engagement Seydoux' für das Studienkomitee wurde deshalb auch die »lobby économique et financier ${ }^{47}$ am Werke gesehen, um so mehr als mit Etienne Fougère und René-Paul Duchemin die Leiter der zwei größten französischen Industrieverbände, der Association pour l'Expansion économique und der Conféderation générale de la Production française, im Komitee vertreten waren. Seydoux wies diese Sicht der Dinge

42 Vgl. Viénot an seinen Vater, 25.9.1925: NL Viénot.

43 Vgl. Remarque, vermutlich aus der Feder Viénots, die dem »Projet de fondation d'un comité franco-allemand d'information « aus aktuellem Anlaß der unterzeichneten LocarnoVerträge beigelegt wurde: NL d'Ormesson I, CFA, Fondation 1925, Notes de base.

44 Jacques Seydoux (1870-1929) war seit dem 24.10.1924 stellvertretender Leiter der Abteilung für politische und Handelsangelegenheiten im Quai d'Orsay. De facto war sein Einfluß jedoch so groß, daß er den Zeitgenossen als eigentlicher Direktor der Abteilung galt, die offiziell von Jules Laroche geleitet wurde. Dabei arbeitete Seydoux besonders eng mit Philippe Berthelot, dem Generalsekretär des Quai d'Orsay, zusammen. Vgl. Laurence BADEL, Le Quai d'Orsay, les associations privées et l'Europe (1925-1932), in: René GIRAULT, Gérard Bossuat (Hg.), Europe brisée, Europe retrouvée. Nouvelles réflections sur l'unité européenne au XXe siècle, Paris 1994, S. 109-131, hier S. 113.

45 Das erste Gespräch zwischen Mayrisch und Seydoux in dieser Angelegenheit fand am 3.11.1925 statt. Vgl. Mayrisch an Seydoux, 26.10.1926: MAE, PA-AP Seydoux, 261, d. 40; Note du directeur-adjoint de la direction politique, 10.11.1925: MAE-CAD, Ambassade de France à Berlin, B, 463, d. CFAID.

${ }^{46} \mathrm{Zu}$ den deutschlandpolitischen Vorstellungen Seydoux' vgl. Clemens A. WURM, Die französische Sicherheitspolitik in der Phase der Umorientierung 1924-1926, Frankfurt a.M. u.a. 1979 , S. $496-500$.

47 BADEL, Le Quai d'Orsay, S. 117 
jedoch zurück ${ }^{48}$. Bis zu seinem Ausscheiden aus dem Komitee im Februar 1929 unterhielt er ein enges Verhältnis zu Viénot, von dem der intensive Briefwechsel zwischen beiden zeugt ${ }^{49}$. Zwar ist es richtig, daß Seydoux während dieser Zeit eine Art »conseiller de l'ombre « ${ }^{50}$ für Viénot war, doch schreckte dieser nicht davor zurück, Seydoux mitunter kritisch seine Meinung zu sagen und unabhängig von diesem $\mathrm{zu}$ agieren ${ }^{51}$.

Nach seiner ersten Unterhaltung mit Seydoux im November 1925 äußerte sich Viénot sehr zufrieden: "Seydoux est enthousiaste. [...] nous sommes pleinement d'accord. ${ }^{52}$ Ähnlich wie Seydoux unterstützte auch die französische Botschaft in Berlin, die ebenfalls von Viénot ins Bild gesetzt wurde, die geplante Gründung. »Il est hors doute«, so schrieb der französische Geschäftsträger André de Laboulay an Außenminister Briand, squ'un instrument de travail comme celui que constitueraient les bureaux d'information de Berlin et de Paris rendrait les plus grands services à la cause de l'apaisement. ${ }^{53}$ Gerade nach $\mathrm{Ab}$ schluß der Locarno-Verträge müsse ein derartiges Vorhaben gefördert werden.

Bald mußte Viénot, der sich die erste Komiteesitzung bereits für Januar 1926 wünschte ${ }^{54}$, allerdings feststellen, daß das Projekt auf deutscher Seite größerer Distanz begegnete. Im Dezember 1925 reiste er nach Berlin und führte Gespräche mit in Frage kommenden Personen. Ein Abendessen beim früheren sächsischen Staatsminister Alfred von Nostitz, dessen Frau Helene einen der bedeutendsten Berliner Salons unterhielt, führte Viénot die Schwierigkeiten vor Augen: "Les difficultés pour constituer le Comité sont plus grandes ici qu'en France. Les gens sont incertains, hésitants; la Société est plus morcelée, les intellectuels impossibles à mettre d'accord. ${ }^{55}$ Als Intermediär Mayrischs trat in Berlin vor allem Bruno Bruhn von der Krupp AG auf, der dem Auswärtigen Amt das geplante Unternehmen vorstellte. Er verwies auf das Engagement Mayrischs und führte Alfred Fabre-Luce als französischen Teilnehmer auf. Viénot, der als Initiator des Projekts präsentiert wurde, war bereits als Leiter des Berliner Büros vorgesehen. Weiterhin appellierte Bruhn an die Reichsregierung, wegen der voraussichtlich hohen Kosten eine finanzielle Un-

Vgl. Note du directeur-adjoint de la direction politique, 3.6.1926: MAE, PA-AP Seydoux, 261, d. 41; Note du directeur-adjoint de la direction politique, 15.6.1926: MAE, PA-AP Seydoux, 261, d. 6.

Dieser findet sich in: MAE, PA-AP Seydoux, 261, d. 6.

so Laurence BADEL, Un milieu libéral et européen. Le grand commerce français 1925-1948, Paris 1999, S. 96.

s1 Vgl. dazu ausfuihrlich Kap. III.1.3.3.

52 Viénot an de Cénival, 13.11.1925: NL Viénot.

53 De Laboulay an Briand, 17.11.1925: NL d'Ormesson I, CFA, Fondation 1925, Notes de base. Viénot wurde von seiten der Botschaft als einer der besten Deutschlandkenner eingeschätzt.

54 Vgl. Viénot an de Cénival, 13.11.1925: NL Viénot.

55 Viénot an seine Mutter, 7.12.1925: NL Viénot. 
terstützung von $75000 \mathrm{RM}$ pro Jahr zu leisten ${ }^{56}$. Im Auswärtigen Amt zeigte man sich zurückhaltend. Zwar wurde der grundsätzliche Nutzen des Projekts für die Verständigungspolitik anerkannt, doch gab es Befürchtungen, daß damit vor allem schwerindustriellen Sonderinteressen gedient werden sollte. Eine finanzielle Unterstützung sollte keinesfalls regelmäßig und erst dann erfolgen, wenn sich das Komitee als lebensfähig erwiesen habe ${ }^{57}$.

Bruhn konnte das Auswärtige Amt nicht überzeugen. Das Projekt wurde dort für nicht realisierbar gehalten. Ministerialdirektor Köpke hielt Fabre-Luce für eine Belastung, Viénot für zwar geeignet, aber zu jung und unerfahren. Auch die anderen vorgeschlagenen Kandidaten überzeugten ihn nicht ${ }^{58}$. Der deutsche Botschafter in Paris, Leopold von Hoesch, stellte die praktische Durchführung des Programms ebenfalls in Frage. Zum einen wären die Zeitungskorrespondenten seiner Meinung nach alles andere als erfreut, wenn sich die Leiter des Informationsbüros in ihre Berichterstattung einmischten und zum anderen schätzte er die ihnen zugewiesene Aufgabenvielfalt als zu groß ein ${ }^{59}$. Noch schärfer fiel das Urteil des Pressereferenten der Botschaft, des Legationsrates Kühn, aus. Er hielt die vorgebrachten Vorschläge gar für abwegig. Kühn konnte sich nicht vorstellen, »dass die Informationspresse Frankreichs und Deutschlands, von der in der Druckschrift richtig gesagt wird, dass die nur die Erhöhung ihrer Auflage anstrebt, einer antisensationellen Informationsquelle ihre Spalten öffnet«. ${ }^{60}$ Die personelle wie finanzielle Ausstattung der Informationsbüros wurde als unzureichend und das Vorhandensein eines »Informationsdirektors« als schlichtweg überflüssig eingestuft, da die interessierten Kreise beider Länder auch direkt miteinander in Kontakt treten könnten.

Diese gravierenden Einwände des Auswärtigen Amts, die zentrale Probleme wie die Gefahr von Pressezensur durch die Komiteedirektoren und die Erfolgsaussichten des Unternehmens thematisierten, wurden von Viénot als Beanstandungen von Bürokraten, noch dazu mittelmäßigen, abqualifiziert. Dennoch mußte er die Wogen glätten, die seine geplante Pressebeeinflussung bei den Deutschen hervorgerufen hatte ${ }^{61}$. Schließlich nahm man auf französischer Seite von der weitreichenden Zielsetzung Abstand und begnügte sich mit der Einwirkung auf die Presse, die auf direktem und indirektem Weg mittels dis-

${ }^{56} \mathrm{Vgl}$. Aufzeichnung ohne Unterschrift, 7.12.1925: ADAP, B, I, 1, Nr. 10, S. 35-37.

57 Vgl. ibid. S. 37.

SB Vgl. MÜLLER, Deutsch-französische Gesellschaftsbeziehungen, S. 193

59 Vgl. von Hoesch an Hempel, 10.2.1926: PAAA, Botschaft Paris, DFS, Bd. 1.

${ }^{60}$ Aufzeichnung von Kühn, 25.11.1925: PAAA, Botschaft Paris, DFS, Bd. 1. Vgl. auch die Aufzeichnung von dems., 9.2.1926: ibid.

${ }^{61}$ Vgl. Viénot an seine Mutter, 25.2.1926: NL Viénot. Dabei machte Viénot kein Hehl daraus, was er von den Kritikern hielt: "Je viens déjeuner chez les Nostitz avec l'imbécile bonhomme de la Presseabteilung qui a rédigé la note plein d'objections contre la >Beeinflussung der Presser. Encore une belle discussion diplomatique en perspective«. Ders. an Schlumberger, 24.2.1926: BLJD, Fonds Schlumberger, Ms 1823. 
kreter Intervention erfolgen sollte. An diesem Vorhaben nahm auch das Auswärtige Amt keinen Ansto $B$ mehr ${ }^{62}$, wenngleich Botschafter von Hoesch grundsätzliche Bedenken wegen der Besetzung der Informationsbüros beibehielt: "Um es etwas krass auszudrücken, es scheint mir normaler, die beiderseitigen Direktoren hinsichtlich ihrer Pressearbeit zu Propagandachefs für ihr eigenes Land, als zu pro-französisch bezw. [sic] zu pro-deutsch eingestellten Oberberichterstattern für deutsche bezw. französische Presse zu machen [...]. « $^{63}$

Viénot klagte zwar über die »situation confuse «, die »incertitudes« und die "obstacles " $"$, denen er in Berlin begegnen mußte, doch steckte er seine ganze Energie seit Ende 1925 in die Mitgliederrekrutierung. Bis zur endgültigen Konstituierung des Komitees Ende Mai 1926 pendelte Viénot immer wieder zwischen Paris, Berlin und Colpach hin und her, um Gespräche mit Beitrittskandidaten zu führen oder Persönlichkeiten zu finden, die Mayrisch als Vermittler dienen könnten ${ }^{65}$. Am 20. Dezember 1925 fand bei Jacques Seydoux ein Treffen statt, an dem Mayrisch, Viénot, Schlumberger, Henri de Peyerimhoff, der Präsident des Comité des Houillères, der Physiker Maurice de Broglie, Arthur Fontaine, der Präsident des Verwaltungsrates im Internationalen Arbeitsamt, und Félix de Vogüé teilnahmen. Dabei wurde die definitive Liste derjenigen Personen erstellt, an die man sich wenden wollte. Auf ihr fanden sich auf französischer Seite der Germanist Henri Lichtenberger, der Stahlindustrielle Eugène Schneider, der Vizepräsident des Comité des Forges Théodore Laurent, der Seidenindustrielle Etienne Fougère, der Generaldirektor der Kuhlmann-Chemiewerke René-Paul Duchemin, die Bankiers Charles Sergent und René Debrix, der Reedereibesitzer John dal Piaz sowie Monseigneur Baudrillart, der Rektor des Institut catholique. Auf der deutschen Liste standen die Namen des ehemaligen Außenministers Walter Simons sowie der Industriellen Felix Deutsch und Karl Haniel. Dem Ansinnen Peyerimhoffs, der im Gegenzug für seine Zusage eine großzügige Erweiterung des Komitees gefordert hatte, wurde Genüge getan. Die Aussicht, daß sein Konzept in absehbarer Zeit realisiert werden sollte, versetzte Viénot in ein Hochgefühl aus Stolz und Freude, zumal er darin die Umsetzung eines neuartigen, smodernenc Projektes sah:

Pour une fois, j'ai aimé mon pays sans restriction, parce que je l'ai senti en ces gens, pour un instant, moderne, décidé, jeune, oui jeune, enfin! Et cela, au lendemain du jour où je venais, en Allemagne, de nous présenter comme tels, [...] en représentant une France vivante, réaliste,

Vgl. Aufzeichnung von Bülow, 10.5.1926: ADAP, B, I, 1, Nr. 214, S. 511 f.; Aufzeichnung von Kühn, 11.3.1926 und Note über die Beziehungen der Institute zur Presse, o.D.: PAAA, Botschaft Paris, DFS, Bd. I.

63 Von Hoesch an AA, 16.3.1926: PAAA, Botschaft Paris, DFS, Bd. I.

64 Viénot an de Cénival, 10.3.1926: NL Viénot.

65 So knüpfte er bei seinem ersten Berlin-Aufenthalt Ende 1925 Kontakte zur Herausgeberin der Zeitschrift Nord und Süd, Antonina Vallentin, schez qui l'on rencontre toute l'Allemagne«. Mit der französischen Botschaft in Berlin stand er ebenfalls in engem Kontakt. Vgl. Viénot an seinen Vater, 11.12.1925: NL Viénot. 
vigoureuse à laquelle l'Allemagne ne résiste pas... Je suis heureux [...]: je touche au bout de mes peines pour pouvoir être Français avec joie ${ }^{66}$.

Das von Viénot geforderte enge Verhältnis zur französischen Regierung erwies sich als überaus wichtig, da eine Reihe von Mitgliedskandidaten ihre Zusage von einer positiven Haltung des Quai d'Orsay abhängig machten. So konnte René Debrix, der Direktor der Société générale alsacienne de Banque, erst nach einer diesbezüglichen Versicherung Seydoux' gewonnen werden. Der Stahlindustrielle Théodore Laurent zeigte sich nach einem Gespräch mit Mayrisch interessiert, wollte aber vor einer definitiven Zusage erst mit Briand sprechen. Obwohl Seydoux in einer Notiz betonte, der Charakter der Initiative sei rein privater Natur und die Regierung werde keinerlei Verantwortung übernehmen, bat er doch Philippe Berthelot, den Generalsekretär des Quai d'Orsay, Laurent zum Beitritt zu ermutigen ${ }^{67}$. Charles Sergent, Präsident des Verwaltungsrates der Banque de 1'Union parisienne versuchte Seydoux ebenfalls mit einer amtlichen Zusicherung zu gewinnen ${ }^{68}$, die diesen jedoch nicht von einer Absage zurückhalten konnte. Seydoux zögerte auch nicht, Sergent zu bedrängen, als er inn wissen ließ: "Votre abstention affaiblit certainement notre position, car nous n'aurons personne d'aussi représentatif que vous à mettre en face des financiers allemands qui figurent dans le Comité. $\ll^{69}$ Doch auch von diesem Druck ließ sich Sergent nicht umstimmen.

Neben Seydoux wurde Viénot vor allem von Lyautey und Teilen der früheren »équipe« unterstützt, namentlich von Wladimir d'Ormesson und Félix de Vogüé. So hatte Lyautey zusammen mit Félix de Vogüé, von dessen Vermittlungsversuchen Viénot allerdings nicht besonders angetan war $^{70}$, beim Duc de Broglie interveniert. Weiterhin warb er um den Eintritt von Monseigneur Baudrillart als Vertreter der Kirche ${ }^{71}$. Nach einem persönlichen Gepräch mit dem Bischof zweifelte Viénot jedoch an dessen Eignung, denn er fand bei ihm, »l'attitude d'un homme qui n'a pas dépassé l'état d'esprit naturel après 1870 , qui garde, après la victoire, les protestations, les méfiances et la passivité du

Vgl. Note du directeur-adjoint de la direction politique, 9.1.1926 und Note du directeuradjoint de la direction politique pour Berthelot, 3.2.1926: MAE, PA-AP Seydoux, 261, d. 6. Laurence Badel führt dies zu dem Schluß, daß die Komiteegründung »sous l'égide du Quai d'Orsay« erfolgt sei. Vgl. BADEL, Un milieu libéral, S. 160.

${ }^{68}$ Note du directeur-adjoint de la direction politique, 9.1.1926: MAE, PA-AP Seydoux, 261, d. 6.

${ }^{69}$ Seydoux an Sergent, 16.3.1926: MAE, PA-AP Seydoux, 261, d. 41.

70 So äußerte er sich über diese: „Félix est seulement le plus mauvais des intermédiaires, empêtré et inapte à toute action, sans aucune décision et aucune fermeté«. Viénot an de Cénival, 13.11.1925: NL Viénot.

${ }^{71}$ Lyautey an Viénot, 28.12.1925: NL Viénot. Vgl. auch den Dankesbrief Mayrischs an Lyautey für dessen Bemühungen, abgedruckt in: BocK, Émile Mayrisch und die Anfänge, S. 580. 
vaincu..$^{72}$ Als Baudrillart schlieBlich absagte, konnte Monseigneur Julien, der Bischof von Arras, gewonnen werden. Lyautey selbst trat dem Komitee nicht bei $^{73}$. Zwar sah Seydoux dessen Teilnahme als überaus wünschenswert an, doch seine Tätigkeit im Conseil supérieur de Guerre stand dem im Wege ${ }^{74}$. Um Interessenkonflikte zu vermeiden, war der Ausschluß von aktiven Politikern oder Diplomaten festgelegt worden.

Wladimir d'Ormesson engagierte sich indessen besonders bei der Mitgliederwerbung. Viénot hätte den aktiven d'Ormesson gerne fest mit dem Komitee verbunden und bot ihm Ende Dezember 1925 einen Posten im Pariser Büro des Komitees an ${ }^{75}$. Anfang 1926 führte d'Ormesson Gespräche im Quai d'Orsay, wo er sich am 7. Januar 1926 mit dem Diplomaten René Massigli traf, mit dem er befreundet war $^{76}$. Einen Tag später fand er sich bei Seydoux ein, um diesen hinsichtlich Viénots Vorschlag zu Rate zu ziehen. Seydoux schien davon auszugehen, daß d'Ormesson das Angebot annehmen werde, doch dieser lehnte schließlich aus Gesundheitsgründen und wegen seiner vielfältigen publizistischen Tätigkeit $\mathrm{ab}^{77}$.

Im Januar 1926 reiste Viénot wieder nach Berlin, um dort alles für Mayrisch vorzubereiten. An der Spree führte Bruhn unterdessen Gespräche mit Stresemann und mit Reichskanzler Luther, der sich sehr für das Projekt zu interessieren schien. Obwohl Viénot die vielfältigen Demarchen von Mayrisch, Nostitz und Bruhn als sehr positiv beurteilte, war er doch erschrocken über die politische Ausrichtung der Mehrzahl der Komiteemitglieder: »Mais quelle abondance des gens de droite! Vous savez que je ne suis pas très $>89$ (, mais l'envie me démangeait, hier dans une grande conversation avec Bruhn - qui est lui aussi Deutschnational - Mayrisch et Nostitz, d'entonner un péan à la gloire de la Déclaration des Droits de l'Homme. ${ }^{78}$ Offensichtlich schien die Realität sich

72 Viénot an Lyautey, 24.1.1926: AN, 475 AP 311.

73 Sein Neffe, Pierre Lyautey, wurde jedoch Mitglied des Komitees.

${ }^{74} \mathrm{Vgl}$. Note du directeur-adjoint de la direction politique, 21.12.1925: MAE-CAD, Ambassade de France à Berlin, B, 463, d. CFAID.

75 D'Ormesson hielt das Angebot Viénots in seinem Tagebuch fest. Vgl. de VOGUE, Wladimir d'Ormesson et le rapprochement, S. 37. Da das Büro von einem Deutschen geleitet werden sollte, konnte es sich eigentlich nur um den Posten des Beigeordneten handeln, der aus dem jeweiligen Land selbst rekrutiert werden sollte.

76 Vgl. dazu ibid. S. 38. René Massigli (1888-1988) war Sekretär bei der Botschafterkonferenz 1920, stellvertretender Generalsekretär der Konferenz von Washington 1921 sowie Leiter des Sekretariats der Genfer Konferenz 1922. 1928 berief ihn Briand zum Chef der Völkerbundsabteilung im Quai d'Orsay. Ab 1933 war Massigli stellvertretender Direktor und von 1937-1938 Direktor der politischen Abteilung.

77 Vgl. de VoGUE, Wladimir d'Ormesson et le rapprochement, S. 37. Zum Gespräch mit Seydoux siehe Note du directeur-adjoint de la direction politique, 9.1.1926: MAE, PAAP Seydoux, 261, d. 6.

${ }^{78}$ Ders. an Schlumberger, 13.1.1926: BLJD, Fonds Schlumberger, Ms 18318. 
noch weitaus inationaler` zu gestalten, als Viénot es selbst in seiner Broschüre geplant hatte.

Die Ernsthaftigkeit, mit der sich die wichtigsten Persönlichkeiten aus Politik und Wirtschaft dem Unternehmen widmeten, schien Viénot zeitweise selbst zu überraschen ${ }^{79}$. Dennoch gab es auch einige Absagen von prominenter Seite. So konnte Eugène Schneider nicht für das Unternehmen gewonnen werden. Dieser hatte Seydoux zu verstehen gegeben, er finde es delikat, mit einem Vertreter der Firma Krupp im selben Komitee zu sitzen und wollte nur dann daran partizipieren, wenn Seydoux ihm dies offiziell als vaterländische Pflicht befehle ${ }^{80}$. Eine derartige Erklärung wollte Seydoux jedoch nicht abgeben. Ebenso erteilte der lothringische Stahlproduzent und Präsident des Comité des Forges, François de Wendel ${ }^{81}$, dem Komitee eine Absage. Auf deutscher Seite blieb Robert Bosch, der Chef des Stuttgarter Elektrokonzerns, dem Komitee fern ${ }^{82}$. Über die Gründe dafür geben die herangezogenen Quellen keine Auskunf ${ }^{83}$. Fritz Thyssen trat dem Komitee zunächst bei, um nach kurzer Mitgliedschaft Ende 1926 im Eklat wieder auszutreten, ohne jemals an einer Sitzung teilge-

79 Vgl. ders. an seine Mutter, 14.1.1926: NL Viénot. Vgl. auch ders. an Schlumberger, 18.1.1926, Ms 18319: BLJD, Fonds Schlumberger: "Au côté allemand, série d'acceptations aussi et sérieux frappant dans la façon d'accepter. Intérêt évident et grande importance accordés au projet«.

${ }^{80} \mathrm{Vgl}$. BADEL, Un milieu européen, S. 160.

${ }^{81} \mathrm{Zu}$ Wendel vgl. Jean-Noël JEANNENEY, François de Wendel en République. L'argent et le pouvoir 1914-1940, 3 Bde., Paris 1976; Serge BERSTEIN, L'argent et le pouvoir: A propos de François de Wendel, in: RHMC 25 (1978) S. 487-499.

82 Die Darstellung Joachim Scholtysecks über Robert Bosch, den er als Mitglied der deutschen Sektion des Studienkomitees bezeichnet, ist in diesem Punkt unzutreffend. In keiner der Mitgliederlisten des Deutsch-Französischen Studienkomitees taucht der Name Robert Boschs auf. Auch in den ausgewerteten Quellenbeständen gab es keinen Hinweis auf eine Mitgliedschaft Boschs. 1930 trat jedoch Carl Bosch in das Studienkomitee ein. Scholtysecks Ausführungen lassen darauf schließen, daß hier eine Verwechslung mit der im September 1926 gegründeten Internationalen Rohstahlgemeinschaft vorliegt, denn das Deutsch-Französische Studienkomitee war eben gerade nicht das Gremium, sdas auf der Basis bilateraler Kooperation privatwirtschaftliche Vereinbarungen über Absatz- und Produktionsquoten traf«. Joachim SCHOLTYSECK, Robert Bosch und der liberale Widerstand gegen Hitler 1933-1945, München 1999, S. 88. Vgl. dazu eine Notiz von Jacques Seydoux aus dem Quai d'Orsay: »Or, le Comité d'information ne doit s'occuper d'aucune négociation économique ou politique de quelque nature qu'elle soit, et ce serait donner une idée tout à fait fausse de sa nature et des préoccupations qui l'animent si l'on faisait croire qu'il s'agit d'une réunion d'industriels ayant pour objet de se mettre d'accord sur le marché de tôle ou de l'acier «. Note du directeur-adjoint de la direction politique, 15.6.1926: MAE, PA-AP Seydoux, 261, d. 6.

83 Hans Manfred Bock geht davon aus, daß Bosch sals südwestdeutscher Liberaler und sozialpolitisch engagierter Unternehmer sich im elitär-jungkonservativen Konsens der deutschen Sektion des Komitees kaum vertreten sehen konnter. BocK, Das Deutsch-Französische Institut, S. 39. Scholtyseck beurteilt dagegen gerade die nationale Interessengrundlage als besonders anziehend für Bosch. Vgl. SCHOLTYSECK, Robert Bosch, S. $88 f$. 
nommen zu haben ${ }^{84}$. Während Mayrisch dies auf den »caractère impulsif de cet industriel zurückführte $^{85}$, wertete unterdessen Seydoux die vorgebliche Verständigungsbereitschaft Thyssens als Schachzug, um an anglo-amerikanische Kredite zu gelangen ${ }^{86}$.

Gleichzeitig mit den Bemühungen Seydoux' setzte auch die Gruppe um Lyautey ihre Bestrebungen fort, dem Komitee Form zu verleihen. Im Februar fand in Lyauteys Pariser Wohnung ein weiteres Treffen statt, an dem Viénot, d'Ormesson, de Peyerimhoff, Fontaine, Goyau, dal Piaz, Schlumberger, Lichtenberger und Vogüé teilnahmen ${ }^{87}$. Kurze Zeit später gelang es Peyerimhoff, den ehemaligen Botschafter in Berlin, Charles Laurent ${ }^{88}$, zur Teilnahme am Komitee zu gewinnen. Viénot zeigte sich darüber regelrecht begeistert und bezeichnete die Rekrutierung durch Peyerimhoff als einen "coup de maître ${ }^{89}{ }^{89}$ Von den später zwischen den beiden auftretenden Differenzen war zu diesem Zeitpunkt noch nichts zu ahnen. Vielmehr schätzte Viénot die Teilnahme Laurents als sehr positiv für ssein، Komitee ein: »ll est passionné par la chose, fait figure de chef de file [...]... ${ }^{90}$

Auf deutscher Seite blieben weiterhin Reserven gegenüber der geplanten Pressearbeit des Komitees bestehen ${ }^{91}$. Die ursprünglich für März geplante Gründungssitzung mußte vertagt werden, da eine Reihe deutscher Mitglieder wegen der verzögerten Aufnahme Deutschlands in den Völkerbund verstimmt waren $^{92}$. Schließlich fand die Konstituierung des Komitees am 29./30. Mai

84 Thyssen hatte seinen Austritt erst der Presse verkündet, bevor er die Mitglieder darüber informierte. Vgl. Compte rendu du Comité exécutif de la Section française du Comité franco-allemand d'Information et de Documentation, $\mathrm{N}^{\circ} 2$, Mois de décembre 1926: NL d'Ormesson III, CFA, Documents des procès-verbaux 1926; Krukenberg, Suggestions personelles relatives à une méthode de travail du Comité franco-allemand de Documentation et d'Information, 16.10.1926: PAAA, Botschaft Paris, DFS, Bd. 1

${ }^{85}$ Carbonnel an Briand, 11.2.1927: MAE-CAD, Ambassade de France à Berlin, B, 463, d. CFAID.

${ }^{86} \mathrm{Vgl}$. Note du directeur-adjoint de la direction politique, 15.6.1926: MAE, PA-AP Seydoux, 261, d. 6.

${ }^{87}$ Laut Tagebucheintrag d'Ormessons fand das Treffen am 19.2.1926 statt. Vgl. de VoGUÉ, Wladimir d'Ormesson et le rapprochement, S. 38.

${ }^{88}$ Charles Laurent (1856-1939) war von 1920-1922 Botschafter in Berlin gewesen. Vgl. MARTENS, KESSEL, Documents diplomatiques, Bd. 1, S. 99-105 und DERS., DIES., Documents diplomatiques, Bd. 2, S. 1305. Viénot an de Cénival, 5.4.1926: NL Viénot.

90 Ibid.

91 Vgl. MƯLLER, Deutsch-französische Gesellschaftsbeziehungen, S. 201.

92 Von den deutschen Teilnehmern hatten Deutsch, Simons und Hagen wegen Krankheit bzw. anderweitiger Verpflichtungen abgesagt. Vgl. Mayrisch an d'Ormesson, 25.3.1926: NL d'Ormesson I, Presse, Correspondance générale, divers; Schlumberger an Seydoux, 30.3.1926: MAE, PA-AP Seydoux, 261, d. 6. Bruhn sah die Verzögerung als Gelegenheit, noch einige »Herren zu finden, die, ohne gerade Parlamentarier zu sein, ausgesprochen rechts gerichtet und Anhänger der deutschnationalen Partei sind. Durch ihre Mitwirkung würden Angriffe, die sonst von jener Seite kommen könnten, leichter vermieden. Bruhn 
1926 in Luxemburg statt. Das dort verabschiedete Programm war kürzer und straffer als die ursprünglichen Vorschläge, doch wurden die Grundgedanken über Zielsetzung und Wirkungsweise beibehalten. Ergänzt wurde die Ausführung durch eine Definition dessen, was das Deutsch-Französische Studienkomitee nicht sein sollte. Es wurde klargestellt, daß es nicht zusammenfalle "mit der Tätigkeit der verschiedenen Organisationen mit seuropäischer` Tendenz « ${ }^{93}$ sowie mit den Aufgaben der Internationalen Handelskammer. Es sollte sich jedoch erweisen, daß diese Aufgabentrennung in der Praxis nicht immer einfach zu realisieren war.

Als Gründungsmitglieder zählten zum Komitee auf französischer Seite ${ }^{94}$ :

- Duc Maurice de Broglie, Mitglied der Académie des Sciences

- Henri Chardon, Mitglied des Staatsrates, Mitglied des Institut de France

- René Debrix, Generaldirektor der Société générale alsacienne de Banque

- René-Paul Duchemin, Präsident der Confédération générale de la Production, Präsident der Union des Industries chimiques

- Arthur Fontaine, Präsident des Verwaltungsrates im Internationalen Arbeitsamt

- Etienne Fougère, Präsident der Association nationale d'Expansion économique, Präsident des Syndicat des Fabricants de Soieries de Lyon

- Monseigneur Eugène Julien, Bischof von Arras, Mitglied des Institut de France

- René Laederich, Präsident des Syndicat général de l'Industrie cotonnière française

- Charles Laurent, ehemaliger französischer Botschafter in Berlin, Präsident des Verwaltungsrates der Compagnie française pour l'Exploitation des Procédés Thomson-Houston und der Banque des Pays du Nord

- Théodore Laurent, Vizepräsident des Comité des Forges

- Henri Lichtenberger, Germanistikprofessor an der Sorbonne

- Comte Wladimir d'Ormesson, Publizist

- John dal Piaz, Präsident des Verwaltungsrates der Compagnie générale transatlantique, Präsident des Comité central des Armateurs de France

- Henri de Peyerimhoff, Präsident des Comité des Houillères de France

an von Bülow, 30.3.1926: ADAP, B, I, 1, Nr. 185, S. 447. Vgl. auch MỚLLR, Deutschfranzösische Gesellschaftsbeziehungen, S. 199. Zur mißglückten Aufnahme Deutschlands in den Völkerbund im März 1926 vgl. KROGGER, Außenpolitik, S. 304-311.

93 Deutsch-französischer Studien- und Informationsausschuss: PAAA, Botschaft Paris, DFS, Bd. 1. Das französische Manuskript findet sich in: NL d'Ormesson I, CFA, Fondation 1925 , Notes de base.

94 Vgl. Agence Havas, 31.5.1926: PAAA, Botschaft Paris, DFS, Bd. 1. Vgl. auch die handschriftliche Notiz von Viènot: ibid. Weiterhin finden sich Mitgliederlisten im Nachlaß d'Ormesson: NL d'Ormesson I, CFA, Fondation 1925, Notes de base und in: MAECAD, Ambassade de France à Berlin, B, 463, d. CFAID. 
- Jean Schlumberger, Schriftsteller

- Edmé Sommier, Präsident des Verwaltungsrates der Société des Raffineries Sommier

- Comte Félix de Vogüé.

Auf der deutschen Seite zählten zu den Gründungsmitgliedern:

- Bruno Bruhn, Mitglied des Aufsichtsrates der Firma Krupp, Essen

- Victor Bruns, Professor für Internationales Recht in Berlin

- Hermann Bücher, Vorstandsmitglied des Reichsverbandes der Deutschen Industrie

- Ernst Robert Curtius, Professor für romanische Literatur, Heidelberg

- Felix Deutsch, Vorstandsvorsitzender der AEG

- Wilhelm Haas, Professor an der Hochschule für Politik in Berlin

- Louis Hagen, Bankier, Präsident der Handelskammer Köln, Mitglied des Reichswirtschaftsrates und des Staatsrates von Preußen

- Fürst Hermann zu Hatzfeld-Wildenburg, Minister a.D.

- Gustav Krukenberg, Jurist

- Franz von Mendelssohn, Bankier, Vorsitzender der Handelskammer Berlin, Mitglied des Reichswirtschaftsrates

- Georg Müller-Oerlinghausen, Fabrikbesitzer, Mitglied des Reichswirtschaftsrates und des Vorstands des Reichsverbandes der Deutschen Industrie

- Alfred von Nostitz-Wallwitz, Staatsminister a.D.

- Alfred Graf von Oberndorff, Minister a.D.

- Alfred Graf von Praschma, Mitglied des Reichsrates

- Edgar Schlubach, Konsul, Kaufmann in Hamburg

- Friedrich Schmidt-Ott, Staatsminister a.D., Vorsitzender der Notgemeinschaft der deutschen Wissenschaft

- Walter Simons, Außenminister a.D., Präsident des Reichsgerichts in Leipzig

- Emst von Simson, Staatssekretär a.D., Mitglied des Verwaltungsrates der IG Farben und des Vorstandes des Reichsverbandes der Deutschen Industrie

- Emil von Stauss, Direktor der Deutschen Bank

- Fritz Thyssen, Vorsitzender des Aufsichtsrates der Vereinigten Stahlwerke AG, Mühlheim

Die Mitgliederzusammensetzung zeigt deutlich, daß in der Folge der LocarnoHochstimmung in Deutschland wie in Frankreich zahlreiche Spitzenvertreter von Wirtschaft, Banken und Kultur an der Gründung einer Verständigungsorganisation exklusiver Eliten interessiert waren. In beiden Ländern wurde der Großteil der Mitglieder aus Wirtschaft, Handel und Finanzen rekrutiert, wobei auf beiden Seiten die Stahl- und Kaliindustrie vertreten war. Gleichzeitig lassen sich jedoch auch länderspezifische Schwerpunkte feststellen. So dominierten 
bei den Wirtschaftsvertretern unter den deutschen Mitgliedern Repräsentanten der Elektro- und der chemischen Industrie, unter den Franzosen die Textil- und Nahrungsmittelindustrie, je nach jeweiligem Exportschwerpunkt. Diese Schwerpunktsetzung blieb konstant bis zum Ende der Organisation 1938. Während in Deutschland stets die Vertreter von Industrie und Wirtschaftsverbänden ein Übergewicht besaßen und gleichzeitig mehr Aristokraten vertreten waren als in der französischen Sektion, war der Anteil der Kulturrepräsentanten unter den französischen Mitgliedern höher als bei ihren deutschen Kollegen. Dabei »wurden die Intellektuellen aufgrund ihrer spezifischen Kenntnisse über das Nachbarland rekrutiert, und zum Teil kam ihnen als Mittlerpersönlichkeiten eine herausragende Rolle für die Deutung des Nachbarlandes zu (Curtius, Bergsträsser, Lichtenberger, Vermeil)«. ${ }^{95}$

Zum Vorsitzenden des Komitees wählten die Teilnehmer Émile Mayrisch. In der Folgezeit wurde die Persönlichkeit des Vorsitzenden so stark mit dem Komitee identifiziert, daß sich die Bezeichnung Mayrisch-Komitee im allgemeinen Sprachgebrauch einbürgerte. Die Leitung der deutschen Sektion übernahm Alfred von Nostitz-Wallwitz, die der französischen Charles Laurent. Es gehörte zu den Statuten des sich als überparteilich verstehenden Komitees, daß Politiker ihr Amt oder Mandat für die Zeit der Mitgliedschaft ruhen ließen. Auf diese Art und Weise kam es zu einer regelmäßigen Mitgliederfluktuation, wobei die neuen Mitglieder nach eingehender Prüfung einvernehmlich hinzugewählt wurden ${ }^{96}$. Die Mitgliederzahl wurde auf je 25 pro Sektion begrenzt. Leiter des Berliner Büros, welches Anfang August 1926 eröffnet werden sollte, wurde erwartungsgemäß Pierre Viénot. Zum Direktor des Büros in Paris wurde Gustav Krukenberg emannt, ein Jurist und ehemaliger Berufssoldat ${ }^{97}$.

95

Vgl. zu den soziologischen Besonderheiten Hans Manfred BocK, Kulturelle Eliten in den deutsch-französischen Gesellschaftsbeziehungen der Zwischenkriegszeit, in: Rainer HUDEMANN, Georges SOUTOU ( $\mathrm{Hg}$.), Eliten in Deutschland und Frankreich im 19. und 20. Jahrhundert. Strukturen und Beziehungen, Bd. 1, München 1994, S. 73-91, hier S. $86 f$. und DERS., Projekt deutsch-französische Verständigung, S. 30f.

96 Vor der Zuwahl eines neuen Mitglieds wurden Exposés über dessen Vita erstellt. Vgl. BELITZ, Befreundung mit dem Fremden, S. 194.

97 Gustav Krukenberg (1888-1980) war Referent des früheren Außenministers Simons und Mitarbeiter Büchers im Reichsverband der deutschen Industrie gewesen. Nach 1933 trat er der NSDAP bei und arbeitete als Reichsrundfunkkommissar für Goebbels' Propagandaministerium, bevor er 1934 in die Wirtschaft ging. 1944/45 organisierte er die WaffenSS-Einheit "Charlemagne» mit französischen Freiwilligen im Kampf um Berlin. Vgl. MÜLLER, Deutsch-französische Gesellschaftsbeziehungen, S. 211f., FN 175.

Zunächst war für den Posten der Legationsrat der Sächsischen Gesandtschaft Berlin, W. Hempel, vorgesehen, der jedoch eine Zusichenung zur Aufnahme in den Auswärtigen Reichsdienst verlangte. Schließlich zog Hempel seine Kandidatur angesichts der "candidature souterraine [de] Krukenberg, soutenue par Bucher« zurück. Von Viénot, Haas und Nostitz wurde Krukenberg aus Mangel an Finesse und Taktgefuhl als wenig geeignet und als schlechte Wahl eingeschätzt. De Margerie an Seydoux, 23.6.1926: MAE, PA-AP Seydoux, 261, d. 6. Vgl. auch Hempel an von Hoesch, 23.1.1926; von Hoesch an Hempel, 
Aus dem Kreis der Mitglieder wurde ein Exekutivausschuß gewählt, der die Durchführung des Programms gewährleisten und die zwei- bis dreimal jährlich stattfindenden Plenartagungen vorbereiten sollte. Ihm gehörten neben Mayrisch als Vorsitzenden von Nostitz, Bruhn, Bruns, Bücher, Curtius, von Oberndorff und Schmidt-Ott sowie Charles Laurent, Chardon, Lichtenberger, Schlumberger, de Peyerimhoff, de Vogüé und d'Ormesson an. Die beiden Bürodirektoren mit ihren Mitarbeitern nahmen ebenfalls an den Sitzungen teil ${ }^{98}$. Der Exekutivausschuß sollte sich am 17. Juli in Luxemburg wiedertreffen, die nächste Vollversammlung im September in Berlin stattfinden. Die Finanzierung des Unternehmens war zunächst für ein Jahr zu je gleichen Teilen geplant, wobei bis zum 1. Juli 50000 RM oder 400000 Francs furr die Einrichtung der Büros zur Verfügung gestellt werden sollten ${ }^{99}$. Zum Ausgleich der unterschiedlich hohen Lebenshaltungskosten für die Büros in Paris und Berlin wurde ein zu gleichen Teilen finanzierter Fonds eingerichtet, aus dem auch Sonderausgaben bestritten werden konnten. Die Organisationsstruktur des Komitees wurde, im Gegensatz zu der in festen Statuten geregelten Internationalen Rohstahlgemeinschaft, relativ offen und flexibel gestaltet. Um den privaten und vertraulichen Charakter der Sitzungen zu gewährleisten, wurden in den Protokollen lediglich die Ergebnisse, nicht die Diskussionsbeiträge der einzelnen Teilnehmer festgehalten ${ }^{100}$.

Die Gründungssitzung wurde von allen Beteiligten als Erfolg gewertet, auch die Presse berichtete ausführlich über die Entstehung der Verständigungsorganisation ${ }^{101}$. Obwohl während des Treffens auch sensible politische Themen

10.2.1926; Hempel an von Hoesch, 17.2.1926; von Hoesch an AA, 1.6.1926: PAAA, Botschaft Paris, DFS, Bd. 1.

98 Die genaue Anzahl und Zusammensetzung des Exekutivkomitees konnte nicht ermittelt werden. Wladimir d'Ormesson gab die Anzahl der Mitglieder mit je funf aus jeder Sektion an, Jacques Seydoux mit vier, und Guido Müller geht von nur je drei Mitgliedern aus. In den Teilnehmerlisten der Treffen des Exekutivausschusses finden sich die genannten Namen, wobei der Kreis der Teilnehmer wie auch deren Anzahl von Treffen zu Treffen geringfügig variierte. Vgl. Wladimir d'ORMESSON, Le Comité franco-allemand travaille à organiser la Paix franco-allemand, in: La Gazette des Nations, Nr. 46, Beilage zu: La Gazette du Franc, 24.11.1928; Note du directeur-adjoint de la direction politique, 15.6.1926: MAE, PA-AP Seydoux, 261, d. 6.; MULLER, Deutsch-französische Gesellschaftsbeziehungen, S. 203.

99 Das Auswärtige Amt unterstützte das Komitee für die Jahre 1926/27 mit je $6000 \mathrm{RM}$. Vgl. Gülich an AA, 30.5.1926: ADAP, B, I, 1, Nr. 233, S. 561.

${ }^{100} \mathrm{Vgl}$. Mayrisch an die Mitglieder des Studienkomitees, 24.10.1926: NL d'Ormesson, CFA, Documents des procès-verbaux 1926.

${ }^{101}$ Das an die Presse gegebene Kommuniqué findet sich abgedruckt bei L'HULLIER, Dialogues franco-allemands, S. 14lf. Vgl. weiterhin z.B. PERTTAX [André Géraud], Un essai de coopération franco-allemande. La réunion des 29-30 mai à Luxembourg, in: L'Écho de Paris, 1.6.1926; Un comité français-allemand des hauts représentants des intérêts économiques vient de se constituer, in: Le Journal, 1.6.1926; Comité franco-allemand d'information et de documentation, in: Le Journal des Débats, 1.6.1926; Jacques EBSTEIN, Le Dr. Bruhn, administrateur des Usines Krupp, nous dit..., in: L'Avenir, 5.6.1926. In der 
wie die Kriegsschuldfrage und die Kolonialmandate erörtert wurden, herrschte doch bei allen Beteiligten ein Bemühen um gegenseitiges Verständnis und Entspannung vor ${ }^{102}$. Nostitz lobte die Atmosphäre als "sympathique et [...] chevaleresque ${ }^{103}$, und Viénot meinte gar: $»[\ldots]$ ce n'est pas un succès, c'est un triomphe... [...] Tout a été parfait. ${ }^{104}$ Émile Mayrisch zeigte sich zwar ebenfalls zufrieden über die erreichten Ergebnisse, teilte jedoch den Enthusiasmus Viénots nicht. Als Luxemburger mit der deutschen wie der französischen Mentalität vertraut, äußerte er sich kurz nach dem Gründungstreffen zurückhaltend über die Möglichkeiten eines tiefergehenden deutsch-französischen Verständnisses: $"[\ldots]$ au fond il estime que les allemands et les français sont trop essentiellement différents pour qu'il y ait lieu de chercher à établir entre eux une intimité et naturellement rien de ce qui pourrait ressembler à une fraternisation. ${ }^{105}$ Mayrisch war sich einmal mehr darüber im klaren, daß Verständigung nur als langer Prozeß zu begreifen sein konnte.

Strukturelle und personelle Probleme innerhalb des Studienkomitees

Von Beginn an wohnten dem Komitee strukturelle Probleme inne, die zu Spannungen innerhalb der Organisation führen konnten. So herrschte ein ungeklärtes Verhältnis zwischen den Präsidenten der Sektionen und den jeweiligen Bürodirektoren. Zwar sah Viénots Programmentwurf vor, daß die Bürodirektoren dem Studienkomitee unterstellt waren ${ }^{106}$, doch eine Weisungskompetenz der Sektionspräsidenten wurde nicht explizit festgelegt. Schwierig konnte es werden, wenn ein Bürodirektor seine Tätigkeit im Widerspruch zum Sektionsleiter sehr eigenständig ausübte, wie es in der Folgezeit in der französischen Sektion geschehen sollte. $\mathrm{Zu}$ diesem grundsätzlichen organisatorischen Problem trat noch eine persönliche Konkurrenz und zunehmende Antipathie zwischen

linken Presse wurde die Komiteegründung dagegen kaum kommentiert. Vgl. Kühn an AA, 8.6.1926: PAAA, Botschaft Paris, DFS, Bd. 1. Zur deutschen Presseberichterstattung siehe z.B. Deutsch-französische Zusammenarbeit, in: Germania, 31.5.1926; Ein deutschfranzösischer Ausschuß zur »Klarstellung der kulturellen und wirtschaftlichen Tatsachen«, in: Berliner Tageblatt, 1.6.1926; Die deutsch-französischen Eisenverhandlungen. Private Verständigungsversuche, in: Kölnische Zeitung, 1.6.1926. Der Verfasser der Meldung in der Kolnischen Zeitung brachte das Deutsch-Französische Studienkomitee, wie aus dem Titel des Artikels ersichtlich, aufgrund der jeweiligen Beteilung Émile Mayrischs in $\mathrm{Zu}$ sammenhang mit den Verhandlungen zur IRG.

${ }^{102}$ Vgl. Carbonnel an Briand, 30.5.1926: MAE-CAD, Ambassade de France à Berlin, B, 463, d. CFAID.

${ }^{103}$ Von Nostitz an d'Ormesson, 10.6.1926: NL d'Ormesson I, Presse, Correspondance générale, divers.

104 Viénot an seine Mutter, 30./31.5.1926: NL Viénot.

${ }^{105}$ Carbonnel an Briand, 28.5.1926: MAE-CAD, Ambassade de France à Berlin, B, 463, d. CFAID.

${ }^{106}$ Vgl. Pierre Viénot, Vorschlăge zur Errichtung eines deutsch-französischen Informierungsausschusses, Luxemburg o.J. [1925]: PAAA, Botschaft Paris, DFS, Bd. 1, S. 12. 
Viénot und Laurent, welche die Arbeit des Komitees erschwerte und es 1929 in seine schwerste Existenzkrise führte.

Ein weiteres Spannungsfeld war das Verhältnis der Bürodirektoren zueinander. Viénot hatte in seiner Programmschrift die "Gemeinsamkeit der Anschauungen beider Direktoren ${ }^{107}$ gefordert. In der Realität des Komiteealltags mangelte es jedoch daran. Viénots Kollege Gustav Krukenberg hatte von der Komiteearbeit wie auch von seiner eigenen Rolle als Pariser Bürodirektor eine grundlegend andere Auffassung als Viénot. Im Gegensatz zu Krukenberg wollte Viénot unentwegt an allen Planungen beteiligt sein, empfand sich selbst als Schrittmacher und versuchte, aus dem Hintergrund alle Fäden in der Hand zu halten. Krukenberg hingegen warnte vor einer allzu aktiven Rolle des Komitees. Er sah sein Büro vor allem als Vermittlungsagentur deutsch-französischer Wirtschaftskontakte und als Informationsstelle über aktuelle politische, wirtschaftliche und gesellschaftliche Entwicklungen in Frankreich. In erster Linie ging es ihm jedoch darum, deutschen Interessen - und dabei vor allem Wirtschaftsinteressen - zu dienen ${ }^{108}$.

Der sich hier abzeichnende Konflikt zwischen Viénot und Krukenberg weist auf ein tiefes und grundsätzliches Problem des Mayrisch-Komitees hin. Obwohl die Mitglieder alle dem von Viénot entworfenen Programm einer Annäherung durch verbesserte Kenntnis und Verständnis für die andere Mentalität zugestimmt hatten, so gab es de facto innerhalb des Komitees gänzlich verschiedene partikulare Interessen - wie etwa die einseitige Orientierung zur Wirtschaft hin -, die mit Viénots Ideen nicht unbedingt übereinstimmten. Die Ausrichtung auf das Nationalinteresse, das die Mitgliedschaft vieler konservativer Teilnehmer erst ermöglicht hatte, war gleichzeitig eine schwere Belastung für die Verständigungsorganisation. Eine fruchtbare Komiteearbeit konnte es nur dann geben, wenn eine Übereinstimmung der beiden Nationalinteressen oder zumindest ein für beide Seiten akzeptabler Ausgleich erzielt werden konnte. Was in der Euphorie von Locarno und den damit verbundenen Hoffnungen zunächst überdeckt wurde, sollte jedoch bald deutlich sichtbar werden: Das deutsche und das französische Nationalinteresse waren langfristig nicht in Einklang zu bringen. Während auf deutscher Seite die Hoffnung vorherrschte, mittels der Verständigungspolitik eine Revision des Versailler Vertrages zu erreichen, beharrte Frankreich auf den außenpolitischen Status quo und damit auf seine europäische Vormachtstellung. Angesichts dieser konträren nationalen Interessenlagen, die sich im Studienkomitee widerspiegelten, waren seine Erfolgsaussichten von Anfang an fraglich.

Die Haltung Jacques Seydoux' gegenüber den Deutschen war in dieser Hinsicht sehr aufschlußreich. Dieser hielt an seinem grundsätzlichen Mißtrauen gegenüber der deutschen Industrie fest, die in seinen Augen noch immer die

${ }^{107}$ Ibid. S. 18.

${ }^{108} \mathrm{Vgl}$. BocK, Projekt deutsch-französische Verständigung, S. 32f. 
ökonomische Herrschaft über Europa anstrebte. Die Zusammenarbeit mit den Deutschen hatte in seinen Augen vor allem eine strategische Bedeutung:

Plus nous causerons avec l'Allemagne, plus nous pourrons connaître ses ambitions. [...] Nous éviterons également d'être submergé par son industrie: nous pourrons, en somme, sinon le diriger, du moins le limiter dans les mouvements qu'il fera et qui pourrait mettre en danger la paix de l'Europe ${ }^{109}$.

Und letztlich führten diese Öberlegungen Seydoux zu dem erstaunlichen Schluß: »[...] il vaut mieux que nous soyons d'accord avec les Allemands pour dominer l'Europe que de nous trouver contre eux. ${ }^{110}$ Die deutsch-französische Wirtschaftspartnerschaft sollte in den Augen Seydoux' dazu dienen, Kontrolle über die deutsche Industrie auszuüben, eine Vermittlerrolle im erwarteten Konflikt zwischen der deutschen auf der einen und der anglo-amerikanischen Industrie auf der anderen Seite einzunehmen und nicht zuletzt Frankreich von der finanziellen Abhängigkeit von den britischen und amerikanischen Märkten zu befreien. Viénot, der eine ganz andere, auf eine Veränderung der Mentalitäten zielende Konzeption des Studienkomitees vertrat, stand Seydoux trotz seines Respekts vor dem anerkannten Wirtschaftspolitiker mit einer kritischen Distanz gegenüber. Die Einstellung Seydoux' gegenüber Deutschland war in Viénots Augen nicht unproblematisch, und er sah in ihr eine mögliche Konfliktquelle: "Je connais Seydoux. Il est capable de faire des gaffes. " ${ }^{111}$

Seydoux' Konzept der wirtschaftlichen und politischen Zweckorientierung des Komitees war auch den deutschen Mitgliedern nicht fremd. Dies hatte sich bereits in der Gründungsphase des Komitees gezeigt, als Vertreter wie Nostitz und der ehemalige Staatssekretär Ernst von Simson vor allem Vertreter aus der Wirtschaft im Komitee zusammenbringen wollten ${ }^{112}$. Kurz nach der Konstituierung schilderte Nostitz gegenüber dem Auswärtigen Amt seinen Eindruck, daß innerhalb der deutschen Sektion jene Tendenz an Boden gewinne, die das Komitee vor allem wirtschaftlichen Interessen dienstbar machen wolle ${ }^{113}$. Freilich bot das Komitee auch eine einzigartige Plattform des regelmäßigen Zusammentreffens und Austausches für die Industrievertreter beider Seiten. 1927 wurden im Umfeld des Komitees beispielsweise geheime deutsch-französische Verhandlungen geführt über die Möglichkeiten zur Verflüssigung von Kohle. Ziel war es, sich vom amerikanischen und russischen Petroleum unabhängig zu machen ${ }^{114}$.

${ }^{109}$ Note du directeur-adjoint de la direction politique, 15.6.1926: MAE, PA-AP Seydoux, 261, d. 6.

110 Ibid.

III Viénot an d'Ormesson, 1.10.1927: NL d'Ormesson II.

${ }^{112}$ Vgl. MOLLER, Deutsch-französische Gesellschaftsbeziehungen, S. $195 \mathrm{ff}$.

${ }^{113}$ Vgl. ibid. S. 202.

114 Vgl. Pierre BERTAUX, Un normalien à Berlin. Lettres franco-allemandes 1927-1933, hg von Hans Manfred BOCK, Gilbert KREBS, Hansgerd SCHULTE, Asnières 2001 (Publications de l'Institut d'Allemand d'Asnières, 29), S. 117. 
Gegen einen einseitigen Schwerpunkt auf die Beförderung wirtschaftlicher Interessen der Mitglieder wehrte sich jedoch Mayrisch, der auf einer aktiven Pressepolitik insistierte. In dieser Haltung wurde er vor allem unterstützt durch Viénot und d'Ormesson. Letzterer hatte in einem Artikel in Le Temps die Leitidee des Komitees als weder politisch noch ökonomisch motiviert beschrieben. Das Studienkomitee sei auch kein Werk zur Verständigung, denn, so d'Ormesson, sle rapprochement franco-allemand est une question d'ordre politique et le comité ne se place absolument pas sur le terrain politique; une telle action dépasserait et de loin ses pouvoirs et ses attributions «. ${ }^{115}$ In dem durch die Verträge von Locarno geschaffenen Rahmen sah d'Ormesson im Studienkomitee einen Beitrag zur psychologischen Entwicklung der deutsch-französischen Beziehungen. Dabei handle es sich nicht um Propaganda, sondern um sintercompréhension «. ${ }^{116}$ Viénot, der in der Gründungsphase für die programmatische Ausrichtung des Komitees auf die Pressearbeit verantwortlich war, erwies sich in der Folgezeit als der nachdrücklichste Vertreter dieser Linie, unterstützt von einer Gruppe, zu der d'Ormesson, de Peyerimhoff und nicht zuletzt Mayrisch gehörte, der seine Initiativen protegierte.

Dem Komitee wohnte also von Beginn an eine Ambivalenz inne: Befürworter einer eher psychologischen Annäherung mit Hilfe der Presse standen de facto den Vertretern einer Wirtschaftsverständigung gegenüber. In einer Erklärung gegenüber Le Temps versuchte der Vorsitzende der französischen Sektion, Charles Laurent, den Königsweg zu finden. Er sprach vom »éclectisme même de notre Comité ${ }^{117}$ und gab eine Erklärung zur Zielsetzung der Organisation ab, die in ihrer Schwammigkeit nichtssagend blieb: "J'ajoute que nous ne sommes pas non plus, dans un sens rigoureux de l'expression, un comité de rapprochement franco-allemand; nous n'avons pas d'idée préconçue. ${ }^{118}$

Aufgrund der dem Komitee inhärenten Spannungen und Interessengegensätze war auch Viénots Position von Anfang an nicht einfach. Auf der einen Seite betrachtete er das Komitee als sein Werk und sich selbst als unabhängig von Weisungen seines Sektionspräsidenten Laurent. Auf der anderen Seite mußte er als junger und beruflich unerfahrener Bürodirektor seine Kompetenz erst unter Beweis stellen. Dies mag auch dazu beigetragen habe, daß Viénot in der Folgezeit eine unglaubliche Aktivität an den Tag legte, die weit über die festgelegten Tätigkeiten des Büroleiters hinausging und mit der er bisweilen durchaus aneckte. Gleichzeitig versuchte er, seine Sicht des Komiteezwecks

${ }^{115}$ Wladimir d'ORMESSON, L'objet et l'action du Comité français-allemand d'information, in: Le Temps, 20.6.1926.

${ }^{116}$ Ibid.

${ }^{117}$ Déclaration au journal Le Temps par M. Charles Laurent, Ambassadeur de France, Président de la Section française du Comité franco-allemand d'Information et de Documentation à la veille de la Réunion du Comité à Berlin du 6 au 8 février 1927: NL d'Ormesson I, CFA, Fondation 1925, Notes de base.

${ }^{118}$ Ibid. 
als verbindlich durchzusetzten, wozu ihm letztlich jedoch die Mittel fehlten. Viénots selbstbewußte Definition der eigenen Rolle und sein Kampf um deren Akzeptanz im Komitee prägte seine Tätigkeit bis zu seinem Ausscheiden. Von derlei Problematik ließ er sich zu Beginn jedoch nicht entmutigen. Ganz unter dem Eindruck der erfolgreichen Gründungssitzung stehend, wertete er sie auch als seinen eigenen Erfolg: "IJ'ai le droit de dire que j'ai déjà réalisé une belle chose dans ma vie... ${ }^{119}$

\subsection{Ein elitäres Forum deutsch-französischer Zusammenarbeit}

Organisations- und Arbeitsweise des Komitees

Neben den Büros in Berlin und in Paris als Exekutivorgane des Studienkomitees stellten die mehrmals jährlich stattfindenden Plenarversammlungen die zentralen Einrichtungen der Organisation dar. Hier wurden nicht nur Organisations- und Arbeitsfragen besprochen, sondern auch Vorträge zu bestimmten politischen und sozio-ökonomischen Themen im deutsch-französischen Vergleich gehalten. Während die Büros mitsamt ihrer offiziösen Kontakte zu Politik, Diplomatie und Presse in vorsichtiger Weise nach außen wirken sollten, so waren die Versammlungen des Komitees rein interne Angelegenheiten, zu denen zwar bisweilen Gäste eingeladen wurden ${ }^{120}$, die jedoch grundsätzlich den Mitgliedern vorbehalten blieben. Bis zu Viénots Ausscheiden aus den Diensten des Komitees im März 1930 fanden sechs Plenartagungen statt:

am 23. Oktober 1926 in Paris,

vom 6. bis 9. Februar 1927 in Berlin,

vom 14. bis 16. Juni 1927 in Paris,

vom 12. bis 13. Dezember 1927 in Luxemburg,

vom 4. bis 6. Juli 1928 in Baden-Baden,

[am 18. Dezember 1928 in Colpach] ${ }^{121}$

vom 4. bis 7. Februar 1929 in Paris.

119 Viénot an seine Mutter, 30./31.5.1926: NL Viénot.

${ }^{120}$ Viènot hatte anläßlich der Plenartagung in Berlin vom 6. bis 8. Februar 1927 für den Physiker de Broglie ein Diner mit Intellektuellen und Wissenschaftlern organisiert, an dem auch Albert Einstein teilnahm. Einstein kritisierte in seiner Rede den immer noch anhaltenden wverdeckten Kriegszustand " zwischen deutschen und französischen Wissenschaftlem. Vgl. Vortrag von Albert Einstein am 8.2.1927: NL d'Ormesson III, Documents 1926-1932.

${ }^{121}$ Diese Versammlung wird von Robert Meyer erwăhnt, in den durchgesehenen Dokumenten findet sich aber kein Hinweis darauf. Am 16. Dezember 1928 fand eine Sitzung des Exekutivkomitees in Colpach statt, in deren Protokoll die nächste Plenarsitzung im Februar 1929 erwähnt wird. Vgl. Robert MEYER, Colpach, in: CRE, Émile Mayrisch, S. 18-42, hier S. 38; Compte rendu de la séance tenue par le comité exécutif au Château de Colpach, Luxembourg, le 16 décembre 1928: NL d'Ormesson I, Correspondance officielle du Bureau de Paris. 
Neben den Plenartagungen trugen auch die regelmäßig stattfindenden Sitzungen des Exekutivkomitees zum deutsch-französischen Austausch bei. Nach einer umfassenden Reorganisation des Komitees 1929/30, die unmittelbar mit Viénots Ausscheiden verknüpft war, fanden zunächst weiterhin Plenartagungen statt, bis diese Gewohnheit 1933 eingestellt wurde. 1935 erfolgte dann noch einmal ein Gruppenbesuch französischer Komiteemitglieder in Berlin und 1937 ein Gegenbesuch in Paris. Diese festen organisatorischen Strukturen schufen win der gesamten Zwischenkriegszeit die vergleichsweise tragfähigste Grundlage für die Bemühungen um die deutsch-französische Verständigung der Eliten im vorpolitischen Raum «. ${ }^{122}$

Die ersten Tagungen standen vor allem im Zeichen einer genaueren Zweckbestimmung des Komitees und der Definition seiner Aufgaben sowie der finanziellen Organisation. Von Anfang an wurde klargemacht, daß die beiden Büros in Berlin und Paris keine unabhängigen Organismen darstellten, sondern eng mit dem Komitee verbunden sein sollten. Es war vorgesehen, daß die beiden Direktoren jeden Monat einen Tätigkeitsbericht für den Präsidenten Mayrisch und den Vorsitzenden der jeweiligen Sektion verfaßten. Bei den monatlichen Sitzungen der deutschen und französischen Gruppen des Exekutivkomitees war auch die Anwesenheit des Bürodirektors aus dem jeweils anderen Land erwünscht ${ }^{123}$. Darüber hinaus sollte ein enger Austausch der Direktoren mit ihrer nationalen Sektion gewährleistet werden. Als weitere Maßnahme wurde die Errichtung von Kommissionen zur Untersuchung von Einzelfragen beschlossen ${ }^{124}$. Die kurzfristig zur Diskussion gestellte Möglichkeit, zur Untersuchung von Einzelfragen innerhalb des Komitees eine Wirtschaftsgruppe von einer Nicht-Wirtschaftsgruppe zu trennen, wiesen die Komiteemitglieder einstimmig zurück. Diese Vorgehensweise wurde als nicht vereinbar mit $\mathrm{Zu}$ sammensetzung und Zielen des Komitees angesehen. Statt dessen wurden zwei Arbeitsausschüsse eingesetzt zur vertieften Untersuchung von Presseangelegenheiten einerseits und zu Fragen des Studentenaustauschs andererseits ${ }^{125}$. Mitte 1927 stand auch die Einrichtung einer weiteren Kommission zur »Bevöl-

${ }^{122}$ BocK, Kulturelle Eliten, S. 83.

${ }^{123} \mathrm{Vgl}$. Réunion tenue à Luxembourg le 17 juillet 1926 par le Comité exécutif du Comité Franco-Allemand d'Information et de Documentation: NL d'Ormesson III, Séances du Comité exécutif.

${ }^{124} \mathrm{Vgl}$. Procès-verbal de l'Assemblée générale du Comité franco-allemand d'Information et de Documentation tenue à Paris, le 23 Octobre 1926: NL d'Ormesson III, CFA, Documents des procès-verbaux 1926.

${ }^{125}$ Vorsitzender der Studentenkommission wurde der Germanist Henri Lichtenberger. Vgl. Compte rendu des séances tenues à Berlin le 6 et le 8 février 1927 par le Comité exécutif du Comité franco-allemand d'Information et de Documentation; Compte rendu de la Réunion du Comité franco-allemand d'Information et de Documentation du 6 au 8 février 1927: NL d'Ormesson III, 1927. 
kerungsfrage als Wirtschaftsproblem« zur Debatte, ihre Errichtung wurde jedoch verschoben ${ }^{126}$.

Während der Plenartagungen wurden regelmäßig Vorträge zu gesellschaftspolitischen Fragestellungen gehalten. Dabei untersuchte der Redner häufig ein Thema in seinem nationalen Kontext, woran sich eine längere Aussprache im Plenum anschloB. Gesprochen wurde unter anderem über die Herausbildung von Eliten in beiden Ländern (Haas, Schmidt-Ott 1927), über Formen und Tendenzen der industriellen Organisation (Bücher 1927), über das Problem der Rationalisierung in internationaler Perspektive (Duchemin 1927), über die politischen Auswirkungen der wirtschaftlichen Zusammenarbeit (Mayrisch 1927) sowie über die Organisation der Presse in beiden Ländern (Lyautey und Oberndorff 1928), die innenpolitische Situation in Deutschland und Frankreich (Siegfried und von Papen 1929), die wirtschaftlichen Probleme Osteuropas (Bücher 1929), die europäische und amerikanische Kultur (Siegfried 1930) und die Vereinigten Staaten von Europa (Serruys 1930) ${ }^{127}$. Allein an der Themenwahl zeigt sich, daß es bei den Aussprachen der Komiteemitglieder nicht vorrangig um handels- und wirtschaftspolitische Fragen ging, sondern daß beide Seiten sich bemühten, aktuelle Zeitfragen in einen größeren politischen, kulturellen und ökonomischen Kontext einzubetten.

Auf der ersten Plenartagung des Jahres 1927 nahm de Peyerimhoff eine Positionsbestimmung vor. Die anwesenden whommes de culture et hommes d'action« seien weder Pazifisten noch Ideologen, sondern in erster Linie Männer guten Willens, die eine gemeinsame Basis zur gegenseitigen Verständigung suchten und trennende Elemente verringern oder ganz beseitigen wollten ${ }^{128}$. So betrachtete sich das Mayrisch-Komitee vor allem als ein Kommunikationsnetzwerk deutsch-französischer Eliten aus den Bereichen Politik, Wirtschaft und Kultur. Es ging ihm nicht um die Durchführung großer öffentlichkeitswirksamer Aktionen, sondern um den Austausch miteinander sowie mit offiziellen politischen Amtsträgern. Durch die direkten Kontakte der im MayrischKomitee versammelten exklusiven Machteliten zu hochrangigen Vertretern der nationalen Politik in beiden Ländern konnte indirekt und unauffälig, so hoffte man, Einfluß ausgeübt werden. Eine eigene Publikation oder nur die

${ }^{126} \mathrm{Vgl}$. Anregungen für die weitere Entwicklung der Komitee-Arbeit und die Gestaltung der künftigen Tagungen, 25.5.1927: NL d'Ormesson III, 1927.

Auf der Plenartagung im Juni 1930 in Paris wurde auch eine Kommission zu den $"$ Vereinigten Staaten von Europa angeregt. Der Beschluß hierüber wurde jedoch auf die Zeit nach der Antwort der Regierungen auf Briands Europa-Memorandum verschoben. Vgl. Compte rendu de la séance plénière du Comité tenu à Paris le 20 juin 1930, in: NL d'Ormesson III, Documents 1926-1932, CFA 1930.

${ }^{127} \mathrm{Vgl}$. näher dazu BOCK, Projekt deutsch-französische Verständigung, S. 34ff.

${ }^{128} \mathrm{Vgl}$. Allocution de M. de Peyerimhoff prononcée à Berlin le 7 février 27, devant le Comité franco-allemand d'Information et de Documentation: NL d'Ormesson III, 1927. 
Unterstützung anderer Zeitschriften mit Verständigungsabsicht wurden hingegen abgelehnt.

Zur Selbstdefinition des Komitees gehörte auch eine Abgrenzung zu anderen Organisationen. Vor allem die von Otto Grautoff zeitgleich ins Leben gerufene Deutsch-Französische Gesellschaft stieß auf seiten des Studienkomitees, vor allem bei der deutschen Sektion wie auch bei Viénot, auf tiefe Ablehnung. Grautoff suchte beim Studienkomitee Unterstützung für ein deutsch-französisches Zeitschriftenprojekt, das er lancieren wollte ${ }^{129}$. Viénot sabotierte von Beginn an Grautoffs Projekt. Aus persönlicher Antipathie und Konkurrenz um Finanzmittel und Einfluß setzte Viénot auf der Vollversammlung im Februar 1927 die Nichtförderung von Grautoffs Unternehmen durch ${ }^{130}$. Die geplanten Zeitschriften wurden als »des plus médiocres ${ }^{131}$ abqualifiziert. Viénot beschränkte sich jedoch nicht nur darauf, innerhalb des Komitees gegen Grautoff zu arbeiten, sondern versuchte darüber hinaus, dessen Werben um Gelder zu vereiteln. Zunächst hatte das Komitee für eine Subvention die Bedingung gestellt, die von Grautoff ursprünglich geplante deutsche Frankreich-Zeitschrift müßte im anderen Land eine Entsprechung haben. Nachdem Grautoff diese Bedingung zu erfüllen suchte und Viénot um Empfehlungsschreiben für französische Persönlichkeiten bat, bei denen er sein Projekt vorstellen wollte, konterkarierte Viénot Grautoffs Absichten, indem er dieselben Personen, denen er Grautoffs Besuch ankündigte, anhielt, diesem mit größter Reserve zu begegnen ${ }^{132}$. Im Auswärtigen Amt, wo Grautoff ebenfalls um finanzielle Hilfen warb, waren die Vorbehalte des Mayrisch-Komitees bekannt. Vor allem Viénot hatte auch dort »sehr stark gegen das Grautoffsche Unternehmen gearbeitet«. ${ }^{133}$ An dieser Stelle wird deutlich, daß Viénots Engagement für die Verständigung mit persönlichen Karrierestrategien durchaus Hand in Hand ging. Grautoff wurde von ihm nicht als Partner auf dem Weg der deutsch-französischen An-

${ }^{129}$ Der Kunst- und Literaturkritiker Otto Grautoff bemühte sich ab Oktober 1926, eine Förderung für eine geplante deutsche Frankreichzeitschrift zu erreichen. Ende 1927 konstituierte sich die Deutsch-Französische Gesellschaft als Förderverein der Deutsch-Französischen Rundschau.

${ }^{130} \mathrm{Vgl}$. Compte rendu de la réunion du Comité franco-allemand d'Information et de Documentation du 6 au 8 février 1927: NL d'Ormesson III, 1927.

${ }^{131}$ Compte rendu des séances tenues à Berlin le 6 et le 8 février 1927 par le Comité exécutif du Comité franco-allemand d'Information et de Documentation: NL d'Ormesson III, 1927. Siehe auch Pierre Viénot, Compte rendu de l'activité du Bureau de Berlin pendant le mois de novembre 1926: NL d'Ormesson III, Comité franco-allemand, Documents des procès-verbaux 1926.

132 Vgl. Pierre Viénot, Compte rendu de l'activité du Bureau de Berlin pendant le mois de novembre 1926: NL d'Ormesson III, Comité franco-allemand, Documents des procès-verbaux 1926.

${ }^{133}$ Von Hoesch an AA, 22.1.1927: ADAP, B, IV, Nr. 59, S. 135. Vgl. auch Köpke an von Hoesch, 12.2.1927: ibid. Nr. 137, S. 289ff. Köpke blieb Grautoffs Plänen gegenüber reserviert und vermochte sden Optimismus, mit dem Herr Grautoff die Zukunft seiner Gründung beurteilt, nicht ganz zu teilen«. 
näherung betrachtet, sondern als Konkurrent, der schlichtweg kaltgestellt werden sollte. Der verständigungspolitische Idealismus Viénots trat demnach bisweilen doch hinter persönliche Antipathien und Konkurrenzdenken zurück.

Obwohl sich das Mayrisch-Komitee grundsätzlich gegen die Unterstützung von Zeitschriften aussprach, entschloß es sich zur Zusammenarbeit mit der Europäischen Revue, einer der führenden Europazeitschriften der Zwischenkriegszeit ${ }^{134}$. Herausgeber der Europäischen Revue war Karl Anton Prinz Rohan, ein österreichischer Adeliger, der 1922 in Wien den Europäischen Kulturbund als übernationalen Zusammenschluß der geistigen Elite Europas gegründet hatte ${ }^{135}$. Für den wirtschaftspolitischen Teil der Europäischen Revue sollten geeignete Mitarbeiter in Frankreich geworben werden. Viénot setzte sich als Berliner Bürodirektor besonders für eine Unterstützung dieses Vorhabens ein ${ }^{136}$. Hier zeigte sich, daß die selbstgewählte Abgrenzung zu den Europaorganisationen nicht konsequent durchgehalten wurde. Während das Studienkomitee die Paneuropabewegung von Graf Coudenhove-Kalergi ablehnte, unterhielt es gleichzeitig enge Verbindung mit dem Europäischen Kulturbund. Dabei gab es vielfältige personelle Überschneidungen zwischen Kulturbund und DeutschFranzösischem Studienkomitee. Auch Viénot war nicht nur selbst Mitglied der Union intellectuelle, wie sich die französische Gruppe des Kulturbundes nannte, sondern hatte auch seinen Freunden die Organisation empfohlen ${ }^{137}$. Besonders deutlich trat die Verflechtung der beiden Vereinigungen bei der Plenarversammlung des Studienkomitees vom 16. bis 18. Mai 1930 in Heidelberg zutage, die von Mitgliedern der deutschen Gruppe gestaltet wurde. Der Vortrag von André Siegfried fand vor einem gemeinsamen Auditorium aus MayrischKomitee und deutscher Kulturbundsektion statt, und das Kulturbund-Mitglied Alfred Weber empfing die Komiteemitglieder bei sich zum Tee ${ }^{138}$. Darüber hinaus übernahm nach der Neuorganisation des Komitees und seiner Büros der Viénot-Freund und ehemalige Redaktionsleiter der Europaischen Revue, Max Clauss, den Posten in Berlin.

Viénots Bemühungen, die er bei der Sabotierung des Grautoff-Projekts an den Tag gelegt hatte, entsprachen seinem Selbstverständnis als Direktor des Berliner Büros. Er betrachtete das Komitee als sein Werk und fühlte sich für

${ }^{134} \mathrm{Vgl}$. Hans Manfred Bock, Das "Junge Europa«", das "Andere Europa ( und das "Europa der weißen Rasse«. Diskurstypen in der Europäischen Revue 1925-1939, in: Michel GRUNEWALD, DERS. (Hg.), Le discours européen dans les revues allemandes (19331939), Bern u.a. 1999 (Convergences, 11), S. 311-351.

${ }^{135}$ Zu Rohan und dem Europäischen Kulturbund siehe ausfuhrlich Kap. IV.2.2.

${ }^{136}$ Vgl. Viénot, Compte rendu de l'activité du Bureau de Berlin pendant le mois de novembre 1926: NL d'Ormesson III, Comité franco-allemand, Documents des procès-verbaux 1926.

${ }^{137}$ Zur Mitgliedschaft Viénots vgl. ders an seine Mutter, 29.1.1928: NL Viénot. Viénot versuchte, Schlumberger und Lyautey zur Mitarbeit zu überreden. Vgl. ders. an Schlumberger, 30.3.1924: BLJD, Fonds Schlumberger, Ms 8307; ders. an Lyautey, 7.2.1926: NL Viénot.

${ }^{138}$ Vgl. Programm für die Tagung des Deutsch-Französischen Studienkomitees vom 16.18. Mai 1930 in Heidelberg: PAAA, Botschaft Paris, DFS, Bd. 2. 
dessen Erfolg verantwortlich. Alle Fragen, die Gestaltung und Entwicklung der Komiteearbeit betrafen, zählte er daher zu seiner ureigensten Domäne. Seine persönlichen Bemühungen gingen von Beginn an dahin, das Komitee zu einer aktiven Rolle zu drängen. Dabei bildete sich schon bald ein Kreis um den Berliner Bürodirektor heraus, mit dem er in engem Kontakt stand und der Viénots Initiativen unterstützte. $\mathrm{Zu}$ diesen Vertrauten zählten neben seinem Freund d'Ormesson vor allem Henri de Peyerimhoff und, zumindest in der Anfangszeit, Jacques Seydoux. Im weiteren Umfeld gehörten auch Jean Schlumberger, Pierre Lyautey und Félix de Vogüé dazu, die jedoch nicht zum engsten Zirkel der Antreiber und >Macher (gehörten. Doch Viénot gewann in seiner von ihm selbst definierten Rolle als »homme d'action« nicht nur Freunde im Komitee. Vor allem zum Präsidenten der französischen Sektion, Charles Laurent, entwickelte sich bald ein gespanntes Verhältnis, da diesem die Unabhängigkeit des umtriebigen Viénot zu weit ging.

Beispielhaft zeigte sich die steigende Interessendivergenz zwischen französischem Vorsitzenden und Bürodirektor bei der Frage der Rekrutienung neuer Mitglieder. Von Beginn an wurde eine Erweiterung des zunächst auf je 25 Mitglieder beschränkten exklusiven Zirkels ins Auge gefaßt. Vor allem die deutsche Sektion sprach sich bereits im Juli 1926 für eine Aufstockung auf 30 Mitglieder pro Gruppe aus ${ }^{139}$. Dadurch konnten sowohl die finanzielle Basis als auch der Einfluß des Komitees durch die Kontakte seiner Mitglieder vergrößert werden. In Vorbereitung der Vollversammlung im Oktober 1926 machte sich Viénot Gedanken über die geplanten Neuzugänge, für die er ein oder zwei Bankiers, einen Vertreter der »forces hydrauliques«, einen Repräsentanten des Comité des Assurances sowie zwei Intellektuelle vorgesehen hatte ${ }^{140}$. Als einer der ersten Neuzugänge sollte der Schriftsteller Paul Valéry für das Komitee gewonnen werden. Dieser wollte jedoch nur akzeptieren, wenn zeitgleich mit ihm ein anderes Mitglied der Académie française dem Komitee beitrat ${ }^{141}$. Viénot war offenbar ungehalten über Valérys Unentschlossenheit. Während eines Zusammentreffens mit Gide und Curtius in Paris im Umfeld der Plenartagung kritisierte er heftig dessen Verhalten:

${ }^{139}$ Vgl. Réunion tenue à Luxembourg le 17 juillet 1926 par le Comité exécutif du Comité Franco-Allemand d'Information et de Documentation: NL d'Ormesson III, Séances Comité exécutif.

${ }^{140}$ Handschriftliche Aufzeichnung von Viénot zur Vorbereitung auf die Plenarversammlung im Oktober 1926, o.D.: NL d'Ormesson III, Comité franco-allemand, Documents des procès-verbaux 1926. Bei den Intellektuellen dachte Viénot besonders an den Professor der École libre des Sciences politiques, André Siegfried. Vgl. Viénot an d'Ormesson, 9.10.1926: NL d'Ormesson II.

141 Valéry begründete dies mit seiner noch ungesicherten Position in der Académie française, die seine Handlungsfreiheit einschränke. Vgl. Viénot an d'Ormesson, 12.11.1926: NL d'Ormesson II. 
Viénot a mis Valéry sur le tapis. Il lui reproche de manquer de caractère à propos de son attitude vis-à-vis du Comité d'Information, dont il ne sait s'il veut être ou ne pas être, à cause de sa situation à l'Académie. Gide le défend chaleureusement. Pour lui, à la hauteur où est Valéry, et avec le mépris profond qu'il a à peu près pour tout, cela n'a aucune importance. [...] Viénot ne lâche pas son attaque $[\ldots]^{142}$.

Während die Aufnahme Valérys zunächst ungewiß blieb, konnte Anfang 1927 Jacques Seydoux als offizielles Mitglied aufgenommen werden, nachdem er aus gesundheitlichen Gründen aus dem Quai d'Orsay ausgeschieden war $^{143}$. Viénot drängte den Vorsitzenden Laurent unterdessen, eine Entscheidung über die Mitgliedschaft Valérys und, als zweiten Académicien, Gabriel Hanotaux ${ }^{144}$ noch vor der für Dezember 1927 geplanten Vollversammlung in Luxemburg herbeizuführen ${ }^{145}$. Gleichzeitig mobilisierte Viénot seine Mitstreiter, führte Gespräche mit de Peyerimhoff und bezog Seydoux in seine Überlegungen ein. Die anvisierte Erweiterung um Angehörige der Autoindustrie - Renault und Citroën - war gescheitert, und de Peyerimhoff schlug statt dessen die Aufnahme eines großen Wollwarenfabrikanten vor ${ }^{146}$. Wie in der Gründungsphase sollten vor allem exportorientierte Industriezweige in das Komitee eingebunden werden. Während André Siegfried bereit war zum Eintritt, wartete Valéry noch immer ab. Auf deutscher Seite wollte man offensichtlich Altkanzler Hans Luther als Repräsentanten der Politik für das Komitee gewinnen, und Viénot bedauerte, daß in Frankreich kein vergleichbar wichtiger Aspirant zur Verfügung stehe, denn, so Viénot, sen France, les hommes politiques ne prennent jamais leur retraite! ${ }^{147}$ Die Plenarsitzung im Dezember 1927 brachte jedoch noch keine Entscheidung zur Mitgliederfrage. Um aber während der kommenden Wahlkampfperiode in Deutschland und Frankreich ${ }^{148}$ öffentlich präsent zu sein, beschloß das Komitee eine baldige Erweiterung und einen Abdruck der Mitgliederlisten in Zeitungen beider Länder. Jede Sektion des Komitees sollte dem Präsidenten Mayrisch vor dem 1. Februar 1928 eine Liste mit den Namen der geplanten Neuaufnahmen übergeben. Als die französische Sektion jedoch Ende Januar 1928 noch nichts unternommen hatte, ergriff Viénot erneut die Initiative und wandte sich an de Peyerimhoff, der Laurent ein wenig raktivieren، sollte. Die Deutschen, so hatte Viénot erfahren, würden ihre Liste rechtzeitig übergeben. Er hielt es für wichtig, es ihnen gleichzutun.

${ }^{142}$ Van RYSSELBERGHE, Cahiers de la Petite Dame, S. $294 \mathrm{f}$.

${ }^{143} \mathrm{Vgl}$. Mayrisch an Seydoux, 17.1.1927; Seydoux an Mayrisch, 27.1.1927: MAE, PA-AP Seydoux, 261, d. 6.

${ }^{144}$ Gabriel Hanotaux (1853-1944) setzte sich als Außenminister 1894/95 und 1896 bis 1898 für eine Annäherung an Rußland ein und schrieb eine fünfzehnbändige »Histoire de la nation française $\ll$.

${ }^{145} \mathrm{Vgl}$. Viènot an Laurent, 2.5.1927: NL d'Ormesson III, 1927.

${ }^{146}$ Ders. an Seydoux, 21.6.1927: MAE, PA-AP Seydoux, 261, d. 6.

${ }^{147}$ Ibid.

${ }^{148}$ In beiden Ländern fanden 1928 Parlamentswahlen statt. In Frankreich am 22. und 29.4.1928 und in Deutschland am 20.5.1928. 
Laurent sollte nach Meinung Viénots das französische Exekutivkomitee versammeln, um einen Beschluß herbeizuführen ${ }^{149}$. Von Laurent, dem Viénot in dieser Frage geschrieben hatte, erhielt er eine beschwichtigende Antwort. Die französische Gruppe, so sah es der Sektionspräsident, sei in keiner Weise verpflichtet, dem deutschen Bespiel zu folgen. Die Wahl neuer Mitglieder betrachtete Laurent als dermaßen delikate Angelegenheit, daß sie keine massive Unterstützung vertrage ${ }^{150}$. Viénot reagierte alarmiert. Er beauftragte seinen Freund d'Ormesson, in Paris hinter dem Rücken von Laurent Gespräche mit de Peyerimhoff und einigen anderen Mitgliedern zu führen, derer man sich sicher sein konnte wie etwa Arthur Fontaine vom Internationalen Arbeits$a m t^{151}$. Laurent gegenüber machte Viénot klar, daß die deutsche Gruppe mit ihrer pünktlichen Übergabe der Liste nur einem französischen Wunsch zu folgen glaube und verwies auf die Beschlüsse des Exekutivkomitees vom 10. November 1927, in denen dieses Vorgehen festgelegt worden sei. Viénot fürchtete Unstimmigkeiten innerhalb des Komitees, wenn die französische Sektion das von ihr angeregte Vorgehen ignoriere ${ }^{152}$. Den Brief Laurents, in dem dieser ein vorsichtiges Vorgehen anmahnte, betrachtete Viénot, der sich auf einen offiziellen Komiteebeschluß berief, als null und nichtig. Viénot hatte erfahren, daß die deutsche Sektion einen Repräsentanten der Kaliindustrie aufnehmen wollte und schlug wegen des Interesses dieser Industriebranche an den deutsch-französischen Beziehungen dasselbe Vorgehen für die eigene Gruppe vor ${ }^{153}$. Offensichtlich war Viénot in weitaus stärkerem Maße an einer Abstimmung mit der deutschen Gruppe und an einem deutsch-französischem Gleichschritt in der Mitgliederfrage interessiert als Charles Laurent. Für die deutsch-französische Harmonie innerhalb des Komitees war er auch bereit, eine Verstimmung mit seinem Sektionspräsidenten zu riskieren. Mitte Februar legten die Deutschen ihre Liste vor, auf der sich der Generaldirektor des Deutschen Kalisyndikats, August Diehn, und der Vizepräsident des Reichsverbandes der Deutschen Industrie, Abraham Frowein, ebenso fanden wie der Historiker Hermann Oncken, der Philosophieprofessor Willy Hellpach und der Soziologe und Viénot-Freund Arnold Bergsträsser. Die Zuwahl der neuen Mitglieder erfolgte dann im März. Viénot hatte mit seinem Drängen indessen sein Ziel erreicht, da sich auch die Franzosen in der Zwischenzeit auf fünf Neuzugänge verständigt hatten. $\mathrm{Zu}$ ihnen zählten Henri Robert, der Mitglied der Académie française war, der Industrielle Ernest Mercier, Graf Jean de Nicolai, Vizepräsident der Société des Agriculteurs de France, der Publizist Lucien Romier sowie

\footnotetext{
${ }^{149}$ Vgl. Viénot an de Peyerimhoff, 23.1.1928: NL d'Ormesson II.

${ }^{150}$ Vgl. Laurent an Viénot, 28.1.1928: NL d'Ormesson II.

151 Vgl. Viénot an d'Ormesson, 30.1.1928: NL d'Ormesson II.

${ }^{152}$ Vgl. ders. an Laurent, 30.1.1928: NL d'Ormesson II.

${ }^{153} \mathrm{Vgl}$. ders. an de Peyerimhoff, 30.1.1928: NL d'Ormesson II.
} 
André Siegfried $^{154}$. Da in beiden Sektionen die Höchstteilnehmerzahl jedoch nicht ausgeschöpft worden war, blieb das Thema weiterhin aktuell. Im April 1929 sprach Viénot Laurent emeut an, wieder mit dem Hinweis auf deutsche Pläne, neue Mitglieder wie etwa Carl Bosch von den IG Farben, den Bankier Otto Wolf und den ehemaligen Staatssekretär des Äußeren Wilhelm Solf zu rekrutieren. Viénot schlug unterdessen die Aufnahme des Germanisten Edmond Vermeil ${ }^{155}$ vor, die 1930 dann auch erfolgte. 1930 wurde die personelle Obergrenze der nationalen Sektionen von 30 auf 40 erhöht, wobei die effektive Mitgliederzahl bis 1938 leicht darunter blieb. Da das Komitee einige Austritte und Todesfälle zu verzeichnen hatte ${ }^{156}$, war die Fluktuation letztlich größer, als die sehr beschränkte Anzahl von 30 bis 40 Mitgliedern auf jeder Seite vermuten ließe. Innerhalb des beschränkten Kreises der politischen, wirtschaftlichen und kulturellen Eliten beider Länder etablierte sich somit ein stabiles deutschfranzösisches Kommunikationsnetz. Bei dessen Ausgestaltung wurde jedoch ein erster Interessenkonflikt zwischen Viénot und Laurent offenbar. Während Laurent eine vorsichtige und zurückhaltende Herangehensweise unabhängig von der deutschen Sektion favorisierte, drängte Viénot auf deutsch-französische Parallelität im Rekrutierungsverhalten und der Mitgliederstruktur.

Viénots Bemühungen um eine aktivere Rolle des Komitees

Bereits kurz nach der Aufnahme seiner Tätigkeit als Berliner Bürodirektor begann Viénot mit Planungen zur künftigen Gestaltung der Komiteearbeit. Nach der Plenarsitzung im Februar 1927 zeigte sich Viénot sehr befriedigt über die bisher erreichten Ergebnisse. Die herzliche Atmosphäre nahm er als Indiz für die entstehende Normalität im deutsch-französischen Umgang ${ }^{157}$. Vor allem aber sah Viénot seine persönliche Situation und seine Autorität innerhalb des Komitees gestärkt. Peyerimhoff sei "vraiment entièrement à ma disposition et me suit les yeux fermés «. ${ }^{158}$ Durch diese Erfolge ermutigt, wollte Viénot nun daran gehen, ssein Komitee in eine praktischere Richtung zu lenken. Zunächst ging es ihm darum, die Beziehungen des Komitees zu erweitern. In einem Rundbrief an die Mitglieder der französischen Sektion forderte er diese auf, eine Liste aller Personen, Vereinigungen und Organisationen zu erstellen, zu denen persönliche Kontakte bestehen und an die man sich wenden könne. Er dachte dabei vor allem an Wirtschafts- und Presseorganisationen, an intellek-

${ }^{154} \mathrm{Vgl}$. Krukenberg an von Hoesch, 20.3.1928: PAAA, Botschaft Paris, DFS, Bd. 1.

${ }^{155}$ Viénot an d'Ormesson, 18.9.1929: NL d'Ormesson II. Katja Marmetschke (Kassel) bereitet zur Zeit eine Dissertation zum Deutschlandbild Edmond Vermeils vor.

${ }^{156}$ Nach dem frühen Austritt Thyssens Ende 1926 verließ auch Seydoux das Komitee im Februar 1929. 1930 folgten die Austritte von Charles Laurent, Debrix und Laederich. Felix Deutsch verstarb 1928 und Bischof Julien 1930.

${ }^{157} \mathrm{Vgl}$. Viénot an d'Ormesson, 10.2.1927: NL d'Ormesson II.

${ }^{158}$ Ders. an seinen Vater, 11.2.1927: NL Viénot. 
tuelle Vereinigungen, Jugendverbände, universitäre Einrichtungen, aber auch an Einzelpersonen wie Germanisten und Publizisten ${ }^{159}$. Die Ergebnisse seines Appells waren jedoch unbefriedigend. Die Antworten, die er erhalten habe, so klagte Viénot, enthielten fast ausschließlich Namen aus der Wirtschaft. Er fürchtete, daß hier ein altes Mißverständnis fortgesetzt werde. Seiner Meinung nach war die Organisation in ihre entscheidende Phase eingetreten, in der die Prinzipien der künftigen Arbeit festgelegt werden müßten ${ }^{160}$. Um seinem Anliegen mehr Nachdruck zu verleihen, diktierte Viénot Émile Mayrisch einen Brief an Charles Laurent in die Feder, in dem er drei Vorschläge entwickelte: Um den intellektuellen Austausch der Mitglieder zu verstärken, sollte zum ersten bei den Plenartagungen der Diskussion nach den Exposés mehr Raum gegeben werden. Zum zweiten wurden größere Anstrengungen gefordert, um weite Teile der öffentlichen Meinung in beiden Ländern zu einer vorurteilsfreien Berichterstattung und zur Kenntnis des Gegenübers anzuregen. Zu diesem Zweck waren auch Kontakte zu neuen Gruppen geplant, zum Beispiel zu Politikern, deren offizielle Mitgliedschaft zwar unmöglich sei, aber deren moralische Unterstützung sehr hilfreich sein könnte. Der dritte Punkt bezog sich auf die Tätigkeit der Büros, und hier definierte Viénot die von ihm angestrebte Funktion. Die Büros sollten gemäß der Programmschrift eine immer aktivere Rolle spielen. Ihre Aufgabe umfaßte demgemäß nicht nur die Gewährleistung einer kontinuierlichen Komiteearbeit, sondern sie sollten vielmehr das Instrument zur gezielten Außenwirkung sein ${ }^{161}$. Der vorgeblich von Mayrisch geschriebene Brief wurde auch an den Vorsitzenden der deutschen Sektion, von Nostitz, adressiert. Er war vorsichtig formuliert und konnte kaum mehr eine Anregung denn eine verbindliche Handlungsanweisung sein. Die Reformvorschläge mußten von den Sektionsvorsitzenden selbst eingebracht werden, und hier zog Viénot Charles Laurents guten Willen in Zweife ${ }^{162}$. Er verdächtigte Laurent, die Angelegenheit in aller Stille begraben zu wollen, ohne die Mitglieder über den Brief in Kenntnis gesetzt zu haben ${ }^{163}$. Viénot ließ Laurent wissen, daß Nostitz den Mayrisch-Brief an alle deutschen Sektionsmitglieder verschickt und eigene Vorschläge für die nächste Sitzung des Exekutivkomitees angefügt hatte. Wie im Falle der Mitgliederrekrutierung drängte Viénot auch in diesem Fall auf einen deutsch-französischen Gleichschritt und schlug Laurent vor, es der deutschen Sektion gleichzutun, die sich vor der nächsten Exekutivsitzung in Luxemburg noch einmal versammelte, um das weitere Vorgehen zu bespre-

${ }^{159} \mathrm{Vgl}$. ders. an die Mitglieder der französischen Sektion des Deutsch-Französischen Studienkomitees, o.D.: NL d'Ormesson II.

${ }^{160} \mathrm{Vgl}$. ders. an Seydoux, 15.2.1927: MAE, PA-AP Seydoux, 261. d. 6.

${ }^{161} \mathrm{Vgl}$. [Pierre Viénot], Projet de lettre de $M$. Mayrisch à $M$. Charles Laurent, o.D.: NL d'Ormesson II; Mayrisch an Laurent, 15.3.1927: PAAA, Botschaft Paris, DFS, Bd. 1. Der Wortlaut von Entwurf und fertigem Brief ist identisch.

${ }^{162} \mathrm{Vgl}$. Viénot an d'Ormesson, 23.3.1927: NL d'Ormesson II.

${ }^{163}$ Vgl. ders. an de Vogüé, 1.4.1927: NL d'Ormesson II. 
chen $^{164}$. Die Vorschläge des Exekutivkomitees, die während der LuxemburgSitzung erarbeitet wurden, nahmen einige Gedanken des von Viénot initiierten Briefes auf. Zunächst wurde festgehalten, daß die Anzahl der Plenartagungen von drei auf zwei pro Jahr begrenzt werden sollte, dafür aber um einen Tag verlängert für die jeweiligen Kommissionssitzungen. Das Exekutivkomitee hielt weiterhin an vier jährlichen Treffen fest. Die Büros in Paris und Berlin sollten stärker als bisher Kontakte mit der Presse pflegen und in ihren Räumen Treffen zwischen Journalisten beider Länder und Komiteemitgliedern sowie ihnen nahestehenden Kreisen veranstalten. Darüber hinaus wurde auch geplant, sich verstärkt mit dem Studentenaustausch zu beschäftigen, Kontakte zu Aspiranten einer diplomatischen oder politischen Karriere zu knüpfen und politische und anderweitig einflußreiche Kreise für das Komitee $\mathrm{zu}$ interessieren ${ }^{165}$. Ihnen sollte das Studienkomitee seine Mittel zur Information über das jeweils andere Land zur Verfügung stellen und dadurch aktiv auf eine bessere Kenntnis und ein tieferes Verständnis für das Nachbarland hinwirken.

Trotz dieses Teilerfolgs stieß Viénot aufgrund seiner offensiven Herangehensweise auch auf Widerstände. Neben der "ssourde résistance de $M$. Charles Laurent ${ }^{166}$ traf Viénot auch bei seinem deutschen Amtskollegen auf Reserven. Während Viénot sich für die Entwicklung des Komitees verantwortlich fühlte und dessen Aktivitäten und Wirkungsreis ausdehnen wollte, war Krukenberg der Auffassung, da $B$ ses nicht in den Absichten der Komiteegründung gelegen hat, daß dieses selbst oder in Dritten sichtbarer Weise direkte Aktionen irgendwelcher Art unternimmt ${ }^{167}$ Einzige Aufgabe sei es, die Situation der deutschfranzösischen Beziehungen unter Einbeziehung der psychologischen Faktoren aufzuklären.

Im Laufe des Jahres 1927 machte sich Pessimismus bei Viénot breit. Angesichts der mitunter zermürbenden Tagesarbeit und des beständigen Widerstandes gegen seine Versuche, die Komiteearbeit auszuweiten, spielte Viénot, wenngleich nicht wirklich ernsthaft, mit dem Gedanken zurückzutreten: „Si vous saviez«, so vertraute der d'Ormesson an, »comme j'ai envie [...] de lâcher mon Comité et la fréquentation des >puissants, des importants $[\ldots ..] \ll .{ }^{168}$ Hinzu kam einige Monate später auch eine Verstimmung zwischen Viénot und seinem langjährigen Mentor Lyautey. Lyautey, der seinem Schützling in der Anfangsphase des Komitees mit seinen Beziehungen bei der Mitgliederrekrutierung

${ }^{164}$ Vgl. ders. an Laurent, 2.5.1927: NL d'Ormesson III, 1927.

${ }^{165}$ Vgl. Suggestions du Comité exécutif concernant le développement du travail du Comité et l'organisation des futures réunions, 4.5.1927: NL d'Ormesson III, 1927. Siehe auch Anregungen für die weitere Entwicklung der Komitee-Arbeit und die Gestaltung der künftigen Tagungen, 25.5.2927: ibid.

${ }^{166}$ Viénot an d'Ormesson, 14.11.1927: NL d'Ormesson II.

${ }^{167}$ Krukenberg an d'Ormesson, 24.5.1927: NL d'Ormesson I, Correspondance officielle du Bureau de Paris.

${ }^{168}$ Viénot an d'Ormesson, 1.8.1927: NL d'Ormesson II. 
geholfen hatte, fühlte sich nun in die Ecke gedrängt und machte Viénot wie auch d'Ormesson Vorwürfe. Obwohl er aufgrund seiner militärischen Situation keine Führungsrolle innerhalb des Studienkomitees hätte einnehmen können, so ließ er Viénot wissen, hätte er sich dennoch gewünscht, ein "guide officieux et averti ${ }^{169} \mathrm{zu}$ sein. Es kränkte ihn, daß er nach dem ersten Treffen in seiner Wohnung nicht mehr in die Planungen einbezogen und daß Charles Laurent ohne seinen Rat ins Spiel gebracht worden war. Der einstige Generalresident von Marokko, der nun den Ruhestand im lothringischen Thorey verbrachte, litt ohne gewohnte Macht und Einfluß bisweilen unter depressiven Verstimmungen und mochte sich nicht recht damit abfinden, daß seine ehemalige `équipe ‘ nun eigene Wege ging.

Trotz dieser zeitweiligen Entmutigungen fuhr Viénot jedoch mit seinem Vorhaben fort, den Aktionsradius des Komitees zu erweitern. Im Vorfeld der Exekutivsitzung in Paris im November 1927 versuchte er wieder, neue Anstöße zu geben. Seiner Meinung nach sollte das Komitee auch einen größeren öffentlichen Einfluß ausüben, zum Beispiel durch Resolutionen zu wirtschaftspolitischen Zeitfragen, die dann in der Presse veröffentlicht werden sollten ${ }^{170}$. Auf der Tagung des Exekutivkomitees wurden Viénots Vorschläge diskutiert. Angesichts der bevorstehenden Wahlen in beiden Ländern stellte sich das Komitee die Frage »de savoir si ce fait doit nous amener à nous replier sur nousmêmes ou au contraire à nous affirmer et à nous manifester «. ${ }^{171}$ Es entschied sich für die zweite Variante und stellte ein Aktionsprogramm vor. Das Komitee wollte verstärkt auf Parteien und politische Gruppierungen Einfluß nehmen und für seine Verständigungsideen werben. Die bisherige Zurückhaltung sollte einer aktiveren Öffentlichkeitsarbeit weichen, um die Aktivitäten des Komitees stärker als bisher publik zu machen. Weiterhin war eine intensivere Zusammenarbeit mit der Presse vorgesehen ${ }^{172}$. Um den Aktionsradius auszudehnen, wurde eine Erhöhung der Mitgliederzahl von je 30 pro Sektion beschlossen. Schließlich - und das ging wohl auf eine Initiative Émile Mayrischs zurück ${ }^{173}$ - wurde der Vorschlag gemacht, innerhalb des Komitees drei Arbeitsgruppen einzurichten: eine für wirtschaftliche Fragen, eine für intellektuelle und kulturelle Angelegenheiten und eine letzte für Pressefragen. Wichtige Beiträge zu den deutsch-französischen Beziehungen, wie etwa die regelmäßigen Vorträge und Diskussionen, sollten zudem veröffentlicht werden.

${ }^{169}$ Lyautey an Viénot, 18.11.1927: NL Viénot.

${ }^{170} \mathrm{Vgl}$. Viénot an de Peyerimhoff, 1.10.1927: NL d'Ormesson II

${ }^{171}$ Compte rendu de la réunion plénière tenue les 12 et 13 décembre à Luxembourg. Propositions du Comité exécutif concernant le travail futur du Comité, 12.12.1927: NL d'Ormesson I, Comité Mayrisch 1927, $2^{\mathrm{c}}$ année.

in $\mathrm{Vgl}$. ibid.

${ }^{173}$ Vgl. Propositions de M. Mayrisch concernant le travail des Commissions, o.D.: PAAA, Botschaft Paris, DFS, Bd. 1. Der Wortlaut der Mayrisch-Note und des Protokolls des Exekutivkomitees ist nahezu identisch. 
Die Vermutung, die Vorschläge zur Umstrukturierung des Komitees seien allein von Émile Mayrisch initiiert und »kontrastierend mit der dominierenden Viénot-Linie « gewesen, geht fehl ${ }^{174}$. Entgegen der Deutung von Ina Belitz, Mayrisch habe versucht, gegen den Widerstand Viénots Neuerungsvorschläge zur Popularisierung des Komitees zu lancieren, ist vielmehr von einer deutlichen Interessenübereinstimmung von Mayrisch und Viénot auszugehen. Wie bereits in der Gründungsphase des Komitees scheint auch hier eine Aufgabenteilung zwischen Mayrisch als Auftraggeber und integrierender Führungspersönlichkeit einerseits und Viénot als Ideenlieferant und Ausgestalter der praktischen Arbeit andererseits vorzuliegen. Der von Viénot verfaßte und von Mayrisch unterzeichnete Brief, der strukturelle Reformen anmahnte, bringt genau diese Kooperation zum Ausdruck. $\mathrm{DaB}$ die beschlossenen Vorschläge nicht umgesetzt wurden, kann nicht Viénot angelastet werden. Dieser fühlte sich nach wie vor von Charles Laurent ausgebremst und bezeichnete den von ihm initiierten Brief Mayrischs als einen Schlag ins Wasser. In seinen Augen trug allein Charles Laurent die Verantwortung für die Verschleppung seiner Initiativen: "J'accepte encore que $\mathrm{M}$. Ch. Laurent ne soit plus bon à rien, mais je n'entends pas qu'il m'empêche, moi, qui n'ai pas soixante-dix ans [...] de faire du travail utile. ${ }^{175}$

Der Tod Mayrischs, der am 5. März 1928 einem Autounfall bei Châlons-surMarne zum Opfer fiel, bedeutete einen tiefen Einschnitt für das Komitee. Mit dem Verlust des luxemburgischen Industriellen, der kurze Zeit vorher noch die Ehrendoktorwürde der Universität Heidelberg für sein verständigungspolitisches Engagement verliehen bekommen hatte, machte sich nicht nur das Fehlen einer überparteilichen Autoritäts- und Integrationsfigur bemerkbar, sondem auch der Wegfall der schützenden Hand über Viénots Reforminitiativen. Die Präsidentschaft wurde forthin abwechselnd vom deutschen und französischen Sektionsvorsitzenden ausgeübt. Weiterhin wurde Aline Mayrisch, die auf diese Weise dem Andenken ihres Mannes einen Dienst erweisen wollte, als Ehrenmitglied in das Komitee aufgenommen. Alois Meyer, der neue Generalsekretär der ARBED-Werke, wurde als außerordentliches Mitglied zugewählt und über-

${ }^{174}$ BELITZ, Befreundung mit dem Fremden, S. 202. Belitz bezieht sich dabei auf ein Memorandum von Mayrisch vom 12. Dezember 1927. Dieses konnte in den durchgesehenen Quellen nicht gefunden werden. Wohl aber existiert ein Protokoll über die Sitzung des Exekutivkomitees vom 9. Dezember, das dann am 12. Dezember von Émile Mayrisch anläßlich der Vollversammlung verlesen wurde. In diesem Protokoll finden sich exakt dieselben Punkte wieder, die dann vom Plenum beschlossen wurden. Vgl. Compte rendu de la Séance par le Comité exécutif le 9 novembre 1927 à Luxembourg, lu par M. Mayrisch à la Séance plénière du Comité, le 12 décembre 1927: NL d'Ormesson I, Comité Mayrisch 1927, $2^{\mathrm{e}}$ année. Das von Belitz angesprochene Memorandum ist in den zitierten Passagen im Wortlaut identisch mit dem Protokoll des Exekutivkomitees wie auch mit den Beschlüssen der Vollversammlung vom 12. Dezember.

${ }^{175}$ Viènot an de Vogüé, 1.4.1927: NL d'Ormesson II. 
nahm die Verwaltung des Gemeinschaftsfonds ${ }^{176}$. Gleichzeitig versuchte Viénot, einen Machtzuwachs Laurents zu verhindern: „J'ai travaillé par tous les moyens, à Paris, pour que ces nouvelles fonctions n'apportent pas un surcroît d'autorité à Ch. Laurent. ¿ $^{177}$ Viénot kündigte die Gründung eines Büros innerhalb der französischen Sektion an, mit Laurent als Präsidenten und de Peyerimhoff sowie Arthur Fontaine als Vizepräsidenten. D'Ormesson sollte das Amt des Schatzmeisters übernehmen ${ }^{178}$. Damit wäre Laurent von drei Viénot-Getreuen eingerahmt gewesen, und dieser erhoffte sich auf diese Weise wohl eine Neutralisierung des ungeliebten Präsidenten und somit eine Stärkung seiner eigenen Position. Allerdings hat Viénot die Realisierung dieses Vorhabens offensichtlich nicht durchsetzen können, zumindest finden sich keine Hinweise darauf in den Dokumenten. Während sich der Konflikt zwischen dem Präsidenten und dem Berliner Büroleiter anläßlich der Frage der Finanzen weiter verschärfte, versuchte Viénot nun, ein tragfähiges Konzept der Komiteearbeit hinter dem Rücken Laurents bei den französischen Mitgliedern zu propagieren. Er verfaßte eine Notiz zur künftigen Ausgestaltung der Aktivitäten, die er während der Plenartagung in Baden-Baden im Juli 1928 an de Peyerimhoff, Fontaine und einige andere vertrauenswürdige Mitglieder verteilte und darüber hinaus auch Seydoux zukommen lie $\beta^{179}$. Als besonderen Erfolg des Studienkomitees wertete Viénot die Sensibilisierung jener Kreise, die traditionellerweise der Verständigungspolitik ablehnend gegenüberstanden. Doch dies reichte in seinen Augen noch nicht aus: "Pour mériter d'exister, le Comité ne doit pas seulement être utile ou efficace, mais encore sirremplaçable ${ }^{1180} \mathrm{Um}$ diesem Ziel näher zu kommen, wollte Viénot das Studienkomitee auf eine neue Grundlage stellen. Nicht mehr die Erinnerung an den Weltkrieg und die anhaltende Kriegspsychose in beiden Ländern sollten als Ursache und Begründung der Annäherungspolitik dienen, sondern es müßten neue, auch längerfristig tragfähige Verständigungsinhalte gefunden werden ${ }^{181}$. Aufgabe des Komitees sollte es sein, diese zweite Etappe der bilateralen Annähenung vorzubereiten. Dazu war es in Viénots Augen nötig, die neuen Determinanten der außenpolitischen Entscheidungsfindung zu untersuchen, wie etwa die öffentliche Meinung und die internationale wirtschaftliche Verflechtung. Auch die intellektuellen Beziehungen und die staatenübergreifende Wirkungsmacht von Ideen zählten zu diesen po-

${ }^{176}$ Vgl. ders. an Laurent, 28.3.1928; ders. an de Peyerimhoff, 29.3.1927; Laurent an d'Ormesson, 12.4.1928: NL d'Ormesson II; Bericht über die sechste Vollversammlung des Deutsch-Französischen Studienkomitees in Baden-Baden, 4.-6.7.1928, S. 4f.: NL d'Ormesson III, Documentation 1926-1932.

177 Ders. an Schlumberger, 1.4.1928: BLJD, NL Schlumberger, Ms 18340.

${ }^{178} \mathrm{Vgl}$. ibid.

${ }^{179}$ Vgl. ders. an Seydoux, 11.7.1928: NL d'Ormesson II.

${ }^{180}$ Pierre Viénot, Note sur l'activité du Comité franco-allemand d'Information, 30.6.1928: MAE, PA-AP Seydoux, 261, d. 6.

181 Vgl. ibid. 
litischen Faktoren ${ }^{182}$. Das Komitee sollte also künftig eine intellektuelle Vorreiterrolle übernehmen, die internationale Lage studieren, auf die öffentliche Meinung im Sinne von mehr Objektivität einwirken und darüber hinaus auch in der ein oder anderen Form Politikberatung betreiben aufgrund der guten Beziehungen seiner Mitglieder zu den Regierungseliten. Dieses ehrgeizige Projekt war Viénots Antwort auf ein viel tiefer liegendes Problem, welches ihn seit Ende des Ersten Weltkrieges beschäftigte, nämlich die Diskrepanz zwischen den sich rasch wandelnen politischen, gesellschaftlichen, sozio-ökonomischen und auch technischen Gegebenheiten nach 1918 und der dahinter zurückbleibenden geistigen und intellektuellen Entwicklung. Viénot teilte dieses Gefühl einer geistigen Krise mit einem großen Teil der jungen Intellektuellen seiner Generation, und seine außenpolitischen Aktivitäten müssen in diesem Kontext gesehen werden $^{183}$. Dem von ihm mitbegründeten Studienkomitee kam die Aufgabe zu,

à vaincre, du point de vue franco-allemand, les difficultés que nous éprouvons à adapter nos idées aux réalités nouvelles et à reprendre notre pouvoir sur elles, et cela dans un domaine où, pour reprendre les termes de Valéry, cette 'Crise de l'esprit‘ se fait plus sentir que dans n'importe quel autre ${ }^{184}$.

Viénot betonte die Notwendigkeit für das Komitee, eigene Studien zur deutschfranzösischen Frage zu verfassen und diese der breiten Öffentlichkeit mit konkreten Lösungsvorschlägen zu bestimmten Problemen vorzulegen. Erst dann konnte es seiner Ansicht nach wirklichen Einfluß ausüben und einen positiven Beitrag zum deutsch-französischen Verhältnis liefern. In seiner Tätigkeit als Direktor des Berliner Büros verfolgte Viénot seine offensive Strategie von Beginn an und versuchte, die Einrichtung des Mayrisch-Komitees zu einer wichtigen Anlaufstelle für deutsch-französische Fragen in der Hauptstadt zu machen.

\subsection{In offiziöser Mission: Viénot als Direktor des Berliner Büros}

Ein »ambassadeur privé« mit dem Auftrag der Verständigung

Die beiden Büros des Studienkomitees hatten in erster Linie die Aufgabe, die Komiteesitzungen vorzubereiten und die Verbindung zu den nationalen Sektionen zu gewährleisten. Darüber hinausgehende Aktivitäten sowie die konkrete Ausgestaltung der Büroarbeit waren in hohem Maße von der Persönlichkeit und den Interessen des Bürodirektors abhängig. Gemäß seiner Natur ging Viénot von Anfang an energisch an die neuen Aufgaben heran, in deren Mittelpunkt zunächst die Einrichtung des Büros in Berlin und die Herstellung der

${ }^{182} \mathrm{Vgl}$. ibid.

${ }^{183}$ Vgl. dazu ausführlich Kap. IV.

${ }^{184}$ Pierre Viénot, Note sur l'activité du Comité franco-allemand d'Information, 30.6.1928: MAE, PA-AP Seydoux, 261, d. 6. 
ersten Kontakte standen. Viénot begann mit einer deutsch-französischen Dokumentation sowie mit der Einrichtung einer Bibliothek, die Besuchern offenstehen sollte. Neben den Büchern standen im Lesesaal die wichtigsten deutschen und französischen Zeitungen und Zeitschriften zur Verfügung. Einen Aufenthalt in Genf anläßlich der Aufnahme Deutschlands in den Völkerbund nutzte Viénot, um in zahlreichen Gesprächen für das Mayrisch-Komitee zu werben. So traf er sich mit Außenminister Aristide Briand, mit dem Wirtschaftspolitiker Louis Loucheur und anderen Mitgliedern der französischen Delegation. Daneben knüpfte er Kontakte zu den Vertretern der maßgeblichen französischen Presseorgane wie etwa Louise Weiss ${ }^{185}$ und Roger Lévy von L'Europe nouvelle, Jules Sauerwein von Le Matin ${ }^{186}$, Auguste Gauvain von Le Journal des Débats ${ }^{187}$ und Pertinax alias André Géraud von $L^{\prime}$ Écho de Paris $^{188}$. In der Genfer Atmosphäre konnte Viénot auch leicht mit deutschen Journalisten und Politikern in Kontakt treten, mit dem Zentrumspolitiker Ludwig Kaas und dem Sozialdemokraten Rudolf Breitscheid ebenso wie mit Georg Bernhard, dem Chefredakteur der Vossischen Zeitung, mit Wolf von Dewall von der Frankfurter Zeitung sowie mit Vertretern der Kölnischen Zeitung und des Lokal-Anzeigers. Darüber hinaus suchte Viénot auch Beziehungen zu diversen Organisationen herzustellen, so zu dem von Julien Luchaire geleiteten Institut de Coopération intellectuelle oder dem Comité d'Études et d'Informations des Germanisten Edmond Vermeil ${ }^{189}$. In dieser Vorbereitungsphase stellte sich Viénot in Berlin in der Presse- und der Kulturabteilung des Auswärtigen Amts vor und traf sich mit Vertretern des Reichsverbandes der Deutschen Industrie. Gleichzeitig bat er die Komiteemitglieder um aktive Mithilfe bei seiner Tätigkeit, zum Beispiel durch spontane Zusendung relevanter Zeitungsartikel oder Dokumente ${ }^{190}$. Nicht ohne Stolz bezeichnete Viénot sich als "ambassadeur privé « ${ }^{191}$ oder »agent officieux $«{ }^{192}$ und betrachtete sich zweifellos als Ergänzung zur offiziellen Diplomatie der französischen Botschaft. Sein Parkett war weniger das diplomatische als das kulturelle, intellektuelle und gesellschaftliche, freilich mit engen Verbindungen zu Politik und Wirtschaft. Jenseits der offiziellen Kanäle konnte Viénot so in diskreterer

${ }^{185}$ Louise Weiss (1893-1983) war seit 1918 Direktorin der auf außenpolitische Fragen spezialisierten Wochenzeitschrift $L$ 'Europe nouvelle. Sie galt als Briand-Vertraute und publizistische Unterstützerin seiner Verständigungspolitik. Vgl. Célia BERTIN, Louise Weiss, Paris 1999.

${ }^{186} \mathrm{Vgl}$. BELLANGER, Histoire générale de la presse, S. 309-314.

${ }^{187}$ Vgl. ibid. S. 556ff.

${ }^{188}$ Vgl. ibid. S. 532f.

${ }^{189}$ Vgl. Pierre Viénot, Rapport sur l'activité du bureau de Berlin jusqu'au premier Octobre 1926: NL d'Ormesson III, CFA, Documents des procès-verbaux 1926.

${ }^{190}$ Vgl. ders., Compte-rendu de l'activité du bureau de Berlin pendant le mois de novembre 1926: NL d'Ormesson III, CFA, Documents des procès-verbaux 1926.

${ }^{191}$ Ders. an seine Mutter, 8.10.1926: NL Viénot.

192 Ders. an dies., 14.11.1926: NL Viénot. 
Weise und auch bei anderen Zielgruppen für die deutsch-französische Verständigung werben.

Die aktive Kontaktaufnahme mit maßgeblichen Persönlichkeiten und Organisationen, die Viénot in Berlin pflegte, fand keine direkte Entsprechung durch das Pariser Büro. Der dortige Leiter Krukenberg legte das Hauptaugenmerk auf die Anfertigung der Dokumentation sowie auf die Erstellung von Studien zur deutsch-französischen Wirtschaftszusammenarbeit. Gleichzeitig warnte er davor, sich in eine Alltagsarbeit zu stürzen, über die der Überblick verloren gehen könnte ${ }^{193}$. Viénot, dem die guten Beziehungen Krukenbergs zu deutschen Politikern und hohen Beamten bekannt waren, wollte ihn indessen mit d'Ormessons Hilfe zu einem ")agent ‘ à nous « ${ }^{194}$ machen. Als sich Krukenberg bei Viénot beklagte, daß er in Paris von niemandem eingeladen werde, nutzte Viénot seine Kontakte, um Krukenberg an der Seine die gesellschaftlichen und politischen Türen zu öffnen. Seinen Freund d'Ormesson beschwor Viénot, Krukenberg in größerem Rahmen einzuladen und mit maßgeblichen Persönlichkeiten zusammenzubringen. Auch die französischen Komiteemitglieder sollten ihn aus der Isolation herausholen ${ }^{195}$. Neben d'Ormesson kamen dieser Aufforderung vor allem Viénots Freunde Félix de Vogüé und Pierre Lyautey nach $^{196}$. Trotz seiner Klagen gab Krukenberg seine Zurückhaltung doch nicht auf. Er war weiterhin darauf bedacht, bei allen Schritten "mit bewußter $\mathrm{Zu}$ rückhaltung nach außen ${ }^{197}$ vorzugehen und allzu großen Eifer zu vermeiden. Die ersten Monate seiner Tätigkeit betrachtete er als »la période du travail quasi-souterrain ${ }^{198}$, in der er weder das Komitee noch sich selbst in das Licht der Öfentlichkeit rücken wollte. Die permanenten Warnungen Krukenbergs vor überstürzten Handlungen kontrastierten deutlich mit Viénots Drängen nach gesteigerter Aktivität.

Mehr als Krukenberg war dessen französischer Mitarbeiter Poupard Viénot ein Dorn im Auge. Viénot fürchtete bei ihm eine zu starke Ausrichtung auf das Ökonomische, was er als um so gefährlicher einschätzte, als Poupard offenbar gute Beziehungen zu Laurent unterhielt ${ }^{199}$. Dazu kam, daß Viénot Poupard Nachlässigkeit und Unzuverlässigkeit vorwarf, unter der sowohl die Beziehungen der Büros untereinander als auch die Effizienz der gesamten Organisation

${ }^{193}$ Vgl. Gustav Krukenberg, Suggestions personnelles relatives à une méthode de travail du Comité franco-allemand de Documentation et d'Information, 16.10.1926: NL d'Ormesson III, CFA, Documents des procès-verbaux 1926

194 Viénot an d'Ormesson, 1.12.1926: NL d'Ormesson II.

${ }^{195}$ Vgl. ders. an dens., 29.11.1926: NL d'Ormesson II.

$196 \mathrm{Vgl}$. Gustav Krukenberg, Bericht über die Tätigkeit in Paris in den Monaten November und Dezember 1926, 27.12.1926: PAAA, Botschaft Paris, Deutsch-Französisches Studienkomitee, Bd. 1.

197 Ibid.

${ }^{198}$ Seydoux an Viénot, 18.3.1927: MAE, PA-AP Seydoux, 261, d. 6.

${ }^{199} \mathrm{Vgl}$. Viénot an d'Ormesson, 25.9.1926: NL d'Ormesson II. 
leiden könnten ${ }^{200}$. Die Meinungsverschiedenheiten und Interessengegensätze zwischen Krukenberg, Poupard und Viénot wurden in der Anfangsphase des Komitees zwar überspielt, doch der unausgesprochene Konflikt über die Ausrichtung der Büroarbeit schwelte weiter und kam schließlich 1929, im Zeichen einer allgemeinen Krise des Komitees, zum Ausbruch.

Ende November 1926 bezog Viénot zusammen mit seinem Mitarbeiter, dem früheren Marineoffizier Sidney Jessen ${ }^{201}$, seine endgültigen Räumlichkeiten in der Matthäikirchstraße in Berlin, und zwei Monate später fand der offizielle Eröffnungsempfang statt, zu dem Politiker, Diplomaten, Journalisten und Industrielle eingeladen waren. Obwohl er die Lancierung seines Büros als vollen Erfolg einstufte, war Viénot dennoch unzufrieden mit seiner Arbeit. Er wünschte sich für die Büros eine stärker schrittmachende Funktion innerhalb des Komitees und wollte öfter zu Rate gezogen werden. Gleichzeitig mußte er jedoch erkennen, wie wenig Spielraum ihm aufgrund der materiellen und personellen Beschränkungen zur Verfügung stand, um fruchtbare Initiativen zu entwik$\operatorname{keln}^{202}$. Viénots Aktionsradius war also von Beginn an durch diese Ausgangslage begrenzt. Zudem erwies sich seine Tätigkeit auch als abhängig von der allgemeinen politischen Situation. Der Zeitpunkt seiner Büroeröffnung, die Jahreswende 1926/27, stellte dabei einen Einschnitt für die deutsch-französische Verständigungspolitik dar. Seit Ende Januar 1927 regierte in Deutschland ein Kabinett mit Beteiligung der DNVP ${ }^{203}$, von der keine Bereitschaft zu außenpolitischen Zugeständnissen zu erwarten war. Dem gegenüber stand auf französischer Seite eine von Poincaré geführte Regierung, in der auch die Wirkungsmöglichkeiten von Briand eingeschränkt waren ${ }^{204}$. So konnte vor allem in Deutschland außenpolitisch kaum mehr als eine Politik der kleinen Schritte vermutet werden. Gleichzeitig drängte jedoch die Zeit, die anstehenden zwischenstaatlichen Probleme zu lösen, um nicht jeglicher Basis für eine weitere Annährung verlustig zu gehen. In Frankreich blieb währenddessen ein Gefühl des Mißtrauens gegenüber Deutschland bestehen. Viénot registrierte die zunehmenden Probleme in den deutsch-französischen Beziehungen und führte diese

${ }^{200}$ Vgl. ders. an de Vogüé, 15.11.1926: NL d'Ormesson II. An seine Mutter schrieb Viénot, er mißtraue Poupard stark und würde ihn aus dem Komitee werfen, wäre da nicht Laurent. Vgl. ders. an seine Mutter, 30.1.1927 und ders. an dies., o.D. [Februar 1927]: NL Viénot.

201 Jessen trat später in die NSDAP ein und wurde Direktor des Kieler Instituts für Weltwirtschaft. Ende der dreißiger Jahre verließ er die NSDAP wieder. Wegen seiner Beteiligung am Attentatsversuch auf Hitler am 20. Juli 1944 wurde Jessen am 20. November 1944 erhängt. Vgl. MƯLLER, Deutsch-französische Gesellschaftsbeziehungen, S. 21 lf., FN 175.

${ }^{202}$ Vgl. Viènot an seine Mutter, 20.2.1927: NL Viénot

${ }^{203}$ Vgl. Hagen SCHULZE, Weimar. Deutschland 1917-1933, Berlin ${ }^{4} 1994$, S. 302; Heinrich August WINKLER, Der lange Weg nach Westen, Bd. 1, Deutsche Geschichte vom Ende des Alten Reiches bis zum Untergang der Weimarer Republik, München 2000, S. 427.

${ }^{204} \mathrm{Vgl}$. Édouard BonNEFOUS, Histoire politique de la Troisième République, Bd. 4, Cartel des gauches et Union nationale (1924-1929), Paris 1960, S. 164ff., zur Außenpolitik des Poincaré-Kabinetts S. 184-196. 
einmal mehr auf die mangelnde Kenntnis der politischen Psychologie des Gegenübers zurück. Während er in Deutschland wachsende Enttäuschung über die erwarteten und ausbleibenden Rückwirkungen der Locarnopolitik ${ }^{205}$, in erster Linie die Räumung des gesamten Rheinlandes und die Reduzierung der Besatzungstruppen, ausmachte, bescheinigte er seinen Landsleuten eine unglaubliche Ignoranz gegenüber der Stimmung im Nachbarland. In Frankreich, so sein Vorwurf, sei noch nicht einmal der negative Symbolcharakter Poincarés bekannt, den dieser in Deutschland besitze ${ }^{206}$. Auch die französischen Hoffnungen bezüglich der Gegenleistungen für eine vorgezogene Evakuation hielt Viénot für illusorisch. Was zum Zeitpunkt des deutschen Eintritts in den Völkerbund oder in Thoiry an Vorteilen für Frankreich möglich gewesen wäre, könne nun nicht mehr erreicht werden ${ }^{207}$. D'Ormesson vertraute er an, er sehe die Lage sehr schwarz und plädierte für eine rasche Aufnahme von Verhandlungen, zu denen Frankreich als Siegermacht die Initiative ergreifen sollte ${ }^{208}$. Angesichts der sich abzeichnenden Desillusionierung in Deutschland wie in Frankreich nach Abklingen der Locarno-Euphorie sah Viénot einzig in Gustav Stresemann den Gewährsmann für eine realistische Politik:

Évidemment ce demier n'est pas un ’pacifisteı, c'est-à-dire [...] qu'il ne considère pas la paix comme une fin, mais comme un moyen. Cependant à défaut de doctrine idéologique, il me semble bien qu'il y a chez lui un puissant bon sens moderne qui lui fait désirer [...] un ordre politique raisonnable adapté aux conditions nouvelles de la vie en Europe. C'est une doctrine toute réaliste, mais cependant une doctrine, et qui nous garantit dans une certaine mesure la continuité de ses efforts pour la paix et l'entente ${ }^{209}$.

${ }^{205}$ Vgl. dazu KRUGER, Außenpolitik, S. 296; HILDEBRAND, Das vergangene Reich, S. 477; HAGSPIEL, Verständigung, S. 275f.

${ }^{206} \mathrm{Vgl}$. die von Viénot für die Komiteemitglieder verfaßte Note: La presse française et le discours de M. Stresemann du 23 juin 1927: MAE, PA-AP Seydoux, 261, d. 6.

${ }^{207}$ Vgl. ders. an Seydoux, 23.3.1927: NL d'Ormesson II. Beim Gespräch in Thoiry zwischen Briand und Stresemann am 17. September 1926 wurden die Möglichkeiten einer deutschfranzösischen Gesamtbereinigung ausgelotet. Deutschland sollte mit einer Finanzhilfe die französische Währung stützen und dafür im Gegenzug die vollständige Räumung des Rheinlandes und die Rückgabe des Saargebietes erhalten. Die Durchführung scheiterte jedoch am Widerstand der USA und Poincarés, dem es in der Folgezeit gelang, den Franc ohne deutsche Hilfe zu stabilisieren. Vgl. Jacques BARIÉTY, Finances et relations internationales. A propos du "plan de Thoiry « (septembre 1926), in: Relations internationales 21 (1981) S. 51-70; Heinz-Otto SIEBURG, Das Gespräch zu Thoiry 1926, in: Emst SCHULN (Hg.), Gedenkschrift Martin Göhring. Studien zur europäischen Geschichte, Wiesbaden 1968 (Veröffentlichungen des Instituts für Europäische Geschichte Mainz, 50), S. 317337; WURM, Die französische Sicherheitspolitik, S. 392-541; Jon JACOBSON, Locarno Diplomacy. Germany and the West 1925-1929, Princeton, New Jersey 1972, S. 84-98; DERS., John T. WALKER, The Impulse for a Franco-German Entente: The Origins of the Thoiry Conference 1926, in: JCH 10 (1975) Nr. l, S. 157-181; KRUGER, Außenpolitik, S. 356-364; HILDEBRAND, Das vergangende Reich, S. 488-492.

${ }^{208} \mathrm{Vgl}$. Viénot an d'Ormesson, 24.3.1927: NL d'Ormesson II.

${ }^{209}$ Ders. an Seydoux, 15.2.1927: NL d'Ormesson II. 
Der Realist Stresemann, der seine Politik jenseits starrer Ideologien an den modernen Nachkriegsgegebenheiten orientierte, mußte Viénot sympathisch sein ${ }^{210}$. Um so mehr besorgten ihn Informationen, wonach Stresemann im Frühjahr 1927 eine Krise durchmachte und anscheinend selbst am Erfolg der Verständigungspolitik zu zweifeln begann ${ }^{211}$. Der erlahmende Schwung der in Locarno initiierten Annäherungspolitik sowie eine tägliche Routine, in der Viénot hauptsächlich gegen Ignoranz und Dummheit zu kämpfen glaubte, entmutigten ihn im Laufe des Jahres 1927 zunehmend. Seydoux zeigte sich besorgt über »ce brave Viénot qui m'a l'air très découragé $[\ldots] \ll{ }^{212}$

Trotz zeitweiligen Anflügen von Resignation legte Viénot weiterhin ein über das Notwendige hinausgehendes Engagment an den Tag. Gerade angesichts der abklingenden Verständigungseuphorie war eine intensive Arbeit des Studienkomitees in seinen Augen wichtiger denn je. Viénots Berliner Büro wurde zu einer "verständigungspolitischen Vielzweck-Agentur «. ${ }^{213}$ Von Beginn an war Viénot der Ansprechpartner für die in der Hauptstadt weilenden Franzosen, und er arrangierte Aufenthalte und Vortragsreisen für seine Gäste. So betreute er beispielsweise den radikalsozialistischen Politiker Georges Bonnet bei einem Berlin-Besuch im November $1927^{214}$, organisierte eine Vortragsreise von

${ }^{210}$ In der Hervorbringung modemer Politikerpersönlichkeiten wie Stresemann war Deutschland seinem Nachbarland in den Augen Viénots ein großes Stück voraus: "Je cherche en vain chez nous, en politique étrangère, des hommes smodernesı, c'est-à-dire des hommes qui sachent penser les faits d'aujourd'hui avec des idées adaptées à ces faits et non avec des idées d'il y a cinquante ans ou même cents ans«. Viénot an Lyautey, 10.7.1927: AN, 475 AP 311. Das Problem lag seiner Meinung nach also nicht darin, daß Stresemann viel mehr Realpolitiker als Friedensapostel war, sondern in der mangelnden Entsprechung in Frankreich. Viénots Einschätzung von Stresemann entspricht dem in der neueren Stresemann-Forschung etablierten Bild des Politikers, der es verstand, nationale Machtpolitik mit internationalen Erfordernissen und Interessenlagen zu verbinden. Außenpolitische Revision und europäische Friedenssicherung gingen dabei Hand in Hand. Vgl. z.B. Martin WALSDORFF, Westorientierung und Ostpolitik. Stresemanns RuBlandpolitik in der Locarno-Ära, Bremen 1971; Wemer WEIDENFELD, Die Englandpolitik Gustav Stresemanns. Theoretische und praktische Aspekte der Außenpolitik, Mainz 1972; JACOBSON, Locamo Diplomacy; Manfred BERG, Gustav Stresemann und die Vereinigten Staaten von Amerika. Weltwirtschaftliche Verflechtung und Revisionspolitik 1907-1929, Baden-Baden 1990; DERS., Gustav Stresemann. Eine politische Karriere zwischen Reich und Republik, Göttingen, Zürich 1992; Christian BAECHLER, Gustave Stresemann (1878-1929). De l'impérialisme à la sécurité collective, Strasbourg 1996; Jonathan WRIGHT, Gustav Stresemann. Weimar's Greatest Statesman, Oxford, New York 2002; John P. BIRKELUND, Gustav Stresemann. Patriot und Staatsmann, Eine Biographie, Hamburg, Wien 2003. Zu den einzelnen Etappen der Stresemann-Forschung siehe Eberhard KOLB, Die Weimarer Republik, München ${ }^{3} 1993$ (Oldenbourg Grundriß der Geschichte, 16), S. 206-210; NIEDHART, Die Außenpolitik, S. 49f.

${ }^{211} \mathrm{Vgl}$. Viénot an d'Ormesson, 27.4.1927: NL d'Ormesson II.

${ }^{212}$ Seydoux an dens., 11.8.1927: MAE, PA-AP Seydoux, 261, d. 6.

213 BOCK, "Connaître l'Allemagne et la reconaître «, S. 35.

${ }^{214} \mathrm{Vgl}$. Viénot an seine Mutter, 22.11.1927: NL Viénot; ders. an d'Ormesson, 23.11.1927: NL d'Ormesson II. Zu Georges Bonnet (1889-1973) vgl. John E. DREIFORT, Bonnet, 
Jean Champetier de Ribes in verschiedenen deutschen Städten Anfang $1928^{215}$ und fungierte als Gastgeber von André Gide bei dessen Visite an der Spree im Januar $1928^{216}$. Auch um Henri de Peyerimhoff kümmerte er sich, als dieser im Dezember 1928 eine Rede vor dem Reichstag hielt ${ }^{217}$. Im März 1928 traf sich Viénot zu einem längeren Gedankenaustausch mit Alexis Léger, dem Kabinettschef Aristide Briands, über das Studienkomitee, die deutsche Jugendbewegung und die Ansichten der Universitätskreise. Der Vertreter des Quai d'Orsay ermunterte Viénot, künftig mit ihm Kontakt zu halten ${ }^{218}$. Auch mit der französischen Botschaft stand er in engem Kontakt, und Pierre de Margerie, der Botschafter in Berlin, sah in Viénots Büro offensichtlich keine Konkurrenz zur offiziellen Diplomatie, sondern eine willkommene Ergänzung zu seinen eigenen Bemühungen um gute bilaterale Beziehungen ${ }^{219}$. Über die berufliche Ebene hinaus waren auch die persönlichen Beziehungen zur Botschaft gut, was sich in der Freundschaft zwischen Viénot und de Margeries Sohn und Mitarbeiter Roland widerspiegelte. Viénot selbst begab sich auch auf Vortragsreisen durch die Republik und plante, zusammen mit seinem Freund Arnold Bergsträsser an der Heidelberger Universität ein Seminar zu Problemen der internationalen Politik zu veranstalten ${ }^{220}$. Bei einem von französischer Seite initiierten Treffen zwischen Vertretern des Katholizismus in beiden Ländern fungierte Viénot als Vermittler zwischen deutschen Mitgliedern der Zentrumspartei und französischen Politikern und Publizisten ${ }^{221}$.

Aufgrund seiner Bemühungen und Verdienste um die deutsch-französische Annäherung schlug Botschafter de Margerie Viénot im November 1927 für das Kreuz der Légion d'Honneur vor. Sowohl wegen seiner militärischen Leistungen im Ersten Weltkrieg wie auch und vor allem aufgrund seiner Tätigkeit als Direktor des Berliner Komiteebüros sollte Viénot geehrt werden: »Dans la direction du bureau berlinois $M$. Viénot a fait preuve de qualités éminément

Georges, in: Patrick H. HUTTON u.a. (Hg.), Historical Dictionary of the Third French Republic, 1870-1940, London 1986, S. 111f.

215 Vgl. ders. an dens., 28.1.1928: NL d'Ormesson II. Champetier de Ribes (1882-1947) war Schüler Albert de Muns und beeinflußt vom Sozialkatholizismus. Er gründete den Parti démocrate populaire und bekleidete zwischen 1929 und 1940 diverse Staatssekretärs- und Ministerposten. Vgl. Benoit YVERT (Hg.), Dictionnaire des Ministres de 1789 à 1989, Paris 1990, S. 401f.

${ }^{216} \mathrm{Vgl}$. Viénot an seine Mutter, 20.1.1928 und ders. an dies., 29.1.1928: NL Viénot.

$217 \mathrm{Vgl}$. ders. an dies., 11.12.1928: NL Viénot.

${ }^{218} \mathrm{Vgl}$. ders. an d'Ormesson, 2.4.1928: NL d'Ormesson II.

${ }^{219} \mathrm{Vgl}$. Bernard AUFFRAY, Pierre de Margerie (1861-1942) et la vie diplomatique de son temps, Paris 1976, S. 481ff. Auffray betont das enge Verhältnis zwischen dem Botschafter und Viénot.

${ }^{220} \mathrm{Vgl}$. Viénot an seine Mutter, 27.10.1928: NL Viénot. Anscheinend wurde das Projekt jedoch nicht verwirklicht.

${ }^{221}$ Vgl. ders. an Campetier de Ribes, 27.6.1927 und ders. an d'Ormesson, 28.6.1927: NL d'Ormesson II; ders. an seine Mutter, 30.6.1927: NL Viénot. 
diplomatiques. [...] En organisant ces contacts individuels, il fait ainsi, au meilleur sens du mot, œuvre de rapprochement franco-allemand. ${ }^{222}$ Ein Problem stellte jedoch Viénots junges Alter dar, aufgrund dessen eine Ehrung unwahrscheinlich erschien. Die Auszeichnung war Viénot so wichtig, daß er wieder seinen alten Mentor Lyautey einschaltete. Dieser sollte gegenüber Philippe Berthelot, dem Generalsekretär des Quai d'Orsay, ein gutes Wort für ihn einlegen. Es ist zu vermuten, daß sich Viénot neben dem persönlichen Prestigegewinn - für den er sicherlich nicht unempfänglich war - auch eine Stärkung seiner Position innerhalb des Komitees erhoffte. Berthelot versprach, sein möglichstes zu tun, um Viénots Emennung zu unterstützen, räumte jedoch auch ein, daß gemäß dem Anciennitätsprinzip eine mindestens fünfundzwanzigjährige Dienstzeit nötig sei ${ }^{23}$. Viénot bekam am Ende das Kreuz der Ehrenlegion nicht verliehen, hatte aber immerhin den Trost, vorgeschlagen worden zu sein ${ }^{224}$.

Die Parlamentswahlen in Deutschland und Frankreich 1928 verbesserten die politische Situation in den Augen Viénots nicht. In Deutschland hatte der Urnengang vom 20. Mai 1928 einen Linksruck zur Folge, und die SPD übernahm zum erstem Mal seit acht Jahren wieder die Regierung unter Kanzler Hermann Müller $^{225}$. Die Franzosen setzten hingegen auf Stabilität: Die Parlamentswahlen vom 22. und 29. April brachten ein klares Votum für die Fortsetzung der Poincaré-Regierung ${ }^{226}$. Viénot plädierte nach der Neuformierung der Kabinette in beiden Ländern einmal mehr für eine rasche Rheinlandräumung. Gleichzeitig war er aber auch davon überzeugt, daß in Frankreich aus innenpolitischen Gründen die Frage der Evakuierung weiterhin mit der endgültigen Lösung der Reparationsfrage verknüpft werden würde ${ }^{227}$. Diese Strategie wurde in Frankreich bewußt gewählt, um daraus in den Verhandlungen mit den USA über die interalliierten Schulden Vorteile zu ziehen. Dagegen versuchte die deutsche Politik, die beiden Problemfelder getrennt voneinander zu behandeln ${ }^{228}$. Viénot faßte hinsichtlich der Rheinlandräumung jedoch eine ganz andere Lösung ins Auge, für die ihm die Große Koalition in Deutschland mit einer Regienungsbeteiligung der SPD neue Chancen zu eröffnen schien. Da die Sozialdemokraten

${ }^{222}$ De Margerie an Briand, 15.11.1928: AN, 475 AP 311.

${ }^{223}$ Vgl. Viénot an Lyautey, 20.11.1928; ders. an dens., 29.11.1928; Berthelot an dens., 23.11.1928: AN, 475 AP 311.

${ }^{224}$ Im März 1930 wiederholte de Margerie seinen Vorschlag. Erst 1931 erhielt Viènot schließlich dann doch das Kreuz der Ehrenlegion »à titre militaire«. Vgl. de Margerie an Briand, 19.3.1930: MAE-CAD, Ambassade de France à Berlin, B, 463, d. CFAID; Viénot an seine Mutter, 18.8.1931: NL Viénot.

${ }^{225}$ Vgl. zum Wahlergebnis ausführlich WINKLER, Der Schein der Normalität, S. 521-527. Zur Regierungsbildung siehe ibid. S. 528-538.

${ }^{226} \mathrm{Vgl}$. BONNEFOUS, Histoire politique, Bd. 4, S. 250-253.

${ }^{227}$ Vgl. Viénot an d'Ormesson, 26.5.1928: NL d'Ormesson II.

${ }^{228}$ Vgl. KRUGGER, Außenpolitik, S. 428ff.; Philipp HEYDE, Das Ende der Reparationen. Deutschland, Frankreich und der Young-Plan 1929-1932, Paderborn u.a. 1998, S. 38ff. 
als erklärte Gegner des russischen Bolschewismus galten, könnte die französische Regierung, so glaubte Viénot, für die vorzeitige Evakuierung des Rheinlandes den deutschen Bruch mit Moskau erreichen ${ }^{229}$. Der für Frankreich traumatische Vertragsschluß von Rapollo zwischen dem Deutschen Reich und Rußland $^{230}$ wäre somit hinfällig geworden und Deutschland könnte fest an Frankreich gebunden werden. Eine engere Verbindung zwischen Deutschland und Frankreich würde in Viénots Kalkül zudem ein Gegengewicht zu Großbritannien schaffen, dem er mißtraute. Er betrachtete es als unsicheren Partner, der Frankreich in der Vergangenheit bei den Verhandlungen mit Deutschland immer wieder fallen gelassen und Konzessionen von seiner Seite erwirkt hatte. Die anglo-französischen Beziehungen waren in seinen Augen von untergeordneter Bedeutung und durften auf keinen Fall die französischen Annäherungsbestrebungen an Deutschland kompromittieren ${ }^{231}$. Obwohl die Gedanken Viénots mit den Grundlagen von Briands deutschlandpolitischer Strategie übereinstimmten - Loslösung des Deutschen Reichs von der Sowjetunion, enge Verbindung mit dem Nachbarstaat als Gegengewicht zu Großbritannien und im Falle Briands auch der USA ${ }^{232}$ - zog er die Kenntnis des Quai d'Orsay über die deutschen Vorgänge in Zweifel. Er glaubte nicht, daß sein Vorschlag dort auf fruchtbaren Boden fallen könnte ${ }^{233}$. Viénots Überzeugung, daß die Verständigung mit Deutschland ein nationales Interesse Frankreichs sei, zeigt sich an dieser Stelle besonders deutlich. Mit den von ihm vorgeschlagenen Maßnahmen argumentierte Viénot als Vertreter vorrangig französischer Interessen. Gleichzeitig glaubte er offenbar, auf diese Art und Weise die deutsch-französische Annäherung voranzubringen. Verständigungspolitik und französische Interessenpolitik waren für ihn weitgehend identisch. Das deutsche Nationalinteresse verfolgte jedoch andere Ziele als die von Viénot anvisierten. Was Viénot in sein Kalkül nicht mit einbezog war die Tatsache, daß Stresemann mit seiner außenpolitischen Strategie der Ost-West-Balance ${ }^{234}$ genau jene einseitige Bindung an Frankreich zu vermeiden suchte. Nur durch die Absage an eine endgültige Option für West oder Ost konnte er dem militärisch schwachen Reich einen ausreichenden außenpolitischen Handlungsspielraum für seine Politik der

${ }^{229} \mathrm{Vgl}$. Viénot an d'Ormesson, 26.5.1928: NL d'Ormesson II.

${ }^{230}$ Vgl. Renata BOURNAZEL, Rapallo. Ein französisches Trauma, Köln 1976.

${ }^{231}$ Vgl. Viénot an Lyautey, 17.9.1928: AN, 475 AP 311.

${ }^{232}$ Siehe dazu WURM, Frankreich und die Rolle Deutschlands, S. 152f.

${ }^{233}$ Vgl. Viénot an d'Ormesson, 26.5.1928: NL d'Ormesson II.

${ }^{234}$ Vgl. dazu ausführlich Michael-Olaf MAXELON, Stresemann und Frankreich 1914-1929. Deutsche Politik der Ost-West-Balance, Düsseldorf 1972. Die Ost-West-Balance bedeutete jedoch nicht gleichwertige Beziehungen des Deutschen Reiches mit den Westmächten und der Sowjetunion. De facto behieit die politische und wirtschaftliche Hinwendung nach Westen stets die Priorität für Stresemann, zumal die Weimarer Republik Bestandteil des westlich-liberalen Systems war. Die Beziehungen zur Sowjetunion sollten als Ausgleich gegenüber den Westmächten und zur Vergrößerung des politischen Handlungsspielraums dienen. Vgl. NIEDHART, Die Außenpolitik, S. 90f. 
friedlichen Revision verschaffen. Da Viénot die Abhängigkeit der neuen deutschen Regierung von außenpolitischen Erfolgen erkannt hatte, sprach er sich für eine großzügige Geste Frankreichs ihr gegenüber aus. Andernfalls rechnete er mit dem Ende der Verständigungspolitik:

L'Allemagne a entendu répéter trop souvent en France que le ralentissement qui s'est fait sentir dans la politique de rapprochement depuis un an et demi avait sa cause dans la participation des nationalistes au pouvoir [...]. [...] Ce serait aujourd'hui provoquer une déception grave dans les couches les plus profondes du peuple allemand [...] que de ne pas tenir compte du changement qui vient de se produire dans la composition du Reichstag ${ }^{235}$.

Viénot bezog sich in seinen Überlegungen immer wieder auf Thoiry, das er offensichtlich als verpaßte Chance zur endgültigen Bereinigung der deutschfranzösischen Probleme betrachtete. Nach den Wahlen 1928 sah er noch eine allerletzte Gelegenheit, Deutschland durch Zugeständnisse, vor allem in der Räumungsfrage, in den französischen Orbit zu ziehen ${ }^{236}$. Die Zeit spielte allerdings gegen Frankreich, und dessen war sich Viénot bewußt. Wollte Frankreich für eine vorzeitige Rheinlandräumung noch eine Gegenleistung erreichen, dann mußte es schnell handeln. Bereits drei Monate später hatte Viénot jedoch den Eindruck, daß die Ära des , Geistes von Locarno - an dessen magische Kraft er im übrigen nie wirklich geglaubt hatte - endgültig vorüber sei: »Les mois qui viennent seront pleins d'incidents, de peurs, d'exaspérations, de difficultés. $<^{237}$ Die im September 1928 in Genf aufgenommenen Verhandlungen über eine Reparationsregelung und die Evakuierungsfrage ${ }^{238}$ schienen Viénots pessimistischer Zukunftssicht recht zu geben. In dem darauffolgenden Ringen um eine Lösung sah Viénot die gesamte deutsch-französische Politik der letzten drei Jahre gefährdet. Die Belastungen der bilateralen Beziehungen spiegelten sich auch im Studienkomitee wider, das im Jahr 1929 eine existentielle Krise durchlebte. Die Konflikte und Inkohärenzen, die der Organisation von Beginn an innegewohnt hatten, brachen nun auf, und Viénots Position selbst wurde in Frage gestellt.

${ }^{235}$ Pierre VIENOT, Les dernières élections allemandes et leurs conséquences, in: La Revue de Paris 35 (1928) Nr. 4, S. 63-79. Der Artikel erschien anonym, da Viénot sich nicht der Kritik der deutschen Studienkomiteemitglieder, die teilweise der DNVP nahestanden, aussetzen wollte. Für Viénot war die Geheimhaltung seiner Autorenschaft so wichtig, daß er Lyautey bat, die Passage des Briefes, in dem er von seinem Artikel berichtet hatte, zu vernichten. Vgl. Viénot an Lyautey, 15.6.1928: AN, 475 AP 311; ders. an d'Ormesson, 6.6.1928: NL d'Ormesson II. Vgl. zur Gefährdung der Verständigungspolitik durch mangelndes französisches Entgegekommen ders. an Seydoux, 30.5.1928: MAE, AP Seydoux, 261, d. 6.

${ }^{236} \mathrm{Vgl}$. Viénot an Lyautey, 15.6.1928: AN, 475 AP 311.

${ }^{237}$ Vgl. ders. an dens., 17.9.1928: AN, 475 AP 311.

${ }^{238}$ Vgl. KRUGER, Außenpolitik, S. 453-461; Franz KNIPPING, Deutschland, Frankreich und das Ende der Locarno-Ära 1928-1931. Studien zur internationalen Politik in der Anfangsphase der Weltwirtschaftskrise, München 1987, S. 34-44. 
„Toute cette bêtise dans laquelle je travaille journellement«: Viénots tägliche Pressearbeit

Gemäß seiner Überzeugung, daß der deutsch-französische Konflikt weniger auf realen Interessengegensätzen beruhe, als vielmehr auf einer verfehlten Berichterstattung und der Tradierung von Stereotypen über das Nachbarland, gehörte eine aktive Pressepolitik zu den wichtigsten und vordringlichsten Aufgaben von Viénot. Er sollte dabei französische Presseorgane auf falsche Nachrichten hinweisen und im persönlichen Kontakt zu den Auslandskorrespondenten zur objektiveren Berichterstattung beitragen. In der französischen Botschaft in Berlin war bekannt, daß die Korrespondenten »mal intentionnés ${ }^{239}$ gegenüber Deutschland waren, und ihre Beziehungen zur Botschaft waren nur sehr locker. Der französische Geschäftsträger de Laboulaye schätzte es als sehr schwierig ein, Einfluß auf sie zu gewinnen und hoffte eher auf personelle Wechsel. Auch zur Presseabteilung des Auswärtigen Amts hielten die französischen Korrespondenten Distanz, vor allem die Vertreter nationalistischer Zeitungen wie L'Écho de Paris, L'Éclair oder Le Journal. Mit ihrem Festhalten an Klischeebildern vom preußisch-militaristischen Deutschland führten sie die Beziehungen mit der auswärtigen Presseabteilung bisweilen an den Rand des Bruchs. Bereits vor der Gründung des Studienkomitees gab es im Auswärtigen Amt Überlegungen, diesem Mißstand abzuhelfen. So schlug der FrankreichReferent der Presseabteilung, Schwendemann, vor, die Pariser Redaktionen zur Entsendung von Sonderberichterstattern zu ermutigen, von denen er sich mehr Objektivität erwartete. Der Vergleich ihrer Artikel mit denen der permanenten Korrespondenten könnte letztere zu einer realistischeren Berichterstattung anhalten ${ }^{240}$.

Viénots Aufgabe war also von Anfang an keine einfache, und bisweilen schien sein Ringen um eine objektive Berichterstattung einem Kampf gegen Windmühlen gleich. Bereits im Oktober 1926 bat ihn das Auswärtige Amt, gegen Artikel des Journalisten Henri Béraud in der Boulevardzeitung Le Journal vorzugehen $^{24}$. Béraud veröffentlichte dort eine morgendliche Artikelserie mit dem Titel »L'Allemagne, telle que je l'ai vue«, in der er in spektakulären Berichten seine Berlin-Impressionen schilderte, wodurch er die Auflage der Zeitung immens steigern konnte. Auch in der deutschen Presse erregten die po-

239 Aufzeichnung über ein Gespräch mit dem franzठ̋sischen Geschäftsträger de Laboulaye, ohne Unterschrift, 23.9.1926: NL d'Ormesson III, CFA, Documents des procès-verbaux.

${ }^{240}$ Vgl. Hans Jürgen MÓLLER, Auswärtige Pressepolitik und Propaganda zwischen Ruhrkampf und Locarno (1923-1925). Eine Untersuchung über die Rolle der Offentlichkeit in der Außenpolitik Stresemanns, Frankfurt a.M. u.a. 1991 (Moderne Geschichte und Politik, 8), S. $60 \mathrm{f}$.

${ }^{241}$ Vgl. MOLLER, Deutsch-französische Gesellschaftsbeziehungen, S. 215. Zu Le Journal vgl. BELLANGER, Histoire générale de la presse, S. $520 \mathrm{ff}$. 
lemischen Béraud-Artikel Aufsehen ${ }^{242}$. Viénot sah in Bérauds Äußerungen, die auch als Buch erschienen ${ }^{243}$, die alten Stereotypen, die jeglicher Kenntnis über Deutschland entbehrten. "Je ne peux plus discuter, pour ma part«, so erzürnte er sich über Bérauds mangelndes Einfuihlungsvermögen in die Mentalität des Gastlandes, »avec des Français qui prétendent `comprendre ('Allemagne sans sortir d'eux-mêmes [...].... ${ }^{244}$

Viénot wies französische Publizisten auf die Problematik von Bérauds Verallgemeinerungen hin und versuchte, damit kritische Besprechungen zu initiieren. Er verschickte eine Aufzeichnung, in der er alle seiner Meinung nach von Béraud beschriebenen Inkorrektheiten berichtigte, an d'Ormesson und Edmond Vermeil sowie an Mitarbeiter von La Revue bleue, Le Correspondant, La Revue hebdomadaire und La Revue universelle. Lucien Maury in der Revue bleue setzte sich dann mit Bérauds Artikel auseinander ${ }^{245}$, um den $\gg b e-$ dauernswerten Eindruck ${ }^{246}$ wieder wettzumachen, den das Buch in Deutschland hinterlassen hatte. Darüber hinaus zog auch $L$ 'Europe nouvelle Viénots Unwillen auf sich. Bei der Herausgeberin Louise Weiss protestierte er gleich zu Beginn seiner Tätigkeit zweimal wegen tendenziöser Berichte ${ }^{247}$. Eine weitere Intervention Viénots verursachte ein groß aufgemachter Artikel in Le Figaro mit dem Titel »La plus grande escroquerie des temps«, in dem behauptet wurde, die Reichsbank habe seit Kriegsende Falschgeld gedruckt und in Umlauf gebracht ${ }^{248}$. Viénot schrieb der Angelegenheit eine große Wichtigkeit zu und setzte sich sofort mit Mitarbeitern der Dawes-Plan-Kommission in Verbindung, um Aufklärung zu erhalten. Seinen Mitarbeiter Jessen schickte er mit einem Fragebogen zur Reichsbank ${ }^{249}$. Nach der Einholung von Informationen und Datenmaterial kam Viénot zu dem Schluß »que l'article d'André Lefèvre est vraiment d'une stupidité quasi-inconcevable«. ${ }^{250}$ Er verfaßte wie-

${ }^{242}$ Vgl. z.B. Friedrich SEBURG, Mit Blitzlicht und Pandorabüchse. Zu H. Bérauds Deutschland-Artikeln, in: Frankfurter Zeitung, 15.10.1926.

${ }^{243}$ Henri BÉRAUD, Ce que j'ai vu à Berlin, Paris 1926.

244 Viénot an Lyautey, 28.11.1926: AN, 475 AP 311.

${ }^{245}$ Vgl. Lucien MAURY, A Berlin, in: La Revre bleue 64 (1926) Nr. 23, S. 730-733.

${ }^{246}$ Pierre Viénot, Compte-rendu mensuel, $N^{\circ} 1$, Mois de novembre 1926: NL d'Ormesson III, CFA, Documents des procès-verbaux 1926.

${ }^{247} \mathrm{Vgl}$. Compte-rendu de l'activité du bureau de Berlin pendant le mois de novembre 1926 : NL d'Ormesson III, CFA, Documents des procès-verbaux 1926. Hierbei handelt es sich um ein Manuskript mit handschriftlichen Korrekturen Viénots. Im offiziellen Monatsbericht ist die Passage über L'Europe nouvelle gestrichen.

${ }^{248} \mathrm{Vgl}$. André LEFÉVRE, La plus grande escroquerie des temps. La Reichsbank a fait de la fausse monnaie, in: Le Figaro, 2.12.1926. Gemäß Lefêvres These habe die Reichsbank nach Ende des Krieges auf die Vorkriegszeit datierte Noten nachgedruckt, um dem Geld mehr 'moralischen Wert ‘ zu verleihen.

${ }^{249} \mathrm{Vgl}$. Viénot an d'Ormesson, 7.12.1926: NL d'Ormesson II.

${ }^{250}$ Ders. an dens., 14.12.1926: NL d'Ormesson II. 
derum eine Mitteilung ${ }^{251}$, in der er die Behauptungen Lefèvres entkräftete und verschickte sie an die Mitglieder der französischen Sektion. Die von Viénot erhoffte offizielle Richtigstellung im Figaro blieb jedoch aus ${ }^{252}$.

In einer weiteren Presseaffäre stand das Komitee selbst im Mittelpunkt des Interesses. In einem Artikel des Berliner Lokalanzeigers wurden Erklärungen einer politischen Persönlichkeit zur Räumungsfrage vorgetragen, die unschwer als Jacques Seydoux identifiziert werden konnte. Gleichzeitig wurden die Komiteemitglieder Simons, Deutsch und von Simson, die sich in Paris mit Seydoux getroffen hatten, so zitiert, als stimmten ihre politischen Ansichten mit denen Seydoux' überein. Viénot fürchtete, die Opposition könnte aus diesem Artikel Gewinn ziehen und der Politik Stresemanns Schaden zufügen bis hin zu einer ernsthaften politischen Verstimmung zwischen Berlin und Paris ${ }^{253}$. Seydoux bestritt jedoch, dem Korrespondenten von Heimburg jemals ein Interview gegeben $z u$ haben. Er habe lediglich einige banale Sätze zu den Ergebnissen von Thoiry geäußert, sich zufrieden über das Studienkomitee gezeigt und noch nicht einmal erwähnt, daß er sich mit den erwähnten deutschen Mitgliedern getroffen habe ${ }^{254}$. Auf Seydoux' Wunsch hin sollte Viénot Stresemann über die Vorgänge ins Bild setzen und zwar "plus souple et plus officieuse que l'Ambassade elle-même « ${ }^{255}$ Viènot traf sich mit dem Leiter der Presseabteilung von Zechlin, mit dem er gute Beziehungen pflegte, und stellte die Angelegenheit ihm gegenüber richtig ${ }^{256}$. Gleichzeitig sprach Krukenberg in Paris mit von Heimburg, der die Richtigkeit von Seydoux' Ausführungen bestätigte ${ }^{257}$. Kurze Zeit später ergab sich für Viénot dann auch ein informelles Gespräch mit Stresemann, der sich in bezug auf das Komitee interessiert und gut unter-

${ }^{251}$ Vgl. Pierre Viénot, Note sur l'article »La Reichsbank a fait de la fausse monnaie«: MAE, PA-AP Seydoux, 261, d. 6.

${ }^{252}$ In einer Meldung des Figaro vom 28.1.1927 wird auf einen Vortrag Bérauds vor dem Comité Dupleix hingewiesen, in dem dieser seine Thesen zum Falschgeld wiederholte. Die Zeitung distanzierte sich dabei nicht von Lefêrres Ausfuihrungen. Vgl. Le Figaro, 28.1.1927. Siehe auch Note du Bureau de Paris, o.D.: NL d'Ormesson II.

${ }^{253}$ Vgl. Pierre Viénot, Auszug aus dem Bericht über die Tătigkeit des Berliner Büros im Monat November 1926, Dezember 1926: PAAA, Botschaft Paris, DFS, Bd. 1; ders., Compterendu mensuel, $\mathbf{N}^{\circ} 1$, Mois de novembre 1926: NL d'Ormesson III, CFA, Documents des procès-verbaux 1926. Daß die Befürchtung Viénots nicht unbegründet war, geht aus einer Aufzeichnung Stresemanns vom 1.11.1926 hervor, der gegenüber Botschafter de Margerie sein »schärfstes Befremden « darüber zum Ausdruck brachte, daß Seydoux "diesem ausgesprochensten Feind meiner Außenpolitik und der deutsch-französischen Verständigungspolitik überhaupt, ein Interview gewähre«. ADAP, B, I, 2, Nr. 176, S. $412 \mathrm{f}$.

${ }^{254}$ Vgl. dazu auch von Hoesch an das AA, 11.11.1926: ADAP, B, I, 2, Nr. 188, S. 442.

${ }^{25 s}$ Seydoux an Viénot, 12.11.1926: MAE, PA-AP Seydoux, 261, d. 6. Gleichzeitig schrieb Seydoux auch einen Brief an Botschafter de Margerie und erklärte die Entstellungen seiner Aussagen. Vgl. Seydoux an de Margerie, 12.11.1926: ibid. Siehe auch Aufzeichnung Stresemann, 18.11.1926: ADAP, B, I, 2, Nr. 199, S. 471.

${ }^{256} \mathrm{Vgl}$. Viénot an Seydoux, 16.11.1926: MAE, PA-AP Seydoux, 261, d. 6.

${ }^{257}$ Vgl. ders. an von Simson, 16.11.1926: MAE, PA-AP Seydoux, 261, d. 6. 
richtet zeigte. Er befragte Viénot zur Situation der öffentlichen Meinung in Frankreich, und dieser nutzte die Gelegenheit, die Affäre um das angebliche Seydoux-Interview richtigzustellen. Stresemann zeigte sich verwundert darüber, daß im Quai d'Orsay erklärten Gegnem der von ihm praktizierten Verständigungspolitik Interviews gewährt würden und fürchtete innenpolitische Angriffe aufgrund des Artikels ${ }^{258}$. Viénot, der nicht mehr tun konnte, als in offiziöser Form zu dementieren, vermochte es offenbar nicht, Stresemann dadurch zu beruhigen.

Diese ersten Erfahrungen mit verzertter Berichterstattung machten deutlich, daß die Maßnahmen des Studienkomitees noch nicht den gewünschen Erfolg erzielten und eine stärkere Einwirkung auf die Presse dringend geboten war. Innerhalb der Pressekommission wurden konkrete Handlungsmöglichkeiten ausgelotet. Da den deutschen Korrespondenten in Paris ein großer Einfluß auf ihre Zeitungen zugesprochen wurde, sollte Krukenberg vor allem über diese auf die deutsche Presse einwirken. In Berlin gestaltete sich der Sachverhalt jedoch anders, und nach allgemeinem Dafürhalten wurde der Einfluß der französischen Korrespondenten als ungleich geringer eingestuft. Eine Einwirkung auf die Berichterstattung mußte demnach in erster Linie direkt über die Redaktionen in Frankreich erfolgen. Beide Bürodirektoren sollten sich darüber hinaus auch als Ansprechpartner für die Presse des Gastlandes präsentieren und aufgrund der Beziehungen der Komiteemitglieder immer über die neuesten Nachrichten unterrichtet $\operatorname{sein}^{259}$. Die Pressekommission erstellte daraufhin eine Liste von französischen Journalisten - mit Schwerpunkt auf der Provinzpresse im elsaß-lothringischen Grenzgebiet -, die regelmäßig die von Viénot verfaßten Pressemitteilungen zugeschickt bekommen sollten ${ }^{260}$.

Im Sommer 1927 registrierte Viénot besonders heftige Pressekampagnen in Frankreich, in denen die Angst gegenüber dem Nachbarland geschürt wurde und durch die er sich "nationalement humiliè « ${ }^{261}$ fühlte. Seiner Meinung nach entsprach eine Beendigung der Kampagnen in erster Linie dem nationalen Interesse Frankreichs, da sonst keine effektive Politik gestaltet werden könne ${ }^{262}$. Viénot wurde indes vorgeworfen, er trete in Berlin als "Anwalt Deutschlands" auf. Als in zwei Artikeln nationalistischer Zeitungen von angeblichen deutschen Vorbereitungen für einen Revanchekrieg berichtet wurde ${ }^{263}$, war Viénot am Ende seiner Geduld. Die vor Augen geführte Ohnmacht stellte die Existenz-

${ }^{258} \mathrm{Vgl}$. ders. an Seydoux, 16.11.1926 und 18.11.1926: MAE, PA-AP Seydoux, 261, d. 6.

${ }^{259}$ Vgl. Pierre Viénot, Compte-rendu de la première réunion tenue par la section française de la Commission de la Presse le 8 juin 1927, 13.6.1927: MAE, PA-AP Seydoux, 261, d. 6

${ }^{260}$ Note, vermutlich von Debrix, 26.7.1927: MAE, PA-AP Seydoux, 261, d. 6.

${ }^{261}$ Viénot an d'Ormesson, 8.8.1927: NL d'Ormesson II.

${ }^{262} \mathrm{Vgl}$. ibid. Siehe auch ders. an Seydoux, 9.8.1927: MAE, PA-AP Seydoux, 261, d. 6.

${ }^{263}$ Unter anderem von Franklin Bouillon in Le Journal vom 15.9.1927. Franklin Bouillon war gleichzeitig Vorsitzender des Auswärtigen Parlamentsausschusses. Die andere Zeitung, La Croix, war mit ihren Provinzausgaben die meistgelesene Zeitung Frankreichs. 
berechtigung des Komitees in Frage, und Viénot spielte mit dem Gedanken des Rücktritts ${ }^{264}$. Doch einfach aufzugeben, das war seine Sache nicht. Statt dessen verfaßte er eine Niederschrift, mithilfe derer er innerhalb des Komitees eine Diskussion über die Beziehungen zur Presse anstoßen wollte. Dabei versicherte er sich der Unterstützung von Seydoux, der Laurent von der Notwendigkeit dieser Maßnahme überzeugen und die Note an alle französischen Mitglieder verteilen sollte ${ }^{265}$.

In seiner Aufzeichnung betonte Viénot die Notwendigkeit für die Komiteemitglieder, wie "wne sorte de police morale des informations publiées sur les relations franco-allemandes ${ }^{266} \mathrm{zu}$ agieren. Er wiederholte einmal mehr seine Überzeugung, daß eine strikt objektive Berichterstattung vor allem im Interesse Frankreichs liege, da sie den Regierenden erst die Möglichkeit gebe, frei von Massenstimmungen eine vernünftige Politik zu führen. Angesichts des Vorwurfs der einseitigen Interessenvertretung für Deutschland sah Viénot offensichtlich auch Bedarf, sich selbst und seine Vorgehensweise zu rechtfertigen. Aufgrund seiner Erfahrungen in Deutschland hatte Viénot den Eindruck, daß die deutsche Öffentlichkeit weitaus besser über Frankreich unterrichtet war als umgekehrt. Nur bei der extremen Rechten herrsche ein verzerrtes FrankreichBild vor, das Viénot jedoch weniger auf Unkenntnis zurückführte, als vielmehr auf die senfance politique ${ }^{267}$ der Weimarer Republik und ihrer retardierten politischen Erziehung. Gefährlicher für den Verständigungsprozeß hielt er jedoch die französischen Deutschlandberichte, die in Deutschland große Zweifel an der französischen Bereitschaft zur Zusammenarbeit aufkommen ließen. Darüber hinaus konstatierte Viénot in verständigungsfeindlichen Kreisen ein neuartiges Gefühl der Geringschätzung gegenüber Frankreich, dem sein Sieg kein Selbstvertrauen geschenkt hatte und das weiterhin auf Sicherheitsgarantien pochte. Die abnehmende Verhandlungsbereitschaft von deutscher Seite führte Viénot auf das sinkende Prestige Frankreichs zurück. D'Ormesson hielt gerade diese Ausführungen Viénots für überaus gefährlich, da sie einen Aufschrei unter den französischen Komiteemitgliedern provozieren würden ${ }^{268}$. Dieser Gefahr war sich Viénot jedoch durchaus bewußt und rechnete den Skandal mit ein, den seine Mitteilung verursachen könnte ${ }^{269}$. Offensichtlich glaubte er, nur auf diesem Wege eine Diskussion anstoßen zu können. Um dem Übel in Zukunft abzuhelfen, schlug er eine engere Zusammenarbeit mit ausgewählten und dem Komitee bekannten Journalisten vor. Diese sollten direkt vom

${ }^{264} \mathrm{Vgl}$. Viénot an d'Ormesson, 16.9.1927 und ders. an Sommier, 19.9.1927: NL d'Ormesson II.

${ }^{265} \mathrm{Vgl}$. ders. an Seydoux, 26.9.1927: MAE, PA-AP Seydoux, 261, d. 6.

${ }^{266}$ Ders., Note sur les relations du Comité avec la Presse, S. 2: NL d'Ormesson I, Comité Mayrisch, 1927, $2^{e}$ année.

${ }^{267}$ Ibid. S. 4.

${ }^{268}$ Vgl. die handschriftlichen Anmerkungen von d'Ormesson, ibid.: NL d'Ormesson I, Comité Mayrisch, $1927,2^{e}$ année.

${ }^{269} \mathrm{Vgl}$. Viénot an Seydoux, 26.9.1927: MAE, PA-AP Seydoux, 261, d. 6. 
Komitee Informationen zu aktuellen politischen und wirtschaftlichen Fragen erhalten. Um seiner Aufgabe der intensiven Auswertung der Presseberichterstattung nachgehen zu können, forderte Viénot, der sich durch seine vielfältigen Aktivitäten völlig überlastet sah, einen Mitarbeiter. Von den einzelnen Mitgliedern erhoffte er sich auch persönliches Engagement und Eigeninitiative gegenüber Journalisten, mit denen sie in Kontakt standen.

Ein weiteres Problemfeld erkannte Viénot in den finanziellen Verflechtungen zwischen Presse und Industrie. Die konservative Presse Frankreichs, die von führenden Köpfen in Wirtschaft und Politik gelesen - und bisweilen finanziert - wurde, erschwerte in seinen Augen durch verzerrte und unrichtige Darstellungen eine Zusammenarbeit mit jenen Kreisen im politisch rechten Spektrum, die das Mayrisch-Komitee für die Verständigung gewinnen wollte. Gleichzeitig speiste sich diese Presse jedoch nicht zuletzt aus Fonds von Industriegruppen, deren Vertreter im Studienkomitee saßen. Für die Zeitung L'Avenir machte Viénot beispielsweise finanzielle Unterstützung von seiten des Comité des Forges und des Comité des Houillères aus ${ }^{270}$. Vertreter dieser Organisationen im Studienkomitee waren Théodore Laurent und Henri de Peyerimhoff, den Viénot ansonsten zu seinen Verbündeten zählte. Viénot war sich darüber im klaren, daß die Angelegenheit sehr delikat war und nicht im Plenum diskutiert werden konnte. Er bat darum Seydoux, ein Gespräch unter vier Augen mit de Peyerimhoff zu führen und ihm die Problematik bewußt zu machen. Peyerimhoff sollte seinerseits auf Théodore Laurent einwirken. Viénot schlug vor, die Vergabe von finanziellen Zuwendungen an Presseorgane in Zukunft von deren Zustimmung zur Locarno-Politik abhängig zu machen. Als Adressaten sah Viénot $L$ 'Avenir ebenso wie Le Journal und Le Temps ${ }^{271}$.

Viénot, der sich über diese Probleme auch mit André de Laboulay von der französischen Botschaft interhalten hatte, sah noch ein weiteres Hindernis. Die Mitarbeiter der Nachrichtenagentur Havas hatten seiner Meinung nach die Polemik des Ruhrkampfes noch immer nicht hinter sich gelassen und betrachteten die deutsch-französischen Beziehungen weiterhin als notwendigen Kampf. Für Viénot war dies der Schlüssel des ganzen Problems, da seiner Meinung nach ein intelligenter und gut informierter Havas-Direktor die französische Presse verändern könnte. Da allerdings keine Aussicht auf einen personellen Wechsel bestand, sah Viénot weiterhin die einzige Möglichkeit in einer dezidierteren Haltung des Studienkomitees zum Problem der Berichterstattung ${ }^{272}$.

Diese ließ sich jedoch vorerst nicht durchsetzen, und so blieb Viénot weiterhin in Berlin auf einem einsamen Posten im Kampf gegen unrichtige Pressemeldungen. Als der Korrespondent des Journal, Georges Blun, Anfang 1928

\footnotetext{
${ }^{270}$ Vgl. BELLANGER, Histoire générale de la presse, S. 545.

${ }^{27}$ Vgl. Viénot an Seydoux, 28.9.1927: MAE, PA-AP Seydoux, 261, d. 6.

${ }^{272} \mathrm{Vgl}$. ibid.
} 
von regelrechten Orgien in der Berliner Silvesternacht berichtete ${ }^{273}$, sah es Viénot als erwiesen an, daß der Journalist gezielt und absichtlich tendenziöse Berichte über Deutschland verbreitete ${ }^{274}$. Der Vorfall erregte umso mehr Aufsehen, als Blun der Vorsitzende des Vereins der ausländischen Presse war. Die Vossische Zeitung kritisierte Bluns Äußerungen heftig, und Blun entschuldigte sich mit Entstellungen durch seine Redaktion ${ }^{275}$. Dennoch mußte er unter dem Druck seiner ausländischen Kollegen vom Vorsitz ihrer Berufsvertretung zurücktreten ${ }^{276}$. Offensichtlich begnügte sich Viénot hier mit einer passiveren Rolle als gewöhnlich. Er vermutete, die deutsche Presse werde mit ihrer gegen Blun gerichteten Kampagne diesen zum Rücktritt zwingen, so daß er nicht mehr eingreifen mußte $\mathrm{e}^{277}$. Daß Viénot Bluns Absetzung durchgesetzt haben soll ${ }^{278}$, läßt sich nicht belegen und ist angesichts der Sachlage eher unwahrscheinlich.

\section{Die Affäre Seydoux}

Während Viénot noch auf Reaktionen zu seiner Pressenotiz wartete, kam es bereits zum nächsten Zwischenfall. Bischof Julien, der kirchliche Vertreter im Studienkomitee, hielt anläßlich einer Gedenkfeier für zivile Opfer des Ersten Weltkrieges im August 1927 eine Rede in Dinant, in der er die deutsche Kriegsführung verurteilte. Die Presse in Deutschland griff die Angelegenheit auf, und innerhalb der deutschen Gruppe des Studienkomitees kam es zu heftigen Reaktionen. Viénot nahm sich der Sache an und veranlaßte einen Brief Juliens, in dem dieser die seiner Meinung nach unvollständige Wiedergabe seines Vortrages ergänzte. Da Viénot jedoch auch in diesen Erklärungen Passagen fand, die von deutscher Seite mißverstanden werden könnten, entwarf er selbst einen Brief an Nostitz, in dem er Textstellen von Julien zitierte, aber auf die strittigen Zeilen verzichtete. Wie schon einmal praktiziert, setzte Mayrisch seine Unterschrift unter einen von Viénot verfaßten Brief. Nostitz erhielt damit volle Genugtuung, blieb jedoch über den wirklichen Verfasser in Unkenntnis ${ }^{279}$. Die Methoden, mit denen Viénot versuchte, Konflikte innerhalb des Komitees zu ver-

${ }^{273}$ Vgl. Georges BLUN, Nuit de Saint-Sylvestre, in: Le Journal, 2.1.1928.

${ }^{274}$ Vgl. Viénot an d'Ormesson, 5.1.1929: NL d'Ormesson II.

${ }^{275}$ Vgl. Heinz POL, Die Orgien des "Journal «. Wie Berlin Silvester gefeiert haben soll, in: Vossische Zeitung, 5.1.1927. Siehe auch: Der Fall Blun, in: Pressebericht, 6.1.1928.

${ }^{276} \mathrm{Vgl}$. Viénot an d'Ormesson, 10.1.1928: NL d'Ormesson II.

${ }^{277}$ Vgl. ders. an dens., 6.1.1928: NL d'Ormesson II.

${ }^{278}$ Vgl. MULLLER, Deutsch-französische Gesellschaftsbeziehungen, S. 250.

${ }^{279}$ Vgl. ders. an d'Ormesson, 18.9.1927; Julien an Mayrisch, 25.9.1927; Viénot, Projet de lettre à Mgr. Julien, O.D.; ders., Projet de lettre [an von Nostitz] 0.D.; ders. an d'Ormesson, 28.9.1927; ders. an Mayrisch, 28.9.1927; ders. an d'Ormesson, 1.10.1927, alle: NL d'Ormesson II.

Nostitz war so zufrieden über die Klănung der Angelegenheit, daß er den vermeintlichen Mayrisch-Brief in privatem Kreis auch Stresemann zu lesen gab. Vgl. Viénot an Julien, 5.10.1927: ibid. 
meiden, fanden jedoch keine ungeteilte Zustimmung. Viénots jungem Freund, dem Germanistik-Studenten Pierre Bertaux, ging das Vorgehen des Berliner Bürodirektors zu weit ${ }^{280}$.

Konnte die Julien-Affäre relativ rasch geklärt werden, so erregte, kaum daß diese ausgestanden war, Jacques Seydoux' publizistische Tätigkeit die Gemüter. Seydoux war Ende 1926 aus gesundheitlichen Gründen aus dem Quai d'Orsay ausgeschieden und verlegte sich seither vor allem auf das Verfassen von Artikeln zur außenpolitischen Lage. Im August 1926 war er an der Gründung der Zeitschrift Pax beteiligt gewesen, ansonsten veröffentlichte er bevorzugt im vielgelesenen Petit Parisien ${ }^{281}$. Anfang Oktober 1927 erhielt Viénot ein Telegramm von Krukenberg, in dem dieser darlegte, er könne nicht in der Angelegenheit Julien gegenüber der deutschen Sektion intervenieren, da soeben ein Artikel von Seydoux in Le Petit Parisien erschienen sei, der für Aufsehen sorgen werde. Seydoux hatte in seinem Artikel die deutsche Verantwortung für den Ausbruch des Weltkrieges herausgestrichen und gefordert, daß Deutschland endlich seine Schuld einsehe und den Versailler Vertrag als gerecht anerkenne $^{282}$. Diese Äußerungen sorgten unter den deutschen Komiteemitgliedern für allergrößte Aufregung. Krukenberg und Viénot konnten die Presse vorläufig zum Stillschweigen überreden, aber Nostitz befürchtete, daß die rechte Presse die Verbindungen Seydoux' zum Studienkomitee aufgreifen und damit die Arbeit des Komitees diskreditieren könnte. In diesem Fall rechnete Viénot mit einer Serie von Austritten und mit einer nachhaltigen Erschütterung des Komitees insgesamt. Um den negativen Eindruck auszugleichen, bat Viénot Seydoux um einen 'positiven` Artikel, beispielsweise über das Recht der Deutschen auf eine patriotische Einstellung ${ }^{283}$. Viénot wollte die Geschichte zudem durch ein Gespräch zwischen Mayrisch und Seydoux aus der Welt räumen, doch der vielbeschäftigte Komiteepräsident "paraît très fatigué, très énervé et de très mauvais humeur et peu enclin à se charger de cette délicate corvée ${ }^{284}$ Der Verursacher der ganzen Aufregung verstand indes die Panik nicht. Er selbst hielt seine Artikel für »parfaitement modérés « ${ }^{285}$ und unterstrich, daß er uneingeschränkter Anhänger der Verständigungspolitik sei. Seydoux bot auch seinen Rücktritt an, doch Viénot lehnte ab. Nach einer Unterhaltung mit Seydoux erklärte May-

${ }^{280}$ Vgl. BERTAUX, Un normalien à Berlin, S. 117. Zur Freundschaft zwischen Viénot und Bertaux siehe Kap. III.1.3.5.

${ }^{281}$ Vgl. BELLANGER, Histoire générale de la presse, S. 512-515.

${ }^{282} \mathrm{Vgl}$. Jacques SEYDOUX, Notre politique extérieure. L'Allemagne a mieux à faire pour la cause du rapprochement que de chercher à dégager la responsabilité du militarisme impérial, in: Le Petit Parisien, 1.10.1927. Seydoux stellte Frankreich als Gegenbeispiel dar, welches nach 1870 zu seiner »Kriegsschuld « gestanden habe, obwohl sich die französische Verantwortung nach Kenntnis der Emser Depesche als eine wabsurde légende، herausgestellt habe.

${ }^{283}$ Vgl. Viénot an Seydoux, 4.10.1927: MAE, PA-AP Seydoux, 261, d. 6.

${ }^{284}$ Ders. an seine Mutter, 9.10.1927: NL Viénot.

${ }^{285}$ Seydoux an Laurent, 10.10.1927: MAE, PA-AP Seydoux, 261, d. 6. 
risch die Angelegenheit schließlich für beendet. Zudem erzielte ein neuer und versöhnlicher Artikel von ihm »le plus heureux effet ${ }^{286}$, so daß auch Viénot zufrieden war.

Die Freude hielt jedoch nicht lange an, denn schon einen Monat später gab es eine Neuauflage der Verstimmung, die Viénot alarmierte ${ }^{287}$. Seydoux wies in seinem Artikel die deutsche Forderung nach der im Versailler Vertrag festgelegten Abrüstung der Ententemächte nach erfolgter deutscher Abrüstung zurück mit dem Hinweis auf die Schlagkraft des deutschen Berufsheeres. Das Zentrumsblatt Germania kommentierte dies als »das Absurdeste, was man je aus seiner Feder gelesen hat«. ${ }^{288}$ Viénot beruhigte das Auswärtige Amt ebenso wie Nostitz und versicherte sich des Stillschweigens der rechten Presse. Seydoux fühlte sich derweil mißverstanden und zu Unrecht angegriffen. Er habe nicht andeuten wollen, daß Deutschland noch weiter abrüsten solle, sondern daß die Existenz von Berufsarmeen überhaupt Kriegshandlungen nicht ausschließe. Seydoux forderte eine Abschaffung der militärischen Kasten in allen europäischen Staaten, was durch die Orientierung der Wehrverfassung am Schweizer Milizmodell erfolgen sollte ${ }^{289}$. Nach einer Unterhaltung mit Ministerialdirektor Köpke hatte Viénot den Eindruck, auch diese Affäre sei aus der Welt geschafft. Auch auf deutscher Seite sah man kein Problem. Köpke versicherte, die deutschfranzösische Zusammenarbeit sei so eng wie seit 70 Jahren nicht mehr ${ }^{290}$. Obwohl die Wogen vorerst geglättet werden konnten, zeigte sich doch, wie grundlegend und tief die deutsch-französischen Konflikte waren und wie wenig das Komitee dagegen ausrichten konnte. Pierre Bertaux, der durch Viénot über die Angelegenheiten des Komitees ins Bild gesetzt wurde, sprach daher nach der Aufregung um Seydoux dem Mayrisch-Komitee keine großen Zukunftschancen zu. In seinen Augen überlebe dieses »que par miracle (!) ou artifices de Viénot«. ${ }^{291}$

Die publizistische Tätigkeit Seydoux' ließ Viénot nicht zur Ruhe kommen. Ende 1928 antwortete Komiteemitglied Franz von Papen auf einen Artikel Seydoux', in dem dieser zu den kommenden Sachverständigen-Verhandlungen zur Reparationsregelung Stellung genommen hatte. Seydoux' optimistische Einschätzungen der wirtschaftlichen Möglichkeiten Deutschlands stießen bei

${ }^{286}$ Viénot an Seydoux, 19.10.1927: MAE, PA-AP Seydoux, 261, d. 6. Vgl. dazu Jacques SEYDOUX, Notre politique extérieure. Le dernier discours de M. Stresemann, in: Le Petit Parisien, 14.10.1927. Seydoux mahnte allerdings auch hier an: "Il faut que l'Allemagne, qui s'était habituée à la guerre, s'habitue à la paix «.

${ }^{287} \mathrm{Vgl}$. ders. an d'Ormesson, 26.11.1927: NL d'Ormesson II.

${ }^{288}$ Seydoux verlangt weitere deutsche Abrüstung, in: Germania, 26.11.1927.

${ }^{289} \mathrm{Vgl}$. Krukenberg an die Mitglieder der deutschen Gruppe des Studienkomitees, 28.11.1927: PAAA, Botschaft Paris, DFS, Bd. 1; Article de M. Seydoux à paraitre dans le prochaine numéro du "Pax« du Vendredi 2 décembre 1927: Encore le désarmement: ibid.

${ }^{290} \mathrm{Vgl}$. Viénot an Seydoux, 29.11.1927: MAE, PA-AP Seydoux, 261, d. 6.

${ }^{291}$ BERTAUX, Un normalien à Berlin, S. 117. 
deutschen Sachverständigen und in der Presse auf Kritik ${ }^{292}$. Vor allem sorgte aber seine Warnung für deutschen Mißmut, daß bei einer Regelung, die nur ungenügende Garantien für Frankreich vorsah, auf Artikel 430 des Versailler Vertrages rekurriert werden könnte. Dieser ermöglichte einen Einmarsch ins Rheinland bei Nichterfüllung der Reparationsleistungen ${ }^{293}$. Viénot fühlte sich durch diese Passage in Seydoux' Artikel peinlich berührt. Er gab ihm zu verstehen, daß eine Phase des publizistischen Schweigens den deutsch-französischen Beziehungen nützlich wäre ${ }^{294}$. Trotz Viénots Warnungen überlieferte Seydoux in einem weiteren Artikel eine Anekdote über den deutschen Hauptdelegierten Hjalmar Schacht ${ }^{295}$, der in einer Versammlung die Lage Deutschlands als so übertrieben trostlos geschildert haben soll, $\mathrm{da} B$ anschließend ein ausländischer Bankier sein Kapital aus Deutschland habe abziehen wollen ${ }^{296}$. Seydoux hielt die Schilderungen der deutschen Misere für schlichtweg übertrieben und beharrte auf seinem Standpunkt, deutsche Inkorrektheiten richtig stellen zu wollen. Die "gémissements perpétuels ${ }^{297}$ von deutscher Seite wollte Seydoux einfach nicht mehr hören.

Viénot indes fühlte sich durch Seydoux in seiner eigenen Arbeit behindert. Just in dem Augenblick, in der er bei einflußreichen Politikern und Journalisten eine Runde wegen deutscher Presseberichte machen wollte, seien die Artikel erschienen. Vor allem Seydoux' Ausführungen zu Schacht fand Viénot verfehlt und in höchstem Maße undiplomatisch: „Cette histoire est d'ailleurs authentique et je la connaissais moi-même depuis longtemps. Mais je n'aurais pas cru, pour ma part, que vous puissiez désirer la mettre sous les yeux du grand public. $\ll^{298}$

Als ein erneuter Artikel von Seydoux zur Frage der deutsch-polnischen Beziehungen und des polnischen Korridors in der deutschen Presse und im Komitee für Aufruhr sorgte, legte Viénot, obwohl er persönlich Respekt und $\mathrm{Zu}$ neigung für den Politiker empfand, diesem dann schließlich doch den Rücktritt

${ }^{292}$ Vgl. Jacques SEYDOUX, Les négociations sur les Réparations. Conciliation certes, mais des garanties solides, in: Le Petit Parisien, 19.12.1928; Franz von PAPEN, Falsche Methode. Ein Wort zur europäischen Gemeinschaftsarbeit, in: Germania, 30.12.1928; Verhandlung oder Diktat? Was Seydoux vorschlägt, in: Münchner Neueste Nachrichten, 29.12.1928. Siehe auch Viénot an Seydoux, 4.1.1929: MAE, PA-AP Seydoux, 261, d. 6.

${ }^{293}$ Zum Wortlaut siehe Herbert MichAELIS, Emst SCHRAEPLER (Hg.), Ursachen und Folgen. Vom deutschen Zusammenbruch 1918 und 1945 bis zur staatlichen Neuordnung Deutschlands in der Gegenwart, Eine Urkunden- und Dokumentensammlung zur Zeitgeschichte, Bd. 3, Der Weg in die Weimarer Republik, Berlin 1958, S. 414.

${ }^{294} \mathrm{Vgl}$. Viénot an Seydoux, 9.1.1929 und ders. an d'Ormesson, 9.1.1929: NL d'Ormesson II.

${ }^{295}$ Zu Schacht vgl. John WITZ, Hitlers Bankier. Hjalmar Schacht, München 1986.

${ }^{296}$ Vgl. Jacques SEYDOUX, La précise contribution de M. Parker Gilbert aux prochains négotiations des experts, in: Le Petit Parisien, 17.1.1929. Siehe auch: Seydoux gegen Schacht, in: Berliner Tageblatt, 17.1.1929.

${ }^{297}$ Seydoux an Viénot, 11.1.1929: MAE, PA-AP Seydoux, 261, d. 6.

${ }^{298}$ Viénot an Seydoux, 18.1.1929: MAE, PA-AP Seydoux, 261, d. 6. 
nahe $^{299}$. Seydoux hatte erklärt, Deutschland müsse sich für alle Zukunft mit der Tatsache des polnischen Korridors und eines erstarkenden polnischen Staates abfinden. Die Deutschen, so sah es Seydoux, dürften sich über die neue Staatenordnung von Versailles nicht beklagen, da sie den Ausbruch des Ersten Weltkriegs nicht verhindert hätten ${ }^{300}$. Mit diesen Äußerungen hatte Seydoux zwei für die deutsche Seite hochsensible Punkte angesprochen, die Frage des polnischen Korridors und der deutschen Kriegsschuld. Die Forderung nach Anerkennung des europäischen Status quo im Osten traf den empfindlichsten Nerv der deutschen Außenpolitik, denn die Revision der deutschen Ostgrenze blieb für sie während der gesamten Weimarer Republik ein Hauptziel. Auch Gustav Stresemann dachte nicht daran, diesen von allen Weimarer Kabinetten geteilten Konsens aufzukündigen und den territorialen Status quo anzuerkennen. Ein »Ost-Locarno« kam für ihn nicht in Frage ${ }^{301}$.

Wladimir d'Ormesson erachtete wie Viénot die Position Seydoux' innerhalb des Komitees nunmehr als unhaltbar. Dessen Artikel hielt er für absurd, unintelligent und undifferenziert ${ }^{302}$. Seydoux erklärte daraufhin den Austritt aus dem Komitee und zeigte selbst Erleichterung über diesen Schritt: »Je suis fort heureux de ne plus être lié par le Comité que je gênais et qui me gênait également. $\ll^{303}$

Die Ausfihrungen Seydoux' in seinen Artikeln machen deutlich, daß er sein Mißtrauen gegenüber Deutschland niemals völlig abgelegt hat. Er schwankte innerlich zwischen seinen Zweifeln an der deutschen Verständigungsbereitschaft und seinem Willen zu wirtschaftlicher Kooperation. Wie viele Politiker seiner Generation war er von der Fortexistenz eines preußisch-deutschen Militarismus auch über den Zusammenbruch des Kaiserreiches hinaus überzeugt. Gleichzeitig beteuerte er, er trete für Annäherung und Verständigung ein ${ }^{304}$. Eine schwere Erkrankung behinderte Seydoux' Kontakt mit der Außenwelt und

${ }^{299}$ Vgl. Seydoux an d'Ormesson, 26.2.1929 und ders. an Laurent, 26.2.1929: NL d'Ormesson II; Viénot an seine Mutter, 27.2.1929: NL Viénot; d'Ormesson an Seydoux: MAE, PA-AP Seydoux, 261, d. 6; Aufzeichnung von Bassenheim, 1.3.1929: ADAP, B, XI, Nr. 104, S. 227.

${ }^{300}$ Vgl. Jacques SeYdOUX, La Pologne ressuscitée et l'Allemagne, in: Le Petit Parisien, 24.2.1929.

${ }^{301}$ Vgl. HIIDEBRAND, Das vergangene Reich, S. 460-465; KolB, Weimarer Republik, S. 67f: NIEDHART, Die Außenpolitik, S. 21f.; KRUGER, Außenpolitik, S. 77-81, S. 213-218 und S. 301-311. Zur Bedeutung des Revisionismus in der Innen- und Außenpolitik der Weimarer Republik vgl. Michael SALEWSKI, Das Weimarer Revisionssyndrom, in: APuZ B 2 (1980) S. 14-25; Andreas HILLGRUBER, »Revisionismus« - Kontinuität und Wandel in der Außenpolitik der Weimarer Republik, in: HZ 237 (1983) S. 597-621; Hans-Jürgen SCHRODER, Von Versailles nach Potsdam. Deutsche Frage und internationales System, in: APuZ B 28 (1995) S. 3-12, v.a. S. 4f.

${ }^{302}$ So d'Ormesson in seinem Tagebuch am 24.2.1929. Vgl. de VoGUE, Wladimir d'Ormesson et le rapprochement, S. 66 .

${ }^{303}$ Seydoux an Krukenberg, 1.3.1929: MAE, PA-AP Seydoux, 261, d. 6.

${ }^{304} \mathrm{Vgl}$. Jacques SEYDOUX, Les négociations sur les Réparations. Conciliation, certes, mais des garanties solides, in: Le Petit Parisien, 19.12.1929. 
förderte dadurch vermutlich sein Festhalten an starren Positionen. In der Zeit nach seinem Ausscheiden aus dem Quai d'Orsay schien die alte Besorgnis bei ihm wieder Oberhand zu gewinnen. Dadurch brachte er zum einen das Komitee in Gefahr, zum anderen zeigte sich aber an seinem Beispiel, daß in einer Situation verstärkter politischer Anspannung die Grundlage des Komitees, die Verständigung auf nationaler Basis, zur Zerreißprobe für die Organisation werden konnte. Viénot empfand jedoch auch die persönliche Tragik des schwerkranken Seydoux, der sich seiner Meinung nach vor allem deshalb derart unnachgiebig zeigte, um sich seines verbliebenen Einflusses zu vergewissern: "[...] cela me fait vraiment de la peine, car c'est un homme qui va mourir. Lui demander sa démission en ce moment, c'est d'une certaine manière, le lui faire comprendre. ${ }^{305}$

In der deutschen Botschaft in Paris bemühte man sich unterdessen um Schadensbegrenzung. Botschafter von Hoesch wollte Seydoux nicht gänzlich fallen lassen und ihn damit in Gegnerschaft zur Verständigungspolitik bringen. Eine Unterhaltung zwischen Seydoux und Botschaftsrat Rieth verlief furr beide Seiten zufriedenstellend, und es wurde vereinbart, weiterhin in Kontakt zu bleiben ${ }^{306}$. Für das Komitee hatte das Ausscheiden von Seydoux aber auch einen bedauerlichen Aspekt. Die Banque de Paris, in deren Verwaltungsrat Seydoux nach dem Ausscheiden aus dem Quai d'Orsay eingetreten war, hatte dem Komitee eine großzügige Subvention gewährt. Zusammen mit Seydoux ging das Komitee auch dieser finanziellen Unterstützung, die es dringend nötig hatte, verlustig. Seydoux sah keine Veranlassung, der Bitte d'Ormessons zu entsprechen und noch einmal bei der Bank zu intervenieren: "Si je suis parti, c'est qu'il y a désaccord de principe entre le Comité et moi: il n'y a pas seulement une question de forme, il $\mathrm{y}$ a là une question de fond. ${ }^{307}$ Seydoux, der wegen seiner Krankheit schon aus der Leitung der Zeitschrift Pax ausgetreten war, starb am 26. Mai 1929.

Der Versuch eines Aufbruchs:

Viénots und d'Ormessons pressepolitische Offensive

Viénots Ansichten über die Rolle der Presse in den internationalen Beziehungen wurden von seinem Freund Wladimir d'Ormesson geteilt. D'Ormesson, der sich als Journalist einen Namen gemacht hatte und für renommierte Zeitungen und Zeitschriften wie L'Europe nouvelle, Le Temps, Le Figaro, La Revue hebdomadaire, La Revue de Genève oder La Revue de Paris schrieb ${ }^{308}$, beschäftigte sich auch publizistisch mit den Beziehungen Frankreichs zu Deutsch-

${ }^{305}$ Viénot an seine Mutter, 27.2.1929: NL Viénot.

${ }^{306} \mathrm{Vgl}$. Seydoux an Viénot, 6.3.1929: MAE, PA-AP Seydoux, 261, d. 6.; von Hoesch an von Nostitz, 12.3.1929: PAAA, Botschaft Paris, DFS, Bd. 2.

${ }^{307}$ Seydoux an d'Ormesson, 29.3.1929: MAE, PA-AP Seydoux, 261, d. 6.

${ }^{308}$ D'Ormesson wurde Le Temps direkt von Poincaré empfohlen. 1926 verließ er Le Temps nach Querelen mit dem Direktor Hébrard, kehrte allerdings nach einigen Monaten wieder zurück. Ab September 1928 schrieb er Leitartikel für die briandistische $L^{\prime}$ Europe nouvelle. 
land und veröffentlichte 1928 sein Buch »La Confiance en l'Allemagne? «09. "Plus encore qu'un choc d'intérêts«, so leitete d'Ormesson seine Überlegungen ein, 》le conflit franco-allemand est un choc d'opinions «. ${ }^{310}$ Ausgehend von einem Artikel in der Germania, in dem der Verfasser von den Franzosen mehr Vertrauen zu Deutschland gefordert hatte ${ }^{311}$, griff d'Ormesson die Punkte auf, die seiner Meinung nach beide Länder trennten. Dabei sah er in der politischen Berichterstattung ein zentrales Hindernis für die Beseitigung des gegenseitigen Mißtrauens. Eine objektive und seriöse Berichterstattung fiel seiner Meinung nach dem Zwang zu hohen Auflagenzahlen zum Opfer. Wie Viénot war auch d'Ormesson davon überzeugt, daß die verbreiteten Halbwahrheiten und Tendenzberichte auf beiden Seiten zu Verbitterung und Haß führten und dadurch eine ernsthafte Gefahr für den Frieden darstellten ${ }^{312}$. Um diesen Zustand zu beenden, schlug d'Ormesson zwei Maßnahmen vor: zum einen sollten höhere Standards für den Beruf des Journalisten eingeführt werden, den nur eine intellektuelle und moralische Elite ausüben sollte. Zum anderen empfahl er die Schaffung eines Internationalen Pressegerichtshofes in Genf, von dem Falschmeldungen mit Sanktionen bestraft werden sollten ${ }^{313}$.

Das Buch d'Ormessons entstand zwischen November 1927 und Februar 1928, und Viénot war während dieser Zeit eng an d'Ormessons Überlegungen beteiligt. Er versorgte ihn mit Hintergrundinformationen über die Situation in Deutschland sowie mit Zeitungsartikeln und verfaßte ausführliche Notizen, die er seinem Freund zur Verfügung stellte. Eine Passage zur schon erwähnten Blun-Affäre wurde ebenso auf seinen Vorschlag hin eingefügt wie ein Abschnitt zur deutschen Jugendbewegung. Später las Viénot das Manuskript Korrektur und fuhr selbst zum Château d'Ormesson, um Änderungen zu besprechen $^{314}$. Das Buch, so berichtete er seiner Mutter, sei am Ende ebenso von ihm wie von d'Ormesson ${ }^{315}$. Viénot bemühte sich zudem um eine deutsche Übersetzung. Doch signalisierte ihm Friedrich Sieburg, den er zu diesem Zweck konsultierte, daß das Buch in Deutschland keine ausreichende Leserschaft finden würde $^{316}$. Gleichzeitig bat Viénot Schlumberger, dieser solle seinen Einfluß beim

${ }^{309}$ Wladimir d'ORMESSON, La confiance en l'Allemagne?, Paris ${ }^{10} 1928$ (Les documents bleus, 43). Zunächst erschien das Werk als Artikelserie in La Revue de Paris. Vgl. DERS., La confiance en Allemagne?, in: La Revue de Paris 35 (1928) S. 27-57, S. 363-377 und S. 564595. Es erschien auch in deutscher Ubersetzung unter dem Titel: Vertrauen zu Deutschland?, Berlin 1929.

${ }^{310}$ DERS., La confiance, S. 7.

311 Vgl. Die deutsch-französischen Beziehungen im Lichte der Weltpolitik, in: Germania, 26.1.1927.

${ }^{312}$ Vgl. d'ORMESSON, La confiance, S. 34-53.

${ }^{313}$ Vgl. ibid. S. 53ff.

${ }^{314} \mathrm{Vgl}$. Viénot an d'Ormesson, 6.1.1928 und ders. an dens., 22.2.1928: NL d'Ormesson II; BERTAUX, Un normalien à Berlin, S. 198.

${ }^{315} \mathrm{Vgl}$. Viènot an seine Mutter, 9.1.1928: NL Viénot.

${ }^{316}$ Vgl. ders. an d'Ormesson, 14.4.1928: NL d'Ormesson II. 
Gallimard-Verlag geltend machen, damit d'Ormessons Buch besser vermarktet werde ${ }^{317}$. Der Erfolg stellte sich schließlich ein, als es am 17. November 1928 den erstmals vergebenen politischen Preis der von Louise Weiss herausgegebenen Zeitschrift L'Europe nouvelle erhielt ${ }^{318}$. Eine begeisterte Aufnahme von d'Ormessons Vorschlägen in der französischen Öffentlichkeit blieb jedoch aus.

Die von d'Ormesson in Verbindung mit Viénot propagierten Maßnahmen zur Pressepolitik wurden zum Kern einer von beiden lancierten Initiative, mit der sie dem Studienkomitee neuen Schwung verleihen wollten. In der Plenarsitzung in Baden-Baden im Juli 1928 hielt d'Ormesson einen Vortrag zum »Problème de l'information internationale ${ }^{319}$, in dem er eine enge Beziehung zwischen der Form der Berichterstattung und der Friedenssicherung herstellte. Die Bedeutung der Presse resultierte in den Augen d'Ormessons aus ihrer Funktion als Vermittler von zwischenstaatlicher Kommunikation ${ }^{320}$. Je nachdem, in wessen Händen sich dieses Propagandamittel befinde, könne es zum Nutzen oder zum Schaden der Allgemeinheit eingesetzt werden. In einer Demokratie sollte nach Ansicht d'Ormessons die Presse ein Instrument der intellektuellen und moralischen Erziehung der Massen sein und einen Beitrag zur Friedenssicherung leisten $^{321}$. Bereits im Februar 1927 hatte das Mayrisch-Komitee die Gründung einer Pressekommission beschlossen, der auch d'Ormesson angehörte. Doch der Journalist wünschte weit mehr als die regelmäßigen Treffen, er forderte grundsätzliche Veränderungen in der Presselandschaft. Dazu gehörte eine bessere Ausbildung und Bezahlung der Journalisten, aber auch gesetzgeberische Maßnahmen gegen falsche Presseberichte. D'Ormesson wollte das Problem über den deutsch-französischen Rahmen hinaus behandelt sehen und schlug die Durchführung einer internationalen Konferenz zu Fragen der Berichterstattung vor, die in Genf unter Ägide des Völkerbundes veranstaltet werden sollte. Dies war als erster Schritt zu einer Institutionalisierung gedacht, an deren Ende eine anerkannte internationale Gerichtsbarkeit zu Pressefragen stehen sollte. D'Ormesson faßte dabei die Schaffung einer internationalen Journalistenkommission ins Auge, die, gleich einem Tribunal, Falschberichte verurteilen sollte. Er erhoffte sich dadurch eine neue Ethik der Berichterstattung.

Das Studienkomitee sollte nach dem Willen d'Ormessons die treibende Kraft dieser Initiative werden. Es sollte in Zusammenarbeit mit dem deutschen

${ }^{317}$ Vgl. ders. an Schlumberger, 3.8.1928: BLJD, Fonds Schlumberger, Ms 18341.

${ }^{318}$ Vgl. Louise WeIss, Mémoires d'une Européenne, Bd. 2, Combats pour l'Europe 19191934, Paris 1970, S. 278; BERTIN, Louise Weiss, S. 201.

${ }^{319} \mathrm{Vgl}$. Wladimir d'Ormesson, Le problème de l'information internationale. Son importance - ses solutions, in: Bericht über die sechste Vollversammlung des Deutsch-Französischen Studienkomitees in Baden-Baden, 4.-6.7.1928, S. 35-60: NL d'Ormesson III, Documentation 1926-1932. Der Text wurde anschließend auch in einem Buch veröffentlicht: DERS., Pour la Paix, Paris 1929, S. 15-62.

${ }^{320}$ Vgl. DERS., Le problème, S. 35.

${ }^{321}$ Vgl. ibid. S. 44. 
und dem französischen Außenministerium jährlich einen bilateralen Journalistenaustausch organisieren, damit die Pressevertreter ihre Kenntnisse über das Gastland verbessern könnten. Darüber hinaus sollte es die Regierungen beider Länder zu einem verstärkten Studentenaustausch animieren, der aus finanziellen und personellen Gründen nicht vom Komitee selbst durchgeführt werden konnte. Schließlich schlug d'Ormesson ein deutsch-französisches Pressegericht zur Verurteilung falscher Nachrichten über das andere Land vor, das als erster Schritt hin zu einem Internationalen Gerichtshof in Genf errichtet werden sollte. Die geplante Kommission sollte paritätisch mit mindestens zwölf deutschen und französischen Journalisten besetzt sein, die von den nationalen Pressevereinigungen ernannt würden. Sie sollte sich zweimal jährlich abwechselnd in Deutschland und Frankreich treffen, um sich über aktuelle Probleme der Berichterstattung auszutauschen und konkrete Falschmeldungen zu verurteilen ${ }^{322}$.

Die Ideen d'Ormessons waren eng mit Viénot abgesprochen. Dieser las nicht nur erneut das Manuskript Korrektur, sondern drängte auch auf die Hervorhebung einzelner Fragen, nämlich der Rolle von demokratischem System und allgemeinem Wahlrecht für die Bedeutung der Presse, des Problems der journalistischen Unabhängigkeit sowie der Stellung des Journalisten bei seiner Zeitung $^{323}$. Nach der Plenarsitzung vom Juli 1928 liefen die Anstrengungen des Komitees auf die Schaffung einer deutsch-französischen Journalistenkommission hinaus. Viénot führte Gespräche mit dem Komiteemitglied Franz von Papen und deutschen Journalistenvereinigungen zur Vorbereitung auf ein geplantes deutsch-französisches Journalistentreffen in Heidelberg ${ }^{324}$. Gleichzeitig erfuhr er von einem ähnlichen Projekt belgischer Journalisten, die mit Kollegen vornehmlich der politischen Linken eine französisch-belgisch-deutsche Pressevereinigung zur Verbesserung falscher Nachrichten ins Leben rufen wollten. Die Tatsache, daß es sich hier um eine Vereinigung handelte, die stark nach links tendierte, raubte ihr in den Augen Viénots jeglichen Wert. Sein Ziel war es, gerade die rechten Zeitungen zu größerer Objektivität anzuhalten. In bezug auf das geplante Projekt sah er jetzt raschen Handlungsbedarf, da die konservative Presse von der geplanten linken Vereinigung abgeschreckt werden und ihre Teilnahme verweigern könnte ${ }^{325}$. Im Auswärtigen Amt wurden Viénot die Pläne der Belgier bestätigt, allerdings bevorzugte man hier das Deutsch-Französische Studienkomitee als Partner für eine derartige Unternehmung ${ }^{326}$. Daß die Bemühungen Viénots um eine objektive Berichterstattung nicht wirkungslos waren, bewies ihm Botschafter de Margerie. Dieser zeigte sich sehr interessiert an dem Projekt und erklärte Viénot, in seiner Korrespondenz mit dem

${ }^{322} \mathrm{Vgl}$. ibid. S. $55 \mathrm{f}$.

${ }^{323} \mathrm{Vgl}$. Viénot an d'Ormesson, 23.6.1928: NL d'Ormesson II.

${ }^{324} \mathrm{Vgl}$. ders. an dens., 24.9.1928: NL d'Ormesson II.

${ }^{325} \mathrm{Vgl}$. ders. an dens., 26.9.1929: NL d'Ormesson II.

${ }^{326} \mathrm{Vgl}$. ders. an dens., 27.9.1929 und ders. an dens., 8.10.1929: NL d'Ormesson II 
Quai d'Orsay habe er nun auch eine Rubrik zu falschen Presseberichten eröffnet, deren markanteste Fälle er regelmäßig schildere ${ }^{327}$.

Auf der Sitzung des Exekutiv-Komitees in Luxemburg im Dezember 1928 wurden die Mitglieder ausgewählt, die sich künftig um das Journalistenprojekt kümmern sollten. Auf französischer Seite waren dies d'Ormesson und Arthur Fontaine, auf deutscher Seite von Papen und Oberndorff. D'Ormesson und Krukenberg sollten einen Programmentwurf gestalten, über den sie sich jedoch offensichtlich nicht einigen konnten. Aus diesem Grund nahm sich Viénot zusammen mit von Papen der Sache an. Das Konzept war jedoch nur als Diskussionsgrundlage gedacht, auf deren Basis die eingeladenen Journalisten dann selbst ein Projekt entwickeln und gestalten sollten ${ }^{328}$. Während Viénot auf baldige Durchführung drängte, wollte Krukenberg das Pressetreffen ohne Angabe von Gründen auf Oktober verschieben. Viénot sah sich nun mit einer »résistance passive du groupe allemand ${ }^{329}$ konfrontiert und wollte eine präzise Aussage von deutscher Seite zur Zukunft des Projektes provozieren. Obwohl er bei den deutschen Komiteemitgliedern noch nie viel Enthusiasmus für die Initiative festgestellt hatte, sah Viénot bei Krukenberg, der in seinen Augen immer weiter nach rechts tendierte, das Desinteresse vor allem innenpolitisch motiviert. Auf französischer Seite erblickte auch Charles Laurent keinen akuten Handlungsbedarf. Die Zusammenarbeit zwischen dem Komitee und den Journalisten schätzte er als schwierig und die Standpunkte als zu verschieden ein ${ }^{330}$. Mitte Mai 1929 zeichnete sich somit ziemlich deutlich das endgültige Scheitern der Initiative $\mathrm{ab}$, die d'Ormesson und Viénot knapp ein Jahr vorher lanciert hatten. Viénot interpretierte Laurents Verhalten als bekanntes Muster: „Dès l'instant où il s'agit de ne rien faire, on est toujours sûr de le trouver fidèle à luimême. ${ }^{331}$ Das Presseprojekt scheiterte jedoch nicht nur am Unwillen Krukenbergs und Laurents, sondern auch an den schwierigen äußeren Umständen. Zum einen rückten nun die deutsch-französischen Reparationsverhandlungen ganz und gar ins Zentrum des Interesses und zum zweiten befand sich das Komitee zu diesem Zeitpunkt gerade in einer existentiellen Krise und war vornehmlich mit inneren Angelegenheiten beschäftigt. Eine kraftvolle Aktion, die es gebraucht hätte, um ein deutsch-französisches Presseprojekt ins Leben zu rufen, konnte Mitte 1929 nicht mehr geleistet werden. Viénot konstatierte angesichts der angespannten deutsch-französischen Beziehungen eine Rückkehr zu alten Feindbildern und sah den Erfolg der Verständigungsbemühungen grundsätzlich in Frage gestellt: »[...] j'estime que l'abîme entre les opinions publiques française et allemande et les conceptions des deux pays, est actuellement

${ }^{327}$ Vgl. ders. an dens., 10.10.1929: NL d'Ormesson II.

${ }^{328}$ Vgl. ders. an Fontaine, 16.4.1929: NL d'Ormesson II.

${ }^{329}$ Ders. an d'Ormesson, 2.5.1929: NL d'Ormesson II.

${ }^{330} \mathrm{Vgl}$. Laurent an Viénot, 8.5.1929: NL d'Ormesson II.

${ }^{331}$ Viénot an d'Ormesson, 14.5.1929: NL d'Ormesson II. 
presqu'aussi profond qu'au temps de la Ruhr et que les quelques ponts jetés sur cet abîme sont en train de s'effondrer. ${ }^{332}$

Freundschaften und Beziehungen:

Das Ehepaar Viénot in der Berliner Gesellschaft

Viénots Büro in Berlin war nicht nur eine Verständigungsagentur, sondern von Beginn an auch ein gesellschaftlicher Treffpunkt. Aus der Korrespondenz Viénots geht die Bedeutung dieser informellen Gespräche für die deutschfranzösischen Kontakte hervor, die sich jenseits offizieller Depeschen in den Berliner Salons abspielten. Das Gewicht Viénots als offiziöser Mittler zwischen beiden Ländern resultierte in überwiegendem Maße aus seinen persönlichen Kontakten mit führenden Persönlichkeiten. Bei der Herstellung dieser Verbindungen waren ihm die kulturellen Treffpunkte der Hauptstadt besonders hilfreich. Bereits im Mai 1925 hatte sich Viénot mit zwei Empfehlungsschreiben, einem von Rainer Maria Rilke und einem zweiten von Hugo von Hofmannsthal, beim Ehepaar von Nostitz vorgestellit ${ }^{333}$. Helene von Nostitz, die Frau des späteren Vorsitzenden der deutschen Komiteesektion, war eine Nichte des Reichspräsidenten von Hindenburg und führte ein mondänes Haus. $\mathrm{Zu}$ ihren Freunden gehörten Hofmannsthal und Rilke ebenso wie Harry Graf Kessler und der Bildhauer Rodin. Viénot wurde von ihr freundlich aufgenommen, und sie schätzte an ihm »das überschäumende Gefühl, das überall herausbricht und doch voller sretenuer ist«. ${ }^{334}$ Weiterhin profitierte Viénot auch von den Kontakten Antonina Vallentins, der Chefredakteurin der Zeitschrift Nord und Süd und nachdrücklichen Befürworterin von Stresemanns Verständigungspolitik, bei der Viénot "tout Berlin « antraf $^{35}$. Der Bedeutung der Frauen für die Unterhaltung gesellschaftlicher Kontakte war sich Viénot auch bei seiner ersten Reise in die deutsche >Provinzı, nach Frankfurt, bewußt. Er besuchte Werner von Schnitzler, wune personne importante de l'industrie chimique - intelligent et de second

${ }^{332}$ Ders. an de Peyerimhoff, 23.4.1929: NL d'Ormesson II.

${ }^{333}$ Hofmannsthal hatte Nostitz auch Viénots Artikel über die République allemande et Allemagne nationale zugesandt, den er als meinen Versuch von seltener Ernsthaftigkeit $\mathrm{u}$. candeur finde[t], französischerseits dem Sinn der deutschen schwierigen Evolution nahezukommen «. Hugo von HOFMANNSTHAL, Helene von NOSTITZ, Briefwechsel, Frankfurt a.M. 1965, S. 156.

${ }^{334}$ Oswalt von NoSTITZ, Muse und Weltkind. Das Leben der Helene von Nostitz, München, Zürich 1991, S. 322. Vgl. auch Helene von NosTITZ, Aus dem alten Europa. Menschen und Städte, hg. von Oswalt von NosTITZ, Frankfurt a.M., Leipzig 1993.

${ }^{335} \mathrm{Vgl}$. Viénot an seine Mutter, 17.11.1926: NL Viénot. Antonina Vallentin (1893-1957) leitete seit 1927 die Zeitschrift Nord und Süd, lebte seit 1929 in Paris, wo sie den Direktor des Internationalen Instituts für geistige Zusammenarbeit, Julien Luchaire, heiratete. 1930 setzte sie Stresemann ein Denkmal mit ihrer Biographie: Antonina VallENTIN, Stresemann. Vom Werden einer Staatsidee, Leipzig 1930. Vgl. Kurt KOSZYK, Nord und Süd. Ein elitäres Friedens-Forum, in: Michel GRUNEWALD, Hans Manfred BocK (Hg.), Le discours européen dans les revues allemandes (1918-1933), Bern u.a. 1997, S. 15-34. 
plan. C'est la femme qui compte« ${ }^{336}$ Lily von Schnitzler führte >den Salon Frankfurts und unterstützte zusammen mit ihrem Mann den Europäischen Kulturbund Karl Anton Rohans. Darüber hinaus stand Pierre Viénot auch mit der französischen Botschaft in engem Kontakt, bei deren Empfängen sich die französische Kolonie in Berlin traf. Viénot, der sich mit gewohntem Selbstbewußtsein als »l'un des plus brillants membres de ladite colonie ${ }^{337}$ oder als »le membre le plus éminent « ${ }^{338}$ bezeichnete, gehörte regelmäßig zu ihren Gästen.

Durch seine berufliche Position und seine persönlichen Kontakte wurde Viénot selbst bald zum gesellschaftlichen Ereignis. Er führte "une vie follement agitée«, in dem »tout Berlin défile «. ${ }^{339} \mathrm{Zu}$ seinen Gästen zählten unter anderem die Politiker Yvon Delbos, Paul Reynaud ${ }^{340}$, Georges Bonnet und Adolf Reichwein, der Journalist Fernand de Brinon, der Schriftsteller Gabriel Marcel sowie die Professoren Henri Lichtenberger, Alfred Weber und Ernst Robert Curtius. Eine besonders tiefe Wertschätzung empfand Viẻnot für den preußischen Kultusminister Carl Heinrich Becker ${ }^{341}$, den er Anfang Februar 1927 kennenlernte. Becker galt als wheimlicher Reichskulturminister ${ }^{342}$ und hatte im Juli 1925 einen entscheidenden Beitrag zur Wiederaufnahme der deutsch-französischen Kulturbeziehungen geleistet, als er seinen französischen Amtskollegen, den Erziehungsminister Anatole de Monzie, zu einem Besuch in Berlin empfangen hatte. Viénot erblickte in Becker einen Seelenverwandten, von dem er sich intellektuelle Anregung ebenso erhoffte wie seelische Unterstützung, um dem Gefühl der Einsamkeit zu entkommen, unter dem er bisweilen stark litt ${ }^{343}$. Becker setzte sich in seiner Amtszeit für neue Wege in der Erziehung und Bildung ein, für die sich Viénot im Zusammenhang mit Jugendbewegung und neu zu gestaltender staatlicher und gesellschaftlicher Ordnung brennend interessierte $^{344}$. Nach dem Ausscheiden Beckers aus dem Kultusministerium 1930 drückte ihm Viénot sein Bedauern darüber aus. Becker hatte in seinen Augen Deutschland geholfen, dem Chaos zu entkommen und seine neue Form zu

${ }^{336}$ Viénot an d'Ormesson, 23.11.1926: NL d'Ormesson II.

${ }^{337}$ Ders. an seine Mutter, 31.12.1927: NL Viénot.

${ }^{338}$ Ders. an seinen Vater, 15.7.1928: NL Viénot.

${ }^{339}$ Ders. an d'Ormesson, 22.5.1928: NL d'Ormesson II.

${ }^{340}$ Viénot vermittelte Reynaud im April 1929 Gespräche mit Hesnard und Botschafter de Margerie. Vgl. GRUNER, Paul Reynaud, S. 164f.

${ }^{341}$ Zu Carl Heinrich Becker (1876-1933) vgl. Erich WENDE, C. H. Becker. Mensch und Politiker, Ein biographischer Beitrag zur Kulturgeschichte der Weimarer Republik, Stuttgart 1959; Guido MULLER, Weltpolitische Bildung und akademische Reform. Carl Heinrich Beckers Wissenschafts- und Hochschulpolitik 1908-1930, Köln, Wien 1991 (Beiträge zur Geschichte der Kulturpolitik, 2). Siehe auch DERS. (Hg.), Carl Heinrich Becker. Internationale Wissenschaft und nationale Bildung, Ausgewählte Schriften, Köln 1997 (Studien und Dokumentationen zur deutschen Bildungsgeschichte, 64)

${ }^{342}$ Zit. nach Hans Manfred Bock, Zwischen Locamo und Vichy, S. 34.

${ }^{343} \mathrm{Vgl}$. Viénot an seine Mutter, o.D. [Anf. Feb. 1927]: NL Viénot.

344 Siehe dazu näher Kap. IV.2.2. 
finden. Darüber hinaus symbolisierte er das Deutschland, das Viénot liebte. Seine Präsenz an der Spitze des Ministeriums bedeutete für Viénot

la raison pour laquelle j'aimais l'Allemagne; elle était le symbole de ce que j'aimais en Allemagne, et cela aussi bien du point de vue des relations franco-allemandes que par la joie toute simple, toute spontanée et personnelle, que j'éprouvais, rein menschlich, à voir l'Allemagne, en adhérant à vous, adhérer aux valeurs qui me sont les plus chères ${ }^{345}$.

Nach Beckers Tod 1933 würdigte Viénot seinen Freund in einem Nachruf in $L$ 'Europe nouvelle als "l'un des plus nobles et des plus courageux représentants des meilleurs traditions intellectuelles et morales de l'Allemagne «. ${ }^{346}$

Eine entscheidende Freundschaft für Viénot nahm ebenfalls in seiner Berliner Zeit ihren Ausgangspunkt, und zwar die zu dem zehn Jahre jüngeren Germanistikstudenten Pierre Bertaux. Durch ihn erweiterte sich Viénots Bekanntenkreis vor allem zur literarisch-kulturellen Seite hin. Der Sohn des bekannten Germanisten Félix Bertaux, der regelmäßig deutsche Literatur für die Nouvelle Revue française besprach und Heinrich Mann 1923 bei den Dekaden von Pontigny eingeführt hatte, verbrachte 1927/28 ein Austauschjahr an der HumboldtUniversität und war für den Romanisten Eduard Wechssler als Lektor tätig. Bertaux, der als Student der École normale supérieure und Stipendiat der Humboldt-Stiftung in Berlin Aufsehen erregte, hatte einen privilegierten Beobachterposten in der Hauptstadt ${ }^{347}$. Über den Vater kannte er die Verlegerfamilie Samuel Fischer, die ihm in Berlin zum Bezugspunkt wurde und in deren unmittelbarer Nähe er wohnte. Über sie wurde er nicht nur in die literarische Welt der Hauptstadt eingeführt ${ }^{348}$, sondern auch in die deutsch-französischen Kommunikationszirkel der Helene von Nostitz und Antonina Vallentin, wo er alsbald Viénot kennenlernte. Die Freundschaft mit Viénot, in dem er vor allem

${ }^{345}$ Ders. an Becker, 13.2.1930: GStA PK, NL Becker, 2616.

${ }^{346}$ DERS., Mort de M. C.-H. Becker, ancien ministre de l'Instruction publique en Prusse, in: L'Europe nouvelle, 18.2.1933, S. 151

${ }^{347}$ Die Anwesenheit eines französischen Studenten war derart außergewöhnlich, daß Bertaux zur Sensation in Berlin wurde. Die Briefe Bertaux', die er während dieser Zeit an seine Eltern schrieb, wurden vor kurzem vollständig veröffentlicht. Vgl. BERTAUX, Un normalien à Berlin. Vorher sind Auszüge daraus erschienen: Pierre BERTAUX, Un étudiant français à Berlin (Hiver 1927-1928), in: La Revue d'Allemagne 14 (1982) Nr. 2, S. 337-350. Diese Auszüge wurden auch ins Deutsche übersetzt: DERS., Ein französischer Student in Berlin, in: Sinn und Form 35,1 (1983) S. 314-327 und in: Berliner Begegnungen. Ausländische Künstler in Berlin 1918-1933, Berlin (Ost) 1987, S. 239-254.

Golo Mann, mit dem sich Bertaux anfreundete, beschrieb in seinen Memoiren den immensen Erfolg Bertaux', um den sich die Leute geradezu rissen. Vgl. Golo MANN, Erinnerungen und Gedanken. Eine Jugend in Deutschland, Frankfurt a.M. 1986, S. 234.

${ }^{348}$ Zu Bertaux' Bekannten in Berlin zählten Gerhard Hauptmann, Alfred Kerr, Jakob Wassermann, Alfred Döblin, Hermann Bahr und Walter Benjamin. Mit Heinrich Mann war die Familie befreundet, und auch Thomas Mann, Joseph Roth, Max Rycher und Emst Bloch zählten zu ihren Gästen. Vgl. Pierre BERTAUX, Wie ich Germanist wurde, in: Siegfried UNSELD ( $\mathrm{Hg}$.), Wie, warum und zu welchem Ende wurde ich Literaturhistoriker?, Frankfurt a.M. 1972, S. 27-38, hier S. 32f. 
einen großzügigen Charakter erblickte, sei »décisive et déterminante pour le cours de mon existence ${ }^{349}$ gewesen. Obwohl Bertaux, der sein Leben lang zwischen Wissenschaft und Politik hin- und herwechselte, eine andere berufliche Laufbahn einschlug als Viénot, war ihm doch dessen Konzeption als ein >Intellektueller der Tatı das bestimmende Vorbild.

Auch das Haus der Fischers selbst war ein kultureller Mittelpunkt Berlins, in den Viénot - und mit ihm sein Freund Roland de Margerie - über Bertaux Einzug fand. Die Verlegertochter Brigitte, genannt Tutti, schildert das elterliche Domizil als Treffpunkt europäischer Eliten:

Ein Kreis von jüngeren Schriftstellem und Künstlern scharte sich um uns: Carl Zuckmayer, Kurt Heuser, Alexander Lernet-Holenia, Manfred Hausmann, Joachim Maass, Joseph Roth, Klaus Mann, Enst Toller, Walther Mehring, Erwin Piscator, der in der Berliner Volksbühne ein modernes Theater für die jungen Dramatiker schuf. Schriftsteller aus aller Herren Länder, besonders aus Frankreich kamen zu uns: Jean Giraudoux, Jean Richard Bloch, René Crevel, Pierre Bertaux, Pierre Viénot, Raymond Aron ${ }^{350}$.

Während des Berlin-Besuchs von André Gide im Januar 1928 waren Viénot und Bertaux die Ansprechpartner des Schriftstellers. Anläßlich einer Abendgesellschaft, die Viénot veranstaltete, traf Gide mit Harry Graf Kessler zusammen und las aus seinem $»$ Enfant prodigue ${ }^{351}$. An der Korrektur der Prinzhorn-Übersetzung der »Nourritures terrestres" ins Deutsche war neben Jean Schlumberger auch Viénot beteiligt ${ }^{352}$, und für die Übersetzung von "Corydon« vermittelte Viénot seinem Freund den ehemaligen Französisch-Lektor von Ernst Robert Curtius, Henri Jourdan. Weiterhin bemühte sich Viénot, anläßlich des 60. Geburtstags von Gide, dessen "Saül« in Berlin aufführen zu lassen. Vorgespräche mit Max Reinhardt scheiterten zwar, aber Ende 1929 zeichnete sich eine Zusammenarbeit mit Jürgen Fehling vom Berliner Staatlichen Schauspielhaus ab. Werner Krauss sollte die Rolle des "Saül« übernehmen. Viénot wollte bei dieser Unternehmung jedoch hinter den Kulissen bleiben und nicht als Direktor des Studienkomitees in Erscheinung treten. Max Clauss war für die Finanzienung zuständig ${ }^{353}$. Während Andrée Mayrisch bei ihrer Mutter um finanzielle Unterstützung bat, hatte Viénot eine Hilfszusage von seiten der französischen Botschaft erwirkt. Die politischen Realitäten machten aber auch vor

${ }^{349}$ BERTAUX, Un étudiant, S. 338.

${ }^{350}$ Brigitte B. FISCHER, Sie schrieben mir oder was aus meinem Poesiealbum wurde, München ${ }^{17} 1998$, S. 174.

${ }^{351}$ Vgl. Eintrag vom 19.1.1928, in: Harry Graf KESSLER, Tagebücher 1918-1937, hg. von Wolfgang PFEIFFER-BELLI, Frankfurt a.M., Leipzig 1996 (Erstausgabe 1966), S. 589.

${ }^{352}$ So berichtete Schlumberger am 14.10.1929 André Gide: "Je trouve ici Viénot que l'éditeur allemand, Deutsche Verlagsanstalt, bombarde de télégrammes pour obtenir qu'il corrige, d'accord avec Prinzhorn (qui est en Amérique!) les épreuves des Nourritures. Cette traduction est décidément médiocre, avec des vrais contresens ou des paraphrases tendancieuses [...] «. André GDE, Jean SCHLUMBERGER, Correspondance 1901-1950, hg. von Pascal MERCIER und Peter FAWCETT, Paris 1993, S. 822

${ }^{353} \mathrm{Vgl}$. Andrée Viénot an ihre Mutter, 17.11.1929: NL Viénot. 
dem Kulturleben nicht halt, und Viénot mußte feststellen, daß das negative Echo einer Deutschlandrede André Tardieus zum Problem der Rheinlandräumung auch die Chancen der geplanten Aufführung verschlechterten ${ }^{354}$. Anfang Dezember wurde klar, daß die Auffuhrung nicht mehr in diesem Jahr stattfinden würde, die Verhandlungen zogen sich in die Länge, und das Auffuihrungsdatum blieb im Ungewissen ${ }^{355}$.

Die Beziehungen, die Viénot während seiner Berliner Zeit zu Politikern, Diplomaten, Künstlern und Literaten knüpfte, wurden ergänzt durch die Kontakte seiner späteren Frau, die sich 1925/26 ebenfalls in Berlin aufhielt, um dort bei Professor Gustav Mayer eine Doktorarbeit vorzubereiten ${ }^{356}$. Aufgrund ihrer Herkunft war es für Andrée Mayrisch nicht schwierig, in Berlin Fuß zu fassen. Von Anfang an verkehrte sie regelmäßig bei Helene von Nostitz, über deren Gäste sie bisweilen recht sarkastische Berichte nach Hause schrieb: „Le soir, je sors parfois avec le Spanferkel qui me montre >Berlin bei Nachts. Cela me repose de l'intimidation maladive que me cause l'élite intellectuelle. ${ }^{357}$ Trotz ihrer großbürgerlichen Familie gehörte das Hauptinteresse der Mayrisch-Tochter dem Sozialismus. Im Seminar von Mayer hielt sie ein Referat über »Die Entwicklung der marxistischen Krisentheorie, an Hand des Briefwechsels MarxEngels ${ }^{358}$ Über Pierre Viénot ließ sie sich mit Rudolf Breitscheid bekannt machen. Daneben widmete sie sich der Vielzahl von gesellschaftlichen Bewegungen, die im Berlin der zwanziger Jahre anzutreffen waren. So nahm sie an der "Akademischen Arbeitswoche der Gesellschaft für religiösen Sozialismus" ebenso teil wie am Kostümfest eines »club futuriste ${ }^{359}$. Sie besuchte eine Gruppe der Wandervögel und einen Maler aus ihrem Bekanntenkreis:

Milieu >Reform ( (gymnastique rhythmique + végétarisme). L'hôte prêche sur die Seele et das Schicksal + fait de la mauvaise peinture. Rentrée à pied avec $\mathbf{M}^{\mathrm{me}}$ de Nostitz, qui m'a longuement expliquée, sdass das doch nicht erstklassige deutsche Geistigkeit sei ${ }^{360}$.

Die Freundschaft, die sich zwischen Viénot und Andrée Mayrisch in dieser Zeit entwickelte, führte am 18. Juli 1929 schließlich zur Heirat der beiden.

${ }^{354}$ Vgl. zum Verhältnis Viénot-Gide und zu ihrer Korrespondenz im Jahre 1929 BoCK, Pierre Viènot, der Deutschland-Kenner, S. 201; DERS., Pierre Viénot, un médiateur, S. 260. Zur geplanten Aufführung vgl. Andrée Mayrisch an ihre Mutter, 17.11.1929: NL Viénot. Zu André Tardieu vgl. François MONNET, Refaire la République. André Tardieu, une dérive réactionnaire (1876-1945), Paris 1993.

${ }^{355} \mathrm{Vgl}$. Viénot an Gide, 26.11.1929 und 7.12.1929: NL Gide.

${ }^{356}$ Der Kontakt kam durch die Vermittlung von Bernhard Groethuysen zustande, einem Freund der Familie Mayrisch und einer Zentralgestalt der Dekaden von Pontigny. Vgl. Tony BOURG, Jean-Claude MULLER, Un ami allemand d'André Gide: Bernard Groethuysen (1880-1946), in: Hans T. SIEPE, Raimund THEIS (Hg.), André Gide und Deutschland, Düsseldorf 1992, S. 181-193.

${ }^{357}$ Andrée Mayrisch an ihre Mutter, 25.10.1925: NL Viénot.

${ }^{358}$ Dies. an dies., 14.11.1925: NL Viénot.

${ }^{359}$ Dies. an dies., 25.10.1925 und 14.11.1925: NL Viénot.

${ }^{360}$ Dies. an dies., 23.1.1926: NL Viénot. 
Dabei ergänzten sie sich bezüglich ihrer Interessen und Schwerpunkte. Viénot blieb trotz seiner Tätigkeiten in der Politik stets ein Intellektueller, der auch die politischen Gegebenheiten von einem eher theoretischen Standpunkt aus betrachtete. Andrée Mayrisch hingegen war zwar stets stark politisch interessiert und in ihrem politischen Standpunkt auch dezidierter als Viénot, dies jedoch mit einer viel stärkeren Orientierung zur Praxis. Die sozial engagierte Frau nahm Viénot zum ersten Mal mit in eine Fabrik, wo dieser sich schockiert von den Lebensbedingungen der Arbeiter zeigte ${ }^{361}$. Nach ihrer Hochzeit partizipierte Andrée Mayrisch an der "grande mondanité ${ }^{362}{ }^{2}$, zu der sie als Frau des Direktors der bedeutendsten Verständigungsorganisation in der Hauptstadt verpflichtet war. Ihre wahren Interessen lagen jedoch woanders, und so schickte sie ketzerische Briefe über gesellschaftliche Ereignisse an ihre Mutter, aus denen scharfe Beobachtungsgabe und trockener Humor gleichermaßen sprechen:

Enfin, aujourd'hui, lunch chez les von Stauss. Il y avait, comme cendriers, les souliers galvanisés de la grand'mère à 3 ans. Il y avait parmi les hôtes un monsieur avec le Eisernes Kreuz I. Kl., un monocle, des Schmisse, et un col montant; 2 enfants d'ailleurs jolis qui claquent les talons en disant bonjour; un rgrand avocat qui dit swenn man wie ich einer der bedeutendsten Juristen Deutschlands ist،. On s'est promené dans un yacht sur lequel même les cigarettes portaient le nom du bateau, en facsimilé de l'écriture du propriétaire; le fils aîné est le filleul de Ferdinand de Bulgarie, lequel revient dans la conversation toutes les heures (sans doute la Deutsche Bank lui a-t-elle autrefois prêté de l'argent). On s'est réconforté en pensant qu'il y a encore des gens pareil ${ }^{363}$

Mehr am Herzen lag Andrée Mayrisch eine Studie zur Arbeiter- und Erwachsenenbildung, für deren Durchführung sie Kontakte zu sozial- und bildungsreformerischen Kreisen suchte. So stand sie in verstärktem und freundschaftlichem Austausch mit dem Sozialdemokraten Adolf Reichwein, der ihr bei ihrer Arbeit über die Volkshochschulen behilflich sein wollte ${ }^{364}$. Ferner suchte sie Gertrud Hermes in Leipzig auf, die Mitarbeiterin des Staatsrechtlers Hermann Heller und Autorin eines Standardwerks zur Arbeiterbildung ${ }^{365}$. Andrée Mayrisch war beeindruckt von den sozialen Errungenschaften der jungen deutschen Republik, von den öffentlichen Bibliotheken, der Anzahl der Volkshochschulen sowie von der Internatsschule der Metallarbeitergewerkschaft für die Betriebsräte und Arbeiter-Aufsichtsräte.

Für ihre geplante Volkshochschulstudie besuchte Andrée Mayrisch wiederholt Einrichtungen der sozialistischen Arbeiterbildung. Darüber hinaus machte sie Hausbesuche zusammen mit einer Fürsorgerin und besuchte Tuberkulose-

${ }^{361}$ Viénot an seine Mutter, 25.4.1928: NL Viénot.

${ }^{362}$ Andrée Mayrisch an ihre Mutter, 14.4.1929: NL Viénot.

${ }^{363}$ Dies. an dies., 10.11.1929: NL Viénot. Das Komiteemitglied Emil von Stauss war Direktor der Deutschen Bank.

${ }^{364}$ Vgl. dies. an dies., 17.10.1929, 10.11.1929 und 17.11.1929: NL Viénot.

${ }^{365}$ Vgl. dies. an dies., 10.11.1929: NL Viénot. Vgl. auch Gertrud HERMES, Die geistige Gestalt des marxistischen Arbeiters und die Arbeiterbildungsfrage, Tübingen 1926. Andrée Mayrisch berichtet ihrer Mutter von der Lektüre des Buches: dies. an dies., 9.5.1930: NL Viénot. 
kranke $^{366}$. Ihr soziales Engagement verlieh der bekennenden Atheistin in den Augen ihrer Umwelt einen "caractère de petite sœur des pauvres catholiques«. ${ }^{367}$ Die vermögende Tochter eines der größten europäischen Industriellen verschrieb sich mit dem ihr eigenen Radikalismus der Sache des Sozialismus, empfing zu Hause Henri de Man und las mit Begeisterung Trotzkis Memoiren. 1929 spürte Andrée Mayrisch eine atmosphärische Veränderung in Deutschland im Gegensatz zu ihrem ersten Aufenthalt vier Jahre zuvor: "[...] l'Allemagne que j'aime, l'Allemagne de la Jugendbewegung, l'Allemagne ivre de devenir, de la jeunesse, de vie nouvelle, me semble reculer. ${ }^{368}$ Gleichzeitig registrierte sie eine andere Bewegung, die in der Hauptstadt nicht zu übersehen war. Im Oktober 1929 besuchten die Viénots sinkognitor eine Kundgebung der Nationalsozialisten im Sportpalast. Dabei steckten sie sich ein Hakenkreuz an und hörten Reden »de la démogagie la plus bête que j'ai jamais entendue«. ${ }^{369}$ Trotz Hetzreden, Braunhemden und Straßenschlachten hielt Andrée Mayrisch die Nationalsozialisten zu diesem Zeitpunkt nicht für gefährlich. Sie erschienen ihr eher wie eine eigentümliche, aber vergängliche Erscheinung ${ }^{370}$.

Mit dieser Unterschätzung des Nationalsozialismus war sie nicht allein. Pierre Bertaux nahm an einem Treffen von etwa 30 Schriftstellern bei den Fischers teil, bei dem der Nationalsozialismus thematisiert wurde. Keiner der Anwesenden gab ihm eine Zukunft. Nur Joseph Roth, so erinnert sich Bertaux, drückte seine Überzeugung aus, daß Verfolgung und Emigration auf die Juden zukommen werde. Die Gesellschaft reagierte geniert und wandte sich lieber wieder anderen Themen $\mathrm{zu}^{371}$.

\subsection{Konflikte innerhalb des Komitees und Viénots Ausscheiden}

Die finanzielle Organisation

Obwohl der überwiegende Teil des Studienkomitees aus Repräsentanten der Wirtschaft, Industrie oder Banken bestand, steckte die Organisation, zumindest was ihre französische Gruppe betraf, von Anfang an in Geldschwierigkeiten. Die Bereitschaft zur finanziellen Unterstützung war nur gering ausgeprägt, und aufgrund der verschiedenen Konzepte zur Lösung dieses Problems brach der Konflikt zwischen den jeweiligen Gruppen um Viénot auf der einen und Laurent auf der anderen Seite erneut aus.

${ }^{366} \mathrm{Vgl}$. Andrée Mayrisch an ihre Mutter, 2.11.1929 und 10.11.1929: NL Viénot.

${ }^{367}$ Viénot an seine Mutter, 26.4.1927: NL Viénot.

${ }^{368}$ Andrée Mayrisch an ihre Mutter, 2.11.1929: NL Viénot.

${ }^{369}$ Dies. an dies., 23.10.1929: NL Viénot.

370 Vgl. ibid.

${ }^{371}$ Vgl. Pierre BERTAUX, Mémoires interrompus, hg. von Hans Manfred BocK u.a., Asnières 2000 (Publications de l'Institut d'Allemand d'Asnières, 27), S. 83. 
Von Beginn an war geplant, das Komitee zu gleichen Teilen von beiden Sektionen durch Jahresbeiträge finanzieren zu lassen, wobei diese auf drei Jahre im voraus bereitgestellt werden sollten, um eine längerfristige Planung zu gewährleisten. Für die Unterhaltung ihres Büros und ihres Personals war jede Gruppe selbst verantwortlich ${ }^{372}$. Die französische Gruppe hatte hierfür eine Summe von 38400 Mark pro Jahr vorgesehen. Dazu kamen weitere 10000 Mark, die jährlich in den von Émile Mayrisch verwalteten Gemeinschaftsfonds eingezahlt werden sollten. Weiterhin galt es, eine Summe von 50000 Mark bis zum 1. Juli 1927 für die Unterhaltung des Komitees bereitzustellen ${ }^{373}$. Die Zahlungsmoral der französischen Sektion war jedoch nicht besonders hoch ausgeprägt. Sie zögerte, die 10000 Mark an den Gemeinschaftsfonds zu überweisen und verließ sich statt dessen auf die Großzügigkeit von Mayrisch. Viénot klagte indes kontinuierlich über ausbleibende und nicht ausreichende Schecks, die seine Arbeit ernsthaft gefährdeten. Angesichts der Tatsache, daß die deutsche Gruppe bereits ihren Beitrag für den Gemeinschaftsfonds sowie einen darüber hinausgehenden Geldbetrag eingezahlt hatte und die französische Sektion bisher gar nichts, erblickte Viénot als einzigen Ausweg aus diesem »désastre moral ${ }^{374}$ eine Subvention von seiten der französischen Regierung. Dabei hielt er eine Unterstützung von mindestens 50000 Francs für notwendig ${ }^{375}$. Viénot, der auch persönlich mit der Familie Mayrisch befreundet war, fühlte sich gegenüber dem Komiteepräsidenten besonders für die rasche Rückzahlung von dessen Kredit verantwortlich. Da die Kosten der Büroeinrichtung höher wurden als geplant und von seiner Sektion keine Zahlungen eintrafen, mußte Viénot Mayrisch jedoch erneut um Hilfe bitten ${ }^{376}$. Der Schatzmeister des Komitees, Wladimir d'Ormesson, wandte sich seinerseits hilfesuchend an Jacques Seydoux, da er es nicht vermochte, Charles Laurent zum Handeln zu überreden. Der Präsident der französischen Sektion begriff in seinen Augen nicht »que nous sommes dans une situation tragique et absolument intenable vis-à-vis de M. Mayrisch «. ${ }^{377}$ Vor der Plenarsitzung im Februar 1927 wurden dann zwar die Ausstände für den Gemeinschaftsfonds beglichen, es blieb jedoch noch immer ein Defizit von 50-60 000 Francs, für das Mayrisch

${ }^{372}$ Vgl. Pierre Viénot, Deutsch-französischer Studien- und Informierungsausschuss, in: PAAA, Botschaft Paris, DFS, Bd. 1; Réunion tenue à Luxembourg le 17 juillet 1926 par le Comité exécutif du Comité franco-allemand d'information et de documentation: MAECAD, Ambassade de France à Berlin, B, 463, d. CFAID.

${ }^{373}$ Vgl. ibid; Procès verbal de la séance du Comité exécutif du Comité franco-allemand d'Information et de Documentation tenue à Paris, le 23 Octobre 1926: NL d'Ormesson III, Séances du Comité exécutif.

${ }^{374}$ Viénot an d'Ormesson, 23.11.1926: NL d'Ormesson II.

${ }^{375} \mathrm{Vgl}$. ders. an dens., 1.12.1926: NL d'Ormesson II.

${ }^{376}$ Vgl. ders. an Mayrisch, 17.1.1927: NL d'Ormesson II.

${ }^{377}$ D'Ormesson an Seydoux, 21.1.1927: MAE, PA-AP Seydoux, 261, d. 6. 
wiederum einen Kredit gewährte ${ }^{378}$. De Peyerimhoff führte deswegen Gespräche mit Poincaré und Briand, die Druck auf die Banken ausüben sollten, damit diese das Komitee unterstützten.

Im April 1927 schickte Viénot dann einen Hilferuf an d'Ormesson. Er hatte den Scheck für den kommenden Monat noch nicht erhalten und lebte bereits vom Bankkredit. Kurz darauf drohte er an, die Möbel zu verkaufen, um sich aus seiner mißlichen Situation zu befreien, wollte aber gleichzeitig mit einer Werbeaktion den Bankrott des Studienkomitees publik machen ${ }^{379}$. Unterdessen bemühte sich Seydoux, beim Crédit lyonnais und der Union parisienne eine finanzielle Unterstützung zu erreichen. Die Spendenbereitschaft der im Studienkomitee vertretenen Banken war jedoch gering ausgeprägt, lediglich die Société générale alsacienne de Banque hatte einen Beitrag gezahlt. Der Generaldirektor des Crédit lyonnais lehnte eine Spende für das Mayrisch-Komitee $a b^{380}$. Für Seydoux stand fest, daß die Banken nur auf Druck der Regierung agieren würden. Da der Komiteegruppe zum Budgetausgleich noch immer 160000 Francs fehlten, versuchte Seydoux, Charles Laurent ein Bild von der "situation alarmante de la trésorerie du Comité franco-allemand d'Information ${ }^{381} \mathrm{zu}$ geben. Viénot unterstützte dessen Bemühungen, Laurent mit deutlichen Worten zu einer energischeren Haltung zu bringen. Seiner Ansicht nach konnte die Zahlungsunwilligkeit seiner Sektion als Desinteresse der französischen Wirtschaft an der Verständigungsarbeit interpretiert werden und sich somit auch negativ auf die ökonomischen Beziehungen beider Länder auswirken ${ }^{382}$.

In der französischen Botschaft fand Viénot Beistand bei Roland de Margerie und Oswald Hesnard ${ }^{383}$, die sich sehr betroffen über die Situation des Komitees zeigten. Der Botschafter, dem Viénot ebenfalls die Möglichkeit eines Scheiterns aus finanziellen Gründen darlegte, erklärte sich bereit, einen alarmierenden Brief an die Regierung zu schreiben ${ }^{384}$. Mitte 1927 stellten sich dann die ersten

${ }^{378}$ Vgl. Bericht über die Sitzung des Executiv-Ausschusses des Deutsch-Französischen Studien-Komitees am 6. und 8. Februar 1927 in Berlin: PAAA, Botschaft Paris, DFS, Bd. 1.

${ }^{379} \mathrm{Vgl}$. Viénot an d'Ormesson, 25.4.1927 und ders. an dens., 2.5.1927: NL d'Ormesson II.

${ }^{380} \mathrm{Vgl}$. Seydoux an Masson, 9.4.1927 und Masson an Seydoux, 14.4.1927: MAE, PA-AP Seydoux, 261, d. 6.

${ }^{381}$ Seydoux an Laurent, 6.5.1927: MAE, PA-AP Seydoux, 261, d. 6.

${ }^{382}$ Viénot an dens., 14.5.1927: MAE, PA-AP Seydoux, 261, d. 6.

${ }^{383}$ Der Germanist Owald Hesnard (1877-1936) hielt sich von 1919 bis 1932 in Berlin auf, fungierte als Dolmetscher zwischen Briand und Stresemann und galt als 'graue Eminenz in den deutsch-französischen Beziehungen jener Jahre. Vgl. Stefan MARTENS, Martina KESSEL (Hg.), Documents diplomatiques français sur l'Allemagne 1920. Französische Diplomatenberichte aus Deutschland 1920, Bd. 2: 1. Juli-31. Dezember, Bonn 1993 (Pariser Historische Studien, 33/2), S. 1290. Ausfiihrlicher: Jacques BARIETY, Un artisan méconnu des relations franco-allemandes: le professeur Oswald Hesnard, 1877-1936, in: Media in Francia. Recueil de mélanges offert à Karl Ferdinand Werner, Paris 1969, S. 1-18.

${ }^{384} \mathrm{Vgl}$. Viénot an d'Ormesson, 15.5.1927: NL d'Ormesson II; ders. an Seydoux, 20.5.1927: MAE, PA-AP Seydoux, 261, d. 6. Seydoux unterstützte Viénots Demarche durch einen Brief an Margerie, in dem er auf ein Eingreifen Briands und Poincarés gegenüber den 
Erfolge der vielfältigen Bemühungen ein. Poincaré und Berthelot sprachen mit verschiedenen Mitgliedem der französischen Sektion, und Poincaré ging offenbar sogar soweit, einen Vertrauensmann zu den französischen Großbanken zu schicken, um ein verstärktes finanzielles Engagement für das Komitee zu fordem $^{385}$. Briand seinerseites konnte angesichts der prominenten Mitglieder des Studienkomitees deren mangelnde finanzielle Unterstützung nicht begreifen. Eine Auflösung der Verständigungsorganisation kam für ihn nicht in Frage ${ }^{386}$. Durch seine Interventionen bei Berthelot erreichte d'Ormesson tatsächlich eine Zahlung der französischen Regierung, durch die das Budget wieder ausgeglichen werden konnte ${ }^{387}$. Dagegen bewegte sich in der Bankenfrage jedoch weiterhin nichts. Charles Laurent legte kein besonderes Engagement an den Tag und sah auch nach dem Erhalt der Regierungsgelder und trotz der nachdrücklichen Bitten von d'Ormesson und de Peyerimhoff keinen akuten Handlungsbedarf, die noch ausstehende Summe an Mayrisch zurückzuzahlen ${ }^{388}$.

Da sich bis ins Frühjahr 1928 hinein keine Fortschritte hinsichtlich der Bankenbeteiligung abzeichneten, fand im März ein geheimes Treffen bei Seydoux statt, in dessen Verlauf de Peyerimhoff sich bereit erklärte, selbst Briefe an die wichtigsten Bankdirektoren zu verfassen und diese Charles Laurent zur Unterschrift vorzulegen. Die Finanznot wurde unterdessen chronisch. Auch die Zahlungen des Jahres 1928 konnten nicht vollständig getätigt werden. Immerhin gab es einen ersten Erfolg, als die Banque de Paris Ende März 50000 Francs spendete. Allerdings reichte das gerade aus, um das Budget erneut auszugleichen. Den von Peyerimhoff vorgeschlagenen Rundbrief lehnte Charles Laurent ab, der die Banken lieber persönlich aufsuchen wollte. De Peyerimhoff versprach sich davon jedoch keinen raschen Erfolg ${ }^{389}$. Auch Seydoux zeigte sich pessimistisch. Nach der erfolgten Subvention durch die Banque de Paris erwartete er keine größeren Anstrengungen von seiten Laurents, weitere Geldgeber zu finden. Gleichzeitig sah er es jedoch als lebensnotwendig für das Komitee an, den beiden Büros eine ausreichende finanzielle Ausstattung zu gewährleisen ${ }^{390}$.

Banken drängte. Vgl. Seydoux an de Margerie, 23.5.1927: MAE, PA-AP Seydoux, 261, d. 6.; de Margerie an Briand, 1.6.1927: MAE-CAD, Ambassade de France à Berlin, B, 463, d. CFAID.

${ }^{385} \mathrm{Vgl}$. Krukenberg an Köpke, 13.6.1927: ADAP, B, V, Nr. 226, S. 512.

${ }^{386}$ Vgl. Berthelot an d'Ormesson, 27.6.1927: MAE, PA-AP Seydoux, 261, d. 6

${ }^{387}$ Vgl. d'Ormesson an Laurent, 7.7.1927: NL d'Ormesson I, Comité Mayrisch 1927, $2^{\text {e }}$ année; Viénot an Seydoux, 30.7.1927: MAE, PA-AP Seydoux, 261, d. 6.

${ }^{388}$ Vgl. Viénot an d'Ormesson, 6.8.1927; ders. an dens., 23.8.1927; ders. an de Peyerimhoff, 14.9.1927: NL d'Ormesson II. Aus den durchgesehenen Dokumenten geht nicht hervor, ob die Summe noch vor dem Tod Mayrischs tatsächlich an diesen zurückgezahlt wurde

${ }^{389} \mathrm{Vgl}$. Viénot an d'Ormesson, 26.3.1928; ders. an dens., 29.3.1928: NL d'Ormesson II; ders. an Schlumberger, 1.4.1928: BLJD, Fonds Schlumberger, Ms 18340; de Peyerimhoff an Viénot, 3.4.1928: NL Viénot.

${ }^{390}$ Vgl. Seydoux an Viénot, 19.4.1928: MAE, PA-AP Seydoux, 261, d. 6. 
Nach dem Ausscheiden Seydoux' aus dem Komitee fiel jedoch auch die Unterstützung der Banque de Paris wieder weg. Viénot appellierte deshalb an die Mitglieder des Komitees, sich finanziell stärker zu engagieren. Auch im Frühjahr 1929 war die französische Sektion ihrer pekuniären Probleme noch immer nicht enthoben. Viénot drängte deshalb im April auf eine baldige Sitzung des Exekutivkomitees, in der über neue Mitglieder entschieden werden sollte. Thre Auswahl sollte auch die chronischen finanziellen Löcher stopfen helfen ${ }^{391}$. Zu diesem Zeitpunkt befand sich das Gesamtkomitee jedoch bereits in einer Phase der Neuorganisation. Die Umstrukturierungen waren grundsätzlicher Art und wurden mit Sparmaßnahmen verknüpft. Eine komfortable finanzielle Basis be$s a ß$ die französische Sektion jedoch nie. Als Viénot aus dem Komitee ausschied, spendete er eine größere Summe und verzichtete auf die Auszahlung von 10000 Francs, die ihm noch zustanden ${ }^{392}$.

Der jahrelange Kampf um Budgetausgleich und Subventionen von Regierung und Großbanken macht deutlich, daß die Einschätzung, das Komitee sei "finanziell hervorragend ausgestattet ${ }^{393}$ gewesen, zumindest auf die französische Sektion nicht zutrifft. Zugleich zeigt es auch, daß selbst in der Hochphase der Locarno-Politik auf seiten der französischen Banken und der Industrie starke Vorbehalte gegen die Unterstützung eines Unternehmens bestanden, von dem man sich keinen persönlichen Nutzen versprach. Erst massiver Druck durch Regierung und Quai d'Orsay konnte die Banken zu Spenden bewegen.

Darüber hinaus wird erneut der Grundkonflikt deutlich zwischen Viénot, der einmal mehr auf aktives Handeln drängte, und Laurent, dem der Stil Viénots mißfiel. Die Gruppe um Viénot mit d'Ormesson und de Peyerimhoff an der Spitze versuchte, dem Komitee in inhaltlicher wie finanzieller Hinsicht eine Gestalt zu geben, die von Laurent offensichtlich nicht gutgeheißen wurde. Der Konflikt schwelte also bereits seit einiger Zeit, als er 1929 schließlich offen ausbrach.

\section{Der »Fall Viénot« und die Neuorganisation des Komitees}

Im Mai 1929 erhielt Wladimir d'Ormesson einen streng vertraulichen Brief seines Freundes Pierre Viénot ${ }^{394}$. Es sei gut möglich, so berichtete Viénot, daß er nächste Woche zurücktreten müsse. Aufgrund seiner Aktivitäten sah er eine Intrige der deutschen Gruppe gegen sich im Gange. Viénot, der in der Vergangenheit stets versucht hatte, durch geschicktes diplomatisches Manövrieren die Interessengegensätze zwischen den nationalen Sektionen auszugleichen und Verstimmungen beizulegen, trug durch sein Handeln nun unfreiwillig selbst zur Verschärfung bereits vorhandener Konflikte innerhalb des Komitees bei.

${ }^{391}$ Viénot an d'Ormesson, 11.4.1929: NL d'Ormesson II.

${ }^{392}$ Vgl. ders. an dens., o.D. [vermutlich Juni 1930]; ders. an dens., 8.7.1930: NL d'Ormesson II.

${ }^{393}$ BELITZ, Befreundung mit dem Fremden, S. 197.

${ }^{394} \mathrm{Vgl}$. Viénot an d'Ormesson, 8.5.1929: NL d'Ormesson II. 
Zwei Briefe wurden Viénot zum Vorwurf gemacht, und beide Vorgănge standen in direktem Zusammenhang mit den in Paris stattfindenden Verhandlungen zur Neuregelung der Reparationsfrage ${ }^{395}$. Seit Februar 1929 arbeitete ein Ausschuß internationaler Finanzsachverständiger in der französischen Hauptstadt unter Vorsitz des amerikanischen Bankiers Owen D. Young an einem neuen Plan zur endgültigen Lösung der finanziellen Probleme. Die deutsche Regierung hatte sich mit ihrem Wunsch nach einer unabhängigen Expertenkommission gegen die Franzosen durchgesetzt, doch der deutsche Chefunterhändler Hjalmar Schacht wurde bald zur schweren Belastung. Sein »kompromißlos provozierendes Auftreten ${ }^{396}$ in Verbindung mit seinen Forderungen nach Rückgabe des polnischen Korridors und der ehemaligen deutschen Kolonien brüskierte die Konferenzteilnehmer ebenso wie das Auswärtige Amt. Als von französischer Seite Gold und Devisen in Höhe von mehreren Millionen Mark von deutschen Banken abgezogen wurden, berichtete die rechtsliberale Deutsche Allgemeine Zeitung (DAZ), daß dies »ausdrücklich und völlig unmißverständlich [...] auf Anordnung der französischen Regierung geschehe $\ll{ }^{397} \mathrm{Mit}$ der Aktion sollte laut DAZ politischer Druck auf Deutschland ausgeübt werden. Auf Nachfrage Viénots hin versicherte ihm de Peyerimhoff, daß die französische Regierung nicht hinter dem Kreditabzug steckte. Daraufhin schrieb Viénot einen Brief an den Chefredakteur der DAZ, Fritz Klein, und stellte den Devisenabfluß als spontanen Ausdruck französischer Nervosität und der Furcht vor dem Scheitern der Reparationskonferenz dar ${ }^{398}$. Bis zu diesem Punkt schien es eine Routineangelegenheit $\mathrm{zu}$ sein, wie viele andere vergleichbare Vorgänge auch. Dies änderte sich allerdings, als Viénots Brief ohne dessen Wissen von Klein veröffentlicht und gleichzeitig als roffizielles` französisches Dementi hingestellt wurde ${ }^{399}$. Als Le Temps und Le Journal des Débats eine Meldung der Havas-Agentur über Viénots Brief abdruckten, sah sich dieser veranlaßt, in einem Rundbrief an die französische Sektion des Studienkomitees den Vorgang zu erklären ${ }^{400}$. Es war Viénot peinlich, daß dieser als offizielles Dementi des Quai d'Orsay hingestellt wurde. Gleichzeitig hatte er erfahren, daß die Informationen de Peyerimhoffs offensichtlich nicht ganz exakt gewesen waren

${ }^{395}$ Vgl. dazu HEYDE, Reparationen, S. 45-49; KRÜGER, Außenpolitik, S. 476-488; KNIPPING, Locamo-Ära, S. 44-50.

${ }^{396}$ HILDEBRAND, Das vergangene Reich, S. 499.

${ }^{397}$ Paris mit seinen Manövern isoliert. in: DAZ, 27.4.1929.

${ }^{398}$ Viénot an Klein, 29.4.1929: NL d'Ormesson II.

${ }^{399}$ Vgl. Ein französisches Dementi. Paris habe keine Zurückziehung von Krediten angeordnet, Ein Brief und eine Antwort, in: DAZ, 30.4.1929. Vgl. auch Viénot an Klein, 30.4.1929: NL d'Ormesson II, aus dem hervorgeht, daß Viénot nichts von einer geplanten Veröffentlichung seines Briefes wußte.

${ }^{400} \mathrm{Vgl}$. Viénot an die Mitglieder der französischen Sektion des Deutsch-Französischen Studienkomitees, 3.5.1929: NL d'Ormesson II. 
und daß die Banken bei ihrem Kreditabzug Anweisungen geltend gemacht hatten: »[...] je crois que Peyerimhoff s'est un peu avancé, et moi avec lui. ${ }^{401}$

Zur gleichen Zeit beging Viénot eine Indiskretion, als er einen an ihn adressierten Brief von de Peyerimhoff an Ministerialdirektor Köpke - und damit indirekt an Stresemann - weitergab. Peyerimhoff, der im Auswärtigen Amt als "die wichtigste wirtschaftliche Figur Frankreichs ${ }^{402}$ gesehen wurde, hatte Viénot seine Eindrücke von den Expertengesprächen wiedergegeben und ein Bild der Stimmung in Paris gezeichnet. In den Augen Peyerimhoffs hatte die deutsche Delegation versucht, die Alliierten gegeneinander auszuspielen, während sie gleichzeitig ganz auf die USA setzte. Das Zahlungsangebot Schachts, das lediglich ein Viertel der von den Alliierten erwarteten Summe beinhaltete, bezeichnete Peyerimhoff als lächerlich. Die Rolle Schachts sah Peyerimhoff als nicht unproblematisch, da dieser durch sein Taktieren letztlich die ganze Welt verärgert hatte. Im Falles eines Scheiterns der Gespräche befürchtete Peyerimhoff einen Rückschritt im politischen Prozeß überhaupt. Dennoch äuBerte er sich optimistisch und verwies auf den guten Willen und die Professionalität der Beteiligten ${ }^{403}$.

Bevor Viénot sich entschloß, den Brief an das Auswärtige Amt weiterzugeben, hatte er sich der Zustimmung der französischen Botschaft versichert. Da der Botschafter nicht erreichbar gewesen war, hatte er den Rat von Hesnard und Roland de Margerie eingeholt, die ihm beide zugeraten hatten. Auch Peyerimhoff war mit der Maßnahme einverstanden, allerdings wurde vereinbart, den Vorgang wie eine Indiskretion von Viénot aussehen zu lassen, damit de Peyerimhoff in keiner Weise in die aktuelle politische Debatte verstrickt werden könnte ${ }^{404}$. Die Motivation, die Viénot zu diesem Schritt veranlaßte, war seine Sorge um den Fortgang der Verständigungspolitik, und da er Schacht als Hindernis für diese ansah, sollte der Brief den Kredit Schachts im Auswärtigen Amt weiter schwächen. Viénot verurteilte die »attitude intransigeante ${ }^{405}$ Schachts und wollte mit seiner Informationsmaßnahme die Position Stresemanns unterstützen. Allerdings erzielte diese Maßnahme ein geteiltes Echo. Vor allem in der deutschen Gruppe des Mayrisch-Komitees wurde seine Aktivität als übertrieben und als Einmischung in innenpolitische Angelegenheiten empfunden. Viénot glaubte, daß vor allem Krukenberg, bei dem er starke Sympathien für

${ }^{401}$ Ders. an seinen Vater, 3.5.1929: NL Viénot.

402 Zit. nach MULLER, Deutsch-französische Gesellschaftsbeziehungen, S. 236.

${ }^{403} \mathrm{Vgl}$. de Peyerimhoff an Viénot, 23.4.1929: NL d'Ormesson II.

${ }^{404} \mathrm{Vgl}$. Note confidentielle sur deux initiatives au mois d'avril 1929 et sur les incidents qu'elles ont provoqués, o.D. [vermutlich November 1929], S. 4ff.: NL d'Ormesson II. In der Studie von AUFFRAY, Pierre de Margerie, S. 497, wird auf die Affäre um den PeyerimhoffBrief hingewiesen. Laut Auffray gab Pierre de Margerie seine volle Zustimmung zu Viénots Handeln. Vgl. auch L'HUILLIER, Dialogues franco-allemands, S. 87ff.

${ }^{405}$ Note confidentielle sur deux initiatives au mois d'avril 1929 et sur les incidents qu'elles ont provoqués, o.D. [vermutlich November 1929], S. 2: NL d'Ormesson II. 
Schacht feststellte, darüber verärgert sei »que j'ai fourni à la Wilhelmstrasse l'arme très précieuse que constituait la lettre de Peyerimhoff $«{ }^{406}$ Die Vorwürfe wegen der Weitergabe des Peyerimhoff-Briefes an das Auswärtige Amt fand er schlichtweg lächerlich: »Me voyez-vous amené à quitter le Comité parce que j'ai trop bien renseigné la Wilhelmstrasse? ${ }^{407}$ Gleichzeitig erhielt Viénot eine Rüge von Laurent, der ihm seinen Brief an die DAZ zum Vorwurf machte. Eine Art öffentliches, wenn nicht gar offizielles Dementi entsprach seiner Meinung nach nicht dem Charakter des Studienkomitees ${ }^{408}$. Viénot fühlte sich allerdings zu unrecht angegriffen, da er sich vor der Redaktion des Briefes des Einverständnisses von Nostitz versichert hatte.

$\mathrm{Zu}$ diesem Problem kam jedoch noch eine andere Schwierigkeit hinzu. Innerhalb der deutschen Sektion gab es eine Intrige gegen den Präsidenten Nostitz, die von Krukenberg und Viénots Mitarbeiter Jessen angeführt und von einer Anzahl Mitglieder unterstützt wurde. Da Nostitz von Viénots Brief an die DAZ gewußt hatte, sollte nun ein $»$ Fall Nostitz« konstruiert werden. Zudem hatte Nostitz der Weitergabe des Peyerimhoff-Briefs an Köpke im nachhinein zugestimmt. Viénot machte Krukenberg klar, daß es keinen »Fall Nostitz « ohne einen gleichzeitigen »Fall Viénot« geben und der eine nicht ohne den anderen gehen werde ${ }^{409}$. Gleichzeitig kündigte er Nostitz seinen sofortigen Rücktritt an, falls von deutscher Seite aufgrund seiner Tätigkeit eine Demarche an die französische Sektion gerichtet werde ${ }^{410}$.

Krukenberg, dem Viénot eine Kopie des Peyerimhoff-Briefes hatte zukommen lassen, weigerte sich, diesen zurückzugeben, und Viénot erfuhr kurze Zeit später, daß Bruns und Bücher ebenfalls Kopien von Krukenberg erhalten hatten. Gleichzeitig machte der Direktor des Pariser Büros seinem französischen Kollegen Vorwürfe, dieser sei »trop indépendant, trop catégorique «. ${ }^{411}$ Viénot interpretierte die Auseinandersetzung als Konflikt zwischen sich selbst als Befürworter eines Reparationsabkommens und den deutschen Anhängern von Schacht, die einen Abbruch der Gespräche billigend in Kauf nehmen wollten: "Il a sans doute paru que je servais trop bien les intérêts de la France (en réalité, je ne l'ai jamais fait qu'en suivant une entente franco-allemande), et que j'étais à même de me faire entendre de trop de personnalités influentes. $\aleph^{412} \mathrm{Obwohl}$ Viénot sich weiterhin zu seinem Verhalten und seiner politischen Meinung bekannte, fühlte er sich doch kompromittiert. Er hatte Bedenken hinsichtlich der zukünftigen Zusammenarbeit mit Jessen und Krukenberg, die mit ihrer Intrige gegen Nostitz gescheitert waren. Darüber hinaus war er aber auch zu der Er-

\footnotetext{
${ }^{406}$ Viénot an d'Ormesson, 6.5.1929: NL d'Ormesson II.

${ }^{407}$ Ders. an dens., 8.5.1929: NL d'Ormesson II.

${ }^{408} \mathrm{Vgl}$. Laurent an Viénot, 8.5.1929: NL d'Ormesson II.

${ }^{409} \mathrm{Vgl}$. Viénot an d'Ormesson, 8.5.1929: NL d'Ormesson II.

${ }^{410} \mathrm{Vgl}$. ders. an von Nostitz, 8.5.1929: NL d'Ormesson II.

${ }^{411}$ Ders. an de Peyerimhoff, 11.5.1929: NL d'Ormesson II.

412 Ibid.
} 
kenntnis gelangt, daß das Ziel des Studienkomitees nicht mehr erreichbar war. Angesichts der Befürwortung von "Schachts Obstruktionskurs « ${ }^{413}$ durch die Mehrheit der deutschen Mitglieder und damit deren Ablehnung von Stresemanns Verständigungspolitik hielt Viénot eine fruchtbare Fortsetzung der Komiteearbeit für unmöglich. Er wollte jedoch zunächst auf seinem Posten bleiben, um ein abruptes Ende der Organisation zu vermeiden. Gleichzeitig sprach er sich für ihre Auflösung zum Jahresende aus ${ }^{414}$.

Von seiten der deutschen Sektion bemühte man sich unterdessen um Schadensbegrenzung. Krukenberg wurde nach Berlin gerufen, um sein Verhalten zu erklären. Anschließend organisierte von Simson ein Versöhnungsessen zwischen Viénot, Krukenberg und Jessen, und Viénot erklärte sich bereit, bei der >Komödie $<$ mitzuspielen ${ }^{415}$. Um seine Position sowohl gegen die deutsche Gruppe als auch gegen Laurent abzusichern, erbat er sich vom französischen Botschafter über dessen Sohn ein offizielles Schreiben, welches ihm die Zustimmung der Botschaft zu seinem Handeln versichern sollte. Roland de Margerie gab zu Bedenken, daß sein Vater auf die beiden konkreten Anlässe der Verstimmungen nicht eingehen konnte. Es dürfe keinesfalls der Anschein erweckt werden, daß sich der Botschafter in die inneren Angelegenheiten des Komitees einmischen wolle oder daß Viénot und Peyerimhoff unter Ägide der Botschaft `konspiriert hätten. "Comme vous, je pense«, so versicherte der Botschaftersohn Viénot, "qu'il faut attribuer à des motifs d'hostilité purement personnelle \& nourris à des sources subalternes, la grande offensive de C.[harles] L.[aurent] contre vous. Il avait un peu caché son jeu ces derniers temps, mais vous restait foncièrement hostile. $\aleph^{416}$ Nach Roland de Margeries Einschätzung datierte die Feindseligkeit Charles Laurents gegenüber Viénot bereits aus den Anfangszeiten des Komitees. Laurent hatte seiner Meinung nach nicht begriffen, daß es ohne Viénot das Studienkomitee gar nicht geben würde. Der französische Botschafter zeigte seine Verbundenheit zu Viénot durch einen Brief, der zwar allgemein gehalten war, ihm aber sein Vertrauen aussprach und die gute Zusammenarbeit und Übereinstimmung mit der Botschaft betonte ${ }^{417}$.

$\mathrm{Zu}$ den inneren Spannungen des Mayrisch-Komitees stellte sich zusätzlich die Frage nach der Zukunft der Büros. Bei der Komiteegründung 1926 waren die Einrichtungen in Paris und Berlin für vorerst drei Jahre ins Leben gerufen worden, nach deren Ablauf ihre Wirksamkeit beurteilt werden sollte. Eine grundsätzliche Neuorganisation stand auf der Tagesordnung, die jedoch von den persönlichen Zwistigkeiten überschattet wurde. Es zeigte sich, daß die

${ }^{413}$ HHDEBRAND, Das vergangene Reich, S. 501.

${ }^{414} \mathrm{Vgl}$. Viénot an de Peyerimhoff, 11.5.1929: NL d'Ormesson II.

${ }^{415}$ Vgl. ders. an d'Ormesson, 18.5.1929 und 22.5.1929: NL d'Ormesson II.

${ }^{416} \mathrm{R}$. de Margerie an Viénot, 10.6.1929: NL Viénot.

${ }^{417}$ P. de Margerie an dens., 3.6.1929: NL d'Ormesson II. Der Brief wurde zusammen mit dem Roland de Margeries vom 10.6.1929 an Viénot geschickt. Die Vordatierung sollte den Anschein verhindern, der Brief sei für die Zwecke Viénots diktiert worden. 
'Affäre Viénotc noch längst nicht abgeschlossen war, denn nun bildete sich eine folgenreiche Koalition, die emeut Position gegen den Direktor des Berliner Büros bezog: Gustav Krukenberg und Charles Laurent fanden ihr gemeinsames Interesse darin, Viénot abzusetzen. Viénot hatte nach Krukenbergs Aktivitäten in der ganzen Affäre dessen Vorschlag abgelehnt, die Büros zu verkleinern und nicht mehr der einen oder anderen Sektion zu unterstellen ${ }^{418}$. Innerhalb der französischen Gruppe setzte sich daraufhin ein Antrag zur Auflösung der beiden Büros durch. Laurent begründete diesen Schritt mit der Überzeugung, »daß bei der Entwicklung der allgemeinen Lage, insbesondere nachdem die Arbeiten der Sachverständigenkonferenz zu einem übereinstimmenden Bericht geführt hätten, $[. .$.$] die Besserung der Beziehungen zwischen Deutschland und$ Frankreich, welche das Hauptziel unseres Komitees bildeten, großenteils erreicht sei«. ${ }^{419}$ Diese Meinung widersprach diametral der Ansicht Viénots, der sich auch nach dem positiven Abschluß der Reparationsverhandlungen im August 1929 große Sorgen um den Fortgang der Verständigungspolitik machte. Den erfolgreichen Ausgang der Konferenz wertete Viénot angesichts der schwierigen innenpolitischen Situation in Deutschland als letzten Erfolg der Politik Stresemanns. Sollte die französische Rheinlandräumung - und zwar aller verbleibenden Zonen - nun nicht sofort erfolgen, dann wäre die Reparationsübereinkunft nur ein Pyrrhussieg ${ }^{420}$.

Krukenberg stellte den Sachverhalt so dar, daß die Initiative zur Büroauflösung von Viénot ausgegangen und dann von Laurent aufgegriffen worden war. Laut Krukenberg, der Viénot für die Unstimmigkeiten innerhalb des Komitees verantwortlich machte, wollte sich dieser durch die Büroauflösung »eine Auseinandersetzung über bestimmte Vorfälle ${ }^{421}$ ersparen. Viénot sah sich in seiner Vorsicht gegenüber dem Kollegen bestätigt, als Krukenberg den von Charles Laurent abgesegneten Protokollentwurf zur Sitzung des Exekutivkomitees vom 22. Juni 1929 Viénot vorlegte. Er betonte darin den einseitigen Willen der französischen Sektion, ihr Berliner Büro aufzulösen. Viénot protestierte bei Laurent gegen diese Fassung, die nur die Auflösung seines Büros erwähnte und ihm somit indirekt das Mißtrauen der französischen Mitglieder aussprach ${ }^{422}$.

Nach Rücksprache mit Nostitz erreichte Viénot eine Neufassung des Protokolls durch Krukenberg ${ }^{423}$. Der Machtkampf zwischen Präsidenten und Bürodirektor der französischen Sektion nahm währenddessen kleinliche Züge an. Als das Protokoll zwei Monate später noch immer nicht verschickt worden

${ }^{418} \mathrm{Vgl}$. Viénot an d'Ormesson, 18.5.1929: NL d'Ormesson II.

${ }^{419}$ So äußerte sich Charles Laurent gegenüber Krukenberg. Vgl. Krukenberg, Aufzeichnung über meinen Besuch bei Herm Charles Laurent am 17. Juni 1929: PAAA, Botschaft Paris, DFS, Bd. 2.

${ }^{420} \mathrm{Vgl}$. Viénot an d'Ormesson, 7.5.1929: NL d'Ormesson II.

${ }^{421}$ Krukenberg an von Hoesch, 17.6.1929: PAAA, Botschaft Paris, DFS, Bd. 2.

${ }^{422}$ Vgl. Viénot an Laurent: NL d'Ormesson II.

${ }^{423}$ Vgl. ders. an dens., 5.7.1929 und ders. an de Peyerimhoff, 5.7.1929: NL d'Ormesson II. 
war, vermutete Viénot hinter dieser Verzögerung Laurent, der damit seine Niederlage vertuschen wollte. Dieser stritt dies ab, betonte jedoch gleichzeitig nochmals seinen Standpunkt, demzufolge das Exekutivkomitee lediglich die Auflösung des Berliner Büros beschlossen hatte ${ }^{424}$. Viénot plante derweil, eine Mitteilung über die Vorgänge zu verfassen und direkt an die Mitglieder des Komitees zu verschicken: "[...] je ne vois pas pourquoi je me croirais obligé, au bout de 3 ans, à reconnaître une dépendance vis-à-vis du Président - et non pas vis-à-vis du Comité - que je n'ai jamais reconnue jusqu'à présent. « $^{425}$ Mit diesen Worten charakterisierte Viénot den Kern des Konflikts, in dem es unausgesprochen um die Frage der obersten Autorität in der französischen Sektion ging. Laurent als ihr Präsident sah sich selbst als Spitze der Hierarchie an, während Viénot eine Abhängigkeit vom Präsidenten niemals akzeptiert hatte und das Studienkomitee als ssein (Werk betrachtete. Der Kampf zwischen Viénot und Laurent um die Unabhängigkeit des Ersten und die Autorität des Zweiten spiegelte jedoch auch die Auseinandersetzung innerhalb der französischen Komiteesektion zwischen den Befürwortern einer aktiven Linie, die die Locamopolitik des Auswärtigen Amts unterstützten, und den Vertretern eines politisch zurückhaltenden Kurses, die in erster Linie auf eine Wirtschaftskooperation setzten ${ }^{426}$. In dem Maße, in dem Stresemanns Verständigungspolitik innerhalb der deutschen Sektion jedoch an Unterstützung verlor und die wirtschaftlichen Interessen noch stärker als bisher in den Vordergrund traten, geriet die Gruppe um Viénot und d'Ormesson, die durch ihre Tätigkeit auch zum Erfolg von Stresemanns Politik beitragen wollte, in eine doppelte Defensive. Nach dem Tod des Komiteepräsidenten Mayrisch im Jahr zuvor war zudem niemand der Beteiligten mehr in der Lage, als von beiden Seiten anerkannte Vermittlungsfigur einen Interessenausgleich innerhalb des Komitees herbeizuführen.

Dazu kam noch ein anderes Problemfeld, das sich zu dieser Zeit abzuzeichnen begann. Lange Zeit hatte Viénot über seinen politischen Standpunkt reflektiert, ohne in den Parteien eine passende Antwort auf die ihn bewegenden Fragen zu finden. Sowohl aufgrund seiner Herkunft als auch durch seine Zeit bei Lyautey hatte er sich bis dahin in eher konservativen Kreisen aufgehalten. Durch Kontakte wie die mit dem Kreis um André Gide oder auch durch Pierre Bertaux, der sich als Normalien in einem linksrepublikanisch-pazifistischen Milieu bewegte ${ }^{427}$, begann Viénot jedoch, seinen Horizont zu erweitern. Sein politisches Koordinatensystem veränderte sich allmählich, nicht zuletzt auch unter dem Einfluß seiner Frau, die aus ihrer Sympathie für den Sozialismus kein Hehl

${ }^{424} \mathrm{Vgl}$. ders. an d'Ormesson, 18.9.1929 und ders. an Laurent, 22.9.1929: NL d'Ormesson II.

${ }^{425}$ Ders. an d'Ormesson, 18.9.1929: NL d'Ormesson II.

${ }^{426} \mathrm{Vgl}$. L'HULLIER, Dialogues franco-allemands, S. 89.

${ }^{427} \mathrm{Zu}$ diesem Milieu vgl. SIRINELLI, Génération intellectuelle; Pierre BERTAUX, Amitiés normaliennes, in: Commentaire 28/29 (1985) S. 13-15. 
machte. Die Zusammensetzung des Mayrisch-Komitees, und dabei vor allem der deutschen Sektion, drückte ein Übergewicht von konservativ gesinnten Wirtschaftseliten aus, von denen sich Viénot mehr und mehr distanzierte. Er sah in einem großen Teil der deutschen Mitglieder »les bonzes de la Schwerindustrie« und auch »des amateurs de spolitique aristocratique«, mit denen er politisch weder in Form noch Inhalt übereinstimmte ${ }^{428}$.

Mitte Oktober sollte in einer Sitzung des Exekutivkomitees endgültig über die Zukunft der Komiteeorganisation entschieden werden. Beide Sektionen versammelten sich im Vorfeld getrennt voneinander, um die Vorgehensweise zu besprechen. Innerhalb der deutschen Sektion traten zwei Gruppierungen zutage. Zum einen bildete sich ein Kreis um Nostitz, Bücher, Haas, von Mendelssohn, von Simson und von Stauss, der für eine Auflösung der Büros eintrat, wohingegen eine größere Gruppe um Bergsträsser, Bruhn, Bruns, Curtius, von Hatzfeld, Müller-Oerlinghausen, von Oberndorff, von Praschma, von Papen und Simons gegen diese Maßnahme waren und eine unveränderte Fortführung der Komiteearbeit wünschten ${ }^{429}$. Innerhalb der französischen Gruppe kam es indessen zu noch weitergehenden Änderungsvorschlägen. Laurent präsentierte den Mitgliedern einen Vorschlag, wonach statt der Büros Generalsekretariate geschaffen werden sollten. Viénot erwartete nun, daß ihm der Posten des französischen Generalsekretärs angeboten wurde. Andernfalls bedeutete dies für ihn »le désaveu total ${ }^{430}$, der Hinauswurf aus seinem eigenen Komitee. Laurent hatte jedoch andere Pläne und schickte d'Ormesson, der nicht an dem Treffen teilnahm, ohne dessen Wissen ins Rennen. Die französische Gruppe beauftragte daraufhin Laurent, d'Ormesson das Generalsekretariat anzubieten, was von Peyerimhoff als Sieg über Laurent gewertet wurde. Er schlug Viénot vor, d'Ormesson solle den Posten nur unter der Bedingung akzeptieren, daß die Funktion mit Viénot geteilt werde. Zudem sollte Viénot, der bisher zwar Direktor des Berliner Büros, aber kein formelles Mitglied des Studienkomitees war, offiziell in dieses eintreten. Damit wäre Viénots Verbleiben in der Organisation gesichert. Nach einigen Monaten könnte sich d'Ormesson dann zurückziehen und Viénot den Posten ganz überlassen. Dieser konnte den Optimismus Peyerimhoffs jedoch nicht teilen, denn in seinen Augen hatten ihm die französischen Mitglieder eine bittere Niederlage zugefügt.

In der Presse wurden derweil bereits Nachrichten vom bevorstehenden Ende des Mayrisch-Komitees verbreitet, das »unter allem Umständen zu früh käme« ${ }^{431}$ Auf der gemeinsamen Sitzung des Exekutivkomitees in Düsseldorf am 13. Ok-

${ }^{428}$ Viénot an d'Ormesson, 18.9.1929: NL d'Ormesson II.

${ }^{429}$ Vgl. Krukenberg an von Hoesch, 7.10.1929: PAAA, Botschaft Paris, DFS, Bd. 2.

${ }^{430}$ Viénot an d'Ormesson, 10.10.1929: NL d'Ormesson II.

${ }^{431}$ Das deutsch-französische Studienkomitee. Zur Absicht seiner Auflösung, in: Frankfurter Zeitung, 12.10.1929. In der französischen Presse wurde hingegen von der geplanten Steigerung der Komiteearbeit berichtet. Vgl. Le comité franco-allemand, in: Le Journal des Débats, 15.10.1929 
tober 1929 wurden dann verschiedene Reformmaßnahmen beschlossen, die zwar nicht die Auflösung des Komitees bedeuteten, jedoch scharfe Einschnitte in die Organisation darstellten. Die deutsche Gruppe hatte die Revision des Liquidationsbeschlusses gefordert, was allerdings von Laurent zurückgewiesen wurde. Die Auflösung der beiden Büros wurde daraufhin für Ende Dezember beschlossen. Die an ihre Stelle tretenden Generalsekretariate sollten von Mitgliedern des Komitees ehrenamtlich von ihrem Land aus geführt werden. Diese Umgestaltung stellte eine deutliche Sparmaßnahme gegenüber der ursprünglichen Regelung dar. Diese war geboten angesichts der stagnierenden deutschen Volkswirtschaft einerseits sowie der beschriebenen chronischen Finanzprobleme der französischen Sektion andererseits. Trotz dieser wirtschaftlichen Notwendigkeiten stellt sich dennoch die Frage nach der Vereinbarkeit dieses Reformvorschlags mit den Ursprungszielen des Komitees. Eine Einwirkung auf die Mentalitäten, ein Abbau von gegenseitigen Vorurteilen konnte durch die Generalsekretäre, die nicht mehr in das andere Land eingebunden sein sollten, kaum mehr erreicht werden. Angesichts der bereits längst verpufften Dynamik von Locarno, in deren Zug das Studienkomitee dreieinhalb Jahre zuvor gegründet worden war, spiegelte die Strukturreform auch eine Zurücknahme der ehrgeizigen Ziele auf das künftig noch realisierbar Erscheinende. Statt einer aktiven, auf politische Veränderungen hinwirkenden Linie sollte nunmehr eine defensive, auf elitäre und in erster Linie wirtschaftliche Kontaktpflege reduzierte Haltung durchgesetzt werden. Die Reformvorschläge sahen weiterhin jedes Jahr eine Vollversammlung vor, die abwechselnd in dem einen oder anderen Land stattfinden sollte. Mit der Begründung, die einzelnen Mitglieder stärker in die Komiteearbeit einbeziehen zu wollen, wurde nun auf die alten Mayrisch-Vorschläge zurückgegriffen und die Errichtung von drei Kommissionen zu politischen, wirtschaftlichen und kulturellen Fragen entschieden. Als Signal nach außen für den Willen zur Fortführung und Verstärkung der Komiteearbeit, zweifellos aber auch um die finanzielle Basis zu verbreitern, sollte darüber hinaus erneut die Mitgliederzahl erhöht werden. Die deutsche Gruppe brachte zusätzlich den Vorschlag ein, in Paris einen deutsch-französischen Treffpunkt einzurichten, der nach dem Gründer Émile Mayrisch benannt werden sollte. Diese Anregung wurde einstimmig angenommen ${ }^{432}$. Laurent verfolgte derweil offensichtlich das Ziel, Viénot gänzlich aus dem Komitee zu verdrängen. Er äußerte während der Sitzung gegenüber Schlumberger, er werde keinesfalls den Eintritt Viénots in das Exekutivkomitee akzeptieren. Dieser wiederum wollte sich trotz der tiefen persönlichen Kränkung, unter der er litt, nicht geschlagen geben:

${ }^{432}$ Vgl. Bericht über die am 13. Oktober 1929 in Düsseldorf abgehaltene Sitzung des gemeinsamen Executivausschusses [sic], 26.10.1929: PAAA, Botschaft Paris, DFS, Bd. 2; Pressekommuniqué vom 14.10.1929: NL d'Ormesson II. 
Ce qui m'agace le plus, dans cette histoire [...], ce n'est pas de voir un vieux roublard l'emporter. C'est d'avoir à paraittre faire preuve d'un amour-propre qui n'est nullement dans ma nature... Je ne suis pas sensible à ce que pensent les médiocres. Mais vous comprenez bien que je ne peux tout de même pas me laisser désavouer de la sorte, surtout vis-à-vis des Allemands, et parâtre avoir été vidé d'une chose que j'ai créée, en un mot parâtre savoir échouéé ${ }^{433}$.

Getreu dem Motto, daß Angriff die beste Verteidigung sei, führten Viénot und seine Frau bewußt ein intensives gesellschaftliches Leben, das den Gerüchten um die verminderte Stellung des Bürodirektors die Spitze nehmen sollte. Indessen stimmten Viénot und d'Ormesson ihre Strategie gegenüber Laurent ab. D’Ormesson gab dem Präsidenten zu verstehen, daß Viénot der geeignetste Kandidat für die Funktion des Generalsekretärs sei und daß er seine Nominierung als umso selbstverständlicher erachte, als die deutsche Sektion Krukenberg ernannt habe ${ }^{434}$. Laurent wies d'Ormessons Vorschläge entschieden zurück und erinnerte an den einstimmigen Wunsch der französischen Sektion, d'Ormesson an der Spitze des Generalsekretariats zu sehen. Vor allem aber sprach er Viénot erneut sein Mißtrauen aus und lehnte jede weitere Zusammenarbeit mit ihm kategorisch ab: „Loin de partager vos vues sur M. Viénot j'estime qu'il est impossible de songer à lui confier les fonctions de secretaire général. A la suite de maladresses successives qu'il avait commises cet été [...] j'ai dû lui faire savoir qu'il avait perdu ma confiance [...]...435 Das Komitee war indes von dem permanenten Tauziehen zwischen Viénot und Laurent gelähmt. Laurent wurde so tatsächlich, wie Viénot es ebenso scharf wie bitter formuliert hatte, »un souverain absolu régnant sur un désert «. ${ }^{436}$ Viénot seinerseits manövrierte sich jedoch ebenfalls in eine immer stärkere Isolation.

Der Direktor des Berliner Büros verfaßte derweil eine ausführliche, 26 Seiten umfassende Niederschrift, die er an d'Ormesson, de Peyerimhoff, Arthur Fontaine, Chardon, de Vogiué und Pierre Lyautey verteilte. Auf deutscher Seite war sicherlich auch Wilhelm Haas darüber im Bilde, da er mit Viénot befreundet und als einziger Deutscher über dessen Probleme mit Laurent unterrichtet war. Viénot legte die Auseinandersetzung mit Laurent in allen Details dar. Er schilderte, daß Laurent sich die Sicht Krukenbergs zu eigen gemacht und ihm daraufhin das Vertrauen entzogen hatte. Seine Initiativen vom Frühjahr, das Schreiben an die DAZ und die Weitergabe des Peyerimhoff-Briefes, verteidigte er mit seiner Auffassung von der Rolle des Bürodirektors, die eine aktive sein sollte.

${ }^{433}$ Viénot an d'Ormesson, 17.10.1929: NL d'Ormesson II.

${ }^{434}$ Vgl. ders. an dens., 1.11.1929; NL d'Ormesson II. Viénot machte seinem Freund hier Formulierungsvorschláge für den Brief an Laurent. D'Ormessons Brief selbst befindet sich nicht in den Dokumenten. Aus der Reaktion Laurents geht jedoch hervor, daß d'Ormesson inhaltlich wohl weitgehend den Vorschlägen Viénots gefolgt ist.

${ }^{435}$ Laurent an d'Ormesson, 10.11.1929: NL d'Ormesson II.

${ }^{436}$ Viénot an d'Ormesson, 23.11.1929: NL d'Ormesson II. 
Die Mitglieder der französischen Sektion standen offenbar mehrheitlich auf Viénots Seite, versuchten aber einen Kompromiß zu finden, der beiden Seiten gerecht werden konnte. Peyerimhoff und Fontaine schlugen vor, daß Viénot pro forma zum Generalsekretär ernannt werden, aber nach sechs Monaten zugunsten seines Nachfolgers zurücktreten sollte ${ }^{437}$. Für diesen war inzwischen Graf Régis de Vibraye von d'Ormesson ins Gespräch gebracht worden. Viénot, der sich innerlich bereits vom Studienkomitee gelöst hatte und in erster Linie sein Gesicht wahren wollte, war mit dieser Lösung einverstanden, von Laurent wurde sie jedoch abgelehnt. Ein weiterer Vorschlag von Fontaine, wonach Viénot Leiter des neu einzurichtenden Centre Émile Mayrisch werden sollte, stieß bei den Viénots auf Ablehnung, da dieser Posten ursprünglich nicht vorgesehen war. Das Zentrum sollte vom Komitee verwaltet und eigentlich von einem jungen und unerfahrenen Mann geleitet werden. Andrée Viénot fand ihren Mann zutiefst angewidert und entmutigt durch die Auseinandersetzungen. Was den Viénots, vor allem Andrée Viénot, Sorgen machte, war der Gebrauch des Mayrisch-Namens für den geplanten Pariser Treffpunkt. Nach dem Ausscheiden ihres Mannes, so legte es Andrée Viénot ihrer Mutter gegenüber dar, hätte die Familie keinen Einfluß mehr auf diese Institution und „cela pourrait aussi devenir un nid de snobs et de réactionnaires, ou un centre d'intrigues quelconques «. ${ }^{438}$ Auch für Viénots künftige politische Karriere, die zu jener Zeit offenbar bereits geplant wurde, könnte dies ein Hindernis darstellen.

Die weitere Abwicklung der Affäre schleppte sich bis in den Dezember hinein, und das einzige, was festzustehen schien, war die Auflösung der Büros bis zum Jahresende. Während Krukenberg seit zwei Monaten als deutscher Generalsekretär benannt worden war, machte Laurent keine Anstalten, einen Namen festzulegen. In dieser Situation leitete d'Ormesson mit einem Brief an Peyerimhoff ein neues Kapitel im Ringen um die künftige Struktur des Komitees ein. D'Ormesson hatte seinem Freund Viénot einen Besuch in Berlin abgestattet und dabei erkannt »que ce bureau rend ici d'inappréciables services, surtout pour établir des contacts entre Français et Allemands $\ll{ }^{439}$ Der Journalist, der mit dem französischen Botschafter und dessen Mitarbeitern, mit anderen Franzosen in Berlin, mit den Mitgliedern der deutschen Komiteesektion sowie mit einflußreichen Deutschen aus dem politischen Milieu gesprochen hatte, mußte feststellen, daß alle den Weggang Viénots und die Auflösung des Büros heftig bedauerten. Besonders beeindruckt zeigte sich d'Ormesson von einer Unterhaltung mit Hesnard, der die Auflösung des Büros für einen großen Fehler hielt und die Bedeutung eines deutsch-französischen Treffpunktes in der Hauptstadt herausstrich.

${ }^{437}$ Andrée Viénot an ihre Mutter, 28,11.1929: NL Viènot.

${ }^{438}$ Ibid.

${ }^{439}$ D'Ormesson an de Peyerimhoff, 19.12.1929: NL d'Ormesson II. 
Dieses klare Votum gegen die Auflösung überraschte selbst d'Ormesson, der daraufhin in Übereinstimmung mit der französischen Gruppe kurzerhand Viénot die Fortführung der Büroleitung antrug. Obwohl dieser zweifellos Genugtuung über die Wendung verspürte, gab er an, aus persönlichen Gründen nicht länger als bis Ostern 1930 in Berlin bleiben zu können ${ }^{440}$. Zu diesem Zeitpunkt hatte sich Viénot innerlich schon längst vom Mayrisch-Komitee verabschiedet. $\mathrm{Da}$ er seit jeher sehr ehrgeizig war, wußte er, daß sein Posten beim Mayrisch-Komitee nur eine Durchgangsstation sein konnte. Angesichts des Stillstandes bei den deutsch-französischen Annäherungsbestrebungen nach der Regelung von Reparations- und Räumungsfrage einerseits sowie Viénots politischer Distanzierung zur Mehrheit der konservativen Komiteemitglieder andererseits sah er keinen Sinn in einem weiteren Verbleiben auf seinem Posten. Viénots berufliche Ziele waren hochfliegend. Bereits im Februar 1928 hatte er seinem Freund Bertaux anvertraut, er wolle einmal Außenminister werden $^{441}$. Sein weiterer Weg sollte ihn in die aktive Politik führen.

Die französischen Mitglieder setzten ihre deutschen Kollegen über die Änderung der Wünsche in Kenntnis, und d'Ormesson erklärte sich bereit, unter Beibehaltung des Berliner Büros den Posten des Generalsekretärs zu übernehmen. Viénot sollte für eine Übergangszeit seine Funktion in Berlin fortfüh$\mathrm{ren}^{442}$. Damit hatte die französische Sektion ihre Rechnung allerdings ohne ihren Präsidenten gemacht, der sich weiterhin jeglicher Beteiligung Viénots an der künftigen Organisation in den Weg stellte. D'Ormesson trat daraufhin ein zweites Mal vom Posten des Generalsekretärs zurück, da er seine Zusage mit der Beibehaltung der Büros verknüpft hatte. Laurent lehnte eine Revision der Düsseldorfer Beschlüsse ab, da sich die französische Sektion mit diesem Schritt seiner Meinung nach lächerlich machte ${ }^{443}$. Während nun zwischen und innerhalb der Sektionen das Tauziehen um die künftige Organisation weiterging, zog sich Viénot nach Colpach zurück, um der Entscheidungsfindung nicht im Wege zu stehen.

Laurent erklärte derweil gegenüber Nostitz, die Auflösungsbeschlüsse von Düsseldorf behielten ihre volle Gültigkeit. Nostitz war offensichtlich über die gegensätzlichen Aussagen aus Paris irritiert und erachtete »eine baldige Klärung des gegenwärtigen Schwebezustandes [für] dringend wünschenswert«. ${ }^{444} \mathrm{Am}$ 14. Februar setzte Laurent seinen Kollegen Nostitz dann doch davon in Kenntnis, daß sich die französischen Mitglieder des Exekutivkomitees für die Beibehal-

440 Vgl. Viénot an d'Ormesson, 3.1.1930: NL d'Ormesson II.

441 Vgl. BERTAUX, Un normalien à Berlin, S. 184.

442 Vgl. Krukenberg an die Mitglieder der deutschen Gruppe des Studienkomitees, 8.1.1929: NL d'Ormesson III, CFAI 1927-1932.

${ }^{443} \mathrm{Vgl}$. d'Ormesson an Laurent, o.D. und Laurent an d'Ormesson, 11.1.1929: NL d'Ormesson III, CFAI 1927-1932.

444 Von Nostitz an d'Ormesson, 1.2.1930 und ders. an dens., 14.2.1930: NL d'Ormesson I, Presse, Correspondance générale, divers. 
tung eines Repräsentanten in Berlin ausgesprochen hätten, wobei die Vertretung nur noch in verminderter Form weiterexistieren sollte ${ }^{445}$. In der gemeinsamen Sitzung des Exekutivausschusses am 1. März 1930 wurde zum zweiten Mal innerhalb eines halben Jahres eine neue Organisationstruktur vorgestellt. Unter dem Eindruck der Weltwirtschaftskrise wurde die Idee eines gut ausgestatteten und clubähnlichen Centre Émile Mayrisch unter Beibehaltung der beiden Büros aus finanziellen Gründen fallengelassen. Statt dessen sollte im MayrischZentrum ein gemeinsames Generalsekretariat eingerichtet werden. Den beiden Generalsekretären oblag die Erledigung der laufenden Geschäfte des Komitees. Die Einrichtung eines gleichwertigen Treffpunktes in Berlin wurde nicht für notwendig erachtet. Ein deutsches Komiteemitglied sollte die Betreuung von Franzosen in Berlin übernehmen, unterstützt von einem sjungen französischen Hilfsarbeiter ${ }^{446}$ Die Kosten sollten geteilt und für die nächsten drei Jahre übernommen werden.

Gegen diese neue Organisation protestierte jedoch d'Ormesson, der sie als extrem unausgewogen empfand. In seinen Augen lagen alle Vorteile auf deutscher Seite: Das Pariser Büro existierte de facto weiter, und der deutsche Generalsekretär konnte wie bisher in Paris Einfluß ausüben, während in Berlin lediglich ein Student die Organisation vertreten sollte, dem keine Bedeutung zukam. Trotz dieser ungleichen Nutzenverteilung war eine paritätische Kostenbeteiligung vorgesehen. "Ainsi«, so schlußfolgerte d'Ormesson, "la solution adoptée me paraît tout à fait inégale. Elle est simple, nette, et extrêmement avantageuse pour les Allemands. ${ }^{447}$ Einzig in der Rückkehr zum alten System erblickte d'Ormesson die Garantie für ein normales Komiteeleben. Den Posten des Generalsekretärs lehnte er endgültig ab. Laurent selbst stimmte d'Ormesson in dessen Einschätzung von den einseitigen deutschen Vorteilen zu, verwies jedoch darauf, daß dies durch die Aktivität und Autorität des französischen Generalsekretärs ausgeglichen werden könnte. Angesichts des Planes, einen jungen Mann ohne große berufliche Erfahrung nach Berlin zu schicken, erscheint das Argument Laurents vorgeschoben. Gerade die Aktivität und Selbständigkeit Viénots war in den zurückliegenden Jahren bei ihm auf Kritik gestoßen. Offensichtlich ging es Laurent im Gegensatz zu d'Ormesson und Viénot nicht darum, eine symmetrische deutsch-französische Organisation zu verwirklichen, sondern er wollte in erster Linie die Fäden seiner Sektion unangefochten von einem eigenwilligen Bürodirektor selbst in Händen halten. Laurent bat d'Ormesson, Viénot von den Beschlüssen in Kenntnis zu setzen und diesen zu bitten, die nötigen Maßnahmen zur Auflösung seines Büros zu treffen ${ }^{448}$.

\footnotetext{
445 Vgl. Laurent an von Nostitz, 14.2.1929: NL d'Ormesson II.

446 Bericht über die am 1. März 1930 in Paris abgehaltene Sitzung des gemeinsamen Exekutivkomitees, 6.3.1930: PAAA, Botschaft Paris, DFS, Bd. 2.

447 D'Ormesson an Laurent, o.D.: NL d'Ormesson III, CFAI 1927-1932.

${ }^{448}$ Vgl. Laurent an d'Ormesson, 10.3.1930: NL d'Ormesson III, CFAI 1927-1932.
} 
Viénot lehnte die Liquidierung seines eigenen Büros jedoch ab. Er bestand darauf, Berlin endgültig Mitte März 1930 zu verlassen. Zudem hielt er die Beschlüsse des Exekutivkomitees für unsinnig und wollte sich davon distanzieren. Viénot sah in der neuen Institution in erster Linie einen Nachfolger des Pariser Büros und befürchtete ein mögliches Kompetenzgerangel unter den Generalsekretären: "C'est, à mon avis, se faire d'une collaboration franco-allemande une idée trop simpliste que l'envisager sous la forme d'une fusion [...]. (49 $^{449}$ Besonders nachdrücklich kritisierte Viénot die Aufgabe des Berliner Büros. Er erinnerte Laurent daran, daß Émile Mayrisch - nicht zuletzt aber auch er selbst das Komitee auf der Basis von absoluter Gleichberechtigung und Gegenseitigkeit konzipiert hatte. Diese Prinzipien sah er in der neuen Organisation jedoch nicht gewahrt.

Auf den Rücktritt d'Ormessons und die Weigerung Viénots, sein Büro zu liquidieren, folgte ein Brief von Aline Mayrisch, die dem Komitee nunmehr die Ermächtigung entzog, die Organisation mit dem Namen ihres Mannes zu bezeichnen. Als während einer Sitzung der französischen Gruppe de Peyerimhoff und Chardon sich dafür aussprachen, Viénot offiziell den Dank und die Anerkennung des Komitees für seine geleisteten Dienste auszusprechen, überschlugen sich die Ereignisse. De Peyerimhoff verknüpfte den Antrag mit der Forderung nach Eintritt Viénots in das Exekutivkomitee, wogegen Laurent sein Veto einlegte und von den Mitgliedern eine Entscheidung zwischen ihm und Viénot forderte. Daraufhin erfolgte die einstimmige Wahl Viénots in das Exekutivkomitee. Diesen Sieg über Laurent genoß Viénot nicht ohne persönliche Genugtuung:

Sous le regard épouvanté de son portrait (qui, à l'usage des futures générations d'administrateurs de la Banque des Pays du Nord, orne déjà la salle du conseil de ladite), Charles Laurent a donné sa démission, s'est levé, dans un silence mortel, a gagné péniblement, sur ses deux cannes, la porte de sa propre salle des séances [...] tandis que le Comité continuait de siéger sous la présidence de Peyer[imhoff]... ${ }^{450}$.

Viénot war mit dem Ergebnis zufrieden. Laurent war geschlagen, und er selbst war frei zu tun, was immer er wollte. Dabei dachte er an seine künftige politische Laufbahn, für die er sich entschieden hatte. 1932 wollte er an den Parlamentswahlen teilnehmen und plante bereits seine Wahlkampagne. Offiziell wurden für den Rücktritt Laurents gesundheitliche Gründe angefuihrt. Den Vorsitz teilten sich Peyerimhoff, Chardon und Fontaine bis zur Wahl eines neuen Präsidenten. Die Nachfolge Laurents übernahm dann Pierre de Margerie nach seiner Ablösung durch André François-Poncet als Botschafter in Berlin im Oktober $1931^{451}$. D'Ormesson erklärte sich nun wieder bereit, das Generalsekretariat zu übernehmen. Régis de Vibraye sollte d'Ormesson unterstützen und

\footnotetext{
449 Viénot an Laurent, 14.3.1930: NL d'Ormesson III, CFAI 1927-1932

${ }^{450}$ Ders. an de Cénival, 24.3.1930: NL Viénot.

${ }^{451} \mathrm{Vgl}$. Auffray, Pierre de Margerie, S. 497.
} 
zweifellos, nach einer gewissen Einarbeitungszeit, das Generalsekretariat alleine übernehmen ${ }^{452}$.

Krukenberg hingegen war mit der neuen Entwicklung nicht einverstanden und erklärte seinen Rücktritt vom Posten des deutschen Generalsekretärs. In den Augen Viénots hatte Krukenberg ihm die persönliche Niederlage bei seinem Vorgehen gegen Nostitz im Mai 1929 niemals verziehen und seither jede Gelegenheit genutzt, Laurent bei dessen Intrigen zu unterstützen ${ }^{453}$. Laurent war unterdessen ganz aus dem Komitee ausgetreten, gefolgt von Debrix und Laederich. Nach seinem Ausscheiden erhielt Viénot ein offizielles Dankesschreiben von Außenminister Briand, welches von Botschafter de Margerie verfaßt worden war und für das sich Hesnard bei Léger eingesetzt hatte. Viénot sah das Schreiben als »un >Ersatz pour la légion d'honneur trois fois réclamée par Margerie et que mon jeune âge a empêché de me donner... «. ${ }^{454}$ Briand stellte in seinem Dankesbrief heraus, daß Viénots Wirken vor allem auf jene konservativen Kreise gerichtet war, die sich lange gegen den Gedanken der internationalen Zusammenarbeit gesträubt hatten: „Guidé par votre souci patriotique et par votre attachement à l'œuvre de paix, vous avez sû placer la conception de votre tâche au-dessus de toute considération de personnes ou de partis. $\ll^{455}$

An der Plenarversammlung des Komitees im Mai 1930 in Heidelberg nahm Viénot nicht mehr als Direktor des Berliner Büros, sondern als Mitglied des Komitees und seines Exekutivausschusses teil. Die Organisation des Studienkomitees, die hier beschlossen wurde, sah wiederum anders aus als noch zwei Monate zuvor festgelegt. Der Plan zur Einrichtung eines Centre Émile Mayrisch war aus finanziellen Erwägungen endgültig fallengelassen worden. Statt dessen wurde wieder auf die beiden Büros in Berlin und Paris rekurriert, die jedoch künftig als Generalsekretariate bezeichnet wurden. Dabei sollte der französische Generalsekretär in Paris und der deutsche in Berlin sitzen ${ }^{456}$. Die Entscheidung stellte einen Kompromiß zwischen der ursprünglichen Organisation und den Düsseldorfer Beschlüssen dar. Zwar sollten die Generalsekretäre nun nicht mehr als ehrenamtliche Mitarbeiter tätig werden und auch die deutschfranzösische Gleichberechtigung wurde beibehalten, doch die Entscheidung, jeden Generalsekretär in seinem eigenen Land zu beschäftigen, bedeutete den endgültigen Abschied vom ursprünglich in den Programmentwürfen vorgese-

${ }^{452}$ Vgl. de Peyerimhoff an von Nostitz, 27.3.1930: NL d'Ormesson III, CFAI 1927-1932.

${ }^{453} \mathrm{Vgl}$. Viénot an d'Ormesson, 29.3.1930: NL d'Ormesson II.

${ }^{454}$ Ders. an dens., o.D.: NL d'Ormesson II. Vgl. auch de Margerie an Briand, 10.4.1930: MAECAD, Ambassade de France à Berlin, B, 463, d. CFAID.

${ }^{455}$ Briand an Viénot, 25.5.1930: NL Viénot.

${ }^{456} \mathrm{Vgl}$. Réunion plénière du Comité franco-allemand à Heidelberg du 16 au 18 mai 1930: NL d'Ormesson III, Documents 1926-1932, Comité franco-allemand 1930; von Nostitz, Heidelberger Tagung vom 16./17. Mai 1930, 30.5.1930: PAAA, Botschaft Paris, DFS, Bd. 2; Krukenberg an Köpke, 19.5.1930: ADAP, B, XV, Nr. 36, S. 88f. 
henen Komiteezweck. Die ehrgeizige Zielsetzung der Pressebeinflussung hatte sich bereits in den Monaten nach Locarno als schwer realisierbar erwiesen. In einer Phase, in der die Fortsetzung der Verständigungspolitik grundsätzlich zur Debatte stand und die nationalen Interessen Frankreichs und Deutschlands kaum noch durch Verhandlungen in Einklang zu bringen waren, konnte sich innerhalb des Komitees keine Mehrheit mehr zu einer Annäherungsstrategie durchringen, die über eine rein wirtschaftliche Konzeption auf die Beseitigung psychologischer Hemmnisse abzielte.

Nostitz zeigte sich erfreut über die Beendigung der Unstimmigkeiten unter den französischen Mitgliedern und stellte fest, daß diese "zu einer Neuordnung der Geschäftsführung bereit sind, die den deutschen Wünschen völlig gerecht wird «. ${ }^{457}$ Während als Nachfolger von Viénot Graf Régis de Vibraye feststand, brauchte die deutsche Gruppe länger, um einen Generalsekretär zu benennen. Bücher trug Haas den Posten an, und dieser war offensichtlich durchaus bereit anzunehmen. Viénot vermutete jedoch, daß Krukenberg aus persönlicher Feindschaft und wegen der Freundschaft zwischen Haas und ihm alles tun würde, um dessen Ernennung zu verhindern. Darüber hinaus glaubte er, daß die jüdische Herkunft von Haas in den Augen vieler deutscher Komiteemitglieder ein emstes Hindernis darstellte, andernfalls hätte Nostitz ihn schon längst nominiert. Viẻnot, der sich gegenüber den Deutschen nicht für Haas einsetzen konnte, da die beiden als eng befreundet galten, bat d'Ormesson, seinem Wunschkandidaten französische Unterstützung zuteil werden zu lassen ${ }^{458}$. Die Mehrheit der deutschen Mitglieder konnte Haas dennoch nicht für sich gewinnen: Zum 1. November 1930 übernahm Max Clauss den Posten des Generalsekretärs in Berlin.

Mit dem Ausscheiden Viénots aus dem Komitee war auch dessen große Zeit beendet, wenngleich es bis 1938 weiterexistierte. Die Aktivität der Organisation versandete immer mehr, ohne daß ein Einfluß auf die Politik zu bemerken gewesen wäre. Auch d'Ormesson zog sich weitgehend aus dem Studienkomitee zurück und verlegte sich wieder hauptsächlich auf seine publizistische Tätigkeit $^{459}$. In der Zwischenzeit entfernte sich Viénot in politischer Hinsicht immer mehr von seinen Freunden Max Clauss und Amold Bergsträsser. Während er seinen Wahlkampf auf seiten der briandistischen Linken vorbereitete, zeigte sich Clauss, der Generalsekretär des Mayrisch-Komitees, in einem Artikel in der Revue des Vivants als Anhänger eines verschärften außenpoliti-

${ }^{457}$ Von Nostitz, Sitzung der deutschen Gruppe am 16. Mai 1930 im "Europäischen Hof $"$ in Heidelberg, Mai 1930: PAAA, Botschaft Paris, DFS, Bd. 2.

${ }^{458} \mathrm{Vgl}$. Viénot an d'Ormesson, 2.6.1930: NL d'Ormesson II.

${ }^{459}$ Diane de Vogüé berichtet, daß die Tagebucheinträge d'Ormessons zum Mayrisch-Komitee nach 1930 praktisch abbrechen. Sie gelangt zu der Einschätzung, "qu'il considère désormais celui-ci [le Comité franco-allemand] comme inefficace $\ll$. Vgl. de VOGÓE, Wladimir d'Ormesson et le rapprochement, S. 86. 
schen Revisionismus ${ }^{460}$. Ende 1930 versuchte Andrée Viénot dann auf die politische Haltung von Bergsträsser einzuwirken, die ihr Sorgen bereitete. Bergsträsser, der bis Ende der zwanziger Jahre als Anhänger der DDP gegolten hatte, favorisierte zu Beginn der dreißiger Jahre eine autoritäre Umstrukturierung der Weimarer Republik. Der Vorwurf, Bergsträsser hege Sympathien für den Nationalsozialismus, tauchte bereits zu dieser Zeit auf ${ }^{461}$. Auch Andrée Viénot stellte derlei Tendenzen bei dem Staatswissenschaftler fest: "Il fait une crise de nationalisme, presque de national-socialisme, dangereuse et déplorable. Son profond déséquilibre, son manque de jugement, de stabilité, de Zuverlässigkeit, s'exagèrent de plus en plus. Il s'abandonne de plus en plus à des passions politiques dont il ne critique pas la source. $\ll^{462} \mathrm{Zu}$ Andrée Viénots Einschätzung mag Bergsträssers 1930 erschienenes Buch über "Sinn und Grenzen der Verständigung zwischen Nationen « beigetragen haben, in dem er der Verständigungspolitik als erfolgreicher Gestaltungsmöglichkeit des deutsch-französischen Verhältnisses eine Absage erteilte. An erster Stelle standen für ihn »die Interessen des Nationalstaates und der Nation ${ }^{463}{ }^{3}$, so daB Verständigung nurmehr als Weg, nicht als Ziel politischen Handelns betrachtet wurde. Dieses sollte die Überwindung der Versailler Staatenordnung sein. In Zukunft könne es für die deutsche Politik deshalb nur darum gehen, den Versailler Vertrag »in Richtung auf den status quo ante $1919 \mathrm{zu}$ erschüttern ${ }^{464}$. Diese Argumentation, die der außenpolitischen Ungebundenheit und damit Unberechenbarkeit Tür und Tor öffnete, mag Andrée Viénot im Hinterkopf gehabt haben, als sie Berg-

${ }^{460}$ Vgl. Max CLAuSS, L'État politique de l'Allemagne, in: La Revue des Vivants 5 (1931) Nr. 4, S. 406-418.

${ }^{46 !}$ Arnold Bergsträsser (1896-1964) gehörte dann 1932/33 zu den Beratern des Reichkanzlers von Schleicher. Wegen Zweifeln an seiner politischen Zuverlässigkeit und aufgrund jüdischer Vorfahren wurde Bergsträsser im August 1936 die Lehrbefugnis entzogen. 1937 begab er sich ins Exil in die USA und kehrte 1954 in die Bundesrepublik zurück, wo er zu einem Begründer der modernen Politikwissenschaft wurde. Zur Einordnung Bergsträssers zwischen Jugendbewegung, jungkonservativem Denken und Nationalsozialismus vgl. Reinhard BLOMERT, Intellektuelle im Aufbruch. Karl Mannheim, Alfred Weber, Norbert Elias und die Heidelberger Sozialwissenschaften der Zwischenkriegszeit, München, Wien 1999, S. 301-328; SCHMITT, Ein stypischer Heidelberger im Guten wie im Gefährlichen«.

${ }^{462}$ Andrée Viénot an ihre Mutter, 1.12.1930: NL Viénot. Analog äußerte sich Viénot, der Bergsträsser aber immerhin noch ernsthaften Willen zur Verständigung unterstellte: $»[. .$. il est même certain que sur plus d'un point, B. [ergsträsser] a fait un effort sérieux de compréhension et de rapprochement, mais cela n'empêche qu'il passe certainement, à l'heure actuelle, par une crise de nationalisme entretenue par le milieu d'étudiants de Heidelberg aux yeux desquels il a toujours trop tendance à vouloir apparaître comme le grand homme«. Viènot an d'Ormesson, 16.1.1931: NL d'Ormesson II.

${ }^{463}$ Amold BERGSTRÄSSER, Sinn und Grenzen der Verständigung zwischen Nationen, München, Leipzig 1950 [Erstausgabe 1930], S. 88.

${ }^{464}$ Ibid. S. 20. 
strässers Unzuverlässigkeit beklagte. Auch Max Clauss erschien Andrée Viénot nun »un peu ungemütlich, un peu kaltschnäuzig«. ${ }^{465}$

Die stark divergierenden deutschen und französischen Interessen in Fragen der Abrüstung und der Reparationen sowie die Tendenz in beiden Sektionen, sich auf nationale Interessenstandpunkte zurückzuziehen, machten eine produktive Arbeit nahezu unmöglich. Zeitgleich nahm auch die Unterstützung durch die Industrie ab. Hatte das Komitee im Haushaltsjahr 1928/29 noch 143000 Mark an Zuschüssen von Banken und Industrie erhalten, so sank das Spendenniveau kontinuierlich, bis im Jahr 1932 nur noch 42000 Mark gesammelt werden konnten ${ }^{466}$. Das Interesse der Industrie an einem derartigen deutsch-französischen Unternehmen hatte im Zuge einer Renationalisierung der Offentlichkeit und der Politik einerseits sowie angesichts der Weltwirtschaftskrise andererseits offensichtlich stark nachgelassen. Im September 1929 hatte Viénot als Gast am Kongreß des Reichsverbandes der Deutschen Industrie teilgenommen und bereits zu diesem Zeitpunkt eine starke nationalistische Tendenz bemerkt, die sich vor allem gegen Frankreich richtete. Angesichts dieser Repräsentanten der deutschen Wirtschaftselite mußte Viénot feststellen "que l'on est actuellement plus éloigné qu'on ne l'est en France, d'une acceptation vraiment clairvoyante des conditions auxquelles peut et doit s'effectuer un rapprochement $\ll{ }^{467}$ Einzelne Mitglieder des Studienkomitees schienen diese Einschätzung zu bestätigen. Clauss und Bergsträsser waren nicht die einzigen, die sich zu Beginn der dreißiger Jahre vom Gedanken der Verständigung sukzessive verabschiedeten. Gustav Krukenberg stellte 1931 in einem Vortrag fest, daß »unser Drängen und Anbiedern an Frankreich in den letzten Jahren [...] mehr von Schaden als von Nutzen « gewesen sei. Da Frankreich keine Revision der Friedensverträge zulassen wolle, müsse man nun wvor allem durch eine einige nationale Politik dem Franzosen die Hoffnung nehmen, daß er, wie seit Jahrhunderten, so auch jetzt wieder mit der deutschen Uneinigkeit rechnen

${ }^{465}$ Andrée Viénot an ihre Mutter, 25.2.1931: NL Viénot. Max Clauss (1901-1988) bekleidete bis 1932 den Posten des Berliner Sekretärs beim Mayrisch-Komitee. 1933 schloß er sich dem Nationalsozialismus an und wurde einer der führenden Auslandskorrespondenten der NS-Presse. Seit 1934 leitete er den "Dienst aus Deutschland «. Ab 1942 bekannte sich Clauss aus rassistischen, antisemitischen und antibolschewistischen Motivationen heraus zum totalen Vernichtungskrieg im Osten. Als ihm 1943 klar wurde, daß der Krieg nicht mehr zu gewinnen war, setzte er sich nach Lissabon ab, bis er 1956 in die Bundesrepublik zurückkehrte. Dort bekleidete er verschiedene Spitzenpositionen in der Wirtschaft, zuletzt vertrat er die Interessen der Hannover-Messe bei den europäischen Behörden in Brüssel. Vgl. MứlLer, Der Publizist; DERS., "Mitarbeit in der Kulisse...«. Viénots Sympathien für Max Clauss waren Pierre Bertaux von jeher völlig unverständlich. Er sah in ihm wun sale imbecile«, "très content de lui«, der ihm »très antipathique« war. BERTAUX, Un normalien à Berlin, S. 252.

${ }^{466} \mathrm{Vgl}$. L'HUILLIER, Dialogues franco-allemands, S. 99.

${ }^{467}$ Viénot an de Peyerimhoff, 27.9.1929: NL d'Ormesson II. 
könne ${ }^{468}$ Vom Nutzen der Verständigungspolitik für die ersehnte Revision der Versailler Ordnung enttäuscht, wandten sich nicht wenige deutsche Mitglieder des Studienkomitees der neuen Hoffnung Adolf Hitler zu. Selbst vor dem kosmopolitischen Haus der Nostitz machte der Stimmungsumschwung nicht Halt. Als Harry Graf Kessler im Juli 1932 seine Freundin Helene von Nostitz besuchte, stellte er fest, daß »die Atmosphäre im Nostitzschen Haus [...] ganz nationalsozialistisch durchsetzt ${ }^{469}$ war. Kritischen Bemerkungen gegenüber den Nationalsozialisten wurde mit verlegenem Schweigen begegnet.

Nach der Machtübernahme der Nationalsozialisten glitt die Apathie des Studienkomitees langsam in Agonie über, wobei sich das Sterben in Stille vollzog, da sich die Mitglieder seit 1933 in eine "präventive Abkapselung ${ }^{470}$ begeben hatten. Die Gleichschaltung der deutschen Komiteesektion erschien der neuen nationalsozialistischen Führung zunächst als inopportun, da in diesem Fall mit der Auflösung der französischen Gruppe und »mit unerwünschtem Echo in der Öffentlichkeit « ${ }^{471}$ gerechnet wurde. Dies wäre umso unerfreulicher gewesen, als Hitler nach seiner Regierungsübernahme ein kühl kalkuliertes Werben um Frankreich begann und einen vorübergehenden Modus vivendi mit der stärksten Militärmacht des Kontinents suchte. Entweder durch ein Bündnis mit dem seit Beginn der dreißiger Jahre als innenpolitisch geschwächt eingeschätzten Nachbarland oder durch dessen militärische Niederwerfung sollte dann dem Dritten Reich der Rücken frei gehalten werden für den entscheidenden Expansionskrieg im Osten ${ }^{42}$. Für das Studienkomitee bedeutete der Preis der Fortexistenz die weitgehende Lahmlegung aller Aktivităt, wollte man nicht zum Instrument nationalsozialistischer Verständigungspropaganda werden. $\mathrm{Da}$ es seine institutionelle Unabhängigkeit über Jahre hinweg zu wahren vermochte, lag sicherlich auch an der dort vertretenen geballten Wirtschafts- und Finanzmacht seiner Mitglieder. Der Versuch Ribbentrops, das Studienkomitee 1938 als Wirtschaftsausschuß in die nationalsozialistische Deutsch-Französische Gesellschaft einzugliedern ${ }^{473}$, scheiterte. Dennoch entschloß sich das Mayrisch-

${ }^{468}$ Zerstörte Illusionen, in: Lokal Anzeiger, 23.1.1931.

${ }^{459}$ KESSLER, Tagebücher, Eintrag vom 14.7.1932, S. 717.

${ }^{470}$ Bock, Zwischen Locarno und Vichy, S. 45. Der Generalsekretär des Studienkomitees in Paris, Rümelin, stellte im Mai 1933 auf französischer Seite eine "vorhandene Selbstmordstimmung " fest. Vgl. Rümelin an von Nostitz, 19.5.1933: PAAA, Botschaft Paris, DFS, Bd. 2.

471 Aschmann an von Nostitz, 18.4.1933: PAAA, Botschaft Paris, DFS, Bd. 2.

${ }^{472}$ Vgl. zu Hitlers Frankreichpolitik Franz KNIPPING, Frankreich in Hitlers Außenpolitik 1933-1939, in: Manfred FUNKE (Hg.), Hitler, Deutschland und die Mächte. Materialien zur Außenpolitik des Dritten Reiches, Düsseldorf ${ }^{2}$ 1978, S. 612-627; Klaus HIIDEBRAND, Die Frankreichpolitik Hitlers bis 1936, in: Francia 5 (1977) S. 591-625; DERS., Das Dritte Reich, S. 18. Zu Hitlers außenpolitischem Stufenplan siehe DERS., Deutsche Außenpolitik 1933-1945. Kalkül oder Dogma?, Stuttgart u.a. ${ }^{5} 1990$, S. 27 f.

${ }^{473}$ Vgl. Lorenz an das Deutsch-Französische Studienkomitee, 30.11.1938: PAAA, Botschaft Paris, DFS, Bd. 3. 
Komitee schließlich gegen Ende des Jahres 1938 zur Selbstauflösung. Der Vorschlag des deutschen Generalsekretärs Rümelin, das Studienkomitee mit Blick auf England zu einem Komitee für westeuropäische Wirtschaftsfragen umzuwandeln, fand keinen Anklang ${ }^{474}$. Viénot ließ seit der Übernahme eines Parlamentsmandats 1932 seine Mitgliedschaft im Studienkomitee ruhen. Seine Aktivität auf seiten der politischen Linken wurde indes von deutscher Seite mit Skepsis und zunehmenden Mißfallen beobachtet. Nach dem Wahlsieg der Volksfront 1936 erinnerte man sich an Viénot als »distanziertes Mitglied unserer französischen Gruppe«, das »dem heutigen Deutschland feindlich gegenüber« stehe ${ }^{475}$. Obgleich Viénot den förmlichen Austritt aus dem Komitee nie erklärte, hatte er mit seinem Bekenntnis zum Sozialismus und spätestens mit seiner Teilnahme an Léon Blums Volksfrontkabinett den Bruch mit dem Studienkomitee endgültig vollzogen.

In der Retrospektive fanden sich vielerlei Erklärungsmuster für das letztliche Scheitern des Mayrisch-Komitees. Wladimir d'Ormesson bezeichnete später das Experiment des Mayrisch-Komitees als verfrüht, die Konzeption als zu intellektuell ${ }^{476}$. Max Clauss machte den Ausschluß der Mittel- und Arbeiterklasse, der Beamten und Parlamentarier für die Schwäche der Organisation verantwort$\operatorname{lich}^{477}$. Die mangelnde demokratische Verankerung des Komitees dürfte allerdings nicht eine zeitgenössische, sondern eine spätere Einsicht von Clauss darstellen. Gustav Krukenberg schließlich widersprach der Deutung d'Ormessons vom vorzeitigen Verständigungsversuch. Zwar sei die Zeit noch nicht reif für die Durchführung der Ziele gewesen, aber die Ideen letztlich nach vorne gerichtet und zukunftsweisend ${ }^{488}$.

Das Studienkomitee zerbrach zu Beginn der dreißiger Jahre - also Jahre vor seinem offiziellen Ende - sowohl an den inneren Widersprüchen, die ihm seit seiner Gründung innegewohnt hatten wie auch an den Gegebenheiten der äußeren Politik. Ende der zwanziger Jahre trat das Grunddilemma der deutschfranzösischen Beziehungen deutlicher denn je zutage. Während Sinn und Zweck der deutschen Außenpolitik in einer Revision der Versailler Ordnung lag, war das Streben Frankreichs auf die Erhaltung des Status quo ausgerichtet. Versuchte man in Deutschland, durch die Verständigung zum Nachbarland eine friedliche Revision zu ermöglichen, so erhoffte man sich in Frankreich, mittels Annäherung und einzelner Zugeständnisse wie der vorzeitigen Rheinlandräu-

${ }^{474}$ Vgl. von Nostitz an von Welczeck, 21.12.1938; Rümelin, Vorschlag zur Erweiterung des Deutsch-Französischen Studienkomitees (Mayrisch) nach England, Abschrift der Denkschrift an den Herm Reichsaußenminister v. 18.5.1938: PAAA, Botschaft Paris, DFS, Bd. 3.

${ }^{475}$ Schreiben an von Nostitz ohne Unterschrift, 5.6.1936: PAAA, Botschaft Paris, DFS, Bd. 3.

${ }^{476}$ Vgl. d'ORMESSON, Une tentative, S. 26; ders., Pierre Viénot, S. 84: NL d'Ormesson II.

${ }^{47}$ Vgl. Max Clauss, Rede vor der Belgisch-Luxemburgisch-Deutschen Handelskammer am 27.10.1966: Une initiative d'entente franco-allemande avant l'heure: Le Comité Mayrisch (1926-32): NL d'Ormesson III, Documents 1926-1932.

${ }^{478}$ Vgl. Krukenberg an d'Ormesson, 10.3.1962: NL d'Ormesson III, Documents 1926-1932. 
mung, die Akzeptanz der Nachkriegsordnung durch den Nachbarn zu erwirken. Als 1929 die Neuregelung der Reparationen und die vorzeitige Räumung des Rheinlandes zum 30. Juni 1930 beschlossen waren, gab es zwischen Deutschland und Frankreich nichts mehr zu verhandeln. Jede weitergehende Konzession von französischer Seite hätte eine grundlegende Revision des Versailler Vertrages bedeutet ${ }^{479}$. Die deutsch-französische Verständigungspolitik war an ihre Grenzen gestoßen. In dem Augenblick, in dem die Nationalinteressen Deutschlands und Frankreichs immer weiter auseinanderliefen, war auch kein Ausgleich innerhalb des Studienkomitees mehr möglich. Im Zeichen wachsender bilateraler Spannungen brachen nun ideologische Differenzen unter den Mitgliedern hervor, die zu Hochzeiten der Locarno-Politik hatten überspielt werden können. So kollidierte beispielsweise Edmond Vermeils Rückgriff auf universelle Normen der französischen Revolution zur Erklärung eines angemessenen Deutschlandbildes mit der Forderung nach nationaler Selbstdefinition durch Ernst Robert Curtius. Henri Lichtenberger plädierte 1929 für das Weltbürgertum, während Arnold Bergsträsser das nationale Prinzip als Basis für die Größe der abendländischen Welt betonte ${ }^{480}$. Hinzu kam der Konflikt zwischen den Befürwortern einer politisch orientierten Annäherungsstrategie mit Hilfe von Presse und Offentlichkeitsarbeit und jenen einer rein wirtschaftlich ausgerichteten Kollaboration. Obwohl Ina Belitz diesen Grundkonflikt richtig erkannt hat, zieht sie doch die falschen Schlüsse, wenn sie die geringe Breitenwirksamkeit des Komitees auf »die konsequente Umsetzung von Viénots Strategien der indirekten, diskreten und rigide hierarchisierten Einflußnahme auf die Öffentlichkeit ${ }^{481}$ zurückführt. Genau gegen diese Tendenz setzte Viénot seine ganze Aktivität, nicht gegen, sondern in Einklang mit Mayrisch. Erst nach dessen Tod konnte das Abblocken aller Reforminitiativen gelingen, und mit dem Ausscheiden Viénots verlor das Studienkomitee seinen aktivsten und leidenschaftlichsten, aber auch eigenwilligsten und unbequemsten Vertreter.

\section{2. „Les Incertitudes allemandes«: Das Fazit jahrelanger Deutschlanderfahrungen}

Seit sich Viénot in den zwanziger Jahren mit der deutsch-französischen Problematik beschäftigte, war er von der Notwendigkeit einer gegenseitigen Kenntnis der Mentalitäten und sozio-politischen Gegebenheiten überzeugt. In seiner Berliner Tätigkeit als Bürodirektor des Mayrisch-Komitees hatte er versucht, als eine Art kultureller Übersetzer den vorurteilsfreien Dialog und das tiefere

\footnotetext{
${ }^{479}$ Vgl. GIRAULT, FranK, Turbulente Europe, S. 157.

${ }^{480}$ Vgl. BOCK, Kulturelle Eliten, S. 89f.

${ }^{481}$ BELITZ, Befreundung mit dem Fremden, S. 206.
} 
Verständnis zwischen Deutschland und Frankreich zu fördern. In seinen Briefen an Lyautey berichtete er ausführlich über seine Eindrücke aus Deutschland, und seit Mitte der zwanziger Jahre finden sich bereits die Gedanken angelegt, die er 1931 in seinem politischen Essay "Incertitudes allemandes« ausführlich darlegte ${ }^{482}$. Die Idee, ein Buch über die deutsch-französischen Beziehungen zu schreiben, gingen in diese Zeit zurück, und sein Aufsatz in der Revue de Genève aus dem Jahre $1925^{483}$ war ursprünglich als Einleitungskapitel einer größeren Studie gedacht. Die Wiederaufnahme des publizistischen Projekts ergab sich aus zwei Vorträgen, die Viénot Ende 1930 im Pariser Musée social über Deutschland halten sollte ${ }^{484}$. Nach dem großen Erfolg der Referate, die offensichtlich viele Pariser Intellektuelle angesprochen hatten ${ }^{485}$, lag der Gedanke nahe, die vorgetragenen Ideen auszuformulieren. Das Buch wurde von der Librairie Valois verlegt, in der vor allem die Autoren der jungen Nachkriegsgeneration mit ihren Erneuerungsideen zu Wort kamen ${ }^{486}$. Ein weiterer Grund für die Niederschrift seiner Gedanken war für Viénot sicherlich der Wunsch, im bevorstehenden Wahlkampf seinen Ruf als Spezialist für die deutsch-französischen Beziehungen zu unterstreichen. Dennoch wird deutlich, daß die Ausführungen nicht durch politische Zweckbestimmung oder Populismus gekennzeichnet sind. Sie stellen vielmehr die Quintessenz von Viénots

${ }^{482}$ Vgl. va. Viénot an Lyautey, 28.11.1926: AN, 475 AP 311. Der Brief erscheint wie eine Zusammenfassung der später detaillierter ausgearbeiteten Überlegungen. Alle grundsätzlichen Gedanken der "Incertitudes allemandes" sind hier bereits angelegt. Siehe auch ders. an dens., 31.10.1926: ibid.

${ }^{483} \mathrm{Vgl}$. Pierre VIÉNOT, République allemande et Allemagne nationale.

${ }^{484}$ Das Musée social war eine 1895 gegründete, sozialreformerische Einrichtung des protestantischen Milieus. Viénot sah darin den besten Ort für derartige Vorträge in Paris. Vgl. Viénot an Becker, 26.5.1930: GStA PK, NL Becker, 2616.

485 Andrée Viénot berichtete von den Vorträgen, zu denen so viele Leute erschienen seien, $\mathrm{daß}$ sie stehen mußten. Während viele Intellektuelle teilgenommen hätten, sei das Interesse von Politikern jedoch gering gewesen. Vgl. Andrée Viénot an ihre Mutter, 1.12.1930 und 21.12.1930: NL Viénot. An der Diskussion über Viénots Vorträge nahm z.B. André Siegfried teil, den Viénot aus dem Umkreis der Union pour la Vérité kannte. Vgl. BocK, Der Blick, S. 52.

4861912 übernahm Georges Valois (1878-1945) die Leitung der Nouvelle Librairie nationale, des Verlagshauses der Action française. Nachdem er zunächst vom Anarchismus zum Monarchismus konvertiert war, gründete er 1925 die erste faschistische Bewegung in Frankreich, den Faisceau. Nach Auflösung des Faisceau 1928 näherte sich Valois der Linken an. In der Bibliothèque syndicaliste seines zwischenzeitlich in Librairie Valois umbenannten Verlages erschienen die Werke vor allem jener jungen Autoren, die eine Erneuerung des Sozialismus und Überwindung des Marxismus anstrebten. Viele von ihnen zählten in den dreißiger Jahren zu den "nonconformistes" oder den "planistes«. Die Bibliothèque syndicaliste galt als eine Ideenwerkstatt der jungen Generation. Zu ihren Autoren zählten Jean Luchaire, Marcel Déat, Bertrand de Jouvenel und Pierre Mendès France. Vgl. die Einträge von Philippe OLIVERA zu Georges Valois und der Librairie Valois, in: Jacques JULLARD, Michel WINOCK (Hg.), Dictionnaire des intellectuels français. Les personnes, les lieux, les moments, Paris 1996, S. 1144-1147. 
Deutschlandreflexionen der vorangegangenen Jahre dar und sollten den Franzosen eine Anleitung an die Hand geben, wie diese zu einem wirklichen Verständnis für das Nachbarland gelangen können. Nicht zuletzt bedeutete für Viénot die Niederschrift seiner auf Deutschland zentrierten Uberlegungen nach dem Weggang aus dem Mayrisch-Komitee auch die Fortführung seines Verständigungsengagements mit anderen Mitteln.

\subsection{Das Wesen der Kulturkrise in Deutschland}

Nach einem sechsjährigen Aufenthalt in Deutschland [...] hatte ich die Wahl zwischen zwei Methoden. Ich konnte versuchen Deutschland zu beschreiben. Ich konnte andererseits versuchen zu zeigen, unter welchem Gesichtspunkt ein Franzose Deutschland anschauen muß, um es mit möglichster Objektivität in seinem Eigenleben zu begreifen. Ein Werk in zehn Bänden, oder ein Essay von 150 Seiten. Ich entschied mich für den Essay ${ }^{487}$.

Seinen deutschen Lesern erklärte Viénot, um die Krise der bürgerlichen Kultur in Deutschland plastischer darzustellen, benutze er Frankreich, in dem die bürgerlichen Überzeugungen noch immer fortlebten, als Folie. Dennoch sei die von ihm beschriebene Entwicklung nicht allein auf Deutschland beschränkt, denn auch in Frankreich werde in intellektuellen Kreisen »die Allgemeingültigkeit der von mir beschriebenen Krise ${ }^{488}$ anerkannt, wenn sie auch noch nicht so direkt erlebt werde wie in Deutschland. Daß Viénot in seinen Betrachtungen über Deutschland das Hauptaugenmerk weniger auf aktuelle politische Fragen, als vielmehr auf die Auswirkungen soziologischer und kultureller Entwicklungen legte, macht ein Erkenntnisinteresse deutlich, welches über parteipolitische Erwägungen hinauszielte und seine Ursprünge im Krisenbewußtsein der jungen Generation fand. Seine Studie spiegelt genau »die charakteristische Motivverbindung von Friedenssicherung durch den Ausgleich mit Deutschland und politischer Erneuerung jenseits der traditionellen Wertorientierungen ${ }^{489}$ wider, die sowohl von der intellektuellen Jugendgeneration als auch in politischen Kreisen zwischen Sozialisten und Parti radical vertreten wurde.

Viénots Untersuchung zur Krise der bürgerlichen Kultur in Deutschland gliedert sich in vier Abschnitte. Im ersten Teil geht es dabei um die Definition des Begriffs der Kultur und um eine Beschreibung der Krise anhand ausgewählter Beispiele. In einem zweiten Teil werden die Auswirkungen der Krise auf die deutsche Gesellschaft dargestellt, bevor im dritten Abschnitt ihre politischen Rückwirkungen analysiert werden. Das kurze Schlußkapitel gibt schließlich einen Ausblick auf die möglichen Schlüsse, die aus Viénots Darlegungen für das deutsch-französische Verhältnis gezogen werden können.

${ }^{487}$ Pierre VIFNOT, Vorwort zur deutschen Ausgabe: Ungewisses Deutschland. Zur Krise seiner bürgerlichen Kultur, Frankfurt a.M. 1931, S. 13.

${ }^{488}$ Ibid. S, 14.

${ }^{489}$ BocK, Der Blick, S. 46. 
In seinem Einführungskapitel, das er programmatisch mit "Sortir de soi« überschrieben hatte, machte Viénot deutlich, worum es ihm in seiner Studie ging. Der Dialog zwischen Frankreich und Deutschland funktionierte seiner Meinung zufolge nicht, da die falschen Fragen gestellt beziehungsweise den Äußerungen auf beiden Seiten jeweils unterschiedliche Bedeutungen beigelegt würden. Wenn man etwa in Deutschland frage, ob Frankreich Verständigung wolle, dann bedeute dies, ob es akzeptiere, daß die Welt und damit Deutschlands Stellung in dieser sich verändere. Ein Franzose hingegen, der Deutschland nach seiner Verständigungsbereitschaft frage, meine damit implizit dessen Bereitschaft zum Frieden, und mit Frieden meine er den Versailler Vertrag ${ }^{490}$.

Verschiedene, bisweilen entgegengesetzte Konnotationen verhinderten nach Meinung Viénots eine wirkliche Verständigung, so daß anstelle eines Austausches eine Abfolge von Monologen trete. Die tiefere Wirklichkeit Deutschlands, sein Lebensrhythmus und Lebensgefühl, könne durch das Anlegen französischer Maßstäbe nicht ergründet werden. Deshalb forderte Viénot seine Landsleute auf, sich temporär von ihrem Heimatland zu lösen und sich auf das Fremde einzulassen:

Pour qui veut comprendre l'Allemagne, un autre effort est nécessaire que de prendre le train pour Berlin. Il faut s'y défaire quelque temps de la France. Toute description dont la France, par les questions qu'elle pose, a fourni le schéma, est insuffisante, sinon fausse. L'Allemagne doit être regardée de l'intérieur. Il faut l'oubli momentané de soi; au sens profond du mot, le désintéressement. Autrui ne livre rien de ses différences profondes à une curiosité égoïste. Il faut avoir souci de lui, non de soi, pour qu'elle se révèle ${ }^{49 !}$.

Viénot plädierte also dafür, in einem Akt zeitweiliger "Selbstentäußerung" Deutschland unter deutschen Gesichtspunkten zu betrachten. Der ausländische Betrachter sollte es dem deutschen "génie maladif de l'introspection nationale ${ }^{492}$ gleichtun und sich genau jene Fragen stellen, die die Deutschen Ende der zwanziger Jahre so leidenschaftlich bewegten.

Was meint Viénot nun aber mit seinem Zentralthema, der Krise der bürgerlichen Kultur in Deutschland? Als Kultur bezeichnete Viénot einen Zustand kollektiver Glaubensüberzeugung, der eine Lebensordnung garantiert, die Individuen miteinander verbindet und eine Gemeinschaft begründet. Die Kultur verkörpert dabei das Gegenteil der rationalen, in der Aufklärung des 18. Jahrhunderts propagierten Gesellschaft, sie stellt vielmehr ein unbewußtes materielles, geistiges und moralisches Faktum dar. Wenn nun aber eben diese geistigen und moralischen Grundlagen einer Kultur in Frage gestellt oder gar zerstört würden, dann sei das Ende dieser Kultur nicht mehr fern. Deutschland befand sich gemäß Viénots Überzeugung in einer tiefen Kulturkrise. Kein Glaube, kein Be-

\footnotetext{
${ }^{490}$ Vgl. Pierre VIrienOT, Incertitudes allemandes, Paris ${ }^{2} 1931$, S. 13.

${ }^{491}$ Ibid. S. $14 f$

492 Ibid. S. 16.
} 
wußtsein und keine Ordnung würden mehr als absolut angesehen, alles werde einer unerbittlichen relativistischen Kritik unterzogen:

Aucune croyance ne se présente plus comme absolue. Aucune ne saurait échapper à la conscience que nous avons de sa particularité historique ou de sa fonction sociale. Toutes sont frappées à mort... Les liens qu'elles nouaient entre les hommes sont à jamais brisés. Les collectivités véritables sont dissoutes ${ }^{493}$

Diese Gegebenheiten, die grundsätzlich auch auf Frankreich zutreffen, würden in Deutschland, da es in besonderem Maße philosophischen Geist besitze, zu Ende gedacht. Der Ausnahme- und Übergangscharakter der Epoche werde hier deutlicher erkannt als irgendwo sonst. Die Erkenntnis von der Relativität aller Werte stellte in den Augen Viénots das Schicksal des modernen Menschen in der Nachkriegszeit dar. Der Verlust des Glaubens hatte für Viénot jedoch noch eine andere Folge: Der Einklang des Individuums mit seiner Zeit und mit der Welt war für immer verloren.

Mit dem Begriff der bürgerlichen Kultur bezog sich Viénot auf die Kultur des 19. Jahrhunderts, die er vom Glauben an die Vernunft und an ethische Überzeugungen gekennzeichnet sah. Den ausgeprägtesten Zug der Vernunftgläubigkeit macht er im Glauben an Fortschritt und Freiheit aus, als deren Folge der Individualismus entstanden sei. Der Individualismus stellte laut Viénot das Charakteristikum und die Basis der politischen Kultur des 19. Jahrhunderts dar, denn aus ihm resultierten das allgemeine Wahlrecht, die parlamentarische Demokratie und das Prinzip des Nationalstaats sowie, auf wirtschaftlichem Gebiet, der freie Wettbewerb und schließlich der Hochkapitalismus ${ }^{494}$.

Im gegenwärtigen Deutschland sah Viénot diese bürgerliche Ordnung im Zusammenbruch begriffen. Er verzeichnete statt innerer Ordnung einen grundlegenden Relativismus, der sich in vielen widersprüchlichen und zum Teil gegensätzlichen Tendenzen widerspiegelte. Das »Deutschland von Potsdam«, also das preußisch-militärische Deutschland, war nach Viénots Dafürhalten ebenso real wie das »Deutschland von Weimar«, jenes der parlamentarischen Demokratie. Das industrielle Deutschland, so Viénot, existiere neben dem agrarischen, das katholische neben dem lutherischen, das proletarische neben dem der besitzenden Klassen, das demokratische neben dem nichtdemokratischen usw. Trotz des Fortbestehens der alten Kräfte prognostizierte Viénot für die Zukunft die Dominanz des >modernen، Deutschland:

Cette Allemagne d'hier, elle est là, en effet, présent dans une complexité contemporaine, toute réelle encore. Mais elle est prise dans le mouvement d'un présent fluide, dont le flot confus, même s'il paraît souvent ne pas trouver sa pente, entraîne cependant avec lui les grands blocs erratiques abandonnés dans son cours par le passé, les déplace, les mine et parfois les brise, 
gêné sans doute par leur résistance, mais en définitive leur maitre. Le passé influence, mais ne commande pas la vie allemande ${ }^{495}$.

Der von Viénot konstatierte umfassende Relativismus wurde von ihm als eigentliches Signum der Krise betrachtet und am Beispiel moralischer und sozialer Symptome eingehend untersucht. In moralischer Hinsicht sah Viénot eine Veränderung der Werte, eingeleitet bereits durch die Jugendbewegung im Wilhelminischen Kaiserreich und ihrer Revolte gegen die Elterngeneration verbunden mit einer Ablehnung der materialistisch-bürgerlichen Lebensform. Auch in sexueller Hinsicht bemerkte Viénot einen endgültigen Wandel des Moralbegriffs, in dem die Sünde nicht mehr die entscheidende Kategorie darstelle. Schließlich sah er in der Beurteilung des Geldes ein weiteres Zeichen der Werteveränderung. Während im 19. Jahrhundert der Besitz von Geld ethischer Wert und Basis der sozialen Hierarchie gleichermaßen gewesen sei, gelte nun ein großes Vermögen nahezu als unmoralisch.

$\mathrm{Zu}$ der Relativierung der bürgerlichen Kultur trug nach Meinung Viénots in nicht unwesentlichem Maße auch der deutsche Sozialismus bei, zumindest seine theoretische Grundlage der marxistischen Ideologie. Die bürgerliche Kultur erscheine ihm nur als Überbau des wirtschaftlichen Lebens, so daß sich seine Kritik nicht auf die ethischen Gesichtspunkte der alten Einrichtungen richte. Jenseits der Frage nach der moralischen Bedeutung der kulturellen Gegebenheiten werde der Glaube an die Zwangsläufigkeit wirtschaftlicher Gesetze praktiziert. Somit befinde sich der Sozialismus aufgrund der marxistischen Lehre bereits in der Kulturkrise. Weiterhin stehe das Klassenbewußtsein, von dem Viénot Deutschland durchdrungen sah, in direktem Gegensatz zur bürgerlichen Kultur, die auf dem Individuum beruhe. Viénot erkannte hier einen grundlegenden Unterschied zwischen der deutschen und der französischen Gesellschaft. Während in Frankreich ungleiche Chancen aufgrund des Geburtsmilieus durch Stipendien und die Einheitsschule individuell ausgeglichen würden, werde in Deutschland Gerechtigkeit durch die Gleichheit der Klassen gefordert. An die Stelle des individualistischen Ideals bürgerlicher Sozialethik sah Viénot eine neue Moral auf der Grundlage der Solidarität entstehen, die das Interesse der Klasse in den Mittelpunkt stelle.

Über die reine Ideologie hinaus leistete gemäß Viénot auch die Sozialdemokratie durch die von ihr initiierten sozialen Reformen einen Beitrag zur Verdrängung der bürgerlichen Kultur. Die materiellen Verbesserungen des Proletariats, die ihm durch die bürgerliche Kultur bisher verwehrt geblieben seien, sowie die Entwicklung vom liberalen zum Fürsorgestaat bedeute eine tiefgreifende Veränderung. Das Paradoxon des deutschen Sozialismus erblickte Viénot darin, daß er zwar die moralischen Grundlagen der bürgerlichen Kultur unter- 
höhlte, gleichzeitig aber die SPD als `die` große republikanische und staatstragende Partei in der Praxis für die Fortführung dieser Kultur sorgte.

Was Viénot anhand der von ihm ausgewählten Beispiele charakterisierte, waren die Entwicklungen und Verwerfungen in einer Gesellschaft, die sich in einer tiefen Umbruchsphase befand. Dabei sah er mehr Fragen als Antworten. Die beschriebene Verschiebung ethischer Werte und moralischer Prinzipien bewirkte gleichzeitig die Orientierungslosigkeit eines Landes, welches seine alte Kultur hinter sich ließ, aber noch keine neue innere Ordnung gefunden hatte. Viénot bezeichnete diesen Übergangszustand als »disponibilité«, als Bereitschaft. Vor allem bedeutete dies seiner Meinung nach wla tendance des masses à saisir et même, sans doute, à exagérer, la nouveauté du monde présent, leur fait exaspérer la crise à force d'y croire ${ }^{496}$ Deutschland sei sich des inneren Umbruchs völlig bewußt, und anders als andere Völker, die die Unsicherheiten aus ihrem Bewußtsein verdrängten, zeige es leidenschaftliches Interesse an den Umbruchsprozessen. Viénot sah die Gründe für dieses Verhalten in dem militärischen und gesellschaftlichen Zusammenbruch von 1918. Innerhalb weniger Wochen sei der Glaube an vorher unverbrüchliche Wahrheiten erstorben und alles - sogar der Bolschewismus - sei möglich geworden. Die Revolution von 1918/19 war in Viénots Augen der Schlüssel zum Verständnis des 'modernen ( Deutschland. Sie habe die moralische Erschütterung herbeigeführt, die durch die Nachkriegsentwicklungen noch verstärkt worden sei. Viénot führt hier das Anwachsen der Städte, den drohenden Bolschewismus und den technischen Fortschritt an, vor allem aber die Inflation. Er, der während des Jahres 1923 selbst die Auswirkungen von Ruhrkrise und Inflation in Deutschland erlebt hatte, erkannte die Nachhaltigkeit des Schocks, den die Geldentwertung im Bewußtsein der Deutschen hinterlassen hatte. Da das Unvorhersehbare damals eingetreten sei, werde seither nichts mehr als unmöglich betrachtet. Mehr noch: Das Provisorische des gegenwärtigen Lebens sei für die Deutschen gar ein Sicherheitsventil. Das gegenwärtige Chaos und die Unsicherheit stellten demgemäß nur ein Übergangsstadium dar: »Toute l'Allemagne imagine un demain différent d'hier ou même d'aujourd'hui. Elle l'attend, elle le désire, elle l'aime à l'avance. $\ll^{497}$

Der Wunsch nach der Überwindung der gegenwärtigen, ungewissen Situation war in den Augen Viénots auch verantwortlich für die Entstehung des Nationalsozialismus. Er sprach dieser Bewegung jegliches politische Programm ab, sondern sah in ihr vielmehr ein Durcheinander von Absurditäten und Widersprüchen. Der Nationalsozialismus enthalte keinen politischen Willen, sondern sei radikaler Ausdruck der Flucht in die Zukunft. Viénot analysierte richtig, daß die Verunsicherung des Kleinbürgertums und die Suche nach einem neuen

${ }^{496}$ Ibid. S. 73.

${ }^{497}$ Ibid. S. $92 \mathrm{f}$. 
Glauben und nach Sicherheit die Wähler in die Arme der NSDAP trieben ${ }^{498}$. Gleichzeitig wird Viénot dem Phänomen des Nationalsozialismus nicht gerecht, wenn er den Erfolg der NSDAP in den Septemberwahlen von $1930^{499}$ nicht als politischen Sachverhalt sehen will. Zwar trifft seine soziologische Deutung der Attraktivität der Bewegung auf die Wählermassen zu, dennoch geht die Beurteilung der politischen Problematik am Kern vorbei. Für Viénot, der im Nationalsozialismus "un mouvement purement négatif ${ }^{500}$ sah, war diese Bewegung offensichtlich nur eine von vielen Möglichkeiten, die innere Verunsicherung in Deutschland zu überwinden. Seinen Ausfuihrungen läßt sich entnehmen, daß er die Gefahr, die von dieser Bewegung ausging, nicht als vordringlich empfand. Sie war kaum mehr als ein Signum der Suche nach bisweilen eben auch radikalen und revolutionären - Lösungen. Diese Deutung entsprach auch der Einschätzung seiner Frau, die den Nationalsozialismus im September 1929 als vorübergehende Erscheinung charakterisiert hatte ${ }^{501}$. Auch nach ihrem sensationellen Wahlerfolg war offensichtlich für einen hochintellektuellen Mann wie Viénot die politische Brisanz der nationalsozialistischen Bewegung, die weniger an die Ratio als an die Emotionen und Instinkte der Wähler appellierte, nicht nachzuvollziehen.

Gewiß rief der Nationalsozialismus bei Viénot aber auch deswegen keine nachdrücklichere Reaktion hervor, weil in seinen Augen überhaupt keine einheitliche moralische Lehre in Deutschland mehr existierte. Das "Absolute" gebe es nicht mehr, aber aus diesem Leben ohne Gesetze, diesem "Wahnsinn«, erwachse - gleichsam als Trotzreaktion - ein ausgeprägter Lebenswille. Die neuen Wertetafeln des modernen Deutschland, der jungen Generation, beinhalteten Tapferkeit und Männlichkeit, Selbstvertrauen und Freude am Wagnis, Kühnheit und Heroismus. Auch die Gemeinschaft, und mit ihr verbunden Tugenden wie Treue, Gehorsam und Aufopferung würden als moralische Werte betrachtet, wohingegen die Freiheit oft als bloße Leere empfunden werde. Viénot kritisierte allerdings, daß es sich hierbei um eine Moral ohne positiven Inhalt handle, da es nur um die reine Einstellung des Individuums zum Leben gehe, nicht aber um allgemeingültige ethische Fragen ${ }^{502}$.

Gleichzeitig konstatierte Viénot eine jugendliche Vitalität innerhalb der deutschen Gesellschaft. Gleich chemischen Elementen, die bei der Zersetzung Energie freisetzten, entstehe beim Zerfall der bürgerlichen Kultur ein ausgeprägter Dynamismus, begleitet von einer "hyperconscience«, einer Überbewußtheit für die neuen Realitäten und für die Notwendigkeit, sich ihnen anzupassen. Sie

${ }^{498}$ Vgl. ibid. S. 88ff.

${ }^{499}$ Die NSDAP erzielte in den Reichstagswahlen vom $14.9 .193018,3 \%$ der Stimmen im Vergleich zu 2,6\% im Jahre 1928. Gleichzeitig stieg die Zahl ihrer Reichstagsmandate von 12 auf 107 an. Sie wurde damit hinter der SPD zur zweitstärksten Partei im Reichstag.

500 VIÉNOT, Incertitudes allemandes, S. 90.

${ }^{501} \mathrm{Vgl}$. Andrée Mayrisch an ihre Mutter, 23.10.1929: NL Viénot.

${ }^{502} \mathrm{Vgl}$. VIÉNOT, Incertitudes allemandes, S. 104ff. 
äußere sich in permanenter Reflexion und Diskussion. Die Gegenwart erscheine demgemäß nicht mehr als normative Daseinsform:

Pour la première fois dans l'histoire du monde, l'homme n'est commandé que par l'avenir. Le dynamisme allemand s'èlance sur toutes les voies qui paraissent y conduire, convictions morales ou conquêtes matérielles, communisme ou expansion industrielle - mais aveuglement... C'est la fuite en avant, avec une volonté née de l'angoisse, violente et incertaine, rompue par des chutes, surexcitée par des rebondissements subits ${ }^{503}$

Viénot bescheinigte Deutschland eine zweite Jugend, aus der dieser Dynamismus erwachse. Diesen Gedanken hatte er bereits d'Ormesson ausführlich dargelegt, demgegenüber er Deutschland mit einem Jungen in der Pubertät verglichen hatte. Für Frankreich sah Viénot keine andere Möglichkeit, als sich bis zu dessen Volljährigkeit zu gedulden und auf seine Friedfertigkeit zu hoffen ${ }^{504}$. Der Kampf der Weimarer Republik mit ihren Feinden wurde zudem Viénots Einschätzung zufolge von Franzosen meist falsch interpretiert, nämlich als Auseinandersetzung zwischen Fortschritt und Reaktion. In Wirklichkeit müsse sich die Republik jedoch nicht als Regime des Fortschritts verteidigen, sondern als Regime der bürgerlichen Kultur. In diesem Sinne werde es von den Kommunisten und den Nationalsozialisten gleichzeitig bekämpft. Für Viénot stand fest, daß die parlamentarische Republik es in zwölf Jahren nicht geschafft hatte, die Massen an diesen Staat heranzuführen, am wenigsten die Jugend, die ihre Ideale in dieser Republik nicht verkörpert sah. Auch wenn er eine Rückkehr zum Vorkriegsregime für unwahrscheinlich hielt, erstellte Viénot dem aktuellen politischen System doch eine pessimistische Prognose: „ [...] une démocratie individualiste dans un pays où la civilisation bourgeoise est moralement et matériellement en crise ne fournit pas d'expression politique adéquate à des réalités qui la dépassent. ${ }^{505}$

Auch in der deutschen Außenpolitik sah Viénot die Symptome der Ungewißheit. Durch die Verweigerung außenpolitischer Revisionen werde der deutsche Dynamismus zum Äußersten, zum gesteigerten Nationalismus getrieben. Nur durch die Hoffnung auf die Zukunft könne Deutschland leben. Diese Hoffnung habe es in der Folge von Locarno zu Frankreich hingezogen und ebenso wende es sich jetzt von diesem ab. "En réalité«, so resümierte Viénot seine Deutschlandanalyse,

l'angoisse et la passion de l'avenir sont permanentes dans la vie de l'Allemagne, qu'il s'agisse de sa vie intellectuelle, morale, sociale, économique ou politique - parce qu'elles sont les expressions essentielles d'une crise permanente elle aussi, une crise de civilisation, qui atteint toutes les activités individuelles ou collectives ${ }^{506}$.

${ }^{503}$ Ibid. S. 117.

${ }^{504}$ Vgl. Viẻnot an d'Ormesson, 17.8.1930: NL d'Ormesson II.

${ }^{505}$ DERS., Incertitudes allemandes, S. 146.

${ }^{506}$ Ibid. S. 159. 
Viénot, der mit seiner Studie einen Beitrag zum besseren Verständnis des Nachbarlandes in Frankreich leisten wollte, appellierte an seine Landsleute, die deutsche Krisis als Chance zu begreifen. Könne denn Frankreich nicht die deutsche Liebe zur Zukunft teilen, so fragte er rhetorisch die Franzosen, die sich durch die Ungewißheiten auf der anderen Seite des Rheins verunsichert fühlten. Frankreich stehe vor der Gelegenheit, eine im Entstehen begriffene Ordnung auf internationaler Ebene mitzugestalten. Es müsse daher über sich hinausgehen, nicht mehr vom Gegenüber die Bekehrung zur eigenen Lebensform fordern, sondern vielmehr Schöpfergeist und Kreativität für die Gestaltung des kollektiven Lebens an den Tag legen. Trotz der deutschen Ungewißheiten, des inneren Chaos, der verlorenen Orientierungsmaßstäbe und der Neigung zum politischen Extremismus sah Viénot in dieser Phase des Umbruchs eine Chance, sowohl für Deutschland als auch für Frankreich, gemeinsam in Erkenntnis einer europäischen Kulturkrise ${ }^{507}$, an der Gestaltung einer neuen Ordnung mitzuwirken. Von seinen Landsleuten forderte er mehr Mut, sich auf dieses Wagnis einzulassen, denn wchoisir notre conduite envers l'Allemagne, c'est choisir, en premier lieu, l'idée que nous nous faisons de la France ${ }^{508}$

Viénots Studie erschien Mitte 1931 und war binnen zwei Monaten vergriffen, so daß sie noch im selben Jahr neu aufgelegt wurde. Die Übersetzungen ins Deutsche und Englische erfolgten ebenfalls $1931^{509}$. Bereits im Juli 1931 erhielt Viénot eine erste Rückmeldung von Carl Heinrich Becker, der ihm zum hohen Niveau der Arbeit gratulierte und ihm versicherte, dies sei »kein Journalisten-Geschwätz, auch - verzeihen Sie - kein Deputierten-Gerede«. ${ }^{510}$ Allerdings wandte Becker ein, daß der deutsche Bruch mit der bürgerlichen Kultur kein Zeichen von Angst sei, sondern daß gerade Frankreichs Festhalten an einer veralteten Ordnung durch Furcht motiviert sei. Seiner Meinung nach hatte Viénot die französische Furcht vor der deutschen Bevölkerungsüberzahl nicht ausreichend angesprochen, obwohl sie doch die französische Politik bestimme. Er deutete dies als Rücksichtnahme des künftigen Politikers auf seine französischen Leser. Becker drückte seine Besorgnis über den Zustand der deutsch-französischen Beziehungen aus. Seiner Meinung nach konnte von Politikern wie Briand oder Herriot kein neuer europäischer Geist und keine europäische Zukunft geschaffen werden. Warum, so fragte er Viénot, sollte aus-

507 Viénot erinnerte in seinem Buch mehrfach daran, daß diese Krise auch Frankreich erfaßt habe, jedoch in Deutschland ungleich weiter fortgeschritten sei und klarer reflektiert werde.

${ }^{508}$ VIENOT, Incertitudes allemandes, S. 166.

${ }^{509}$ Die englische Ausgabe erschien unter dem Titel: Is Germany finished?, London 1931. Übersetzungen ins Italienische und Tschechische waren geplant, kamen aber offenbar nicht zustande. Vgl. Viénot an Schlumberger, 11.9.1931: BLJD, Fonds Schlumberger, Ms 18355; ders. an Jean-Richard Bloch, 23.10.1931: BN, Papiers Bloch, XLVII, Lettres adressées à Jean-Richard Bloch.

${ }^{510}$ Becker an Viénot, 6.7.1931: GStA PK, NL Becker, 2616. 
gerechnet der bürgerliche Geist des 19. Jahrhunderts Ewigkeitswert besitzen? Becker vermutete, Viénot selbst könnte bereits zur älteren Generation gehören:

Ich hatte den Eindruck, als ob die Altersklasse Pierre Bertaux auch uns Deutsche darin schon ganz anders versteht, und dabei gehöre doch ich selber meiner ganzen Tradition nach auch noch in die bürgerliche Atmosphäre und in den Individualismus hinein. Durch Anlage und Tradition Thnen innerlich verwandt, bejahe ich diese Entwicklung doch sehr viel entschiedener als Sie. Der Unterschied zwischen uns ist vielleicht der, daß Sie die Entwicklung in ihrer inneren Anständigkeit und Naturnotwendigkeit [...] als tatsächlich existent anerkennen, es aber doch als eine Krankheitserscheinung ansehen, während ich es mit einer gewissen Wehmut betrachte, aber doch schließlich innerlich bejahe ${ }^{11}$.

Becker interpretierte Viénots Ausführungen offensichtlich dahingehend, daß dieser die deutsche Beunruhigung, die »angoisse«, und die wie Krankheitssymptome beschriebenen Krisenerscheinungen negativ wertete. Zudem machte er Viénot implizit den Vorwurf, dieser habe in seiner Arbeit doch etwas getan, was Viénot gerade hatte vermeiden wollen, nämlich den französischen Standpunkt eingenommen, indem er auf die deutschen Unsicherheiten verwiesen, jedoch nicht die französische Furcht vor dem bevölkerungsreichen Deutschland thematisiert habe. Becker hatte mit seinem Einwand insofern recht, als die ungleiche Bevölkenungsverteilung in beiden Ländem tatsächlich die Ängste Frankreichs vor dem Nachbarn jenseits des Rheins schürte und zu seinem Sicherheitsverlangen beitrug. Auf der anderen Seite war das Ausloten der französischen Befürchtungen nicht das Thema von Viénots Betrachtungen. Es ging ihm darum, die deutschen Krisenerscheinungen zu beschreiben und zu deuten. Die Ursachen für Frankreichs Festhalten an seinen starren Strukturen wollte er mit seiner Studie nicht ergründen.

Der Einschätzung Beckers, Viénot würde die deutsche Krise nicht nachdrücklich genug befürworten, widersprach Andrée Viénot, die ihm entgegnete, er habe nicht erkannt, "wie weitgehend Pierre [...] die Abkehr von der bürgerlichen Kultur bejaht, und für Frankreich ihre Überwindung hofft ${ }^{512}$ Viénots Ehefrau war an der Redaktion des Buches beteiligt gewesen, das ihr auch gewidmet ist. Gegenüber Becker resümierte sie nochmals die Kernthesen des Buches, wie sie sie verstand:

Frankreich vor der notwendigen Krise, in naiv-unbewußtem Verharren in einer für ewig gehaltenen - in Wirklichkeit längst verknöcherten - bürgerlichen Kultur, in einer 'gesunden`, aber sterilen Epoche; Deutschland mitten in der Krise, noch ohne neue nachbürgerliche Form, Krise als Krankheit, aber notwendige Krankheit (wie Pubertät oder Schwangerschaft), dabei vielleicht (durch äußere Umstände sowohl als durch innere Neigung) ein zu langes Verharren in dieser Pubertät, zu wenig klares Suchen nach der neuen Form ${ }^{513}$.

Diese neue Form zu gestalten, das wäre die gemeinsame deutsch-französische Aufgabe für die Zukunft. Für Frankreich wäre der zu beschreitende Weg je-

SII Ibid.

${ }^{512}$ Andrée Viénot an Becker, 10.7.1931: GStA PK, NL Becker, 2616.

S13 Ibid. 
doch länger, da die bürgerliche Ordnung erst noch zerstört werden müßte, bevor Neues aufgebaut werden könnte. In Deutschland hingegen bestehe bereits die volle Bereitschaft zum Neuaufbau. Den Begriff »angoisse«, den Becker kritisiert hatte, sah Andrée Mayrisch indes nicht negativ. Aufgabe der jungen Generation sei es gerade, diese »angoisse « und sincertitude« nach Frankreich hineinzutragen, um eine Neugestaltung überhaupt zu ermöglichen.

Aus Viénots Ausfuihrungen in seinem Buch wie auch aus den Worten seiner Frau läßt sich schließen, daß die deutsche Krise von beiden nicht in erster Linie als bedrohliche Entwicklung verstanden wurde, die die Demokratie in Deutschland zersetzen und einer Diktatur Tür und Tor öffnen konnte. Zwar hielt Viénot es in bezug auf Deutschland für möglich, daß »nous allons assister soit à la décomposition de son régime, soit à une sémi-dictature ${ }^{514}$, dennoch wurde vor allem die Chance betont, die aus einer Zerstörung der bürgerlichen Kultur erwachsen könnte. Der reine Pessimismus einer konstatierten Kulturkrise, den Viénot mit vielen jungen Intellektuellen seiner Generation teilte, sollte schöpferisch überwunden werden in der Schaffung einer neuen Ordnung. Daher läßt sich Viénots Studie nicht aus dem Kontext einer Intellektuellengeneration lösen, die sich gerade die Überwindung der bestehenden Ordnung auf ihre Fahnen geschrieben hatte ${ }^{515}$. Es darf auch nicht vergessen werden, daß sein Buch ursprünglich und in erster Linie an ein französisches Publikum gerichtet war. Seine Darlegungen verfolgten offensichtlich zweierlei Ziele: Zum einen sollte der französischen Leserschaft ein profunder Einblick in die aktuellen gesellschaftlichen Entwicklungen in Deutschland gegeben werden, wobei diese in ihren historischen Kontext eingebettet und interpretiert wurden. Viénot legte damit gemäß seinem Selbstverständnis als kultureller Mittler seinen Lesern ein Lernprogramm zur bilateralen Kommunikation vor. In einer zweiten Hinsicht reichte das Anliegen Viénots jedoch über diese verständigungspolitische Komponente hinaus. Deutschland wurde zum Modellfall für eine Entwicklung, die von französischen Intellektuellen für ihr eigenes Land herbeigesehnt wurde. Die inneren Verwerfungen und Brüche in der politischen und gesellschaftlichen Struktur des Nachbarlandes wurden, ganz anders als in Deutschland selbst, gerade als Fortschritt empfunden gegenüber der Situation im eigenen Land. Jenseits der parlamentarischen Instabilität, die für die Dritte Republik ebenso charakteristisch war wie für die Weimarer Republik, herrschte in Frankreich zum einen ein weitgehender politischer Konsens über das System einer parlamentarischen Demokratie. Zum zweiten zeichnete sich Frankreich ganz im Gegensatz zum Nachbarland durch eine hohe soziale Stabilität aus. Genau diese Stabilität galt den gestaltungswilligen Intellektuellen jedoch als Erstarrung und Hemmnis. Sie stand der Modernisierung entgegen, der sie sich verschrieben

${ }^{514}$ Viénot an d'Ormesson, 17.8.1930: NL d'Ormesson II. Vgl. auch DERS., Incertitudes allemandes, S. 135-146.

${ }^{515} \mathrm{Vgl}$. ausführlich dazu Kap. IV. 
hatten, und wurde deswegen abgelehnt. Während Deutschland als ein Land der Zukunft erschien, verharrte Frankreich in alten sozio-politischen Ordnungen. Viénots Buch kann daher auch als eine Ermutigung für die Jugend seines eigenen Landes gelesen werden. Was in Deutschland möglich war, das konnte auch in Frankreich verwirklicht werden. Es ist kein Zufall, daß Viénot in der deutschen Ausgabe den Lesern als »ein Franzose der jungen Generation ${ }^{516}$ angekündigt wurde. Gerade an diese Generation beider Länder wandte sich das Buch. Daher freute sich Viénot auch besonders über eine Rückmeldung des sozialistischen Schriftstellers und Journalisten Jean-Richard Bloch, der ihm von dem Interesse der Jugend an seinem Buch erzählt hatte ${ }^{517}$. Die Beobachtung des Nachbarlandes diente zudem auch, wie Viénot es am Ende seines Buches dargelegt hatte, der Selbstreflexion. Viénot konnte, so führte es der Heidelberger Archäologe Ludwig Curtius aus, win der Liebe zu dem, was er Neues und Besonderes in Deutschland entdeckt hatte, beinahe in einen gewissen Enthusiasmus ausbrechen ${ }^{518}{ }^{518}$ Dieser betonte selbst, Deutschlands Zweifeln sei ihm näher als Frankreichs Gewißheiten ${ }^{519}$. Auf einer ganz persönlichen Ebene fand hier eine Identifizierung mit dem Deutschland der Weimarer Republik statt, mit einem Deutschland, das sich im Chaos befand und dessen weiterer Weg noch nicht absehbar war. Lange Zeit drückte diese Ungewißheit genau die Befindlichkeit des ehemaligen Kriegsteilnehmers Viénot aus, der in der Nachkriegszeit seine Rolle in der Gesellschaft und seinen Weg aus der inneren Zerrissenheit zu einem gefestigten politischen Standpunkt suchte. Die in Deutschland beobachteten widersprüchlichen Entwicklungen spiegelten mehr unbewußt sicherlich als bewußt Viénots eigene widersprüchlichen Anschauungen, Ängste und Hoffnungen wider. Viénot liebte Deutschland nicht trotz, sondern gerade wegen seiner Ungewißheiten, weil er sich selbst darin erkannte.

\subsection{Die Rezeption von Viénots Deutschland-Studie}

Das Erscheinen der »Incertitudes allemandes« fiel zusammen mit einer Krise der deutsch-französischen Beziehungen. Die verschleppte Europainitiative Briands vom Mai 1930, der Wahlerfolg der Nationalsozialisten vom September desselben Jahres, das deutsch-österreichische Zollunionsprojekt vom März 1931 und die von deutscher Seite immer lauter und offensiver vorgetragenen Forderungen nach territorialer Revision und militärischer Gleichberechtigung ${ }^{520}$ waren

516 So auf der Umschlaghülle zu VIÉNOT, Ungewisses Deutschland.

${ }^{517}$ Vgl. Bloch an Viénot, 23.10.1931: BN, Papiers Bloch, XLVII, Lettres adressées à JeanRichard Bloch

${ }^{518}$ Ludwig CURTIUS, Deutsche und antike Welt. Lebenserinnerungen, Stuttgart 1950, S. 381.

${ }^{519}$ Vgl. Pierre VÉNOT, Frankreich und Deutschland. Die Überbetonung des Nationalen, in Die Neue Rundschau 42,2 (1931) S. 721-736, hier S. 731.

${ }^{520}$ Vgl. zum politischen Kontext vgl. POIDEVIN, BARIETY, Frankreich und Deutschland, S. 362-367; HAGSPIEL, Verständigung, S. 456-486; HILDEBRAND, Das vergangene Reich, 
Anzeichen und Ergebnisse einer Veränderung des politischen Klimas, welche das »Ende der Locarno-Ära « ${ }^{521}$ endgültig besiegelte. Trotz oder gerade wegen der deutsch-französischen Unstimmigkeiten zeigten sich Intellektuelle beiderseits des Rheins umso aufnahmebereiter für Viénots Deutschlandbetrachtungen. In dem Augenblick, in dem die politischen Beziehungen sich mehr und mehr abkühlten, versuchten diese, die Chancen einer deutsch-französischen Verständigung auszuloten. Eine Diskussion der Union pour la Vérité verdeutlicht exemplarisch das geistige Klima in Frankreich zu dem Zeitpunkt, als Viénots Buch erschien. Im Rahmen der »libres entretiens« wurde nach 1922 erstmals zwischen Dezember 1930 und Juni 1931 wieder eine Folge von Deutschlanddebatten veranstaltet, an denen neben Raymond Aron, Félix Bertaux, Arthur Fontaine, Henri Lichtenberger und Wladimir d'Ormesson unter anderem auch Pierre Viénot teilnahm. Hatten 1922 noch die geistigen Grundlagen einer deutsch-französischen Annäherung im Mittelpunkt gestanden ${ }^{322}$, so war die Thematik der zweiten Nachkriegsdebatte zur Deutschlandfrage stärker auf die politische Dimension der Beziehungen gerichtet. Der Schriftsteller Ramon Fernandez hatte dabei die Diskussionsrichtung vorgegeben mit seiner Feststellung, daß wnous perdrions sans doute notre temps si nous prenions aujourd'hui ces rapports sur un plan autre que le plan politique ${ }^{523}$ Der Journalist Benno Reifenberg, der die Nachfolge Friedrich Sieburgs als Pariser Korrespondent der Frankfurter Zeitung übernommen hatte, mahnte an, das Augenmerk zuallererst auf die Innenpolitik zu legen. Die Außenpolitik stelle lediglich einen Ersatz für diese dar. Reifenberg kam ohne Umschweife zu dem Schluß, eine deutsch-französische Annäherung gebe es nicht mehr: "Il n'y a pas un terrain neutre où s'approcher. Il ne faut pas faire de rapprochement, mais faire chez soi la politique nécessaire. " ${ }^{524}$ Viénot stimmte Reifenberg vor allem in dem Punkt des Ersatzcharakters der deutschen Revisionsforderungen zu. Hinter diesen Ansprüchen finde sich ein Komplex an Fragen und Befindlichkeiten, die auf anderer Ebene entstanden seien. Diese würden lediglich auf die internationale Bühne projiziert, wo sie jedoch nicht gelöst werden könnten: "On peut comparer l'Allemagne à un malade qui, ayant la fièvre typhoïde, réclamerait un cachet - car il a en même temps la migraine - avec l'idée que ce cachet suffirait à le guérir. Donnez à l'Allemagne le cachet de la révision, elle aura toujours la

S. 502ff. und S. 509-534; Andreas RODDER, Stresemanns Erbe. Julius Curtius und die deutsche Außenpolitik 1929-1931, Paderborn u.a. 1996, S. 83-131.

${ }^{521}$ Vgl. KNIPPING, Locarno-Ära. Knipping datiert allerdings den Anfang vom Ende der Locarno-Ära bereits auf das Jahr 1928. Vgl. kritisch zu dieser These KOLB, Weimarer Republik, S. 209; NIEDHART, Die Außenpolitik, S. 61.

522 Vgl. Kap. II.3.1.

${ }^{523}$ Union pour la Vérité, Problèmes franco-allemands d'après-guerre. Entretiens tenus au siège de l'Union pour la Vérité, Paris 1932, S. 36.

524 lbid. S. 53. 
fièvre. ${ }^{525}$ Die tieferen Hintergründe der deutschen Revisionsforderungen zu verstehen, welche eben die »incertitudes allemandes«, die deutsche Kulturkrise, darstellten, sei die Voraussetzung für konstruktive deutsch-französische und europäische Friedensbestrebungen. Den Willen zur weiteren Annäherung trotz aller aktuellen Problematik bekundete auch Arthur Fontaine. Er unterstrich die Bedeutung der deutsch-französischen Verständigung als unabdingbare Voraussetzung für den europäischen Frieden ${ }^{526}$. Henri Lichtenberger, der an der Diskussion selbst nicht teilnahm, aber im Dezember 1931 einen Brief an Paul Desjardin schrieb, welcher der Publikation der Debatten vorangestellt wurde, teilte offensichtlich ganz und gar die Befunde, die Viénot in seinem Buch und auch in der Diskussion dargelegt hatte. Die deutsche Intelligenz, so sah es der Germanistik-Professor,

met en question toutes les valeurs idéologiques du passé, elle répudie la civilisation >bourgeoise، de l'Allemagne ancienne [...]. Hostile à l'état de chose créé par le traité de Versailles, sceptique à l'égard de l'ordre international qui s'élabore à Genève, elle aspire à un stroisième royaumes vers lequel, dans l'incertitude d'à présent, elle se jette comme vers un suprême refuge ${ }^{527}$.

Frankreich könne jedoch nichts anderes tun als abwarten und jeglichen Verdacht der Intervention in die inneren Vorgänge in Deutschland vermeiden. Das Deutschlandproblem befand sich also bereits auf der Tagesordnung der intellektuellen Debatten, als Viénots Buch erschien und einen Beitrag zur bereits im Gang befindlichen Diskussion über die verbliebenen Möglichkeiten einer deutsch-französischen Verständigung leistete.

Tatsächlich stieß Viénots Deutschlandstudie auf breites öffentliches Interesse. Die Rezensionen drückten dabei sowohl den Grad der Sympathie mit den Positionen des Autors aus als auch die Haltung der Kritiker selbst zum deutschfranzösischen Problem. Den Anfang der Besprechungen machte Wladimir d'Ormesson, der in L'Europe nouvelle Viénots Deutschlandstudie lobte als »la plus forte, la plus intelligente, la plus riche en substance et en vérité qui ait été tentée sur le problème d'ensemble de l'Allemagne contemporaine ${ }^{528}{ }^{52}$ Die Originalität und den Verdienst des Buches sah d'Ormesson gerade darin, daß Viénot das deutsche Problem aus der Innenansicht und nicht von außen betrachtet hatte. Die Studie Viénots unterscheide sich von hastig niedergeschriebenen Reiseeindrücken aus Deutschland, die den Leser in die ein oder andere Richtung führen wollen. Sie sei vielmehr die Frucht langjähriger Erwägungen. Als »réflexion infinie ${ }^{529}$ lade sie den Leser zum weiteren Nachdenken über Deutschland ein. Auch Émile Laloy hob in Le Mercure de France die Origina-

525 Ibid. S. 55.

526 Vgl. ibid. S. 60.

${ }^{527}$ Henri LICHTENBERGER, Mise au point en guise d'introduction, in: UNION POUR LA VÉRTTÉ, Problèmes franco-allemands, S. 17-25, hier S. 20.

${ }^{528}$ Wladimir d'ORMESSON, "Incertitudes allemandes « par Pierre Viénot, in: L'Europe nouvelle, 11.7.1931, S. 947-948, hier S. 947.

529 Ibid 
lität von Viénots Essay hervor. In den Ausführungen zum philosophischen Aspekt der deutschen Kulturkrise erblickte der Rezensent den entscheidenden Unterschied zu anderen Arbeiten über das gleiche Thema ${ }^{530}$.

In die Reihe der wohlwollenden Kritiker reihte sich der Germanist Félix Bertaux ein, der 1923 Heinrich Mann nach Pontigny geholt hatte und mit dessen Sohn Viénot eine enge Freundschaft pflegte. Ähnlich d'Ormesson betonte Bertaux vor allem die Offenheit der Studie, die dem Leser kein fertiges Deutschlandbild präsentiere, sondern zu eigenen Schlußfolgerungen ermuntere: "Le lecteur doit au contraire après une telle lecture rester plus que jamais éveillé, entraîné à continuer l'examen d'une matière mouvante, selon une méthode dont le principe est que l'esprit doit garder une constante liberté pour interpréter des faits d'une constante mobilité. ${ }^{531}$ Kein Wort traf in Bertaux' Augen den augenblicklichen Charakter der deutschen Vitalität besser als das der »incertitudes«. Es bezeichne all das Unbestimmte, das Unfertige in der Entwicklung einer Kultur, die nur einmal vorübergehend, während der Wilhelminischen Ära, geglaubt hatte, ihren Endpunkt gefunden zu haben. Die Ungewißheit stellte für Bertaux das Leitmotiv der fluktuierenden politischen Anschauungen in Deutschland dar. Er hielt es nicht für unwahrscheinlich, daß sich die Unentschlossenen der Idee einer Zusammenarbeit der Völker nicht verschließen würden, mahnte aber an, daß hierfür mehr nötig sei als nur guter Wille: »rien n'aboutira sans une lucide et dure volonté d'aboutir«. ${ }^{532}$ Bertaux setzte Viénots Ausführungen über Deutschland darüber hinaus in den größeren Kontext einer Kulturkrise der westlichen Zivilisationen. Am deutschen Beispiel zeige sich »également les possibilités d'une époque aussi féconde en promesses qu'en misères $\ll{ }^{533}$ Die Probleme, die Viénot beschrieb, traten nach Ansicht Bertaux' auch in jenen Ländern auf, die noch immer den Anschein innerer Stabilität erweckten. Für Frankreich bedeute dies, daß es den Blickwinkel auf die internationale Problematik verändern müsse und, da es immer noch über größere Stabilität verfüge als Deutschland, von sich aus einen Schritt auf seinen östlichen Nachbarn zu tun müsse. Die anstehenden Probleme, so Bertaux, könnten nur von beiden gemeinsam gelöst werden.

Die Anzahl der Besprechungen zeigt das große Interesse, auf das Viénots Buch stieß. Dabei wurde ganz überwiegend das hohe intellektuelle Niveau gewürdigt, wenngleich die Schlußfolgerungen nicht immer auf Zustimmung stießen. In La Revue de Paris wurde dem Buch bestätigt, es sei »un ouvrage remarquable qui fournit véritablement la clef de la politique de nos voisins

${ }^{530}$ Vgl. Émile LALOY, Bibliographie politique, in: Le Mercure de France, 1.8.1931, S. 751756.

${ }^{531}$ Félix BERTAUX, Incertitudes allemandes, in: L'Europe 27 (1931) Nr. 105-108, S. 129131, hier S. 129.

532 Ibid. S. 131.

${ }^{533}$ DERS., France - Allemagne. Incertitudes allemandes - Initiative française, in: Les Nouvelles littéraires, 11.7.1931. 
depuis la guerre ${ }^{534}$ Der Rezensent konnte Viénots Sympathie für die deutsche ,Krankheit ( jedoch nicht nachvollziehen. Er sah Frankreich nicht hinter der deutschen Entwicklung zurückgeblieben, sondem im Gegenteil dieser voraus, "parce que nous comprenons ce relativisme sans en tirer de conclusions apocalyptiques $\ll{ }^{535}$ Die Freiheit des Individuums, so der Tenor, sei das höchste aller Güter, und die besten Heilmittel gegen die politischen und ökonomischen Ungewißheiten böten die Instrumentarien des Liberalismus.

Zuspruch erhielt Viénot durch einen Brief des sozialistischen Schriftstellers und Journalisten Jean-Richard Bloch, den Viénot besonders schätzte und über dessen Anerkennung er sich sehr erfreut zeigte. Gleichzeitig gab er Bloch zu verstehen, sein Buch desorientiere häufig die Leser. Ob sie nun auf der politischen Rechten oder Linken stünden, viele zeigten sich erstaunt oder gar schockiert durch eine Fragestellung, die sie zwinge, mit alten Denkschemata zu brechen ${ }^{536}$. $\mathrm{Zu}$ jenen Lesern gehörte zweifellos Charles d'Heristal, der in der nationalistischen Action française einen Artikel über Viénots Buch veröffentlichte, der von Polemik durchtränkt war. Er glaubte, in Viénots Ausführungen zum deutschen Sozialismus Sympathien des Autors für diesen zu entdecken und machte sie ihm zum Vorwurf: "Dès que sa passion socialiste et révolutionnaire le reprend [...], l'auteur du livre ne voit plus clair. Il est comme ces chevaux de bataille que l'odeur de la poudre précipite dans la mêlée, tête baissée, aveuglement. $1{ }^{537}$ D'Heristal beschrieb Viénots Gedanken als konfus, verwirrt und "germanisch«. Er vermutete hinter der Widmung für »Andrée Viénot Mayrisch « ${ }^{538}$ eine deutsche Ehefrau, was er für eine Erklärung der dargelegten Ideen hielt. Man solle Viénot seinem Schicksal überlassen, so der Rezensent, da dieser sich von Frankreich abgewendet habe, um Deutschland zu studieren. Der Verlust sei auf jeden Fall nicht sehr groß: »Mais ce que nous ne saurions admettre, c'est que, sous prétexte de rapprochement, il propose à la France de se suicider pour aider au triomphe du pangermanisme. ${ }^{539}$

Mit dieser Bezichtigung des Vaterlandsverrats und der Komplizenschaft mit dem Alldeutschtum blieb der Autor der Action française jedoch alleine, denn die Aufnahme der Deutschlandstudie in Frankreich war ganz überwiegend positiv. Auch Lyautey griff zur Feder, um seinem alten Schützling zu gratulieren: "Ah le bon livre! C'est excellent. Il y a certes des points sur lesquels je fais des réserves et que je conteste, mais dans l'ensemble, dans l'essentiel, je l'approuve

${ }^{534}$ Marcel ThIÉBAUT, Parmi les livres, Incertitudes allemandes, in: La Revue de Paris 38 (1931) S. 713-716, hier S. 713.

535 Ibid. S. 715.

${ }^{536}$ Vgl. Viénot an Bloch, 10.8.1931, in: BN, Papiers Bloch, XLVII, Lettres adressées à JeanRichard Bloch.

${ }^{537}$ Charles d'HERISTAL, Un nouveau livre sur l'Allemagne, in: L 'Action française, 3.10.1931

${ }^{538}$ VIÉNOT, Incertitudes allemandes, S. 5.

${ }^{539}$ Ibid. 
pleinement. ${ }^{540}$ Viénot zeigte sich gerührt über das Lob seines Förderers und versicherte Lyautey, das Buch sei voll von diesem. In der Art zu denken, der Art, den Untersuchungsgegenstand anzugehen sah sich Viénot noch immer als Lyauteys Schüler ${ }^{541}$. Auch bei Jean Schlumberger bedankte sich Viénot, den er als Paten des Buches betrachtete. Da der Schriftsteller Viénot unterstützt und ihm geholfen hatte, berichtete dieser ihm nun nicht ohne Stolz von der der exzellenten Aufnahme des Buches in der Presse. Sogar Thomas Mann, so erzählte Viénot, halte das Buch für ein Ereignis ${ }^{542}$.

Auch in der deutschen Presse wurde Viénots Studie ausführlich besprochen. Allerdings zeigt sich, daß die deutschen Rezensionen insgesamt kritischer ausfallen als die französischen. Während die französischen Besprechungen vor allem die Originalität und das hohe Niveau der vorgetragenen Gedanken rühmen, so benennen die Rezensenten aus Deutschland bei einer grundsätzlich positiven Würdigung von Viénots Vorhaben jedoch auch die Mängel, die die Studie in ihren Augen besitzt. Der Hamburger Romanist Walther Küchler hob demgemäß zwar die Deutschlandstudie als die bedeutendste der letzten Jahre hervor und betonte Viénots umfassende Kenntnis des Nachbarlandes und dessen Verständigungsbereitschaft. Allerdings kritisierte Küchler, daß Viénot die äußeren Einflüsse auf die deutsche Krise nicht genug berücksichtigt habe. Für die Situation in Deutschland machte Küchler in erster Linie die harten Bedingungen von Waffenstillstand und Frieden verantwortlich, unter anderem die Entwaffnung, die Ruhrbesetzung und die Reparationen ${ }^{543}$. Weniger in den von Viénot gerade so herausgestrichenen innerdeutschen Symptomen der Krise sah Küchler also die Ursachen für die deutschen Ungewißheiten, als vielmehr in einer verfehlten französischen Deutschlandpolitik. Die Bedingungen des Versailler Vertrages spielten jedoch für Viénots Überlegungen keine Rolle, da sich der Zerfall der bürgerlichen Kultur auf geistig-philosophischem Gebiet vollzog. Die Auswirkungen dieser Entwicklung waren zwar in der Politik spürbar, doch war diese nicht für die Ursachen verantwortlich. Die Kritik Küchlers geht also an Viénots Anliegen vorbei, zeigt jedoch auch, daß der Autor der "Incertitudes allemandes" den Stellenwert des Versailler Vertrages und der damit verbundenen realen wie psychologischen Belastungen in Deutschland offenbar unterschätzt hat. Ein weiterer Kritikpunkt zielte auf Viénots These vom in Deutschland zur letzten Konsequenz getriebenen Werterelativismus. In ihr erkannte Küchler die wissenssoziologischen Kategorien von Karl Mann-

${ }^{540}$ Lyautey an Viénot, o.D. [1931]: AN, 475 AP 311. Vor allem Viénots Ausführungen zum Umbruchscharakter der Epoche wurden von Lyautey geteilt: »De ce grand tournant d'histoire définitive dans l'évolution du monde dont tu te souviens que j'ai le sentiment depuis si longtemps «. Ibid.

${ }^{541} \mathrm{Vgl}$. Viénot an Lyautey, 31.8.1931: AN, 475 AP 311

$\$ 42$ Vgl. ders. an Schlumberger, 11.9.1931: BLJD, Fonds Schlumberger, Ms 18355.

${ }^{543}$ Vgl. Walther K0CHLER, Pierre Viénot über Deutschland, in: Die Neueren Sprachen 40 (1932) S. 28-35, hier S. 29. 
heim, die dieser in seinem Buch »Ideologie und Utopie« zwei Jahre zuvor dargelegt hatte ${ }^{544}$. Mannheim hatte darin erörtert, wie der moderne Mensch die ehemaligen Glaubensinhalte und Werturteile als Täuschung erkannt habe. Diese Denkinhalte seien auf Utopien oder Ideologien zurückzufuihren, so daß feststehende Normen nicht mehr existierten. Die Wahmehmungsmöglichkeiten des Geistes wurden auf den Standort des Denkers bezogen. Mannheim konstatierte eine geistige Haltlosigkeit und fragte, wie der Mensch unter solchen Voraussetzungen überhaupt noch denken und leben könne. Küchler ging Mannheims Relativismus allerdings zu weit, und er verwies auf das ebenfalls 1931 erschienene Werk »Die geistige Situation unserer Zeit« von Karl Jaspers. Hätte Viénot dieses Buch gekannt, so Küchler, "so hätte er festellen können, daß der deutsche philosophische Gedanke, ohne die Berechtigung der relativistischen Denkungsart zu verkennen [...], deswegen doch nicht in geistige Unsicherheit verfällt $\ll{ }^{545}$ Trotz Einsicht in die Relativität des Daseins bleibe das Selbstbewußtsein doch vorhanden, sei die intellektuelle Unsicherheit nicht so weit verbreitet wie Viénot es annehme. Viénot war in seinem Buch auf die Kontroverse zwischen Karl Mannheim und Ernst Robert Curtius über Werterelativismus und die Rolle der Soziologie innerhalb der Geisteswissenschaften eingegangen. Bei Mannheim, in dem Viénot »l'intellectuel pur ${ }^{546}$ sah, erkannte er »sous le mépris pour le sbesoin de sécuritér spirituelle, sous la méfiance en face de ceux qui sprétendent c posséder quelque certitude, une sorte de désespoir acharné et le sentiment que la seule attitude courageuse, c'est l'acceptation franche du nihilisme inévitable « ${ }^{547}$ Viénot machte auch deutlich, daß er Mannheims Überlegungen zum Relativismus aller geistigen Werte als repräsentativer für das moderne Deutschland ansah als Curtius' Kritik daran ${ }^{548}$. Küchler widersprach Viénot hier und erachtete die Anhänger der Curtiusschen Kritik am »Soziologismus « für nicht minder charakteristisch als die Vertreter des Werterelativismus.

Bei diesem Kritikpunkt hakten auch andere Rezensenten ein. Der Journalist Bernard von Brentano stellte im Berliner Tageblatt die Allgemeingültigkeit von Mannheims Ansichten in Frage und sah diese nur für eine begrenzte Grup-

544 Vgl. Karl MANNHEIM, Ideologie und Utopie, Bonn 1929 (Schriften zur Philosophie und Soziologie, 3).

${ }^{545}$ KUCHLER, Pierre Viénot, S. 30.

${ }^{546}$ VIÉNOT, Incertitudes allemandes, S. 97.

547 Ibid.

${ }^{548}$ Vgl. ibid. Zur Kontroverse Mannheim-Curtius vgl. Ernst Robert CURTIUS, Soziologie und ihre Grenzen, in: Neue Schweizer Rundschau 22 (1929) S. 727-736; DERS., Deutscher Geist in Gefahr, Stuttgart, Berlin 1932, S. 88-102; Dirk HOEGES, Kontroverse am Abgrund: Ernst Robert Curtius und Karl Mannheim. Intellektuelle und wfreischwebende Intelligenz" in der Weimarer Republik, Frankfurt a.M. 1994; JACQUEMARD-DE GEMEAUX, Ernst Robert Curtius, S. 174-180; BLOMERT, Intellektuelle im Aufbruch, S. 192-221. Wie bei Blomert nachgezeichnet wird, brachte sich Mannheim mit seiner Relativismusthese in Gegensatz sowohl zu Curtius als auch zu Alfred Weber und Karl Jaspers, die niemals »den Glauben an die Transzendentalität des Geistes« verloren hätten. Vgl. ibid. S. 211. 
pe in Deutschland als verbindlich an ${ }^{549}$. Auch der prominenteste deutsche Rezensent, Ernst Robert Curtius, äußerte, ähnlich wie Brentano, Zweifel hinsichtlich der Repräsentativität der beschriebenen Intellektuellenschicht ${ }^{550}$. Ein anderer Einwand bezog sich wie bei Küchler darauf, daß Viénot die Bedeutung des Versailler Vertrages nicht ausreichend berücksichtigt habe. Der von Viénot konstatierten Überbewußtheit, der whyperconscience«, in der Curtius eines der wichtigsten und gleichzeitig positivsten Merkmale der deutschen $\mathrm{Ge}$ genwart sah, stellte er die "mangelnde oder unvollständige Bewußtheit des Franzosen gegenüber«. Er deutete dies als »Angst vor dem Bewußtsein, ja vor dem Geist überhaupt« und vermutete, Viénot stehe dieser Haltung nahe. Anders sah sich Curtius selbst: »Ich bin in dieser Beziehung Optimist und glaube, daß die Menschheit den Einbruch des Maschinenzeitalters und der Technik mit der gleichen gesunden Selbstverständlichkeit überwinden wird wie vor Urzeiten die Entwicklung des Feuers und die Erfindung der Schrift. $4{ }^{551}$ Curtius, dessen Denken in nationalen Antithesen bei dieser Gegenüberstellung deutscher Überbewußtheit und mangelnder französischer Bewußtheit deutlich wird, schätzte Viénot in dieser Hinsicht falsch ein. Anders als er es vermutete, deutete Viénot die deutsche »hyperconscience « als ein positives Signum der Krise, da die von ihr ausgelöste permanente Reflexion und Diskussion über die Zustände in Deutschland zur Dynamik des Wandlungsprozesses beitrug. Insgesamt beurteilte Curtius die Studie positiv, zumal er sie als dazu geeignet erachtete, die Franzosen zu einer Revision ihrer Meinung über Deutschland anzuregen. Er bescheinigte dem Autor eine Kennerschaft Deutschlands und eine verständnisbereite Sympathie. In einem grundlegenden Punkt mißverstand Curtius jedoch das Anliegen Viénots. Diesem ging es, anders als Curtius dies annahm, nicht darum, »Wesenszüge einer anderen Nation zu umreißen«. ${ }^{552}$ Curtius, der in seinen Frankreichbüchern selbst immer den Charakter der Franzosen darzustellen versuchte, konnte sich anscheinend nicht vorstellen, daß in einem Buch über das Nachbarland keine Überlegungen zum Nationalcharakter im Vordergrund stehen könnten. Damit ging er am tieferen Anliegen Viénots, nämlich diese vermeintlichen Völkercharaktere als Projektionen und Klischeebilder zu enttarnen, völlig vorbei.

Benno Reifenberg, der in den Debatten der Union pour la Vérité die Verständigung als nicht mehr existent bezeichnet hatte, verfaßte das Vorwort zur deutschen Ausgabe der »Incertitudes allemandes«. Die Hoffnung, allein durch geistige Annäherung jenseits der politischen Sphäre zum Ziel zu gelangen, war

${ }^{549}$ Vgl. Bemard von BRENTANO, Das geheimnisvolle Deutschland, in: Berliner Tageblatt, 18.8.1931.

${ }^{550}$ Emst Robert CURTIUS, Ein Franzose über die deutsche Krise, in: Kölnische Zeitung, 17.10.1931.

551 Alle Zitate ibid.

552 Ibid. 
seiner Meinung nach nicht umzusetzen, da der politische Gegensatz zwischen beiden Völkern noch immer existiere. Reifenberg wies noch einmal ausdrücklich darauf hin, daß ses ausschließlich von diesen beiden Nationen abhängt, was aus Europa werden soll ${ }^{553}$ Die Studie Viénots sah er als ein Zeichen an, daß in Frankreich die Bereitschaft bestehe, sich im Sinne der Verständigung von der geistigen Sphäre in jene der harten politischen Alltagsarbeit hinab zu begeben. Dieser Schluß ist erstaunlich, handelt Viénots Buch doch in erster Linie von psychologisch-philosophischen Krisenfaktoren und so gut wie gar nicht von konkreten tagespolitischen Themen. Anders als in seinem Diskussionsbeitrag zur Intellektuellendebatte, schloß Reifenberg seine Gedanken mit einem hoffnungsvollen Fazit: »Es ist möglich, daß Frankreich zu begreifen beginnt, was im Herzen der Menschen Deutschlands sich zur Stunde vollzieht. In dem Augenblick, in dem solche Erkenntnis zu wachsen anfängt, wird Frankreich es verschmähen, der verantwortungslose Zuschauer zu bleiben. Hierfür ist dieses Buch ein Beweis. ${ }^{554}$

Die Rezensionen der "Incertitudes allemandes" und ihre unterschiedliche Aufnahme in Deutschland und in Frankreich zeigen symptomatisch die Problematik der deutsch-französischen Annäherungsbemühungen: Während in Frankreich Viénots Studie - mit Ausnahme der rechtsextremen Action française durchweg gelobt wurde als profundes, intelligentes und originelles Buch über den Nachbarn, fühlten sich die Deutschen zum Teil mißverstanden. Zwar lobten auch sie Viénots Willen zur Verständigung, doch die von mehreren Autoren vorgebrachten Kritikpunkte machen deutlich, daß ihrem Empfinden nach die deutschen Gegebenheiten vom französischen Autor eben doch nicht ausreichend berücksichtigt worden waren. Vor allem Viénots mangelnde Würdigung des Versailler Vertrages war für die deutschen Kritiker unverständlich, da dieser in ihren Augen ein fundamentales Problem in den Beziehungen zu Frankreich bedeutete. Es stellt sich die Frage, ob Viénot, der mit seinem Buch der Verständigung dienen wollte, dieses Ziel - zumindest in Deutschland - auch erreichen konnte, oder ob er nicht, aufgrund seiner Interpretation der Krisensymptome als dem Kulturzerfall inhärente Erscheinungen, doch an Deutschland, an der deutschen Sicht der Problematik, vorbeischrieb. Die transnationale Kommunikation zwischen Deutschland und Frankreich, die Viénot mit seinem Buch befördern wollte, stellte sich im internationalen »annus terribilis 1931 « $^{555}$ schwieriger dar denn je.

In Frankreich war Viénot mit seinem Buch als Anwärter für den von der Zeitschrift $L$ 'Europe nouvelle verliehenen "Prix politique« im Gespräch. Diese auf außenpolitische und diplomatische Fragestellungen spezialisierte Revue wurde von der Briand-Vertrauten Louise Weiss herausgegeben. Ihr Redaktionssitz am

${ }^{553}$ Benno REIFENBERG, Vorwort zu VÍ⿴囗十) UT, Ungewisses Deutschland, S. 10.

s54 Tbid. S. 12.

sss Amold J. TOYNBEE, Survey of International Affairs 1931, Oxford, London 1932, S. 1. 
Quai d'Orsay war darüber hinaus auch Organisationsmittelpunkt der Nouvelle École de la Paix, einer Bildungseinrichtung, die der Académie de Paris angegliedert war und Kolloquien mit hochrangigen Rednern und Gesprächsteilnehmern veranstaltete ${ }^{556}$. Viénot glaubte jedoch im Vorfeld nicht an große Chancen, da Louise Weiss aufgrund feministischer Überzeugungen die Autorin Andrée Viollis favorisiere ${ }^{557}$. Am 10. November 1931 wurde Viénot dann doch der Preis von L'Europe nouvelle zuerkannt, vor allem wegen seiner politischen Aktualität und seiner neuartigen methodischen Herangehensweise an das deutsch-französische Problem ${ }^{58}$. Nach Wladimir d'Ormesson (1928), Maurice Pernot (1929) und Salvador de Madariaga (1930) war er der vierte Preisträger. Innerhalb der Jury, der André Tardieu, Léon Blum, Joseph Avenol, Philippe Berthelot, André Siegfried, Georges Bonnet und Maurice Reclus angehörten, zeigte sich Sozialistenchef Léon Blum ${ }^{559}$ sehr beeindruckt von Viénots Buch. Er stimmte für Viénots »Incertitudes allemandes « und gegen die »Perspectives socialistes « seines Parteigenossen Marcel Déat ${ }^{500}$. Déat, der später wegen seiner Thesen zur Revision des Marxismus aus der SFIO ausgeschlossen wurde, nahm es Blum übel, daß dieser die Zeit gefunden habe, sde faire du bruit autour du livre de Pierre Viénot, qui n'était pas du parti, [...] mais il se donna bien des gardes d'entamer une discussion sur les conceptions que je proposais « ${ }^{561} \mathrm{Die}$ Anerkennung durch $L^{\prime}$ Europe nouvelle leistete Viénot wichtige Schützenhilfe für sein Anliegen, sich einen Namen in der politischen Öffentlichkeit zu machen. In den dreißiger Jahren publizierten Viénot und seine Frau darüber hinaus auch selbst Artikel in der Zeitschrift. Daneben ergab sich ebenfalls eine Zusammenarbeit mit der Nouvelle École de la Paix, die ihren Ausgangspunkt

556 Vgl. BERTIN, Louise Weiss, S. 195f.

${ }^{557} \mathrm{Vgl}$. Viénot an Schlumberger, 11.9.1931: BLJD, Fonds Schlumberger, Ms 18355; ders an d'Ormesson, 12.10.1931: NL d'Ormesson II. In ihren Memoiren erwăhnt Louise Weiss Viénot kaum, bescheinigte ihm jedoch einen »ententisme passionné« in bezug auf die deutsch-französischen Beziehungen. Vgl. WEISS, Mémoires, S. 306.

${ }^{558} \mathrm{Vgl}$. M. Pierre Viénot, lauréat du Prix politique de l'Europe nouvelle, in: L'Europe nouvelle, 14.11.1931, S. 1528 .

${ }^{559}$ Zu Blum vgl. Jean LACOUTURE, Léon Blum, Paris 1977; Ilan GREILSAMMER, Blum, Paris 1996; Pierte RENOUVIN, René RÉMOND (Hg.), Léon Blum, chef de gouvernement 19361937, Paris 1967.

${ }^{560} \mathrm{Zu}$ Déat vgl. Reinhold BRENDER, Kollaboration in Frankreich im Zweiten Weltkrieg. Marcel Déat und das Rassemblement national populaire, München 1992 (Studien zur Zeitgeschichte, 38); Alain BERGOUNIOUX, Le néo-socialisme. Marcel Déat: réformisme traditionnel ou esprit des années trente, in: La Revue historique 102 (1978) Nr. 260, S. 389 412. Siehe auch Kap. IV.1.3.

${ }^{561}$ Marcel DEAT, Mémoires politiques, Paris 1989, S. 237. In einem Nachruf auf Viénot berichtete dessen früherer Freund und Mitarbeiter in Lyauteys »équipe «, Christian FunckBrentano, Louise Weiss habe Blum zur Abstimmung für Déat überreden wollen. Dieser habe jedoch abgelehnt, da er Viénots Buch für besser befand. Vgl. Christian FUNCKBRENTANO, Un représentant digne de la France. La mort de Pierre Viénot, in: Combat. Hebdomadaire du Mouvement de Libération et de Rénovation, 23.7.1944. 
in der Einladung an Carl Heinrich Becker zu einem Vortrag im Mai 1931 nahm ${ }^{562}$. Becker sprach zum Thema »Nationales Selbstbewußtsein und internationale Verständigung«, in dem Glauben, »dass jetzt alle vemünftigen Leute in beiden Ländern zusammenhalten müssen, die neue Welle des Missverstehens einzudämmen « ${ }^{563} 1932$ nahm Viénot dann selbst eine Einladung von Louise Weiss zu einer Diskussion mit Friedrich Sieburg über aktuelle Deutschlandfragen an, und auch in die Planungen für einen Vortrag Rudolf Breitscheids im November 1933 über »Hitler und Europa « wurde er mit einbezogen ${ }^{564}$. Die Zusammenarbeit zwischen Viénot und der Gruppe um $L$ 'Europe nouvelle intensivierte sich in der Folgezeit derart, daß er Mitglied im Direktionskomitee der Nouvelle École de la Paix wurde, welches für die Zusammenstellung des Programms und die Auswahl der Redner verantwortlich war ${ }^{565}$.

Nach ihrem Anfangserfolg ging Viénots Deutschlandstudie bald in der Woge des Nationalismus der dreißiger und vierziger Jahre unter. Eine sempathisches Konzeption der gegenseitigen Wahmehmung ${ }^{566}$, die auf der Einfühlung des Beobachters gegenüber dem fremden Land beruhte, konnte nicht mehr vermittelt werden. Dennoch wurden Viénots Ausführungen noch im Zweiten Weltkrieg vom deutschen Romanisten Walter Schulz zur Untersuchung des französischen Deutschlandbildes nach 1918 herangezogen. Der Autor kommt dabei zu dem Schluß, daß Viénots Ausführungen dem Titel nicht gerecht werden, da die von ihm beschriebene Kulturkrise ja gar kein rein deutsches Phänomen sei. Schulz treibt die bereits von Curtius und Küchler angesprochenen Kritikpunkte auf die Spitze, da seiner Meinung nach die beschriebenen chaotischen Nachkriegszustände allein aus den Lasten des Versailler Vertrages resultierten, aus der Tatsache, daß Frankreich als Sieger und Deutschland als Besiegter aus dem Krieg hervorgegangen sei. Durch seine Betrachtungsweise, so Schulz, gelinge es Viénot nicht, seinen Landsleuten Deutschland verständlich zu machen, denn

wenn der Verfasser an der Erkenntnis der entscheidenden Bedeutung der Versailler Friedensordnung für die ganze Lebensordnung des deutschen Volkes nach dem Kriege vorübergeht, dann fehlt ihm selbst das Verständnis, das er anderen vermitteln will. Sollte er jedoch wider

${ }^{562}$ Vgl. Viénot an Becker, 26.4.1931: GStA PK, NL Becker, 2616. Viénot betonte die Ausnahmestellung von Louise Weiss, "notre seule femme politique de grande classe " und insistierte, daß gerade zu diesem Zeitpunkt des wachsenden gegenseitigen Unverständnisses ein Vortrag Beckers in Paris besonders wünschenswert sei.

${ }^{563}$ Becker an Viénot, 29.4.1931: GStA PK, NL Becker, 2616. Becker bedankte sich anschlieBend bei Viénot, der für den großen Erfolg seines Vortrages in der École de la Paix verantwortlich sei. Vgl. ders. an dens., 31.5.1931: ibid.

${ }^{564} \mathrm{Vgl}$. Viénot an Weiss, 14.10.1932; Weiss an Viénot, 10.10.1933: BN, Papiers Weiss, XXI, Correspondance relative aux Conférences de l'École de la Paix.

${ }^{565}$ Vgl. BERTIN, Louise Weiss, S. 196.

${ }^{566} \mathrm{Vgl}$. BOCK, La postérité européenne, S. 103. 
besseren Wissens geurteilt haben, dann ist jedenfalls für ihn der deutsche Vorwurf der 'Hypocrisie françaiser (Viénot gegen Schluß) gerechtfertigt ${ }^{567}$.

Wenngleich an der Kritik Schulz' der bereits im Zusammenhang mit Küchler und Curtius erörterte Einwand zu bedenken ist, ob Viénot nicht tatsächlich die Bedeutung des Versailler Vertrages für die politische Psychologie der Deutschen unterschätzt hat, entging dem Verfasser allerdings, daß Viénot mit den deutschen Ungewißheiten nicht ein Chaos beschreiben wollte, sondern die Chance zum Aufbruch in eine neue Zivilisation. Die implizite Aufforderung von Schulz, Viénot möge sich der deutschen und damit der revisionistischen Interessenlage anschließen, zeigt, inwieweit der Verfasser Viénots Anliegen der unvoreingenommenen transnationalen Kommunikation mißverstand ${ }^{568}$. Der Vorwurf des mangelnden nationalpolitischen Bekenntnisses wurde Viénot nach dem Zweiten Weltkrieg auch von französischer Seite gemacht. Jean-Marie le Carré, der die Irrtümer der französischen Deutschlandwahrnehmung ausräumen wollte, bescheinigte Viénot, er habe sich noch 1931 an eine Hoffnung »d'entente et de détente ${ }^{569}$ geklammert. Der implizite Vorwurf einer allzu naiven und gutgläubigen Gesinnung ergibt sich aus Carrés Einschätzung, Deutschland habe in den zwanziger und dreißiger Jahren alle Konzessionen erhalten, "sans nous accorder une contrepartie réelle, un remerciement, un sourire ${ }^{570}$ Die ebenso nationale wie deterministische Geschichtsauslegung Carrés leugnet jegliche Chance, zu Beginn der dreißiger Jahre überhaupt noch zu einem deutschfranzösischen Ausgleich zu gelangen.

Gerade diese Kritiken zur fehlenden nationalen Parteilichkeit der ViénotStudie zeigen jedoch die besondere Stellung des Buches in der Reihe der Länderstudien der Zwischenkriegszeit. Viénots Deutschlandbuch ließ sich eben nicht propagandistisch für nationale Zwecke instrumentalisieren. Vielmehr durchbrach Viénot mit se.nen »Incertitudes allemandes« gängige Deutungsmuster, die auf völkerpsychologischen und nationalcharakterologischen Grundlagen beruhten. So wie Viénot außenpolitisch ein Gegner nationalistischer Standpunkte war, so demontierte er gleichzeitig in seiner Studie gängige nationale Klischees und Stereotypen, deren Entstehungs- und Wirkungsweise er thematisierte. Anders als die Klassiker der Deutschland- und Frankreichessayistik seiner Zeit ging es Viénot in keiner Weise darum, eine irgendwie geartete deutsche Wesensart zu ergründen und der französischen gegenüberzustellen. Er setzte keine charakterlichen oder psychologischen Eigenschaften eines Volkes als unabänderliche Konstanten voraus, sondern er untersuchte mit kultursoziologischer Methode - die er zweifellos im Umkreis von Alfred Weber kennenge-

${ }^{567}$ Walter ScHULZ, Das Deutschlandbild in der französischen Kritik nach 1918, Berlin 1941

(Beiträge zur Sprach-, Stil- und Literaturforschung, Abt.: Romanistik, 6), S. 33f.

568 Vgl. BOCK, Der Blick, S. 69.

569 Jean-Marie CARRÉ, Les écrivains français et le mirage allemand, Paris 1947, S. 183.

${ }^{570}$ Ibid. 
lernt hatte ${ }^{571}$ - die politische Kultur des Nachbarlandes und dessen Bewußtseinsinhalte. In dieser Hinsicht betrat er Neuland ${ }^{572}$ und unterschied sich beispielsweise von der in Frankreich berühmt gewordenen Studie von Jacques Rivière, "L'Allemand", in der dieser antithetische Völkercharaktere gegenüberstellte $^{573}$. Nicht anders beurteilten Ernst Robert Curtius und Alfred Bergsträsser ihr Nachbarland, dem sie 1930 ein zweibändiges Werk widmeten ${ }^{574}$. Curtius legte darin ein nationalkulturelles Strukturschema zugrunde, »das immer gleichbleibt und zu den psychologischen Konstanten französischen Wesens gehört« ${ }^{575}$ Dergleichen fremdnationale Identitäts- und Wesenszuschreibung, die aus einem Denken in nationalen Antithesen resultierte, war jedoch nicht Ziel und Inhalt von Viénots Reflexionen. Ihm ging es vielmehr um die Feststellung gemeinsamer Ausgangspunkte und Interessenlagen, von denen ausgehend in einem langfristigen interkulturellen Dialog eine europäische Zukunftsperspektive erarbeitet werden sollte. Mit dem Aufbrechen und der Überwindung nationaler Klischeevorstellungen war Viénots Anliegen überaus modern, es zeugt von geistiger Unabhängigkeit und erscheint heute erstaunlich aktuell. Viénot formulierte frühzeitig und eigenständig die Voraussetzungen für eine erfolgreiche transnationale Kommunikation, zu denen die Fähigkeit, sich in eine andere Kultur einzufühlen ebenso zählt wie eine verantwortungsbewußte Berichterstattung in den Medien. Er postulierte die zeitweilige Integration in das fremde Land als Bedingung echten Verstehens, die Akzeptanz nationaler Verschiedenheiten und die Rolle der Mittler zwischen Nationen als die von kulturellen Übersetzern ${ }^{576}$.

${ }^{571}$ Alfred Weber gilt als Begründer der Kultursoziologie, die sich mit der Hervorbringung und den Entfaltungsbedingungen menschlicher Kultur beschäftigt. Eva Karadi bezeichnet »die Alfred Webersche Kultursoziologie als Kulturgeschichte mit [...] gegenwartsorientierter Fragestellung «. Vgl. Eva KARADI, Karl Mannheim und Alfred Weber - eine Heidelberger Schule für Kultursoziologie?, in: Peter ULMER $(\mathrm{Hg}$.), Geistes- und Sozialwissenschaften in den 20er Jahren: Heidelberger Impulse, Symposium vom 20. Januar 1995 in Heidelberg, Heidelberg 1998 (Heidelberger Universitätsreden, 14), S. 155-169. Siehe auch Reinhard BLOMERT, Alfred Weber und Karl Mannheim - eine Heidelberger Schule der Kulturwissenschaften?, in: ibid. S. 129-153.

572 Dies war zu Beginn der dreißiger Jahre umso erstaunlicher, als sich nationalcharakterologische Denkschemata bis in die Nachkriegszeit fortsetzten. Vgl. z.B. André SIEGFRIED, L'âme des peuples, Paris 1950.

${ }^{573}$ Vgl. Kap. II.3.2.

${ }^{574} \mathrm{Vgl}$. CURTuUS, Die französische Kultur; Arnold BERGSTRÄSSER, Staat und Wirtschaft Frankreichs, Berlin, Leipzig 1930. Curtius hatte das Argumentationsmuster offensichtlich von Rivière übernommen, wenngleich er mit dessen Einschätzungen über die Deutschen nicht einverstanden war. Vgl. dazu auch die Darstellung von Hans Manfred Bock zu den dominanten Deutungsmustern des deutschen Frankreichklischees in der Zwischenkriegszeit: Hans Manfred BOCK, Tradition und Topik des populären Frankreich-Klischees in Deutschland von 1925 bis 1955, in: Francia 14 (1986) S. 475-508. Siehe auch DERS., Wechselseitige Wahrnehmung.

${ }^{575}$ CURTIUS, Die französische Kultur, S. 20.

${ }^{576} \mathrm{Vgl}$. BOCK, Der Blick, S. 75f. 
